\title{
New Lessons: The Power of Educating Adolescent Girls-A Girls Count Report on Adolescent Girls
}

Cynthia B. Lloyd

Population Council

Juliet Young

Follow this and additional works at: https://knowledgecommons.popcouncil.org/departments_sbsr-pgy

Part of the Education Commons, and the Family, Life Course, and Society Commons How does access to this work benefit you? Let us know!

\section{Recommended Citation}

Lloyd, Cynthia B. and Juliet Young. 2009. "New Lessons: The Power of Educating Adolescent Girls-A Girls Count Report on Adolescent Girls." New York: Population Council. 
NEW

LESSONS

A GIRLS COUNT REPORT ON ADOLESCENT GIRLS

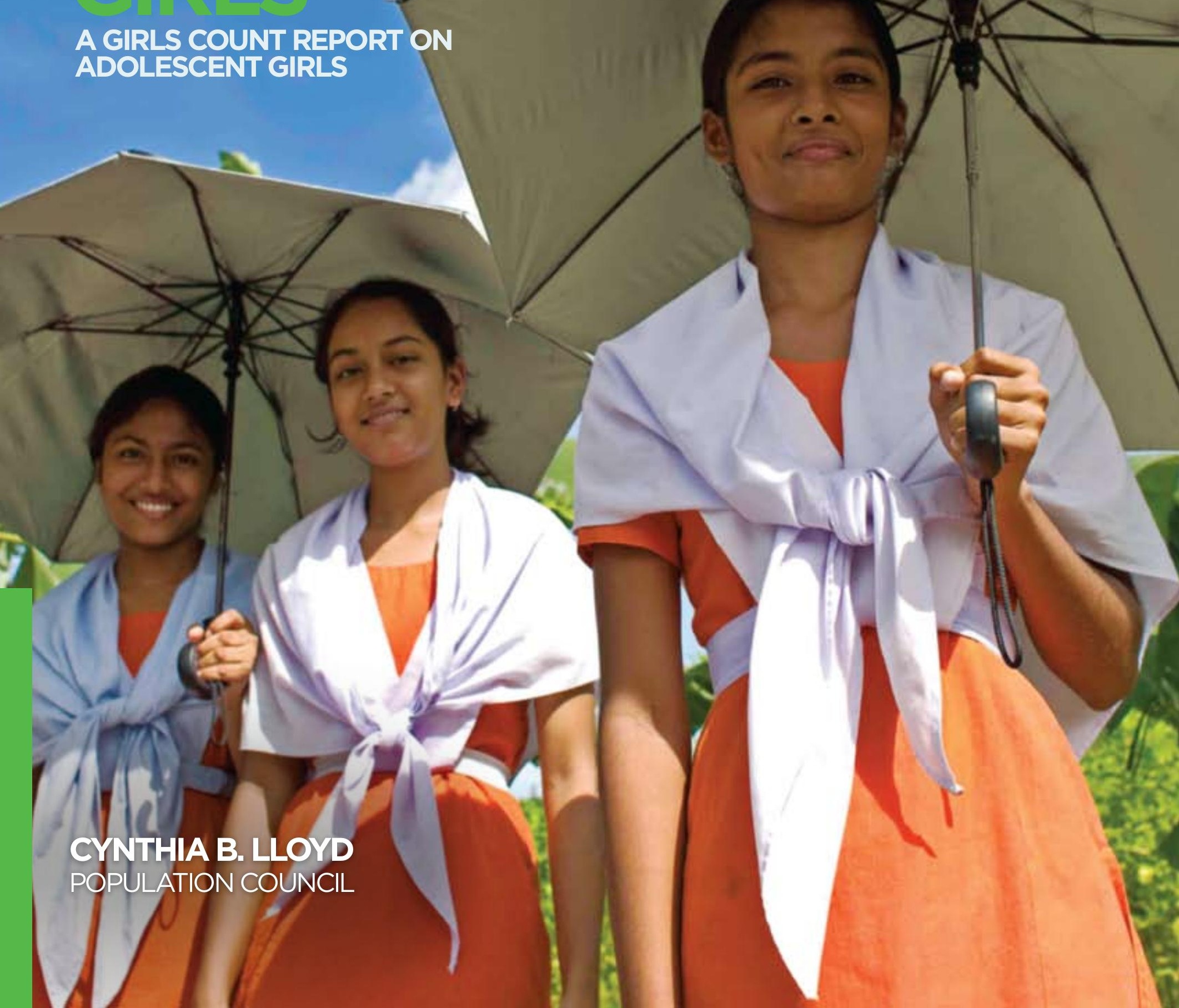


Cover Photo

Girls at a rural secondary school in

Bangladesh head home after class.

Offering new options and access to

Offering new options and access to
secondary school is a major prior-

ity for adolescent girls' education.

Photo Credit: Brent Stirton / Getty Images 
NEW

LESSONS

THE POWER

OF EDUCATING

ADOLESCENT

GIRLS 


\section{TAKING ACTION FOR ADOLESCENT GIRLS EDUCATION}

\section{COUNT}

\section{Collect and compile data on non-formal education}

A questionnaire module on non-formal education should be introduced into national household surveys and censuses to collect data on the extent and coverage of non-formal schooling, and its implementation should be tested on a pilot basis in several countries.

\section{Build and maintain a global database for education programs for adolescent girls}

Our program and project compendium should become the platform for the development of a dynamic global database of education programs that serve adolescent girls. Its scope should be expanded in order to identify promising models appropriate to girls' educational needs in different settings. This database should be made available to donors, practitioners, and international agencies.

\section{INVEST}

\section{Expand opportunities for girls to attend secondary school}

Governments should define basic education as education through lower secondary school, or to age 16. To accommodate the resulting influx of students, governments and the private sector should increase the number of formal and non-formal secondary school places in the educational system by extending existing primary school facilities and offering welltargeted subsidies to disadvantaged girls to attend either public or private secondary schools.

\section{Support the non-formal education system}

The non-formal education system must be well integrated with the formal system and be designed to help adolescent girls to achieve their educational and developmental needs. Non-formal schools must be upgraded, certified, and licensed, and pathways should be established from the non-formal to the formal sector, as well as from the formal to the non-formal sector. Baseline surveys should assess educational backgrounds, skills, and knowledge gaps of population subgroups who are potential beneficiaries, in order that educational systems can be designed to address existing needs.

\section{Develop after-school tutoring and mentoring programs in both primary and secondary schools}

These programs should support girls' education and development and enhance their chances of progressing to or succeeding in secondary school. They can provide one-on-one mentoring and ensure that after-school hours are dedicated to study and not to part-time jobs 
or family obligations. The programs can also provide supplementary training beyond the formal curriculum for the development of skills for social and civic participation-in the process teaching basic health, reproductive health, and financial literacy.

\section{Produce curricula relevant to adolescent girls}

Adolescent girls in the developing world need to acquire remunerative and marketable skills which are not taught at home, such as facility with computers, fluency in an internationally spoken language, financial skills, and knowledge of social systems. New methods to promote interactive and collaborative learning can help develop critical thinking and decisionmaking skills and instill a habit of lifelong learning - capacities that will equip girls for a rapidly changing world.

\section{Offer post-secondary vocational programs}

The majority of girls who complete secondary school do not continue on to university. For girls going directly into the workforce, it is important to offer programs that support them in making a successful transition to remunerative work and household financial management. Such programs must be based on market assessments and provide relevant, flexible skills for employment and professional growth in an ever-changing global economy.

\section{Provide training and ongoing incentives for women to enter and remain in teaching}

Female teachers can reinforce the importance of education to girls, and many girls respond better to female teachers. The number of women who enter teaching is increasing, and teaching appears to be a viable, desirable profession for women who have completed secondary school.

\section{ADVOCATE}

\section{Promote easy transitions between non-formal and formal schools}

Complementary schools should be developed within the non-formal education system to help girls, many of them primary-school dropouts, continue on to formal secondary school. They should also offer younger adolescents the opportunity to reenter formal primary school.

\section{Encourage and evaluate innovation}

The curricula in both formal and non-formal schools attended by adolescents should be revamped to develop new approaches to education. Although many of the current approaches are unproven, some appear particularly promising. To test their effectiveness, research/program partnerships should invest in designing and implementing pilot projects to measure and assess their impact on girls over the short and medium term. 

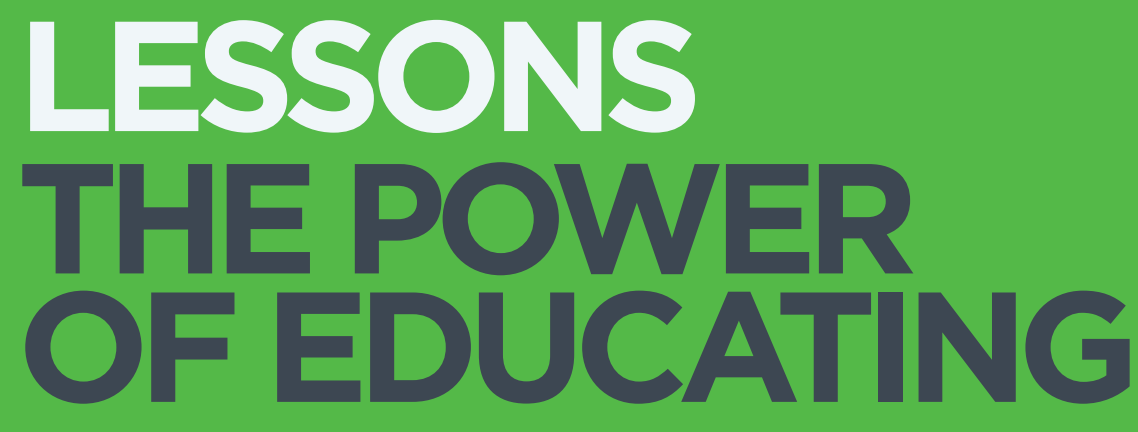

ADOLESCENT

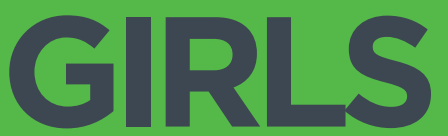

\section{A GIRLS COUNT REPORT ON} ADOLESCENT GIRLS

\section{CYNTHIA B. LLOYD WITH JULIET YOUNG}

\section{(2) Population Council}

(C) 2009 The Population Council, Inc. www.popcouncil.org

The Population Council is an international, nonprofit, nongovernmental organization that conducts research worldwide to improve policies, programs, and products

in three areas: HIV and AIDS; poverty, gender, and youth; and reproductive health. 


\section{NEW LESSONS CONTENTS}

Taking action for adolescent girls' education

$\mathbf{x}$

\section{Foreword}

xii Acknowledgements

1 Introduction

A new global compendium

From analysis to policy agenda

3 Taking action for adolescent girls' education

Chapter 1: Adolescent girls' educationformal \& non-formal

A sequel to Girls Count

Setting the stage

10 Situating adolescents within the education system

15 Collecting information on programs and projects

15 Outline of report

Chapter 2: Where \& how are girls faring

20 Where are they?

23 How are they faring?

$27 \quad$ What are they learning?

34 Chapter 3: The returns to educating adolescent girls

36 By staying in school during adolescence, girls reap immediate benefits

39 By staying in school during adolescence and retaining learning into adulthood, girls reap future social and health benefits for themselves and their families
40 By working for pay after school completion, girls reap future economic benefits for themselves and their families

46 By working in their communities and participating in civic life, girls contribute to economic and social development

47 When girls attend non-formal educational programs, the current and future benefits are unknown

48 Chapter 4: Strategies to address the needs of adolescent girls

$51 \quad$ Lessons from past practice

54 Lessons from research

62 Chapter 5: Features of educational programs for adolescent girls

64 Framework for the compendium

68 Challenges and caveats

$70 \quad$ Results

78 Implications

82 Chapter 6: An educational manifesto for adolescent girls

86 Compendium

86 Compendium: Guide for readers

88 Acronyms \& abbreviations

122 Sources of information

144 References

151 About the authors 


\section{NEW LESSONS BOXES, CHARTS,
FGURES \& IABLES}

\section{Boxes}

1.1 Why girls? Why not boys too?

$13 \quad 1.2$ Definitions

$13 \quad 1.3$ Education for All-Goals of the Dakar Framework for Action (2000)

$23 \quad 2.1$ Menstruation as a cause of absenteeism among adolescent girls in Malawi

393.1 School quality and premarital sex among adolescent girls in Kenya

$40 \quad 3.2$ Maternal literacy and health in Nepal

423.3 A caveat on estimated rates of return

$52 \quad 4.1$ Alternative approaches to addressing the educational needs of adolescent girls

$55 \quad 4.2$ The feminization of Islamic secondary schools in Bangladesh

564.3 Menstruation and education in Nepal

594.4 Evidence on the effectiveness of alternative approaches to addressing the educational needs of adolescent girls

$65 \quad 5.1$ Common girl-friendly features

$67 \quad 5.2$ Tutoring: an important but contentious issue

715.3 Alternative education for adolescent girls in Mali

$78 \quad 5.4$ Examples of "other" girl-friendly strategies

856.1 An educational manifesto for adolescent girls

\section{Charts}

$14 \quad 1.1$ Educational pathways for adolescents

514.1 Girl-friendly strategies and desired outcomes

\section{Figures}

$11 \quad 1.1$ Grade 6 completion rates for 20-24-year-old girls

$12 \quad 1.2$ Percentage point gender gap (boys minus girls) in grade 6 completion rates for 20-24-year-olds

212.1 School attendance of 10-14-year-old girls, by level

$22 \quad 2.2$ School attendance of 15-19-year-old girls, by level

242.3 Secondary school completion rates of girls age 19, sub-Saharan Africa (percent)

$25 \quad 2.4$ Gender differences in percentage of currently enrolled 10-14-year-old students who are falling behind (two or more years behind grade for age)

262.5 Cumulative risk of school-leaving attributable to childbirth or marriage among 15-24-year-olds attending school at age 12 , five sub-Saharan countries

282.6 Ability to read a simple sentence among young women aged 15-24 who never attended secondary school, according to last grade attended (percent)

$30 \quad 2.7$ Girls aged 10-14 who never attended school as a percent of all out-of-school girls aged 10-14

$31 \quad 2.8$ Girls aged 15-19 who ever attended school as a percent of all out-of-school girls aged 15-19

32 2.9 Percent of girls out of school, by age, according to highest grade completed 
$37 \quad 3.1$ Average daily hours in household work for rural, unmarried 15-16-year-olds, by sex and enrollment status

$38 \quad 3.2$ Premarital sex among 15-17-year-old students and non-students (percent)

$41 \quad 3.3$ Economic rates of return to schooling by school level

443.4 Rates of school attendance and labor force participation among adolescents, by region and sex

$45 \quad 3.5$ Transition from school to first job by age, Egypt

$46 \quad 3.6$ Labor force participation rates of adolescents and youth in the United States, 2007

\section{Tables}

725.1 Programs in compendium by type and region

$75 \quad 5.2$ Girl-friendly features of programs in compendium

$79 \quad 5.3$ Programs in compendium according to extent and type of evaluation 


\section{NEW LESSONS FOREWORD}

If you want to change the world, invest in an adolescent girl.

An adolescent girl stands at the doorway of adulthood. In that moment, much is decided. If she stays in school, remains healthy, and gains real skills, she will marry later, have fewer and healthier children, and earn an income that she'll invest back into her family.

But if she follows the path laid down by poverty, she'll leave school and enter marriage. As a girl mother, an unskilled worker, and an uneducated citizen, she'll miss out on the opportunity to reach her full human potential. And each individual tragedy, multiplied by millions of girls, will contribute to a much larger downward spiral for her nation.

Investing in girls is the right thing to do on moral, ethical, and human rights grounds. Perhaps no other segment of society globally faces as much exploitation and injustice, and we owe girls our support as integral, yet overlooked, members of the human family.

Investing in girls is also the smart thing to do. If the 600 million adolescent girls in the developing world today follow the path of school drop-out, early marriage and early childbirth, and vulnerability to sexual violence and HIV/AIDS, then cycles of poverty will only continue.

Yet today, only a tiny fraction of international aid dollars is spent-and spent effectively - on needs specific to adolescent girls. That underinvestment is the reality the Coalition for Adolescent Girls (www.coalitionforadolescentgirls.org) is trying to change.

Launched by the United Nations Foundation and the Nike Foundation in 2005, the Coalition's goal is to offer fresh perspectives, diverse resources, and concrete policy and program solutions to the challenges facing adolescent girls in developing countries. Our first step? Uncover adolescent girl-specific data and insights to drive meaningful action.

In 2008, Girls Count: A Global Investment and Action Agenda did just that. Authored by Ruth Levine from the Center for Global Development, Cynthia B. Lloyd of the Population Council, Margaret Greene of the International Center for Research on Women, and Caren Grown of American University, Girls Count laid out the case for investing in girls and outlined actions that policymakers, donors, the private sector, and development professionals can and should take to improve the prospects for girls' wellbeing in the developing world.

Today, we are pleased that Girls Count has gone into its second printing. More importantly, the authors have continued beyond that groundbreaking work to explore girls' lives further. Together, the results comprise the new Girls Count series:

- In New Lessons: The Power of Educating Adolescent Girls, Cynthia B. Lloyd and Juliet Young demonstrate that education for girls during adolescence can be transformative, and they identify a broad array of promising educational approaches which should be evaluated for their impact.

- In Girls Speak: A New Voice in Global Development, Margaret Greene, Laura Cardinal, and Eve GoldsteinSiegel reveal that adolescent girls in poverty are acutely aware of the obstacles they face, but are full of ambitious, powerful ideas about how to overcome them.

- In Start with a Girl: A New Agenda for Global Health, Miriam Temin and Ruth Levine describe the positive multiplier effect of including adolescent girls in global health programs and policies-and the risks if they continue to be left out.

- Through Girls Discovered: Global Maps of Adolescent Girls, Alyson Warhurst, Eva Molyneux, 
and Rebecca Jackson at Maplecroft join the ranks of Girls Count authors by using their unique quantitative analysis of girl-specific data to literally put girls on the global map.

- Finally, Caren Grown is exploring how income and savings in the hands of girls can drive fundamental social change. This work will be the first to shine a light on this exciting but little-understood area of global development.

Each report takes us deeper into the lives of adolescent girls and contains an action agenda outlining how the global community can count girls, invest in girls, and advocate for girls. Taken together, the Girls Count series presents a powerful platform for action. Please visit coalitionforadolescentgirls.org for more information.

The girl effect is the missing and transformative force needed to achieve the Millennium Development Goals, with the unique power to break the intergenerational cycle of poverty. It is about the lives of 600 million adolescent girls, and the millions more lives that are affected by them. Girls do indeed count.

Mama Fos

Maria Eitel

President

The Nike Foundation

October 2009

\section{Kaing Buahte Caluin}

\section{Kathy Bushkin Calvin}

EVP \& COO

The United Nations

Foundation

October 2009 


\section{NEW LESSONS ACKNOWLEDGEMENTS}

Many people and organizations contributed to this report. I would like to begin by thanking the agencies and nongovernmental organizations and their headquarters staff who provided information about their programs, filling out questionnaires and supplying follow-up information via phone and email to answer many of our questions and help us increase the accuracy and comparability of our compendium on girl-friendly educational programs for adolescents. These include Cheryl Faye and Changu Mannathoko from the United Nations Girls' Education Initiative (UNGEI); Kumkum Kashiparekh, Sarah Bouchie, and Margaret Meagher from CARE; Salina Sanou, Codou Diaw, Marema Dioum, and Hendrina Doroba from the Forum for African Women Educationalists (FAWE); Ruthi Hoffman, Alisa Phillips, Rohit Pradhan, M.H. Tansen, and Renu Bowl of World Vision; Helen Stannard and Nina Weisenhorn of the International Rescue Committee; Emily Leys at Room to Read; Saima Gowani, Kathy Bartlett, and Caroline Arnold from the Aga Khan Foundation; Sharon Nwankwo from the United States Agency for International Development's (USAID) Ambassadors' Girls' Scholarship Program; Michelle Akpo from the Academy for Educational Development (AED); Martha Saldinger from Winrock International; Kadiatou Coulibaly from World Education; Vicky Colbert, Clarita Arboleda, and Carmen Perez of the Escuela Nueva Foundation; Obie Shaw of the Peace Corps in Mauritania; Helge Brochmann and Eldrid Kvamen Midttun of the Norwegian Refugee Council; Sajeda Amin, Martha Brady, Kelly Hallman, Judith Bruce, and Hannah Taboada of the Population Council; and Cynthia Steele of EMpower.

During Juliet Young's field visit to Mali, Yoby Guindo and Dagaba Diakité of CARE took extensive time to facilitate visits to their Development Education for Girls' Empowerment (DEGE) project sites and also to arrange for meetings with leaders of other organizations, including Kadiatou Maiga, National Coordinator for FAWE-Mali, and Maria Keita, Deborah Fredo, and Cheikh Coulibaly at l'Institut pour l'Éducation Popu- laire (IEP) and Ciwara Community School. Amadou Tamara, field manager for Groupe d'Animation Action au Sahel Mali (GAAS-Mali, CARE's local implementing partner), Lapa Augustin Tiama, Kadidia Arama, Suleimane Sarré, Salimata Arama, Issa Guindo, Aminata Arama, Augustin Arama, and other community management committee members, instructors, and students in the communities of Monobondo, Dogobala, Mandoli, and Tiokani in Barasara Commune, Mali, shared ideas and insights in interviews.

Since the beginning of the project, we have been guided by an Advisory Task Force, which met several times at the beginning of the project and provided excellent guidance in setting directions in the early phases of the project. The members of the Task Force include: Elizabeth King at the World Bank; Lynn Murphy at the William and Flora Hewlett Foundation; Jenny Perlman Robinson at the Women's Refugee Commission; George Ingram at the Education Policy and Data Center, AED; Nicholas Burnett at the United Nations Educational, Scientific and Cultural Organization (UNESCO); Sarah Bouchie at CARE; Chloe O'Gara at Save the Children; Deon Filmer at the World Bank; Gene Sperling, formerly at the Council on Foreign Relations and currently at the United States Department of the Treasury; Caren Grown at American University; and Marlaine Lockheed of Princeton University's Woodrow Wilson School of Public and International Affairs.

The project has been supported by two consultants who have successively taken responsibility for the compendium on girls' schooling programs. Ragini Dutt began the project in October 2007 and helped develop the compendium and collect a first round of data. After she left to take up a position at UNGEI a year later, Juliet Young continued the work, deepening the quality of the data through careful checking and follow up, refining the framework for the compendium, and extending its reach through more extensive contacts. Without Juliet, I could not have completed 
this project. I was happy that she was able to coauthor Chapter 5 with me and provide good feedback and advice on the rest of the report as well.

I am grateful for careful comments on the report from the Nike Foundation, the Women and Population Program at the United Nations Foundation; Jenny Perlman Robinson of the Women's Refugee Commission; George Ingram of the Education Policy and Data Center at AED; Sajeda Amin and Judith Bruce at the Population Council; and Mima Perisic at the United Nations Children's Fund (UNICEF).

I want to acknowledge the support of my colleagues on adolescent girls at the Population Council, in particular Judith Bruce, who managed this project as part of a larger project with the United Nations Foundation and the Nike Foundation; Judy Diers, who coordinated administrative details; Christina Tse, who coordinated all aspects of the design and layout; Robert Heidel, who edited the report; Melissa May, who managed all aspects of dissemination and communication; and Barbara Miller, who provided technical support for the development of the compendium and administrative coordination of the project, as well as preparing the figures, tables, and charts. Satvika Chalasani, who served as a summer intern at the Population Council, provided updated tabulations from the DHS for Chapter 2. I am grateful to UNGEI for agreeing to take over the management of the compendium after publication of this report.

Finally I want to acknowledge our donors: the United Nations Foundation and the Nike Foundation.

Cynthia B. Lloyd

Consulting Senior Associate

Population Council 


\section{NEW LESSONS INTRODUCTION}

Over the past 15 years, girls' education in the developing world has been a story of progress. Interest and financial backing from the development community have grown steadily in response to accumulating evidence documenting the many benefits of girls' schooling, and female education is now a major part of global development commitments, including the Millennium Development Goals.

Alongside this global interest, school enrollments have climbed. The large majority of girls now attend primary schools, and most girls attend school into early adolescence. The gender gap is closing, and higher enrollments are boosting economic returns. But there is still a long way to go. Girls' primary school completion rates are below $50 \%$ in most poor countries. According to a 2008 UN report, 113 countries failed to reach the 2005 Millennium Development Goals on gender equality in education. Few show prospects of meeting them by 2015 . The situation is worse by the time girls reach secondary school. In Africa, girls' secondary school enrollments have fallen relative to boys' since 2000 . And throughout the developing world, young women are underrepresented in the workforce.

One of the most significant problems in most developing and conflict-affected countries is the failure of education systems to realize their potential to empower adolescent girls. Fewer girls attend formal education in later adolescence and, of those who do, many are in formal primary rather than secondary school, where one might expect to find them. The fact that the majority of donor funding is directed toward girls' primary school attendance may contribute to this pattern. Existing education programs are bereft of curricula with adolescent learning needs in mind, in particular the needs of girls whose lives often close down rather than open up during adolescence. For girls, this makes the transition to secondary education and the workplace challenging, if not impossible. There has been a notable rise in the number of non-formal educational programs with girlfriendly features. But their coverage and impact for adolescent girls are unknown both in the short run, for their school progress, and in the long run, for how well girls are prepared for adulthood, paid work, and household management.

While primary schooling is a basic need for all children, education for adolescents can be transformative. Many benefits are immediate. The prospect of secondary education motivates girls to complete primary school. Being in school along with boys during adolescence fosters greater gender equality in the daily lives of adolescents. Education for adolescent girls helps them avoid long working hours and early pregnancies, and lowers their risk of HIV/ AIDS. In the long term, secondary education offers greater prospects of remunerative employment, with girls receiving substantially higher returns in the workplace than boys when both complete secondary school.

\section{A new global compendium}

New Lessons goes beyond the global action agenda in Girls Count, our previous report on girls' education, released in 2008. It seeks to increase understanding about the education of adolescent girls. Given the lack of information on education programs for girls, it provides new data and analysis from research on more than 300 past and current programs and projects. It offers evidence on how proven practices, including scholarships for girls and the recruitment and training of female teachers, can increase the number of adolescent girls attending school and highlights the pedagogical approaches that enhance learning and employment.

Very few girl-friendly education programs have been evaluated, and even fewer have made their evaluation reports publicly accessible. Thus most approaches remain promising but unproven. Furthermore, the 


\section{One of the}

most significant problems in most developing and conflict-affected countries is the failure of education systems to realize their potential to empower adolescent girls. information collected for this report suggest that relatively few programs are specifically designed with the developmental and learning needs of adolescent girls in mind. Rather, the evidence suggests that adolescents girls are often subsumed under programs for younger girls or adult women. Our compendium of policies and programs also suggests that skill development and knowledge acquisition vary enormously by grade level, both within and across countries, due to variations in school quality.

The report is also one of the first to stress the need for more data on the growing non-formal education sector. While there has been a rapid rise in NGOfunded non-formal schools, there are no data on enrollments or learning outcomes for those participating in the non-formal sector-and no data on the social and economic returns for girls who enroll in these programs. But evidence suggests that enrollment in non-formal institutions is significant among adolescents and that many girls move between formal and non-formal education in response to the pressures they uniquely experience.

\section{From analysis to policy agenda}

Even with a shortage of information on adolescent programs in the formal and non-formal sectors, this report builds a case for rigorous efforts by governments and NGOs to improve the educational standards for adolescent girls. To continue the progress of the past 15 years, interested parties can collaborate to build on the successful programs discussed in this report.

Flowing from the evidence is our educational manifesto for girls. In that manifesto, we outline three developmental and learning phases during adolescence and, within each, identify learning goals and preferred educational pathways for girls. The strong evidence of a high return for girls from formal secondary school and the lack of evidence of returns from non-formal alternatives underlie our preference for formal school at each phase of adolescent development. In our view, continuing education during adolescence is a necessary first step for girls to overcome a history of disadvantage in civic life and paid employment. We also identify the curricular building blocks that should support girls in their transition to adulthood. 
Education for girls during adolescence alone cannot overcome the gender gap. Social forces that prevent the majority of girls from completing secondary education also manifest themselves in the workplace and in societal norms, making it hard for many girls to translate their educational gains into remunerative employment. Other complementary social efforts will be required to open previously closed pathways for girls. But if girls are not adequately educated during childhood and adolescence, they will not be in a position to seize new opportunities. These complementary efforts, well outlined in Girls Count, include a supportive legal environment that fully recognizes the equal rights of girls and women and enshrines those rights in law and practice.

This is the new landscape of girls' education, and here are ten actions we propose to support it.

\section{Taking action for adolescent girls' education}

\section{Collect and compile data on non-formal education}

A questionnaire module on non-formal education should be introduced into national household surveys and censuses to collect data on the extent and coverage of non-formal schooling, and its implementation should be tested on a pilot basis in several countries.

\section{Build and maintain a global database for education programs for adolescent girls}

Our program and project compendium should become the platform for the development of a dynamic global database of education programs that serve adolescent girls. Its scope should be expanded in order to identify promising models appropriate to girls' educational needs in different settings. This database should be made available to donors, practitioners, and international agencies.

\section{Expand opportunities for girls to attend secondary school}

Governments should define basic education as education through lower secondary school, or to age 16. To accommodate the resulting influx of students, governments and the private sector should increase the number of formal and non-formal secondary school places in the educational system by extending existing primary school facilities and offering well-

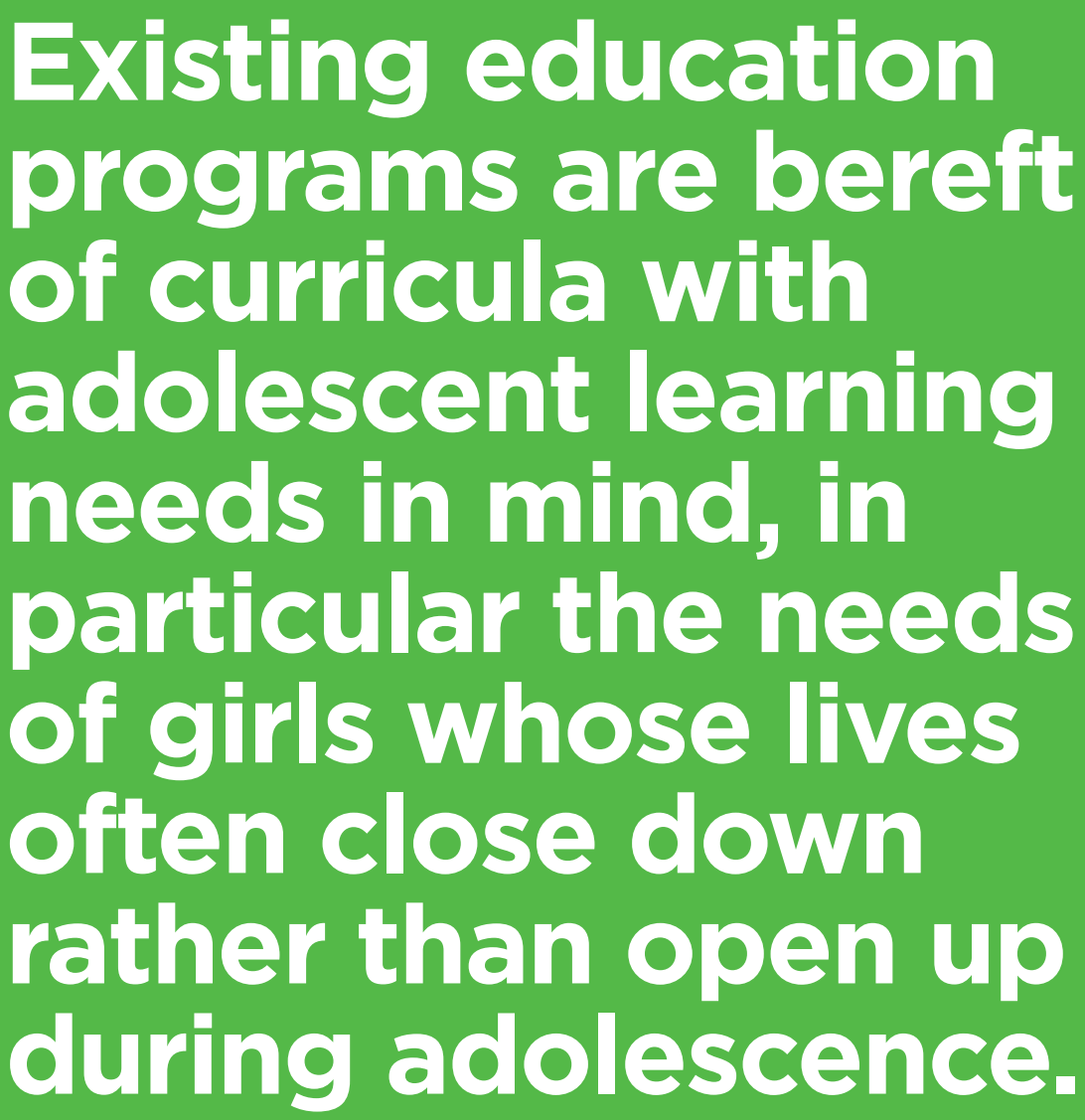

Existing education programs are bereft of curricula with adolescent learning needs in mind, in particular the needs of girls whose lives often close down rather than open up
during adolescence. 


\section{Continuing \\ education during adolescence is a necessary first step for girls to overcome a history : of disadvantage in civic life and paid employment.}

targeted subsidies to disadvantaged girls to attend either public or private secondary schools.

\section{Support the non-formal education system The non-formal education system must be well integrated with the formal system and be designed to help adolescent girls to achieve their educational and developmental needs. Non-formal schools must be upgraded, certified, and licensed, and path- ways should be established from the non-formal to the formal sector, as well as from the formal to the non-formal sector. Baseline surveys should assess educational backgrounds, skills, and knowledge gaps of population subgroups who are potential benefi- ciaries, in order that educational systems can be designed to address existing needs.}

\section{Develop after-school tutoring and mentoring programs in both primary and secondary schools These programs should support girls' education and development and enhance their chances of pro- gressing to or succeeding in secondary school. They can provide one-on-one mentoring and ensure that after-school hours are dedicated to study and not to part-time jobs or family obligations. The programs can also provide supplementary training beyond the formal curriculum for the development of skills for social and civic participation - in the process teaching basic health, reproductive health, and financial literacy.}

\section{Produce curricula relevant to adolescent girls} Adolescent girls in the developing world need to acquire remunerative and marketable skills which are not taught at home, such as facility with computers, fluency in an internationally spoken language, financial skills, and knowledge of social systems. New methods to promote interactive and collaborative learning can help develop critical thinking and decisionmaking skills and instill a habit of lifelong learning - capacities that will equip girls for a rapidly changing world.

\section{Offer post-secondary vocational programs} The majority of girls who complete secondary school do not continue on to university. For girls going directly into the workforce, it is important to offer programs that support them in making a successful transition to remunerative work and household financial management. Such programs must be based on market assessments and provide relevant, flexible 
skills for employment and professional growth in an ever-changing global economy.

8. Provide training and ongoing incentives for women to enter and remain in teaching

Female teachers can reinforce the importance of education to girls, and many girls respond better to female teachers. The number of women who enter teaching is increasing, and teaching appears to be a viable, desirable profession for women who have completed secondary school.

\section{Promote easy transitions between}

\section{non-formal and formal schools}

Complementary schools should be developed within the non-formal education system to help girls, many of them primary-school dropouts, continue on to formal secondary school. They should also offer younger adolescents the opportunity to reenter formal primary school.

\section{Encourage and evaluate innovation}

The curricula in both formal and non-formal schools attended by adolescents should be revamped to develop new approaches to education. Although many of the current approaches are unproven, some appear particularly promising. To test their effectiveness, research/program partnerships should invest in designing and implementing pilot projects to measure and assess their impact on girls over the short and medium term. 


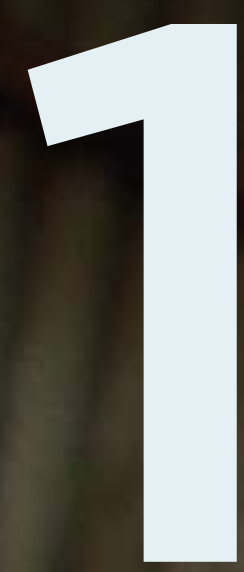

ADOLESCENT GIR
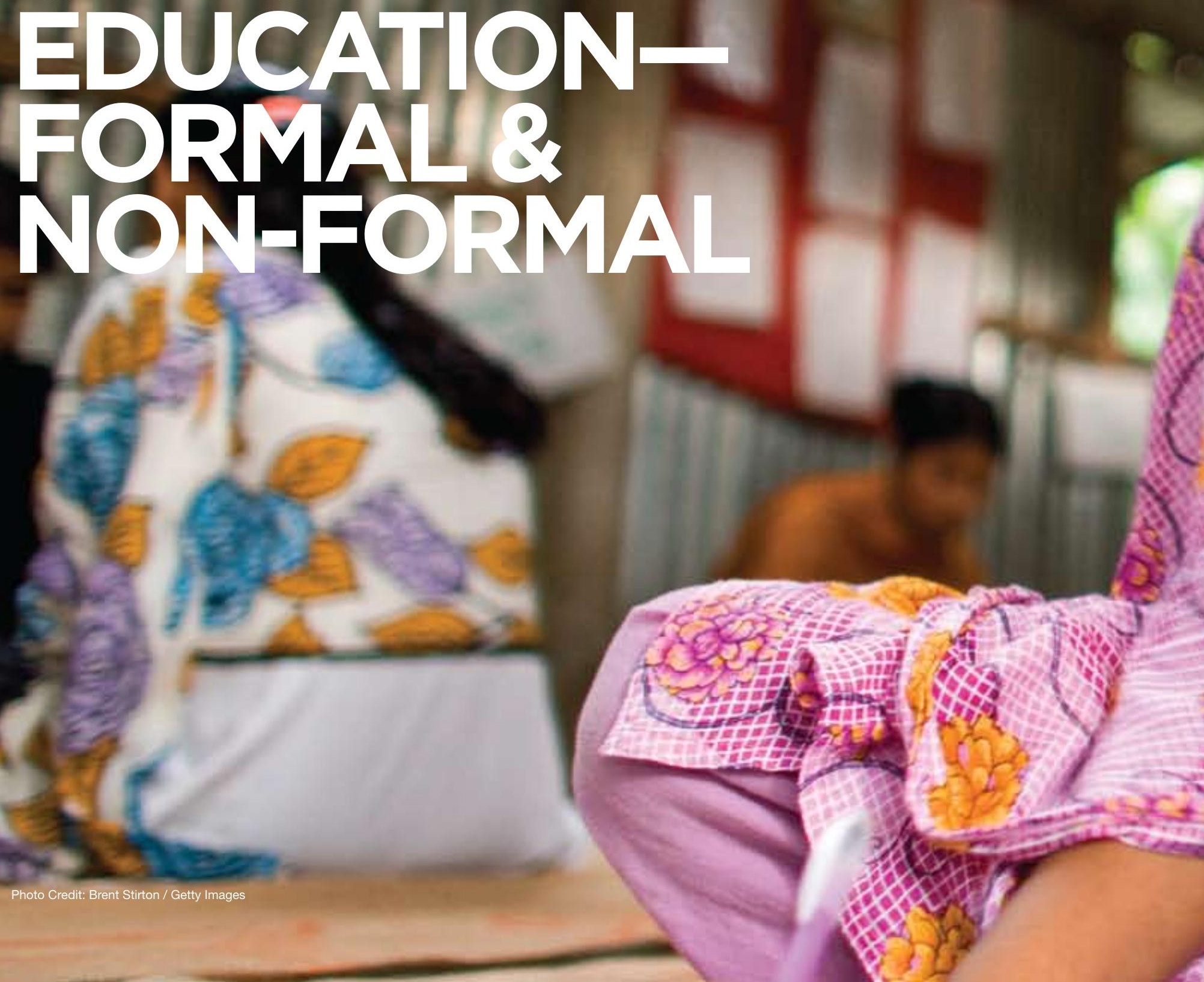


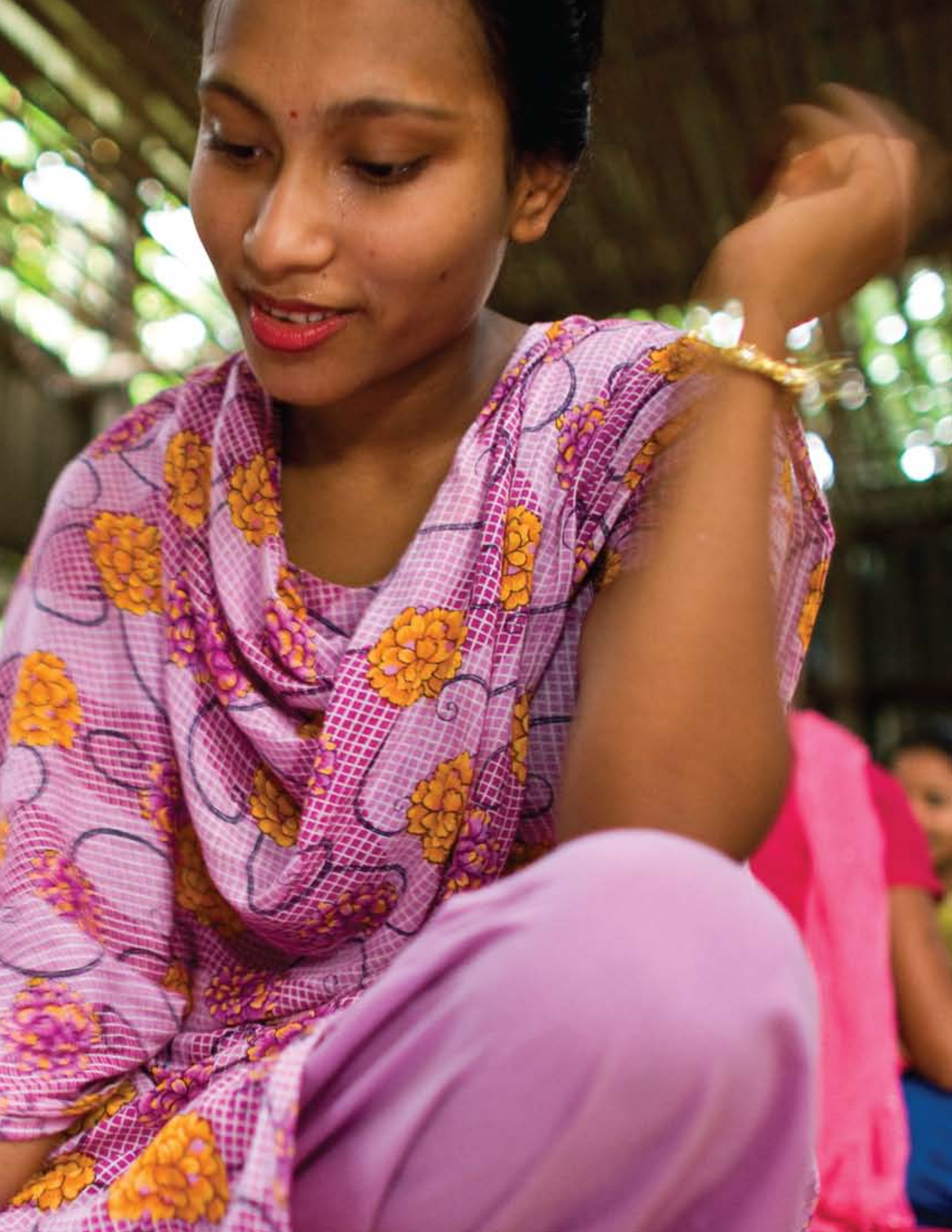


If girls are to make the shift from economic dependency to selfsufficiency, universal access to a range of educational opportunities is essential for sustained learning during adolescence, regardless of girls' prior educational backgrounds. Girls' educational needs during this phase of the life cycle, particularly in the poorest countries and communities, are acute. Girls have not yet translated recent rapid improvements in school enrollments into equivalent gains in economically productive work and civic engagement. This is especially true in settings where the roles of boys and girls begin to diverge sharply in early adolescence. Many factors contribute to the gender imbalances, but enhancing the quality and relevance of learning opportunities for adolescents can prepare and empower girls for a range of adult roles beyond the traditional roles of homemaker, mother, and spouse with benefits not just for the girls but also for their families and communities.

This report is intended as a "call to action" for governments, education ministries, donors, NGOs, and corporations to collaborate, innovate, and invest in a range of educational opportunities for adolescent girls. Those opportunities are transformative not only in the skills and knowledge acquired, but also in the attitudes, aspirations, and self-confidence forgedand in the pathways taken. Further benefits will be reaped by national economies in terms of more rapid rates of economic growth if gender gaps in education were to close more rapidly and the educational needs of adolescent girls were to be more completely addressed (World Bank 2001).

\section{A sequel to Girls Count}

Girls Count: A Global Investment and Action Agenda (Levine et al. 2008) presented a global agenda of investment and action for girls living in the poorest countries and communities. The agenda included recommended actions for four groups of social actors: (1) national governments, (2) donors and technical agencies, (3) employers, and (4) civil society. The agenda includes actions to count girls with better data in order to make them more visible, to invest in girls in strategic areas of need, and to provide them with a fair share of resources and opportunities. These recommendations were informed by rich evidence of the many social and economic benefits that are directly or indirectly tied to girls' welfare and were designed to break the cycle of past neglect.

Within each recommended arena of action, educational investments feature prominently. Governments were called on to provide adolescent girls with equitable access to social services, including all levels of education. Donors and technical agencies were called on to support post-primary education options for girls, including investing in educational quality and lifting constraints limiting the number of girls making the transition from primary to secondary school. Large national and multinational corporations were called on to invest in schools through building construction, teacher training, scholarships, and distance learning. Finally, civil society institutions were encouraged to create safe spaces for girls as a platform for catch-up education, to develop informal educational opportunities for out-of-school girls such as accelerated learning and school-to-work programs, and to provide after-school programs to give girls needed skills.

These education recommendations sit within a larger context of policy and legal frameworks. These societal frameworks continue to discriminate against adolescent girls in law and practice, with the result that girls' aspirations and opportunities are constrained. While a good-quality education is necessary for girls to fulfill their potential for themselves and for society, it is not sufficient. Much more can be done to deepen and enrich girls' educational experiences so that they are poised to capture the opportunities 
unleashed if this global agenda for girls were to become a reality. When girls go to school, they are exposed for the first time to socializing influences beyond those experienced within their families. Thus school as an institution and the experiences it provides have the potential to be transformative by raising a girl's sights for herself beyond those of older women in her community and by providing her with the relevant knowledge and skills to capitalize on an expanding set of opportunities.

New Lessons goes beyond Girls Count in several important ways. First, this report seeks to deepen our understanding of the education of adolescent girls by exploring exactly where they are in the educational system, how they are faring, and what they are learning. Second, it documents some less wellknown educational advantages for girls of staying enrolled during adolescence. Finally, it presents new data on key features of more than 300 programs and projects in support of education for adolescent girls in developing regions of the world. These data are presented within a framework that allows for an assessment of existing educational investments in relation to documented needs and to proven or promising strategies.

\section{Setting the stage}

Girls' education was embraced as a mainstream investment for development around the time Summers (1994) presented his seminal analysis quantifying the high economic and social returns to women's education in poor countries. Since then, attention to girls' schooling among development professionals and researchers has blossomed with strong reinforcement from the international community in the form of major international commitments. In 2000, in several different venues, governments agreed to eliminate gender disparities in primary and secondary education, preferably by 2005 , and at all levels by 2015 (Millennium Development Goal No. 3, and Goal No. 5 in Education for All [EFA] Dakar Framework for Action, see Box 1.3).

Trends in enrollment and gender equity: In parallel with this heightened interest and effort has come rapid growth in girls' primary school enrollment rates and a decline in gender gaps at most levels of education. Nonetheless, primary school completion rates ${ }^{1}$

\section{BOX 1.1}

\section{Why girls? Why not boys too?}

Adolescent boys will also benefit from many of the recommendations in this report. Nonetheless, the report focuses on adolescent girls. Research has taught us that adolescent girls face extra challenges not faced by boys in staying in school. We also know that girls can expect to reap greater returns than boys if they are enabled to do so, and this has positive ripple effects for national economies. First, for adolescent girls, educational attainment and sexual and reproductive transitions are closely interrelated in that an unwanted pregnancy or an early marriage can derail a school career prematurely. As boys typically marry later than girls and do not face the same risks and responsibilities associated with pregnancy, their sexual maturation and behavior do not have the potential to interfere with their school progress in the same way. Second, even where girls and boys attain similar levels of education and perform equally well in school, girls are typically less able to translate their educational accomplishments into remunerative work and civic engagement (Buvinic et al. 2007). This well-documented gender gap in labor force participation among young adults is the expression of many factors, including differences between boys and girls in aspirations and life choices, as well as differences in labor market opportunities. Nonetheless, school is a major factor in the socialization of adolescents, with teacher attitudes and behaviors, the content of the curriculum, and the opportunities within these schools for participation and leadership all potentially limiting girls' visions for themselves and their futures. Third, within all occupations, the earnings increment from an extra year of education is much greater for women than men; as a result, the earnings gap between men and women declines with education (Aslam et al. 2008).
We use grade 6 completion rates as a proxy for primary school completion rates because they are more comparable across countries, given variations in the number of years in the primary school cycle. 
for young women still are below $50 \%$ in the majority of poor countries outside Latin America and the Caribbean (Figure 1.1), and in nearly half of these countries gender gaps in primary completion still exceed 10 percentage points (Figure 1.2). ${ }^{2}$ The situation with respect to secondary school is worse still. Indeed in sub-Saharan Africa, the gender gap in secondary enrollment has actually grown wider since 2000 , with the gender enrollment ratio falling from 82 to 80 girls for every boy in secondary school by 2006 (United Nations 2008). In southern and western Asia, the female-male enrollment ratio for secondary school is around 85 , having improved from a ratio of 77 (southern Asia) and 80 (western Asia) recorded in 2000 (United Nations 2008). The recent UN report on the MDGs (United Nations 2008) states that of the 113 countries that failed to reach the MDG on gender equity in education by 2005 , only 18 are likely to achieve it by 2015 , given current trends. At the midpoint of the trajectory towards 2015 , the United Nations report $(2008,5)$ concludes that "the limited progress in empowering women and achieving gender equality is a pervasive shortcoming that extends beyond the goal itself. Relative neglect of, and de facto bias against, women and girls continues to prevail in most countries."

Recent rapid rise in non-formal schooling: Along with the push to universalize schooling in the past 10 years has come a rapid rise in the number of NGO schools, which are typically non-formal schools (UNESCO 2007). ${ }^{3}$ Indeed, non-formal education is often the main route to learning for disadvantaged girls. Ironically, enrollment in non-formal schools is rarely captured in national school enrollment data, thus minimizing the visibility of these efforts and their ability to contribute to the above-stated goals. Data collection systems have not caught up with the growth of non-formal schools, leaving policymakers at a loss in assessing the value of these initiatives.

Because of the growing importance of NGOs in the delivery of educational services, as well as the growing diversity of educational forms, those responsible for the 2008 UNESCO Education for All report commissioned 19 national studies on nonformal schooling, as well as in-depth case studies of 29 countries' education systems. It is striking that few of the authors of these background papers were able to find data on the extent of participation in the non-formal educational sector or on the impact of non-formal education on overall learning objectives for the countries they were commissioned to study. Typically, the reports catalogued a list of programs or programmatic types without any data on levels of enrollment or learning outcomes.

Part of the challenge to data collection in this area is that non-formal education programs are often run on an ad-hoc basis with little coordination, guidance, control, or funding from the government (e.g. Tanzania, MacPherson 2007). Government regulations for non-state educational providers can often be cumbersome as well, thus creating disincentives for providers to register with the government (UNESCO 2007). Only a few countries with more comprehensive educational policies have been successful in integrating non-formal educational alternatives into the overall system and providing options for graduates to join regular schools (Hoppers 2008; Rose 2007). Without registration, licensing, and ultimately accreditation, students enrolled in non-formal educational programs may have difficulty gaining entry to higher levels of education or obtaining jobs from employers who are unfamiliar with the programs attended. Box 1.2 outlines some of the main differences between formal and non-formal schools.

\section{Situating adolescents within the education system}

When target groups are described in education reports, they typically include children (those of "school-age," under the age of 18 according to the United Nations Convention on the Rights of the Child), youth (those over the age of 15 who have reached the minimum age for work according to the ILO Minimum Age Convention of 1973), or adults who are over the age of 18 . The word adolescent is almost never mentioned. On the other hand, the term adolescent is frequently used in conversations related to health because adolescence is commonly understood to begin with puberty. UNICEF and WHO define adolescents as those aged 10-19. Because formal school systems are designed to follow a set sequence of curricular material regardless of age, those who start late can find themselves sharing a classroom with younger children, a situation that often leads to early dropout, particularly for girls. The very fact that the learning trajectory does not always fit well with the developmental trajectory in many poor 


\section{FIGURE 1.1}

\section{Grade 6 completion rates for 20-24-year-old girls}

In many countries, primary school completion rates fall well below $100 \%$.

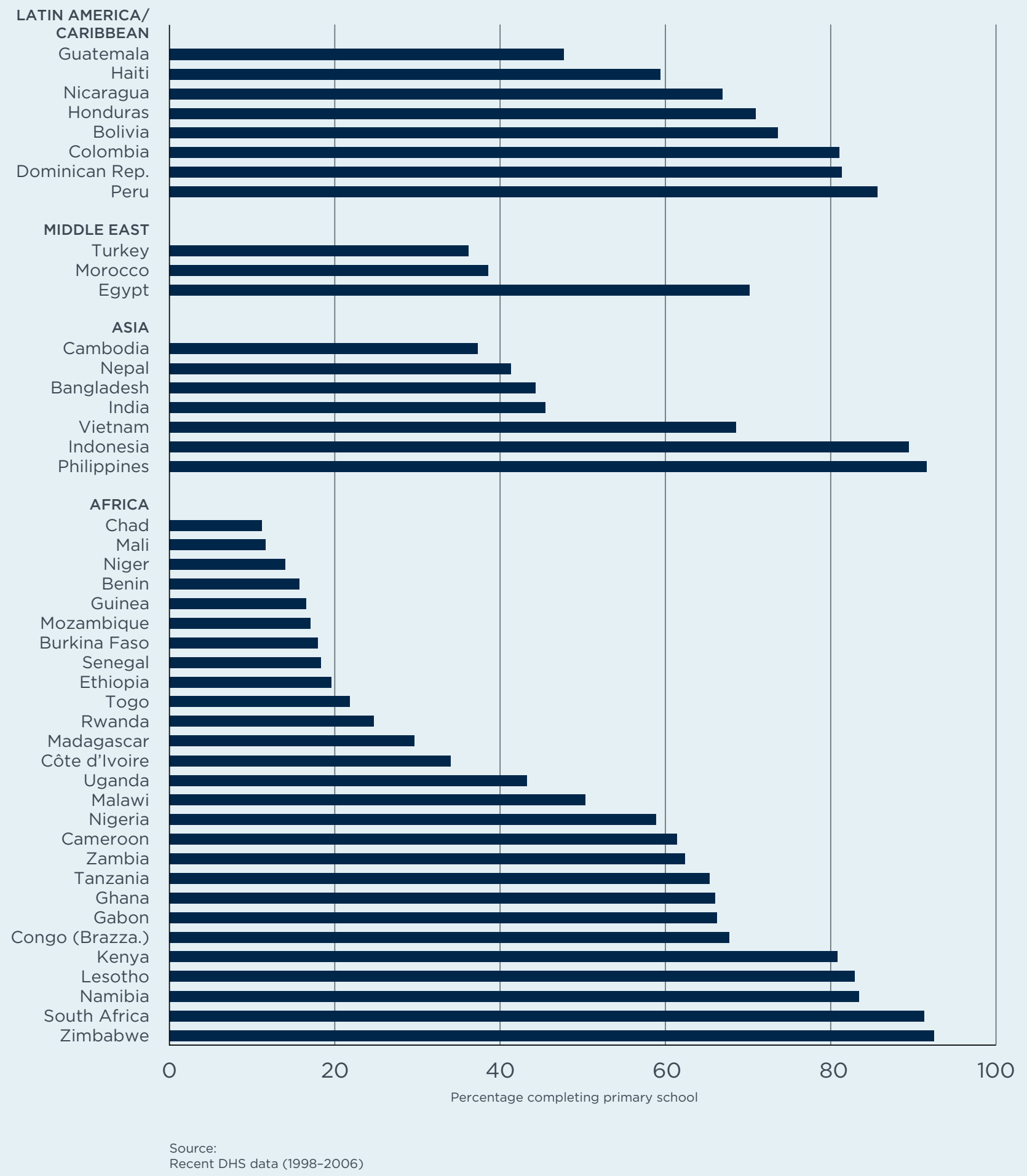




\section{Percentage point gender gap (boys minus girls) in grade 6 completion rates for 20-24-year-olds}

Despite dramatic progress for girls, gender gaps remain.

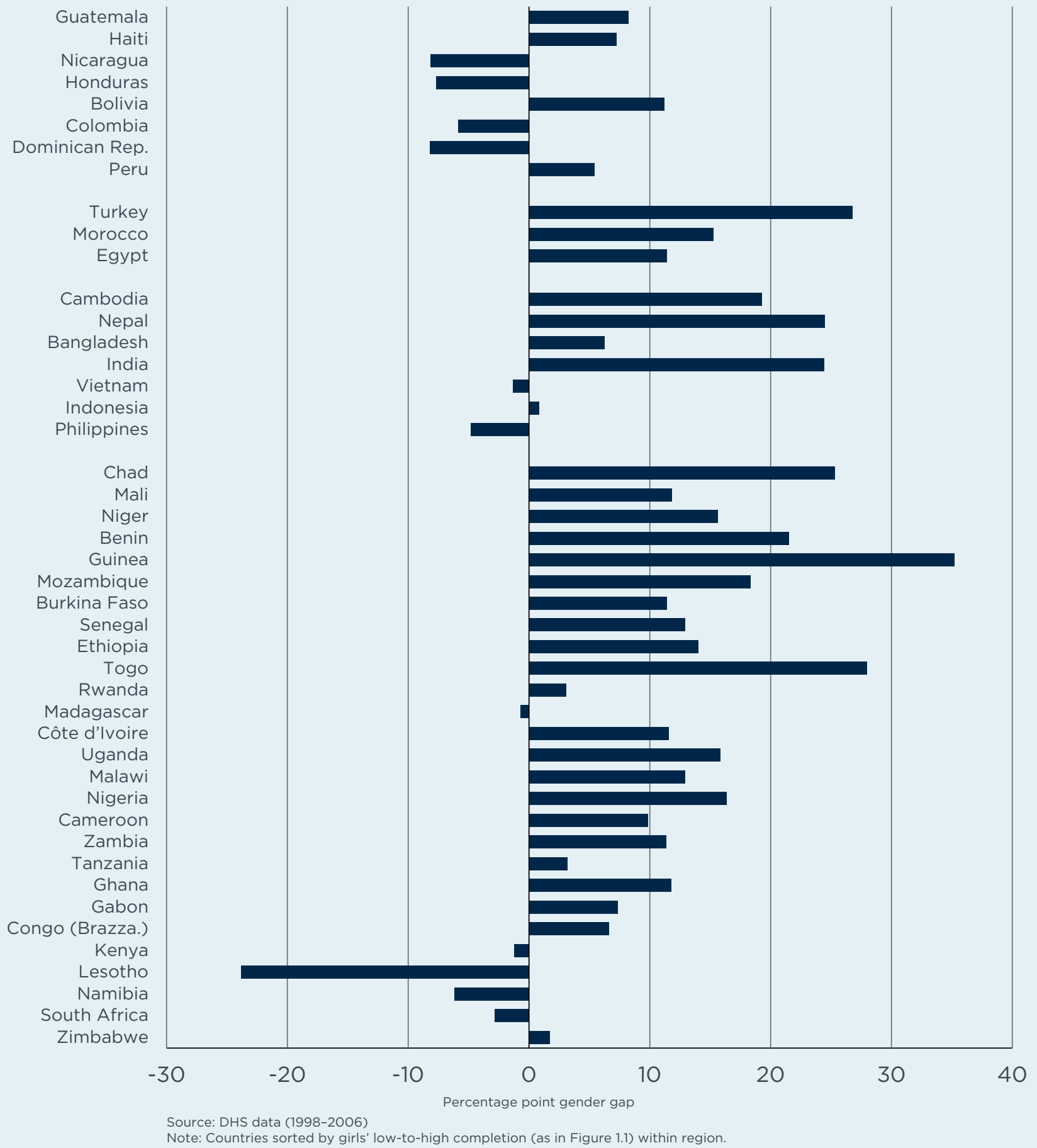


countries - if children get off to a late start or resume their education after some interval-has been part of the rationale for the development of non-formal learning alternatives. Nonetheless, these are often described as serving children, youth, or adults, but rarely adolescents. Indeed, Hoppers (2008) speculates that coverage for adolescents within the non-formal educational sector may be substantially less than for younger children or adults even in countries where non-formal schooling is common.

Among the six goals agreed to under the Education for All (EFA) banner as part of the Dakar Framework for Action (World Education Forum 2000) was one which, until now, has been relatively neglected. EFA Goal No. 3 focuses in particular on the education needs of adolescents without saying so explicitly. In Goal No. 3, governments are committed to "ensuring that the learning needs of all young people and adults are met through equitable access to appropriate learning and life-skills programmes" (see Box 1.3). Obviously included among the target population for this goal are older adolescents, ages 15-19. Despite its importance, this internationally agreed upon goal has been largely neglected, partly because it is poorly defined, partly because its economic and social value is not clear, and partly because data are lacking to monitor progress (UNESCO 2008, 91). Implicit in this goal is the recognition that a primary school education is an insufficient preparation for adulthood, and that adolescents and young adults need to continue learning regardless of their prior educational level. EFA Goal No. 3 remains a challenge and an opportunity, particularly for girls.

We can begin to see the complexity of situating adolescents within the education system when we overlay developmental age on the educational pathways potentially available to adolescents within existing education systems. In Chart 1.1 we sketch the typical formal and non-formal system pathways from an adolescent perspective. At age 10, adolescents may be close to the end of formal primary school if they started on time and live in countries where primary school is only five years, or, as is often the case in many African countries, they may be just beginning primary school. On the other hand, some out-ofschool 10 year olds may be taking advantage of non-formal accelerated learning programs (run either by NGOs or by the government) which provide them

\section{BOX 1.2}

\section{Definitions}

\section{Formal Schools}

Standard curriculum

Set number of grades

Common calendar

Registered, licensed, and accredited

Government or nongovernment

\section{Non-formal Schools}

Nonstandard curriculum

Flexible grading

Flexible calendar

Not necessarily registered, licensed, and accredited

Government or nongovernment

\section{BOX 1.3}

\section{Education for All-Goals of the Dakar Framework for Action (2000)}

- Expanding and improving comprehensive early childhood care and education, especially for the most vulnerable and disadvantaged children

- Ensuring that by 2015 all children - particularly girls, children in difficult circumstances, and those belonging to ethnic minorities - have access to and complete free and compulsory primary education of good quality

- Ensuring that the learning needs of all young people and adults are met through equitable access to appropriate learning and life-skills programmes

- Achieving a 50 percent improvement in levels of adult literacy by 2015, especially for women, and equitable access to basic and continuing education for all adults

- Eliminating gender disparities in primary and secondary education by 2005 , and achieving gender equality in education by 2015 , with a focus on ensuring girls' full and equal access to and achievement in basic education of good quality

- Improving every aspect of the quality of education, and ensuring their excellence so that recognized and measurable learning outcomes are achieved by all, especially in literacy, numeracy, and essential life skills 


\section{CHART 1.1}

\section{Educational Pathways for Adolescents}

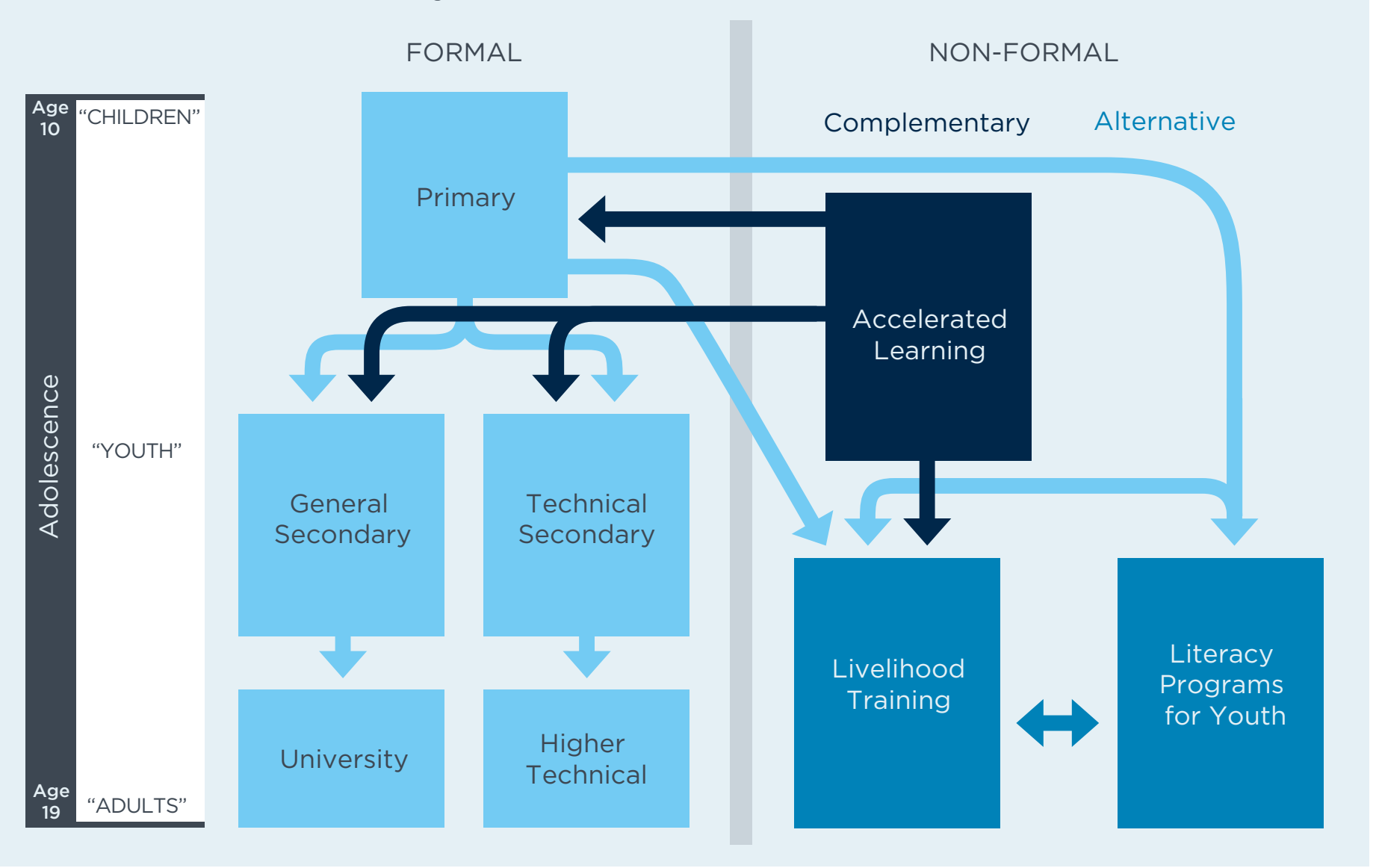

with the opportunity to reenter the formal system in later primary grades or at the beginning of secondary school. Once children reach the age of 15-an age that some programs define as youth (e.g. livelihoods programs) and others define as adults (e.g. literacy programs) - other non-formal opportunities may become available for those who have never been to school or dropped out prematurely including, most typically, literacy and livelihood programs. Primary school completion and transition to either general or technical secondary school can occur almost any time during adolescence depending on the system and the extent of late entry.

Non-formal schools serve a variety of roles for the adolescent population. First, they provide a means for those girls who missed out on school at the right age to catch up and reenter the formal system in the later grades of primary school or enter secondary school directly, if there is proper coordination with the formal system. Non-formal schools serve to complement regular formal schools. Second, non-formal educational programs operate as alternatives (sometimes called equivalency or second-chance programs) to the formal system, addressing the educational needs of adolescents and youth who have missed school all together, dropped out before learning the basics, or opted out of secondary school for academic or financial reasons. Such educational programs can address a range of needs, not only for the educational basics but also for life skills and vocational skills, including leadership training for girls. 


\section{Collecting information on programs and projects}

Convinced of the importance of education for girls during adolescence and lacking good data to document the extent to which their needs are served by both the formal and non-formal educational systems, we decided to build a compendium of recent and current educational programs for adolescent girls as a critical complement to other sources of data. Our goal is to provide a sense of the scope and focus of current activities in relation to girls' educational needs. Initially we had assumed that other groups already working on girls' schooling issues would have assembled at least bits and pieces of such a compendium, but this was not the case.

Throughout the 18 months it took to contact organizations, read websites and project reports, and interview key staff at leading organizations, we were struck again and again by how little was known by the key actors in the field about what was being done, why it was being done, and what lessons were being learned. Indeed, it took many iterations before we developed a workable framework that would fit the diversity of programs and projects that we found and allow us to present the information in a meaningful way. Furthermore, it was rare that we found a program that was explicit in its interest in and support for adolescents; rather, target groups were typically described as children, youth, students, or even sometimes adults, leaving us to try to determine whether those aged 10-19 were eligible and included. In the course of our research, we were contacted several times by other groups that were thinking of embarking on a similar information-gathering exercise, but after learning of our plan, they decided to wait for our results. We were heartened that the United Nations Girls' Education Initiative (UNGEI) was eager to take over and build on our compendium after the publication of this report.

\section{Outline of report}

This report will document the growing diversity of learning needs among adolescent girls in developing countries, as well as current efforts to address them. This diversity is a direct result of recent efforts to universalize schooling. While in the past, non-formal education programs were designed primarily

\section{This report will document the growing diversity of learning needs among adolescent girls in developing countries, as well as current efforts to address them.}


Current class

sizes and teacher

workloads preclude

time for all but

the basics, leaving

life skills-including

HIV prevention

and sexual and

reproductive

health-poorly

taught. to teach basic literacy to those who had never attended school, now non-formal education programs can include: accelerated programs for those interested in reentering the formal educational system after dropping out of school, remedial programs for those who dropped out before completing primary school, flexible but equivalent programs for working adolescents, or livelihoods programs for those who completed formal primary school and were unable to afford or were unsuccessful in competing for a place in secondary school. And even for adolescent girls who are enrolled in formal schooling at the primary or secondary school level, current class sizes and teacher workloads preclude time for all but the basics, leaving life skills-including HIV prevention and sexual and reproductive health-poorly taught. Furthermore, most experts question the educational "relevance" of much of the current curriculum in secondary schools - a curriculum that has been historically resistant to change (World Bank 2005). Thus, even for those in formal schools, some of their learning needs may require supplementary after-school programs in the absence of major curricular reform.

The plan for the report is as follows: In Chapter 2 we look at where adolescent girls are within the education system, how they are faring, and what they are learning. We use the available data to debunk myths, clarify realities, and highlight current and future challenges for adolescent girls' education, including priorities for new data collection. In Chapter 3, we present new evidence about the benefits of education for girls during adolescence and discuss some of the barriers girls face in capturing these benefits, particularly barriers to translating their education into remunerative employment. Chapter 4 draws lessons from past practice and research to identify what strategies have already proven successful, those that are promising but unproven, and those that are unlikely to be successful. Chapter 5 represents the heart of the report with analysis of the information collected in our compendium on 322 programs and projects addressing the needs of girls categorized by key program characteristics. We relate these to lessons learned from past projects and identify gaps in relation to needs. Chapter 6 lays out the educational resources that girls must have access to in order for education to be the transformative experience that will ensure their success. The chapter also outlines some promising new directions for the development 
of programs and projects in light of previously identified gaps. Given the many promising but unproven girl-friendly strategies that have been identified, we offer suggestions for programmatic experimentation complemented by well-designed impact evaluation. 


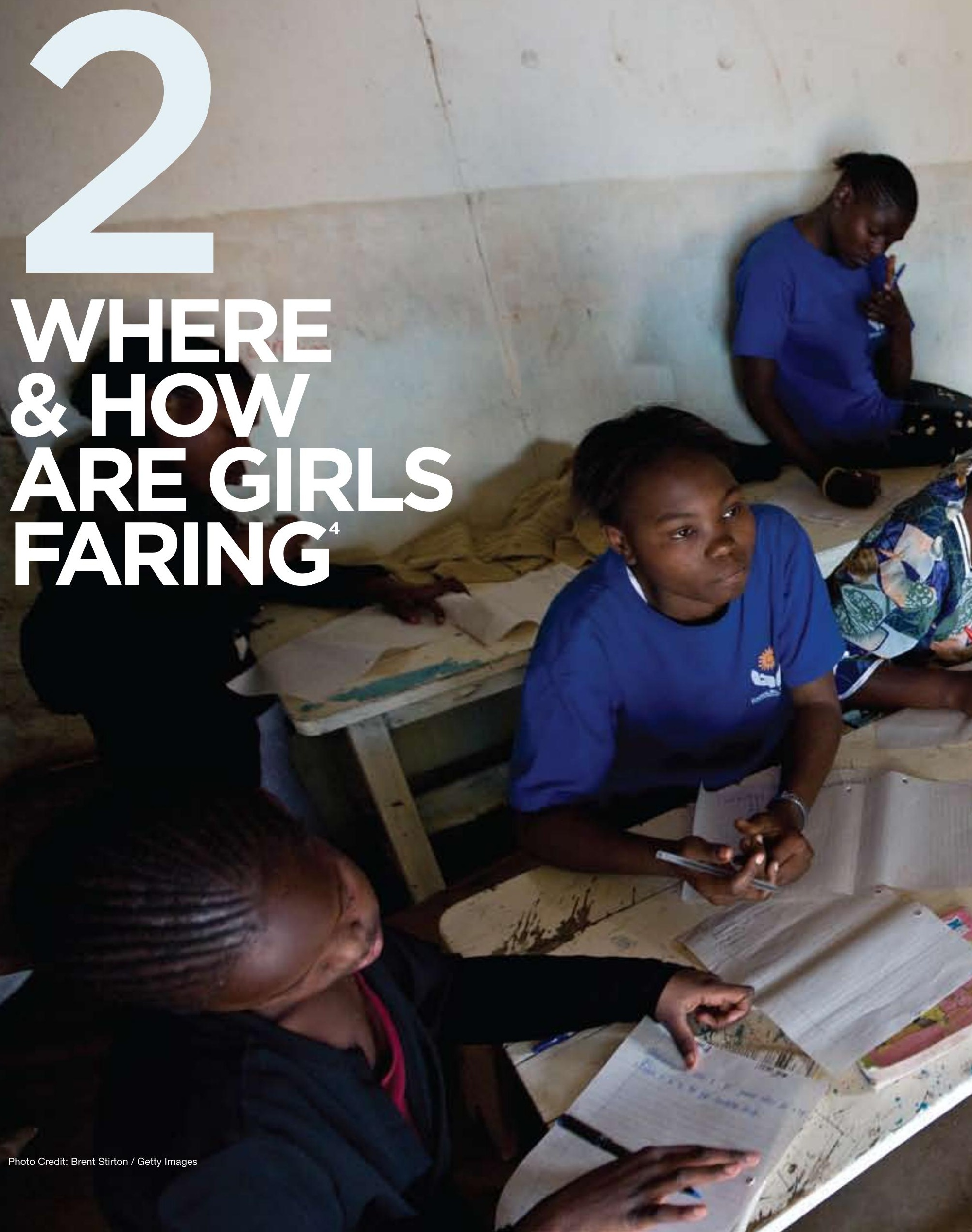




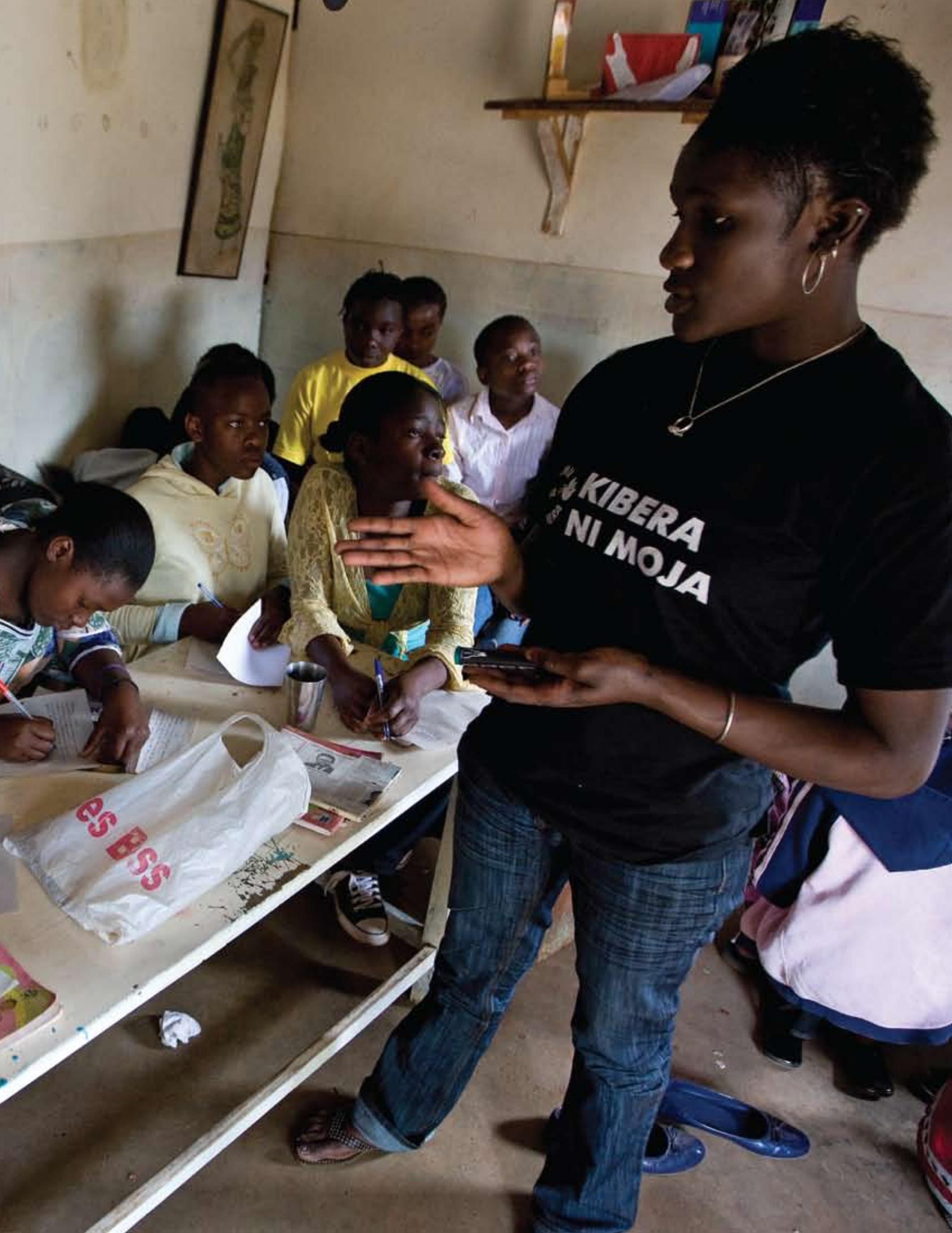


Mass formal schooling has become an institution with recognized features everywhere (Meyer 1992). Possibly for this reason, the main strategy for addressing the learning needs of adolescents has been through the formal educational system-expanding the capacity of secondary and tertiary educational institutions to accommodate higher enrollments. But to address the learning needs of disadvantaged children with learning gaps, learning and skill acquisition through informal or non-formal education has become an increasingly common alternative approach (UNESCO 2007). Because these alternative approaches take on many forms in different settings, their reach and potential effectiveness are less well known. This chapter reviews what is known from existing household survey data about where adolescent girls are within the education system, how they are faring, and what they are learning. Also documented are some of the gaps in knowledge, particularly with respect to participation in various forms of non-formal schooling.

In the slums of Nairobi, girls find educational options at a safe space program called Binti Pamoja. Petit, the older girl at right, was one of the first graduates of the program the space so more vulnerable girls could have the chance to learn and support each other.

The author would like to acknowledge with appreciation Satvika Che chapter in the form of updated tabulations from the Demographic and Health Surveys.

Some formal primary schools, as we will see in Chapter 5, are aso run by NGOs or NGOs in partnership with the government.

\section{Where are they?}

Myth 1: The majority of adolescent girls in poor countries are not in school.

Fact 1.1: In most countries, even the poorest, the majority of younger adolescent girls are attending school, typically formal primary school.
In Figure 2.1 we look at the percent of younger adolescent girls (ages 10-14) currently attending formal primary or secondary school. The data are derived from recent DHS surveys (1998-2007) in 45 countries: 28 from sub-Saharan Africa, eight from Central and Latin America, three from the Middle East, and six from Asia. These data measure educational participation and attainment in the formal educational system for all household members in the sample. We see that, with only a few exceptions in Africa, the overwhelming majority of younger adolescents are attending school with attendance rates nearing $100 \%$ in South Africa, the Philippines, Peru, and the Dominican Republic. With the exception of Colombia and Turkey, the majority of younger adolescent girls attend formal primary school, typically government schools. ${ }^{5}$

The diversity within Africa in school attendance among younger adolescents is particularly strikingvarying from less than $30 \%$ in Burkina Faso and Niger to over $90 \%$ in eight countries including Zimbabwe, Congo (Brazzaville), Namibia, Uganda, Swaziland, Gabon, Lesotho, and South Africa. In some countries, for-profit primary schools are providing an alternative for parents in areas where government schools are of poor quality and where teachers employed by the government are often absent (Ghuman and Lloyd 2007; Phillipson [ed.] 2008; Lincove 2007; Desai et al. 2008; Chaudhury et al. 2006). By following a curriculum similar to that of formal government schools, private primary schools offer students the opportunity to compete for a place in the formal secondary school system through national exams. However, relatively few make that transition during their younger adolescent years.

Fact 1.2: Later in adolescence, fewer girls attend formal schools, but among adolescent students ages 15-19, more are likely to be found in secondary school than primary school, although there are notable exceptions.
As adolescents age, enrollment rates drop off. In Figure 2.2 we look at the percent of older adolescent girls (ages 15-19) currently attending formal primary or secondary school. Among those who remain enrolled, girls are more likely to be found in secondary school, although there are notable exceptions. In Haiti, Chad, Rwanda, Tanzania, Mozambique, Ethiopia, Malawi, Kenya, and Uganda, the majority 


\section{FIGURE 2.1}

\section{School attendance of 10-14-year-old girls, by level}

The majority of younger adolescent girls in most countries are attending school, typically primary school.

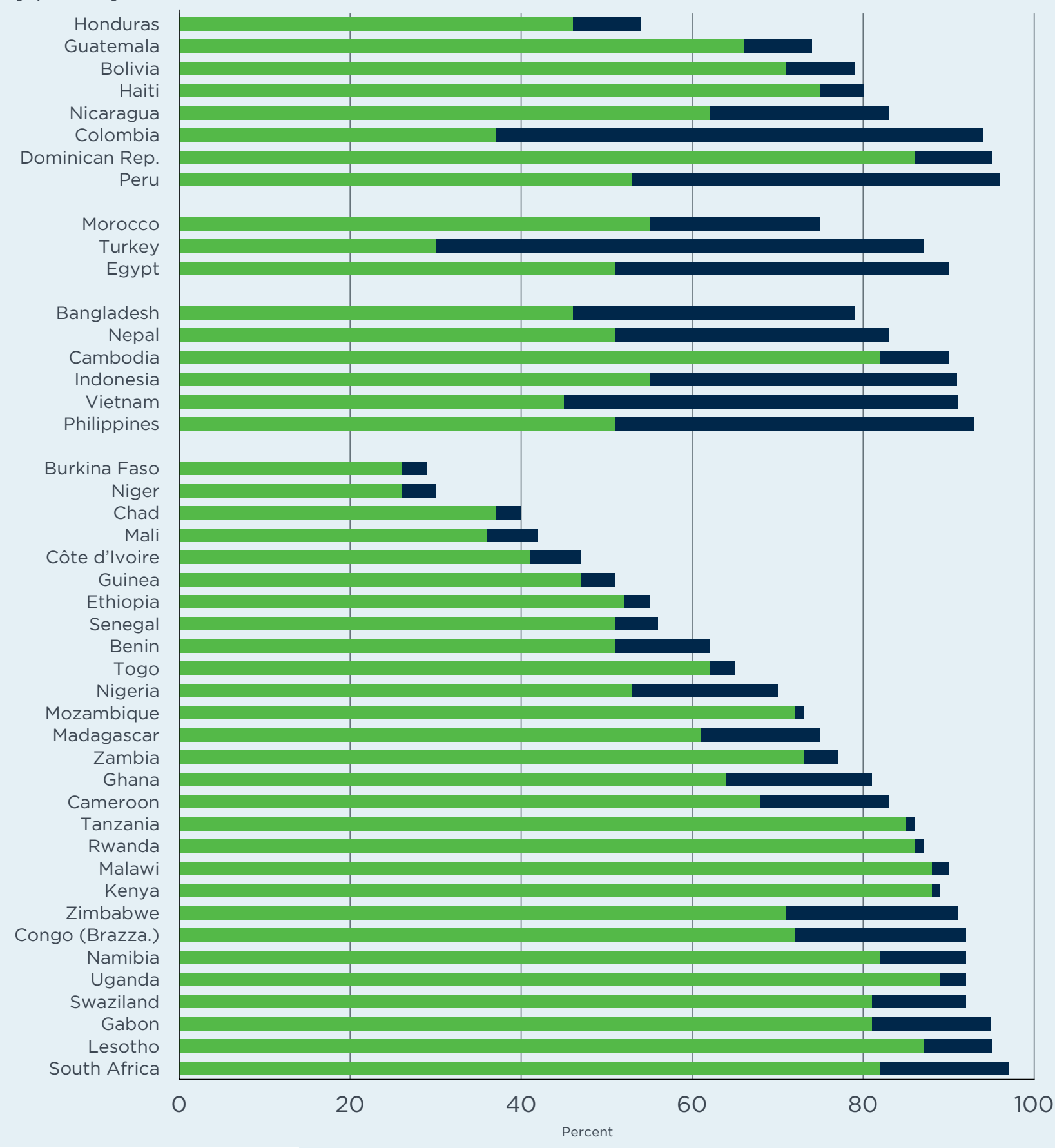




\section{FIGURE 2.2}

\section{School attendance of 15-19-year-old girls, by level}

Girls' enrollment falls off in later adolescence; most older adolescent students attend secondary school.

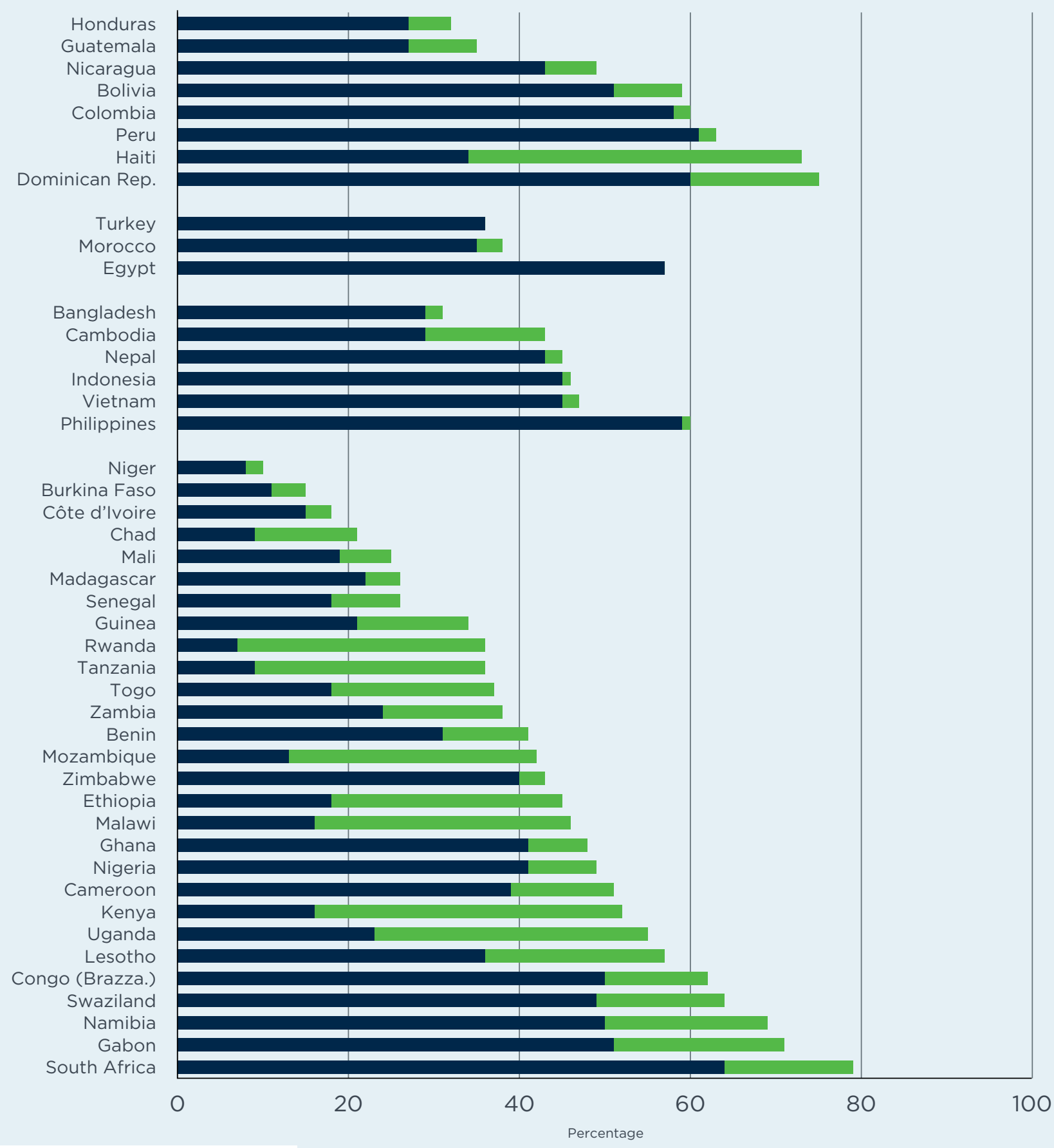


of female students aged 15-19 are still attending primary school, due to late ages of entry, repetition, and limited places in secondary school. Within the formal secondary school system, general secondary school is the most common type of schooling with roughly $90 \%$ of secondary students enrolled (UNESCO 2007). The general secondary school curriculum, which is still a legacy from colonial times, is often abstract and academic and is driven by high-stakes exams geared to university access and elite jobs (World Bank 2005).

Technical or vocational secondary schools represent another option for those going on to formal secondary school but who do less well academically in their primary school leaving exams. While there has been some move away from institutionally distinct vocational secondary schools and increasing discussion about making the curriculum of general secondary school more relevant for life and work, most countries still retain a vocational secondary school option within the formal system (World Bank 2005). Roughly $10 \%$ of secondary school students in developing countries are enrolled in some form of vocational or technical education at the secondary level (UNESCO 2007). ${ }^{6}$ However, "the bias towards academic studies and the perception that vocational education entails an inferior second-class education have deep historical roots in post-colonial states" (Benavot and Resnik 2006,186)

Fact 1.3: In the poorest countries, secondary school completion among girls is relatively rare.

Figure 2.3 shows the extent of secondary school completion among young women in Africa by age 19-the end of adolescence (Loaiza and Lloyd 2008). In only eight of 37 sub-Saharan countries does the secondary school completion rate exceed 15\%: Sao Tome and Principe, Cameroon, Togo, Nigeria, Kenya, the Gambia, South Africa, and Ghana. In 19 countries, the completion rate is below $5 \%$. For both boys and girls, rates of secondary school completion are low. What may be more surprising is that gender gaps in secondary school completion rates are as likely to favor young women as young men.

\section{How are they faring?}

Myth 2: Girls fall behind boys in school.

BOX 2.1

\section{Menstruation as a cause of absenteeism among adolescent girls in Malawi}

A common concern among educationalists is that girls may be more likely to drop out after they reach puberty because of the difficulty of managing menstruation while at school. In a 2007 survey of adolescent students aged $14-16$ in rural Malawi, $20 \%$ of female students and $21 \%$ of male students reported being absent either the day before the survey or during the previous week. While $2 \%$ of the girls reported menstruation as the reason for the absence, the major reasons for absence for both boys and girls were illness (34\%) or various home responsibilities including errands, work at home, or market day, reported by $26 \%$ of boys and $20 \%$ of girls. While $34 \%$ of girls reported having missed school at some time in the past because of their period, primarily due to heavy bleeding, this did not disadvantage them relative to boys in overall rates of absenteeism, which are roughly the same (Grant, Lloyd, and Mensch forthcoming). Data from 12 other African countries participating in the 2005-06 MICS survey confirm these results with similar rates of absence (missing two or more school days in the previous week) for boys and girls (Loaiza and Lloyd 2008).

Fact 2: With the exception of a few countries, younger adolescent girls who remain in school are less likely to be behind in terms of grade-for-age than boys.

Once girls go to school and as long as they stay in school, their progression rates from grade to grade are the same as or better than those of boys. The same is true for their rates of absenteeism (see Box 2.1). In Figure 2.4, we compare gender differences in the percent of young adolescent students ages 10-14 who are two or more years behind grade-for-age. While there is a huge variation across countries in the percent of students who are behind (due to crosscountry differences in starting ages and repetition rates), typically, where gender gaps in progression rates appear, they are to the disadvantage of boys rather than girls.

Myth 3: Pregnancy and early marriage are leading causes of dropout among adolescent girls.

Fact 3: While dropout rates rise with age and are often greater for girls than boys among older
In Africa, technical secondary enrollment, as a percent of tota secondary school enrollment, is much lower $(6 \%)$ than in other developing regions, and the share of enrollment in this sector appears to be falling given high costs and low demand (Lewin 2008). On the other hand, in Arab countries enrollment is roughly $12 \%$ as of 2006 (UNESCO 2007) 
FIGURE 2.3

\section{Secondary school completion rates of girls age 19, sub-Saharan Africa (percent)}

Secondary school completion among girls is relatively rare in most African countries.

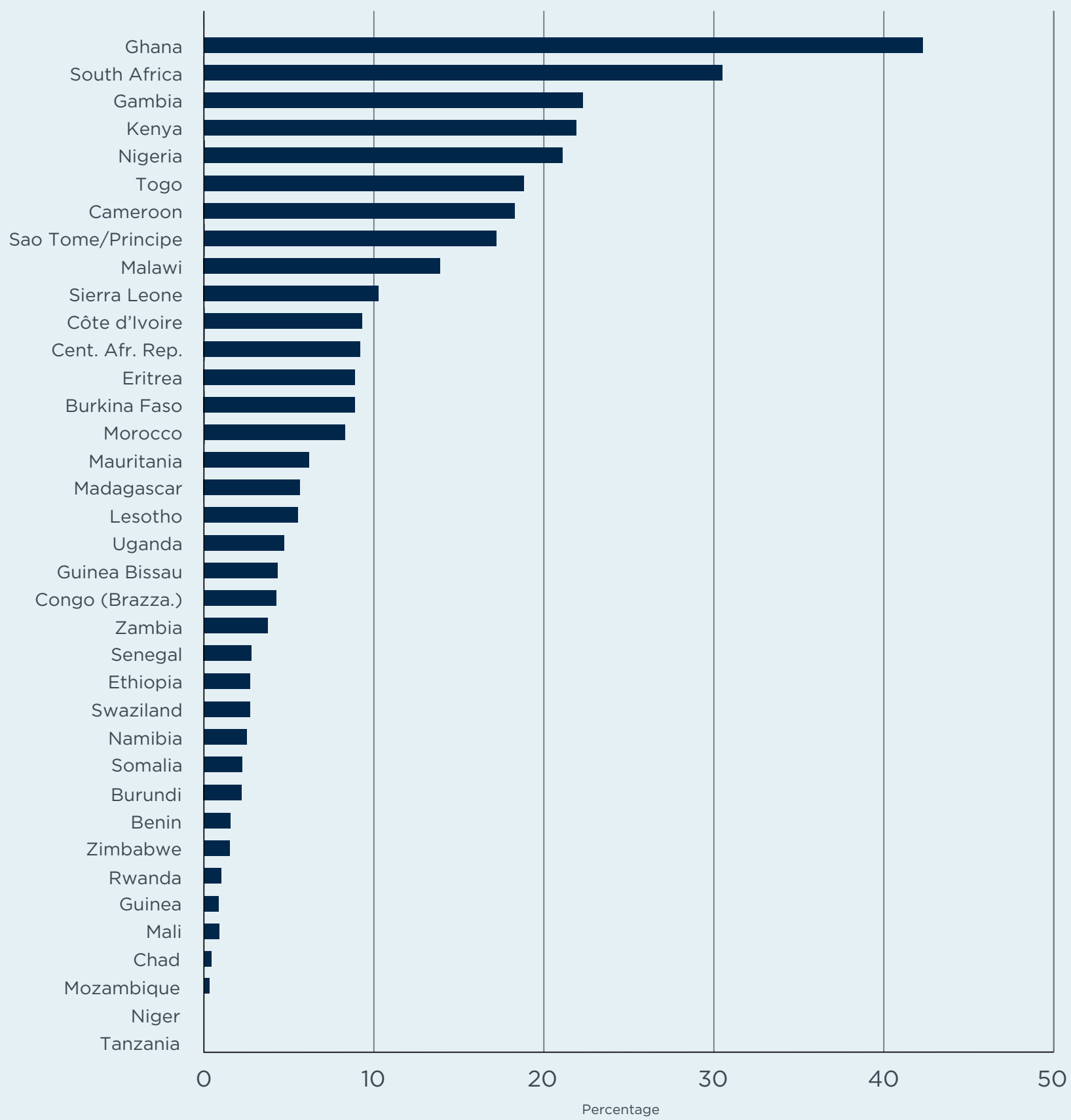

Source: Loaiza and Lloyd (2008)

Note: Countries ranked high to low, by percentage who have completed secondary school. 


\section{FIGURE 2.4}

\section{Gender differences in percentage of currently enrolled 10-14-year-old students who are falling behind (two or more years behind grade for age)}

When girls go to school, they progress from grade to grade at the same rates as or higher rates than boys.

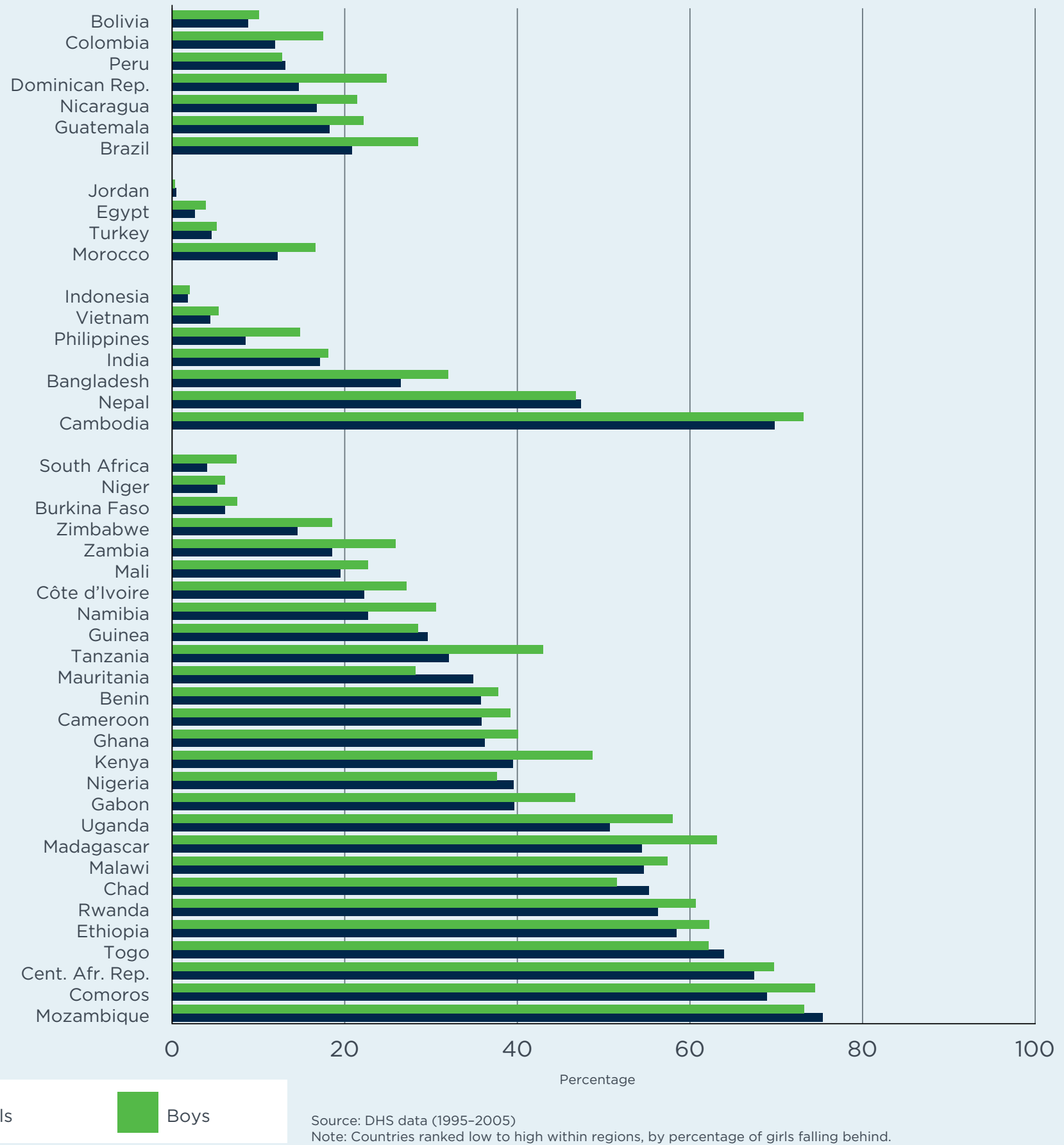




\section{FIGURE 2.5}

\section{Cumulative risk of school-leaving attributable to childbirth or marriage among 15-24-year-olds attending school at age 12, five sub-Saharan countries}

Early marriage and early childbearing are only minor causes of dropout for girls.
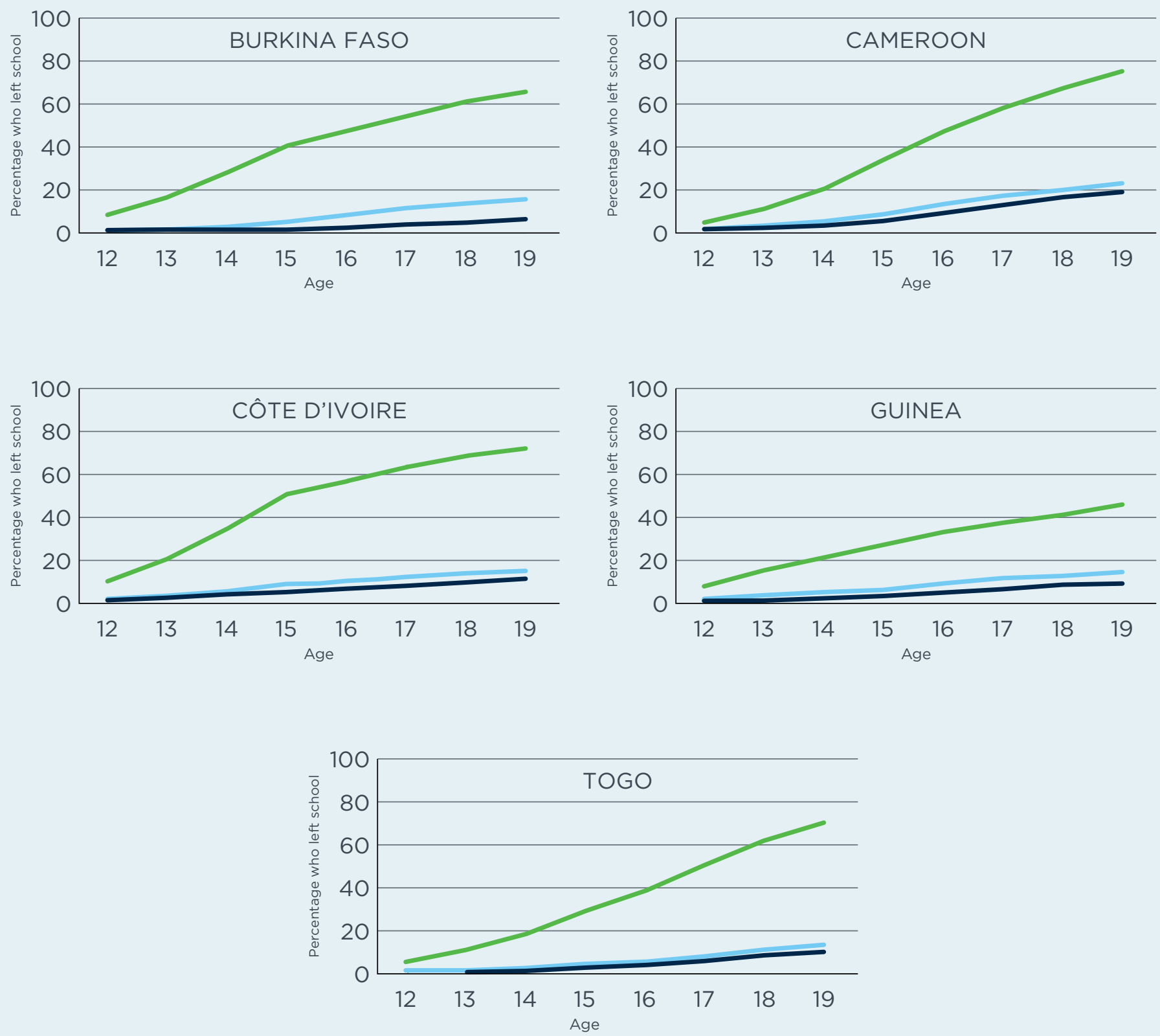

Overall Risk 
adolescents, girls are more likely to drop out for reasons other than pregnancy and early marriage; pregnancy and early marriage tend to occur shortly after dropout.

Both boys and girls drop out of school for myriad reasons including illness, economic difficulties at home, lack of interest, poor performance, low value placed on education, distance to school, or school quality. Pregnancy and early marriage are often mentioned as reasons why girls in poor countries may not be able to continue in school. These reasons are unique to girls. ${ }^{7}$ However, pregnancy and early marriage are more likely to be consequences rather than causes of early school leaving. Typically it is the girls who are lagging behind in school who are most likely to drop out (Grant and Hallman 2008; Marteleto et al. 2008). Given that dropout rates for girls are higher than for boys in many settings during adolescence, but their performance is no worse, this would suggest that poor-performing girls are more vulnerable to dropout than poor-performing boys. Once girls have left school, pregnancy and/or marriage are likely to follow in short order.

Recent data from West Africa on ages at school leaving, as well as reasons for dropout, provide some insight into the issue in the African context (Lloyd and Mensch 2008). Figure 2.5 compares overall dropout rates with dropout rates that can be attributed to early marriage or childbirth. Dropout rates are derived from the highest of a range of estimates based on information about reasons for dropout as well as about the timing of births and marriages in relation to the timing of dropout. By age 18 the percent who had dropped out due to early marriage ranged from $11 \%$ in Guinea to $19 \%$ in Cameroon, and the percent who had dropped out due to a birth ranged from $7 \%$ in Guinea to $15 \%$ in Cameroon. ${ }^{8}$

\section{What are they learning?}

Myth 4: Young women with a formal primary education can be assumed to be functionally literate.

Fact 4: The effectiveness of formal primary schools in teaching literacy varies enormously; girls with three to five years of schooling cannot necessarily be assumed to be literate.

\section{Pregnancy and early marriage are more likely to be consequences rather than causes of girls leaving school early.}

In that marriage for boys is typically at an age beyond that of leaving school, and boys are rarely asked to leave school if they have made a girl pregnant.

The rates for Cameroon were much higher than in the other four countries, where the dropout rate for marriage did not exceed $14 \%$ and the dropout rates for a birth did not exceed $8 \%$. 
FIGURE 2.6

\section{Ability to read a simple sentence among young women aged 15-24 who never attended secondary school, according to last grade attended (percent)}

Girls with three to five years of school have not necessarily acquired basic literacy.

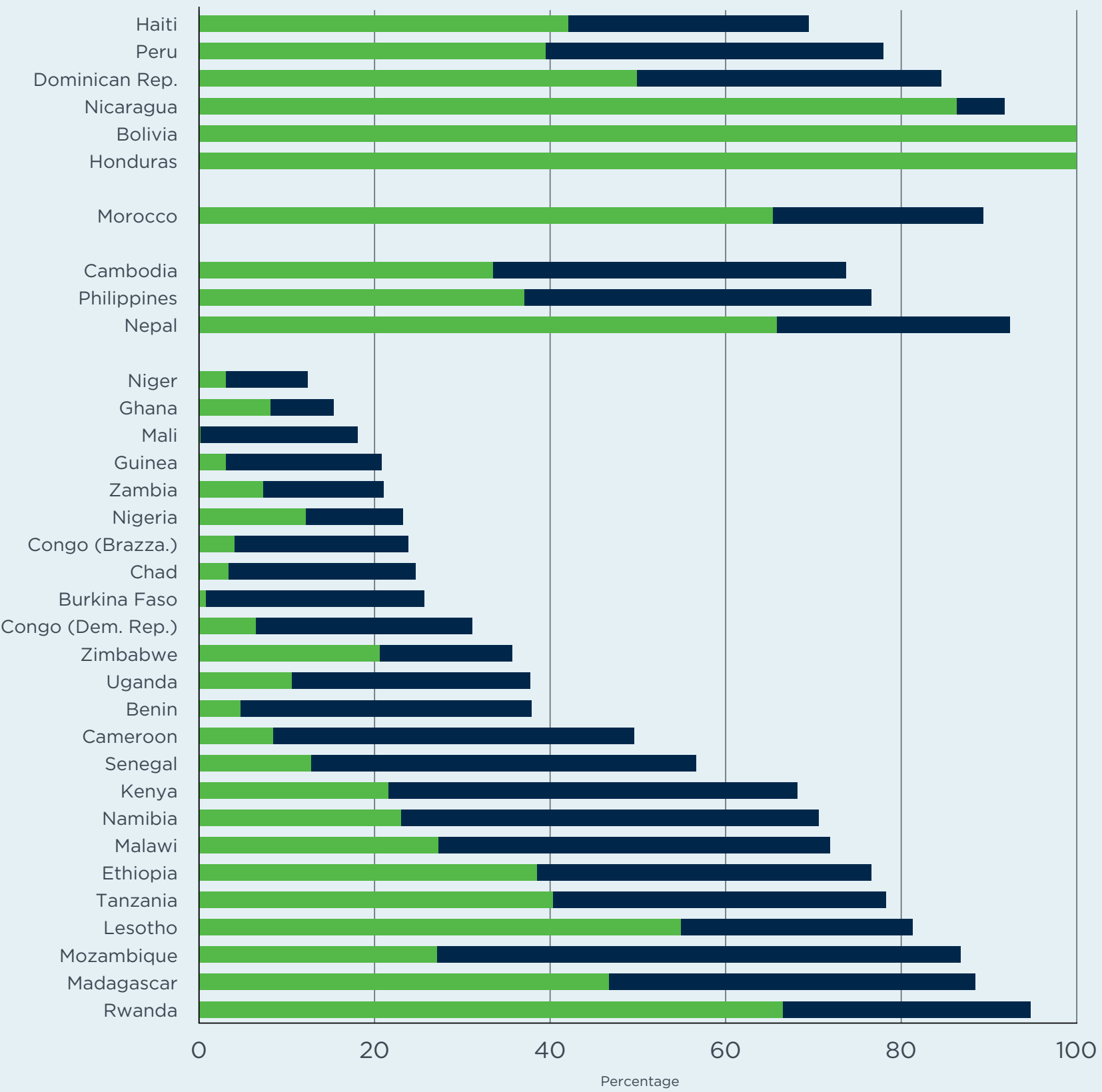


Most adolescents who complete primary school in the formal system retain a functional level of literacy as young adults. However, among those with no more than three to five grades of school, this cannot be assumed. Despite the fact that most curricula developed for the lower grades are based on the assumption of basic literacy by grades 2 or 3 , we can see from Figure 2.6 that this is not the case in most developing countries. The percentages shown reflect the percent of young women, according to the last grade of primary school attended, who could read aloud a simple sentence in their chosen language (their reading comprehension was not assessed). ${ }^{9}$ In most countries, fewer than half of young women have achieved basic literacy by the end of grade 3. Bolivia and Honduras are notable exceptions. In half the African countries included, fewer than $50 \%$ of young women have achieved basic literacy even after grade 5 .

The results make clear that the capabilities and skills of adolescents need to be carefully assessed so that various non-formal educational programs can be effective in meeting their learning needs. Furthermore, it is likely that girls will benefit more when they learn in a context in which instruction is differentiated to address learning needs at different levels.

Myth 5: Out-of-school girls are unschooled and therefore uneducated.

\section{Fact 5.1: Out-of-school adolescent girls represent a} diversity of educational backgrounds with respect to formal schooling.

While it is true that girls who are out of school at ages 10-14-ages when complementary non-formal education can still provide girls with a chance to reenter the formal educational system - are largely unschooled in the formal educational system, this is not the case among older adolescents aged 15-19 (Figures 2.7 and 2.8). In all but a few countries, the majority of young women at these ages who are out of school have previously had some formal schooling. Exceptions include Nigeria, Ethiopia, Benin, Guinea, Senegal, Mali, Chad, Côte d'Ivoire, Burkina Faso, and Niger - almost all countries in West Africa. Among those girls with previous formal schooling, the extent of their schooling varies by age and by country.
Figure 2.9 shows the highest grade completed by age among the out-of-school population for a few countries to illustrate the diversity of patterns that currently exist. In Mali and Ethiopia the overwhelming majority of girls who are out of school have never attended school; this is not true in other countries chosen as examples. In Bangladesh, the overwhelming majority of out-of-school girls have had one to four years of formal school. In Egypt, where primary school extends for only five grades, the majority after age 16 have had five to six years of schooling. Cameroon is an interesting case because of the wide distribution of educational backgrounds among out-of-school girls with one to four, five to six, and seven to nine grades completed. Given the importance of continued learning during adolescence, programs should be designed to suit a range of educational backgrounds, which will vary by context both within and across countries.

Fact 5.2: Data on non-formal education are not currently collected; the number of out-of-school girls participating in non-formal education programs is unknown.

International data collection systems for monitoring trends in enrollment have been organized around common features of formal educational structures including level and grade. Whether we rely on UNESCO to provide annual data on primary and secondary enrollment from Ministry of Education information systems or on international survey programs such as DHS or MICS to measure school attendance and attainment, we will find a good deal of data on formal schooling. No comparable data on non-formal education exist, whether it be private, public, or run by NGOs. Household surveys can be adapted to seek more information about participation in non-formal education but, as of yet, few have done so.

A variety of sources suggest that, at least in some settings, enrollment in these non-formal programs may be significant, particularly among the youngest adolescents. A survey by USAID's EQUIP2 program found 154 such programs serving 3.5 million children (as cited in Rose 2007) with a few countries, including Mali and Togo, reporting $10 \%$ of primary school-age children in these programs (DeStefano et al. 2006). In Bangladesh, as many as $8 \%$ of all primary school age children enrolled in school are enrolled in NGO non-formal schools - schools that do not conform to
Women selected for interview in the DHS survey were presented with cards on which a variety of simple sentences were written and they were asked to choose one at random and read it aloud. The sentences were extremely simple and comprehension was not tested. For example, the four sentences used in the Uganda survey were: (1) "Breast milk is good for babies." (2) "Most Ugandans live in villages." (3) "Immunization can prevent children from getting diseases." (4) "Family planning tiseases." (4) "Family pla 


\section{Girls aged 10-14 who never attended school as a percent of all out-of-school girls aged 10-14}

Out-of-school girls (ages 10-14) are largely unschooled in the formal educational system.

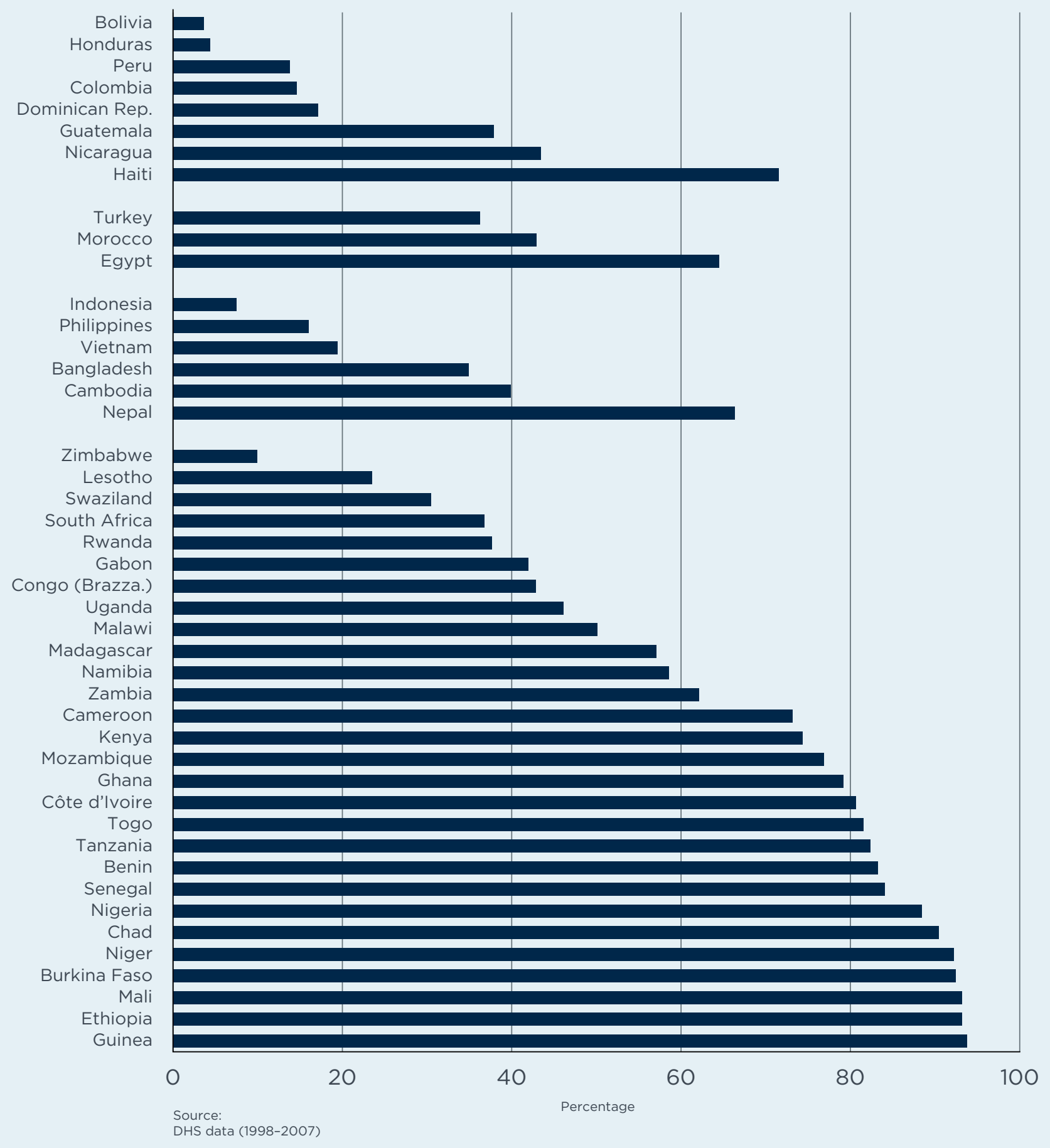


FIGURE 2.8

\section{Girls aged 15-19 who ever attended school as a percent of all out-of-school girls aged 15-19}

In most countries, the majority of older out-of-school adolescent girls have attended some formal schooling.

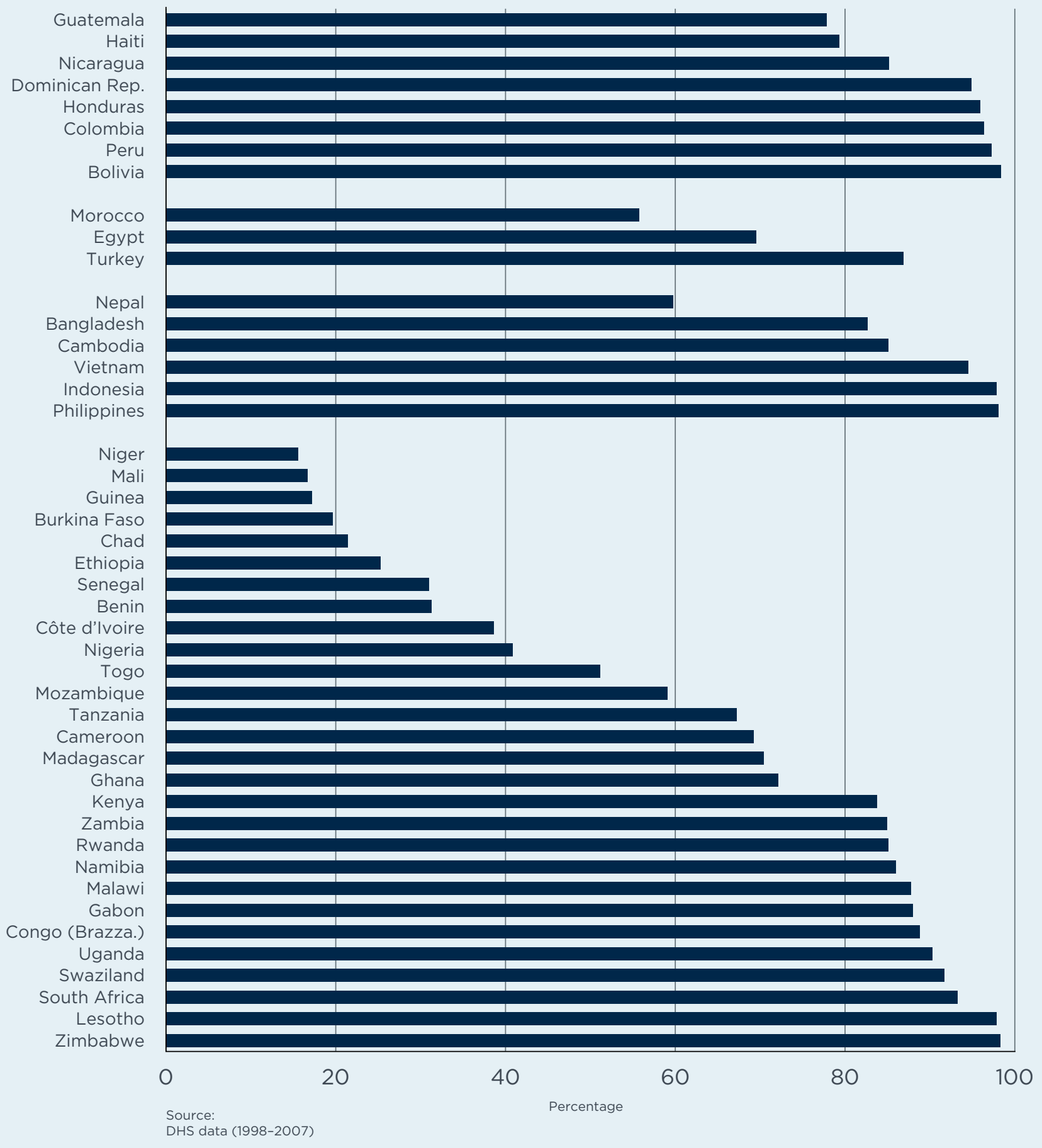




\section{FIGURE 2.9}

\section{Percent of girls out of school, by age, according to highest grade completed}

The educational backgrounds of out-of-school adolescent girls vary substantially across countries.
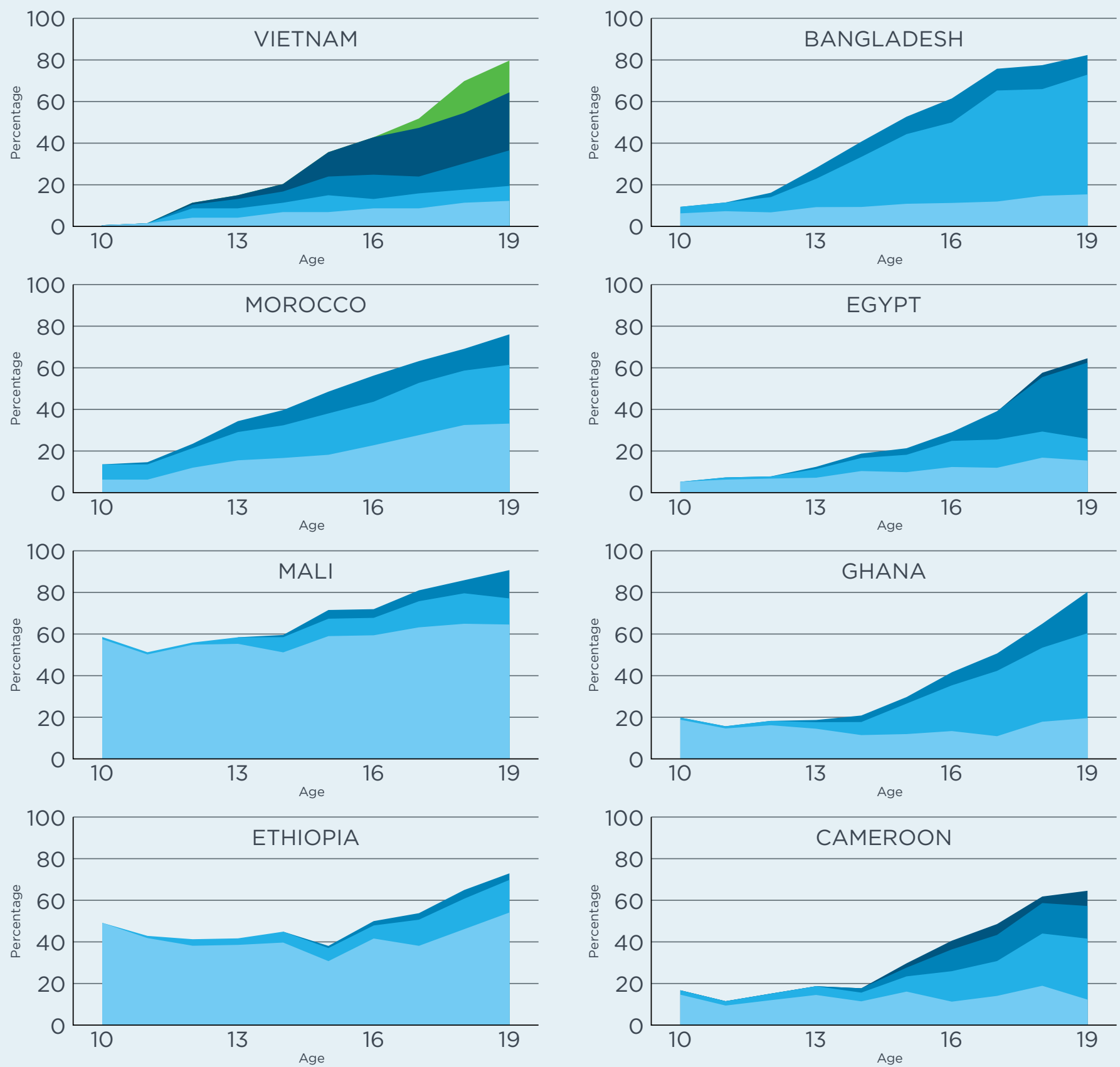

Never

Attended

1 to 4

5 to 6

7 to 9

10 plus 
the formal educational structure in terms of grades or expected ages of entry (Sukontamarn 2005). Such enrollment is typically not recorded, and girls in non-formal education would be grouped with out-ofschool girls.

Furthermore, in the last two rounds of the MICS survey (2000, 2005), information for some countries was collected for all household members on whether the highest level of education attended involved a school with a "non-standard curriculum." This category could have included, depending on the context, not only non-formal schools or educational programs without a traditional grade structure, but also religious schools, such as Koranic schools with exclusively religious content. Rarely do more than $5 \%$ of young people (aged 15-24) report a school with a "non-standard curriculum" as the last or highest attended. ${ }^{10}$ Exceptions include Burundi (20\%), Chad (8\%), Gambia (11\%), Guinea-Bissau (9\%), Niger (14\%), and Senegal (7\%). All of these countries but Burundi have predominantly Muslim populations, ${ }^{11}$ making it hard to know to what extent these levels of participation actually reflect nonformal versus religious education. ${ }^{12}$

We cannot assume from the available data that girls who are not currently enrolled in formal schools are not being educated. The extent of non-formal educational activities among adolescents is unknown but assumed to be on the rise. Nonetheless, various experts conjecture that the adolescent population is currently underserved. EFA Goal No. 3 is impossible to address effectively in the absence of full information on the educational participation of youth.

From the data presented here, we see a diversity among adolescent girls in educational attainment and participation. That diversity would be even more in evidence if we had looked at differentials within countries by income, ethnicity, residence, etc. We also see that educational investments in girls carry no significant extra risks given their progress from grade to grade and the relatively minor role that reproductive factors play in their school progress. As far as what adolescent girls are learning, we can say little about learning outcomes beyond whether or not they achieve basic literacy. Given the many questions that have been raised about the "relevance" of the formal secondary

\section{We cannot assume from the data currently available that girls who are not currently enrolled are not being educated.}

school curriculum for adolescent needs (World Bank 2005), there is much more to learn about specific skills acquired in school in relation to their applicability to the needs and challenges of later life, in particular the development of critical thinking and independent learning skills. Evidence about the immediate and long-term benefits of education for girls is entirely built from data on formal school participation and will be reviewed in Chapter 3. In Chapters 4 and 5, we will look more directly at some of the formal and nonformal educational programs and projects designed to address the specific needs of adolescent girls and how they have evolved over the last 10-15 years.
10

Results from the 2000 round of MICS surveys from 28 countries (Education Policy and Data Center 2008) http://en.wikipedia.org/wiki/ Islam_by_country\#By_country 12

Typically Koranic schools are distinct from other non-formal schools, which are secular. 


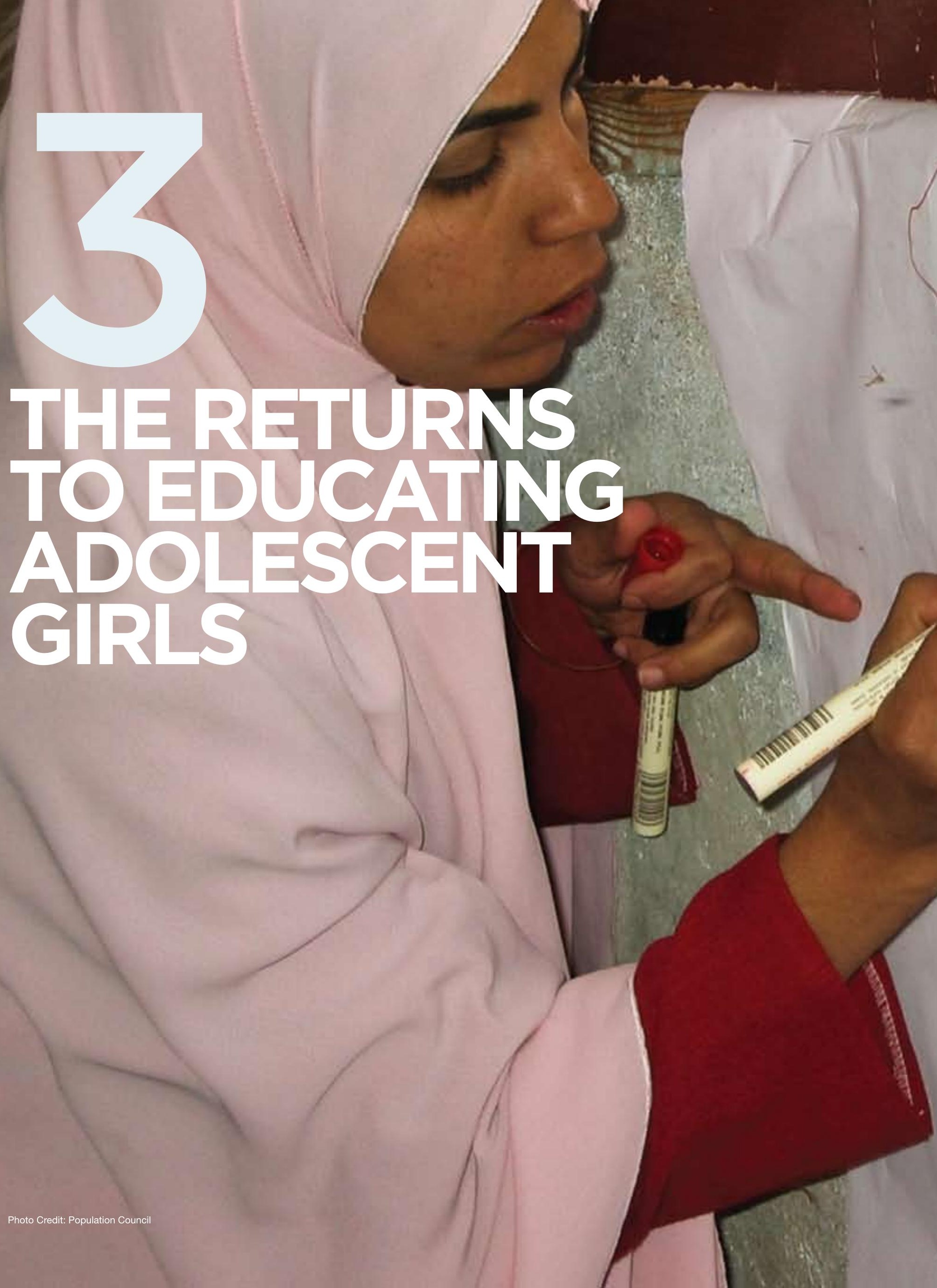


Donors, policymakers, and practitioners have focused on the well-known and well-documented long-term benefits of formal education for adolescent girls in terms of better health and more remunerative employment. Less attention has been paid to the immediate benefits of education for girls during adolescence (particularly the benefits of secondary school attendance and completion) or to the social and economic benefits reaped by their communities from these investments. The immediate benefits of education during adolescence are greater safety, enhanced social status, and better opportunities for selfactualization and empowerment.

Adolescence is "dense" with educational, sexual, work, and family transitions, each transition affecting pathways for the others (Rindfuss 1991). This is particularly true for adolescent girls, whose lives can easily be disrupted by family events such as early marriage or unexpected, unplanned, and unwanted sexual and reproductive events. And it is during adolescence that the differentiation of gender roles intensifies in preparation for adulthood. During this phase of life, an education that heightens a girl's social status, minimizes her social risks, delays her assumption of adult roles, and cultivates a capacity for critical thinking and independent decisionmaking can reshape her future pathways radically and profoundly - with cascading benefits over her lifetime.

\section{By staying in school during adolescence, girls reap immediate benefits}

School attendance has the potential to provide girls with protection during a phase of life when temporary setbacks can have lifelong consequences. Girls' attendance in formal school during adolescence is correlated with delayed sexual initiation, later marriage and childbearing, lower rates of HIV/AIDS and other reproductive morbidities, fewer hours of domestic and/or labor market work, and greater gender equality (Lloyd 2005). The many economic dividends attributable to school attendance for adolescent girls do not detract from the importance of school attendance for adolescent boys. However, it could be argued that the immediate benefits of school-going for girls exceed the immediate benefits for boys. This is because girls carry heavier work burdens than boys during their adolescent years, are more likely to marry and have children at an early age, and are more susceptible to sexual coercion and HIV at younger ages. Obviously the benefits experienced by girls who attend school into their teens will be all the greater if they attend schools that are safe, where boys and girls are treated fairly and respectfully, where learning is valued and the curriculum is relevant and well taught. Furthermore, these benefits are likely to be greatest when girls attend formal schools rather than non-formal schools; indeed all evidence to support the importance of education for girls during adolescence comes from data comparing girls attending formal schools to those who are "out of school" or, more precisely, not attending formal school.

Enhanced social status: When an adolescent girl travels through her community in a school uniform carrying her school books, she gains a protected social status that is recognized and valued. She has the opportunity to develop a social identity beyond her family and is granted respect and protection. Bledsoe (1990) described the symbolic importance of the school uniform in Sierra Leone for adolescent girls as "conveying their status as initiates or trainees who should be recognized as belonging to a protected class." (Lloyd and Mensch 1999: 97). Sometimes regarded with "respect and fear" (Bledsoe, Cohen, and Working Group on the Social Dynamics of Adolescent Fertility 1993, 94), the school girl in her uniform is marked as "sexually unavailable." This enhanced social status has primarily been documented for girls attending formal schools, particularly secondary schools, and may be less likely to apply to girls attending non-formal educational programs. This is because of the popular perception that vocationally oriented education is second-class education. According to Benavot and Resnik (2006) this perception has deep historical roots in many postcolonial societies. 


\title{
Average daily hours in household work for rural, unmarried 15-16-year-olds, by sex and enrollment status
}

\author{
Gender differences in time spent on domestic chores are much greater \\ among those out of school than among students.
}

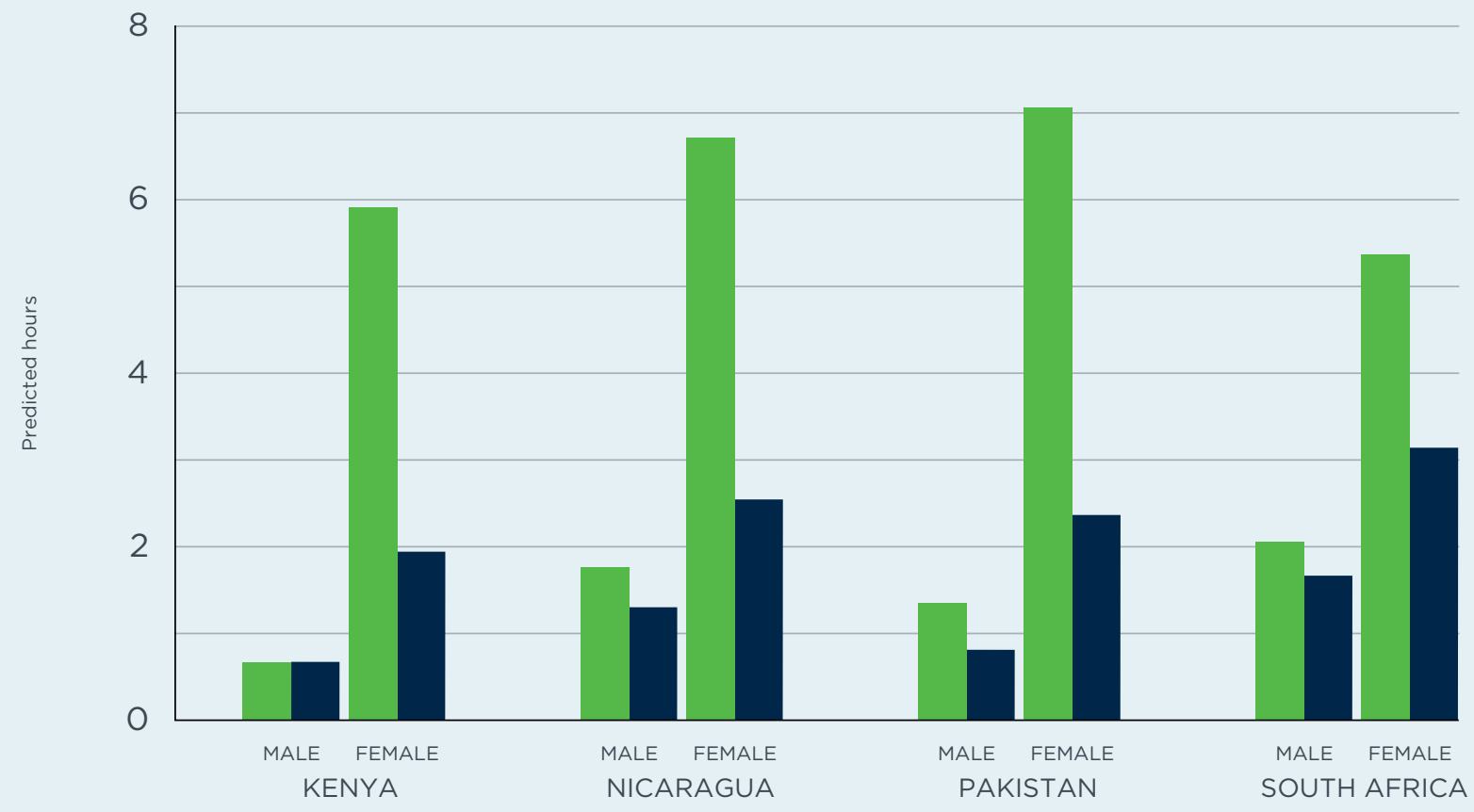

Non-Students

Students

Greater gender equality: If we explore the time-use patterns of adolescent girls and boys according to school attendance, we see that girls who remain students at ages 15-16 work many fewer daily hours in domestic (non-market household) work than those who are not enrolled (Lloyd et al. 2008). Time-use data from diverse rural settings in Kenya, Nicaragua, Pakistan, and South Africa show that the daily hours girls spent in domestic work when they were students ranged from two to three hours a day (Figure 3.1). By contrast, their non-enrolled peers spent upwards of six to seven hours daily in domestic work. On the other hand, boys' enrollment status had little impact on their time spent in domestic work.

When boys attend school, their daily lives are reason- ably similar to girls' (even though female students still put in one to two more daily hours in domestic work than male students do), while the lives of boys and girls diverge sharply when they leave school, as girls take up heavy domestic responsibilities and boys enter the workforce.

Thus, for girls, extending schooling into adolescence can be a first step on a pathway toward greater gender equality, not only because of the learning that takes place in school but also because school attendance brings adolescent boys and girls together to spend their time similarly during a critical phase of their transition to adulthood. School allows them to focus on their own development and learning, to 


\section{Premarital sex among 15-17-year-old students and non-students (percent)}

Adolescent students are less likely to have had premarital sex than their same-age peers who are not in school.

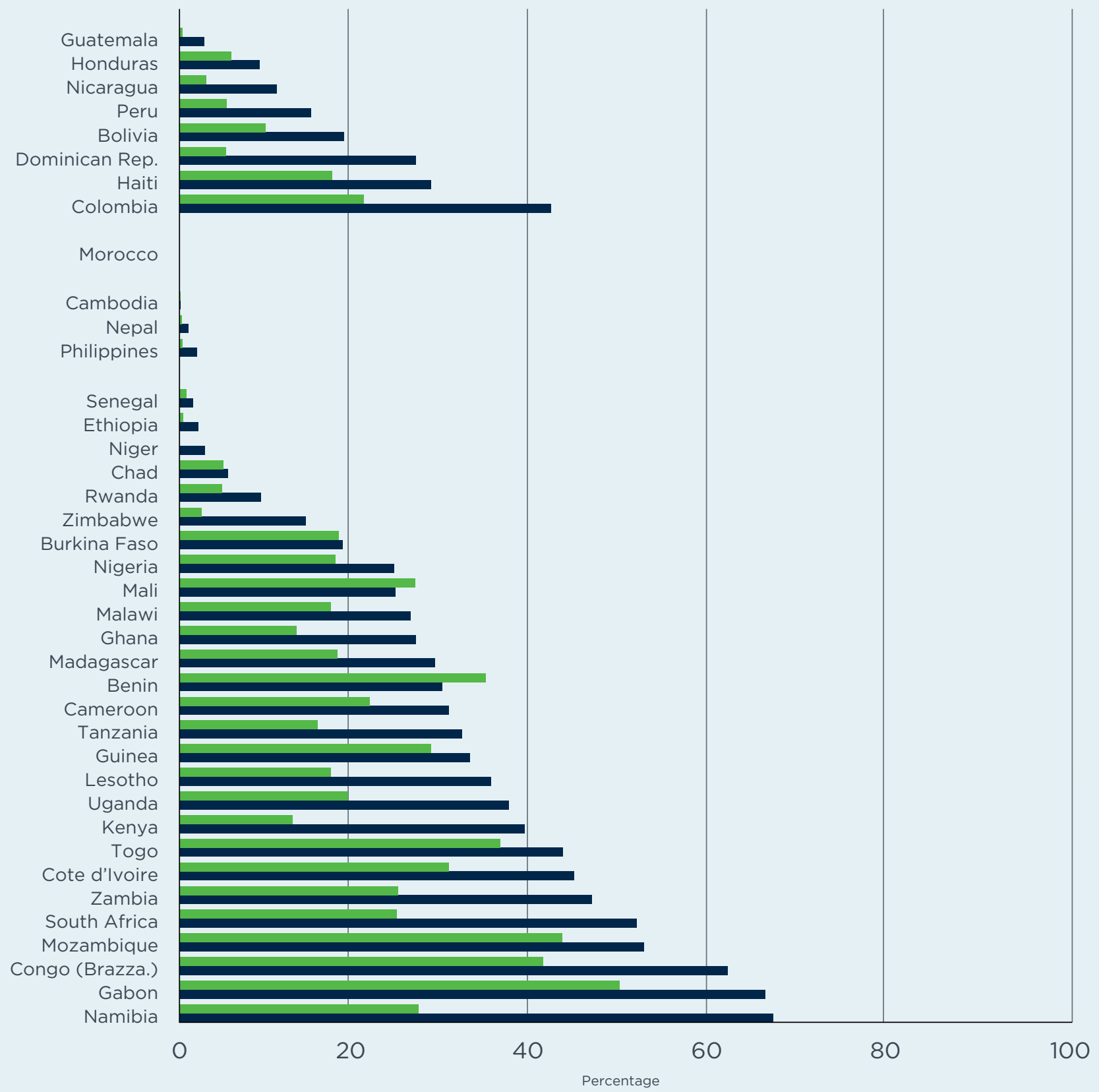


interact with peers and form social networks, and to explore and prepare for a broader range of possibilities for life as an adult. Although female students continue to carry a heavier domestic workload, spend time at home with family members rather than peers, and enjoy less leisure time than male students, these gender differences are small compared with the gender differences in time-use that exist among adolescents who are not in school (Lloyd et al. 2008).

Improved reproductive health: Another immediate benefit to girls of participation in school during adolescence relates to premarital sex. In Figure 3.2, we compare the percent of unmarried girls ages 15-17 reporting premarital sex according to whether or not they were attending formal school. ${ }^{13}$ While reported rates of premarital sex vary widely across countries, it appears that, with the exception of Benin and Mali, girls attending formal school at these ages are much less likely to have had premarital sex than their same-age peers who are not attending school (Lloyd forthcoming). Further support for these findings comes from more in-depth analysis of recent adolescent survey data collected in Burkina Faso, Ghana, Malawi, and Uganda (Biddlecom et al. 2008). Similar patterns exist with respect to contraceptive use among sexually active students; sexually active girls who remain enrolled in school are more likely to protect themselves against unwanted pregnancy than those who no longer attend school (Lloyd 2009). While these effects appear to exist regardless of school quality, it is also apparent that school quality can enhance these effects (see Box 3.1), particularly those aspects of school quality that relate to gender attitudes and behaviors on the part of teachers.

\section{By staying in school during adolescence and retaining learning into adulthood, girls reap future social and health benefits for themselves and their families}

Many of the well-documented social returns from girls' schooling are realized after girls leave school, marry, and have families. Recent reviews of various research studies provide a long list of the many ways that mothers' education can benefit them and their children: through safer health and hygiene practices, more time and resources for children's health and
BOX 3.1

\section{School quality and premarital sex among adolescent girls in Kenya}

The results of a pilot study on the role of formal primary school in the lives of adolescents in rural Kenya laid the groundwork for a broadened perspective on school quality and its benefits for girls (Mensch et al. 2001). At the time of the study in 1996, the majority of adolescents attended primary school (made up of eight grades or standards). Elements of school and classroom dynamics reflect gender systems operating within the school. These include teacher attitudes and treatment. In Kenya, these elements of school quality varied from school to school. At the time of the study, there were no programs providing gender training for teachers. In some schools the attitudes of teachers towards girls was surprising and even shocking, with teachers accusing girls of "lacking common sense," "being lazy," and "not using their heads" (Mensch and Lloyd 1998). In other schools, girls and boys were treated with respect and without prejudice. The results of the study show that girls were more likely to have initiated premarital sex-a risky behavior in a setting where HIV was spreading and where contraceptive use among teens was low - in schools where female students reported that girls and boys were not treated equally by the teachers and the school administration. In fact, this was the only indicator of the school environment, among the many measured (including whether or not family life education subjects were taught), that had any effect on the initiation of premarital sex among girls. By contrast, no school characteristics were important in explaining the sexual behavior of boys. In a companion study, this variable was also found to be an important predictor of dropout for girls but not for boys (Lloyd et al. 2000). Because of the unique risks that girls face during adolescence, this study suggests that schools can make a difference in girls' lives by confronting sexual stereotyping and prejudice in the classroom and instilling equitable values promoting gender equality.
Rates are age standardized by giving single-year-of-age rates equal weight. Sample sizes are sufficiently large for 15,16 , and

17 year olds to permit calcula of rates for single years. 
education, more exposure to information that can be used to support children in various ways, better child nutrition, the use of contraceptives leading to smaller family size, improved household incomes through greater labor force participation and earnings, greater bargaining power within the household, and greater ability to act on preferences for investment in children (World Bank 2007; Grown et al 2005; Herz and Sperling 2004; Rihani et al. 2006). However, it is not always clear how much schooling, or what level of schooling, must be attained for significant benefits to occur, and to what extent the benefits are dependent on a certain number of years of exposure to school or to certain levels of learning.

Indeed, we are learning from a variety of developing country settings that the links between education and health are not just correlational but causal. In studies in settings as diverse as Ghana, South Africa, Nepal, and Guatemala, evidence is mounting that

\section{BOX 3.2}

\section{Maternal literacy and health in Nepal}

LeVine at al. (2004) explored the pathways of influence leading from maternal schooling to literacy and language skills to health knowledge and skills in rural and urban settings in Nepal. The literacy and language skills of 167 mothers of school-aged children were assessed using tests of reading comprehension and academic language proficiency. Mothers' health knowledge and skills were assessed by measuring their comprehension of health messages in both print and broadcast media, their comprehension of instructions on a packet of oral rehydration salts, and their ability to provide a health narrative. Of those women in the sample who reported that they were literate, $28 \%$ proved to have a reading level of zero on the reading test. The study also found a consistent positive association between reported years of school and levels of literacy and language skills as measured on the tests administered by the researchers. Even if these women may have lost some proficiency since leaving school, the correlation between years of school and literacy and language skills was strong. Multivariate results exploring the determinants of various indicators of health competencies found that literacy was the pathway through which the effects of schooling on health competencies were mediated. Most importantly, steady improvements in literacy and language skills led to steady improvements in health proficiencies, thus underscoring the importance of school quality in generating strong social returns to investment in girls' schooling. literacy skills, when acquired in school and retained after school exit, are strongly linked to fertility and child health outcomes (LeVine et al. 2004; Glewwe 1999; Thomas 1999; Khandke et al. 1999). Box 3.2 describes the results of a study in Nepal that measured literacy and language skills of mothers directly and related them to various levels of health knowledge and behavior.

The most promising recent findings relevant to this point are from a 35-year longitudinal analysis of women and their children in Guatemala. The data show that the benefits of mother's schooling for children's health are even greater than previously estimated. Furthermore, a mother's cognitive skills measured roughly at the time of her first birth (around age 20 in Guatemala) have a greater impact on children's health outcomes than a mother's school attainment (measured by grades attended) (Behrman et al. 2009).

While literacy improves with levels of schooling, the correlation is far from perfect because of variations in school quality. Thus the longer-term health benefits of education require the acquisition and retention of basic literacy and language skills, not just the completion of a certain number of grades. Data presented in Chapter 2 on variations across countries in retained literacy among young women who attended primary school for a certain number of grades alert us to the dangers of solely relying on data on educational attainment as an indicator of changes in the underlying knowledge and skills of a population. They further remind us that the extent to which a girl will reap the returns described here will be a direct function of the quality of the school she attends.

\section{By working for pay after school completion, girls reap future economic benefits for themselves and their families}

Economic returns to formal education in the labor market tend to be highest in lower-income countries and slightly higher for women than men (Psacharopoulos and Patrinos 2004). In Figure 3.3 we see that women have lower market returns to primary school completion, relative to no schooling, but higher returns to secondary schooling, relative to primary school completion, than men. Specifically, while the returns to primary school completion in terms of 


\section{Economic rates of return to schooling by school level}

\section{Gender differences in rates of return favor boys for primary school and girls for secondary school.}

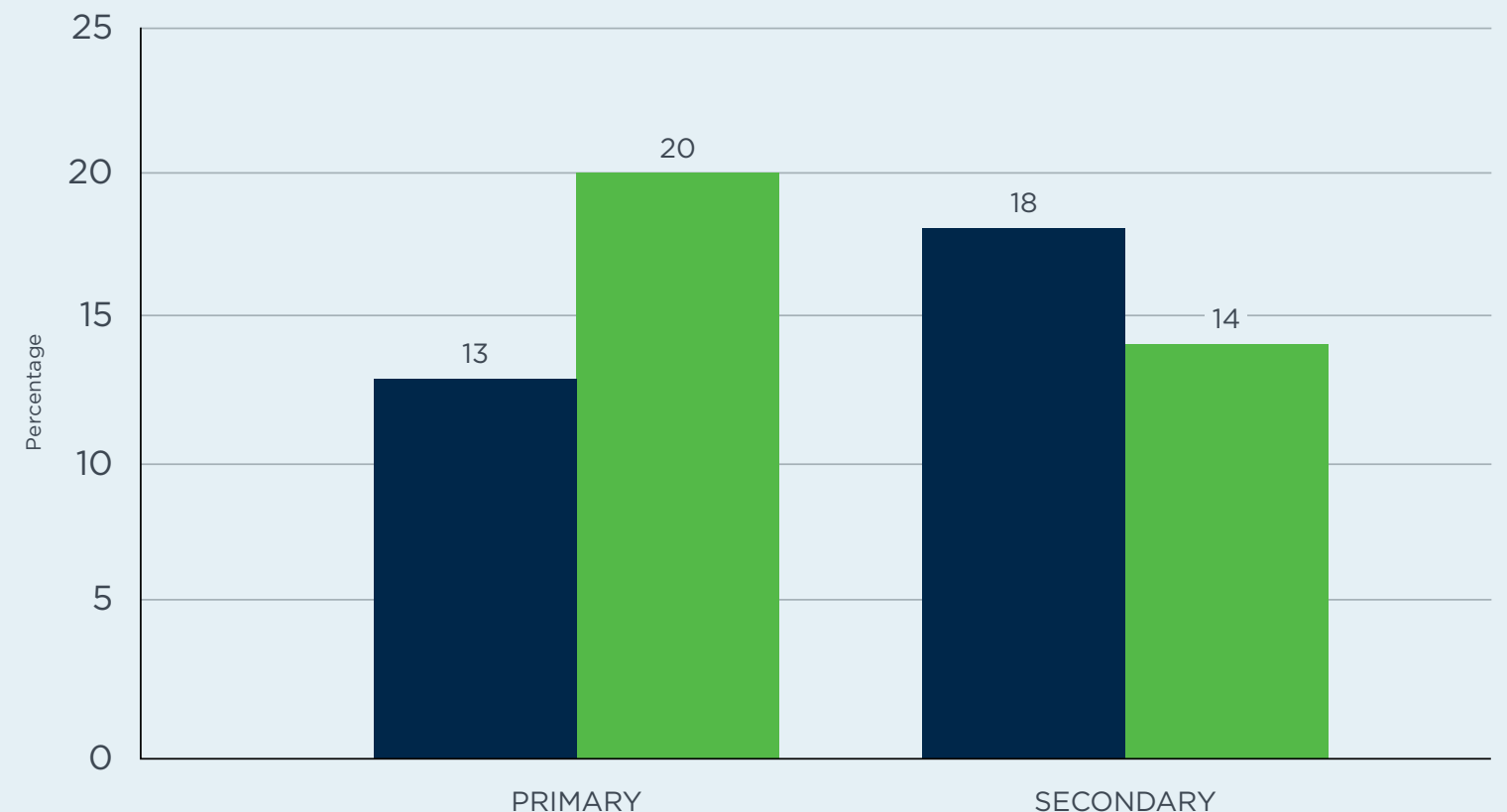

Females

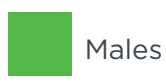

discounted future earnings for men are estimated to be $20 \%$, they are only $13 \%$ for women. By contrast, the returns for men to the completion of formal secondary schooling are $14 \%$, while women can expect to receive returns averaging $18 \%$. There are a variety of explanations for this including occupational segregation and greater gender discrimination in jobs requiring less education. Whatever the explanation, these data make two things clear. First, girls can expect higher market returns from the completion of formal secondary school. Second, the lower returns to primary school, particularly when a secondary school for girls is not available nearby, may discourage girls and inhibit their completion of primary school, thereby increasing the policy challenge in addressing the need for much greater female enrollment in secondary school (Patrinos 2008).
With respect to trends, evidence from countries in all developing regions suggests that market rates of return to formal secondary and tertiary schooling are rising relative to the past, while returns to primary and middle schooling are somewhat lower (Behrman et al. 2003; Heckman and Li 2003; Duraisamy 2002; Lam and Schoeni 1993; Lam and Leibbrandt 2003; Schultz 2003). Changing rates of return are likely to be a function not only of improvements in the distribution of formal education among the population, with a higher percentage than in the past having acquired primary schooling, but also of changes in the global economic climate with increased international trade, privatization, and market liberalization. It is possible as well that declines in primary school quality could have contributed to this shift in rates of return favoring higher levels of formal schooling. While most of the studies 
BOX 3.3

\section{A caveat on estimated rates of return}

Most of the empirical evidence on rates of return to schooling is based on the reported experiences of women who attended formal primary and secondary schools 10-30 years ago. This first generation of women attending or completing formal primary or secondary school was a selective group, particularly those who went beyond primary school. Subsequent generations of educated women will have had a greater diversity of backgrounds and educational experiences, thanks in part to the many policy initiatives designed to increase educational access. For these reasons, current estimates of rates of return to schooling are even more uncertain for women than they are for men, given the more selective population of adult working women on which they are based.

14

It is well documented that literacy and fluency in one's mother tongue is generally considered to be an essential building block towards the development of competency in a second language. Because this report focuses on education for adolescents, we mention the importance of a second language here but recognize that, for some adolescents who are at an early stage of their whotion, litera in the of their tongue will be a first priority. on which these conclusions are based rely on data for men only, it is reasonable to presume that rates of return for women are changing as well. Indeed, studies from all regions show that women with higher levels of education are more likely to engage in paid employment than in the past (Grown, Gupta, and Kes 2005). However, social norms about appropriate gender roles can affect the extent to which an educational expansion among girls leads later in life to greater labor force participation of women, particularly when the expansion is confined to more universal primary enrollment (Hannum and Buchmann 2004). Adolescent girls who do not make it to secondary school, where social norms about gender roles are likely to be more egalitarian, will suffer substantial opportunity costs in terms of lost future earnings.

None of these estimates of rates of return to education have taken account of school quality as a variable. A growing literature is beginning to document the positive effects of school quality on economic rates of return, both because of its effects on the ultimate number of grades attained and because of its effects on specific learning outcomes that are valued in the labor market (Glewwe and Kremer 2006). For example, a recent study based on panel data in Egypt has shown that students attending a lower-quality schoolwhere school-specific quality is proxied by averaging tested achievement gains - were much more like to drop out than those attending a higher-quality school (Hanushek et al. 2008). Further empirical evidence from developing countries documents high rates of return to cognitive skills in the form of earnings (Hanushek 2006). These issues become all the more important given recent international test results documenting poor learning outcomes and possible declines in school quality resulting from the push to universalize schooling. Indeed, it is unlikely that the high social and economic returns to girls' schooling can be sustained without substantial investments in school quality, in particular investments in the development of critical thinking and independent learning skills, which are rarely measured in tests and which may be of particular value for preparation for work roles.

A particular example of the returns to school quality relates to the "relevance" of the curriculum, in particular learning in an international language. ${ }^{14}$ Evidence is beginning to emerge about the rates of return to education in a local language relative to an international language such as English or French. Angrist and Lavy (1997) estimated that the rate of return to post-primary schooling in Morocco dropped by half after the language of instruction (in grade 6 and above) was changed from French to Arabic. This was attributed to a decline in French writing skills. More recently in Mumbai, lower caste young women are responding to growing job opportunities by switching from primary and secondary schools teaching in Marathi to primary and secondary schools teaching in English and, as a result, realizing a substantial premium in earnings (Munshi and Rosenzweig 2003).

Evidence from U.S. education and labor market research also points to the importance of some of the "non-cognitive skills" produced in school for later success in the labor market. "There is substantial evidence that mentoring and motivational programs oriented toward disadvantaged teenagers are effective" (Heckman and Rubinstein 2001, 148). Research on the greater success in later life of graduates of Catholic schools in the United States also suggests the importance of motivation and discipline as key ingredients in education (Coleman and Hoffer 1983, as cited in Heckman and Rubinstein 2001,148). Heckman and Rubinstein recommend the collection of more systematic information on non-cognitive effects of alternative education systems. 
Despite girls' progress in education, however, relatively few girls complete secondary school, and the gap between young men and women in school-towork transitions remains extremely wide, thus limiting girls' potential to reap the economic returns described above. Indeed, in most parts of the world the gender gap in labor force participation far exceeds the gender gap in education. While job discrimination limits the supply of jobs available to young women, and family responsibilities limit the demand for jobs among such women, this report places some of the responsibility for this gap on the education sector. This is because, to date, the education sector has not addressed the needs of a generation of girls who are facing a world far different from the world of their mothers and who, therefore, need extra knowledge and skills. Socialization of children outside the home begins in the classroom with teachers who often reinforce social norms about gender roles and consequently limit girls' horizons at an early stage of their development. Without specific targeted interventions designed to address gender issues in the classroom, as well as the extra needs of girls for training in critical decisionmaking and leadership, these barriers prevent the transformative education that girls need to overcome a history of disadvantage. It is also possible that girls and boys have differential access to some of the diverse forms of education currently provided to adolescents, whether in the form of after-school programs for those continuing in school, vocational secondary school, livelihoods programs for those no longer attending school, or apprenticeship programs.

Figure 3.4 contrasts labor force participation rates by age and sex with school attendance rates for certain regions (Buvinic et al. 2007). The regions chosen have sufficient recent household and labor force survey data to allow the construction of age-specific school and work transitions. If we look first at Latin America and East Asia, where girls and boys have achieved equivalent rates of school attendance by age, we see the huge gap between boys and girls in the extent to which they have entered the labor force, particularly after the age of 18. In East Asia the gap is much smaller than in Latin America at younger ages but becomes equally large after the age of 19. In Africa, where girls have lower school attendance rates than boys in the later teen years, neither boys nor girls fare well in the transition from school to work, with only a little more than a quarter in the labor force by age 18 .

\section{In most parts of the world the gender gap in labor force participation far exceeds the gender gap in education.}




\section{FIGURE 3.4}

\section{Rates of school attendance and labor force participation among adolescents, by region and sex}

Education gains for girls have not been fully reflected in labor force gains.
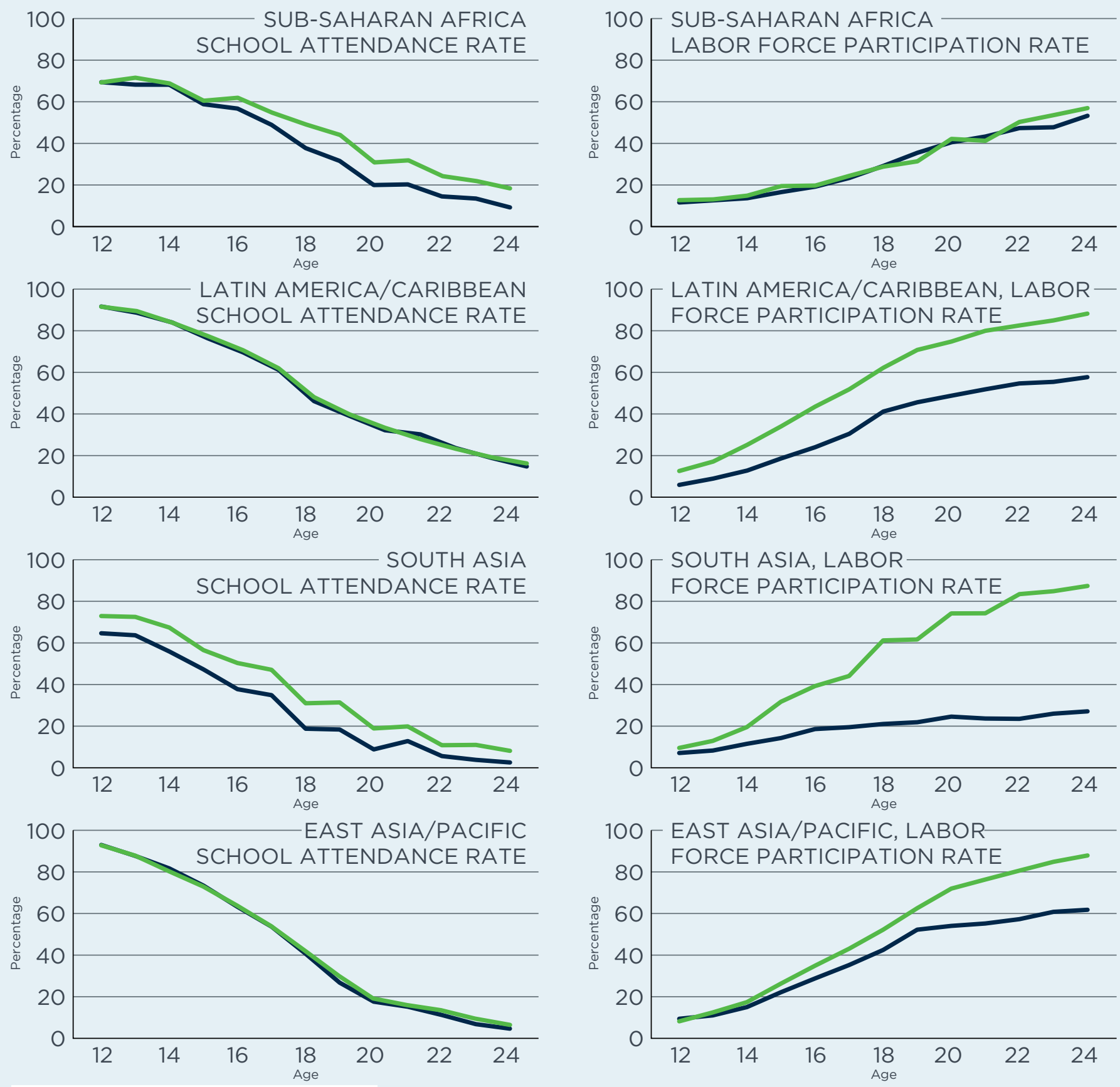

Female 
The widest gaps shown among these comparisons are in South Asia. Here the gender gap in school attendance rates by age exceeds that observed in Africa but is dwarfed by the gender gap in labor force participation rates; for girls, these rates hardly ever exceed $25 \%$.

Data from a recent labor force survey in Egypt paint an even more extreme contrast between young men and women in school-to-work transitions. Here, boys and girls leave school at a similar rate but relatively few women enter the labor force (Figure 3.5). By contrast we can compare young men and women in the United States in terms of labor force participation. By ages $20-24$ over $70 \%$ of young Americans are in the labor force with no gender gap at ages 16-19 and only a small gap at ages 20-24 (Figure 3.6).
Recent research in Latin America has found that facilitating successful school-to-work transitions for young women is the most promising gender-equity strategy for promoting economic growth that differentially benefits the poor (Costa et al. 2009). Using micro-simulation techniques and household data from Argentina, Brazil, Chile, the Dominican Republic, El Salvador, Mexico, Paraguay, and Uruguay, the authors develop estimates of household income distributions in a multivariate model under alternative scenarios capturing various dimensions of gender inequality in the labor market. These include gender gaps in labor force participation (discussed above), gender differences in occupational distribution, wage discrimination, and gender gaps in education. The most dramatic estimated effects on reductions in poverty from their model resulted from the elimination

\section{FIGURE 3.5}

\section{Transition from school to first job by age, Egypt}

The contrast between young men and women in school-to-work transitions in Egypt is pronounced.
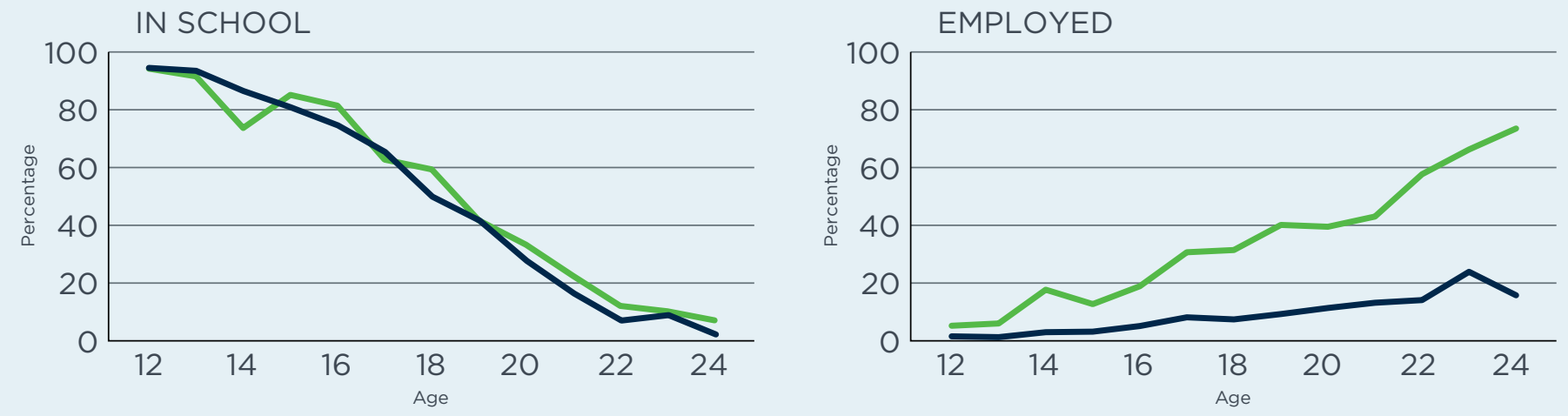


\section{Labor force participation rates of adolescents and youth in the United States, 2007}

In the United States, the gender gap in labor force participation has almost disappeared.

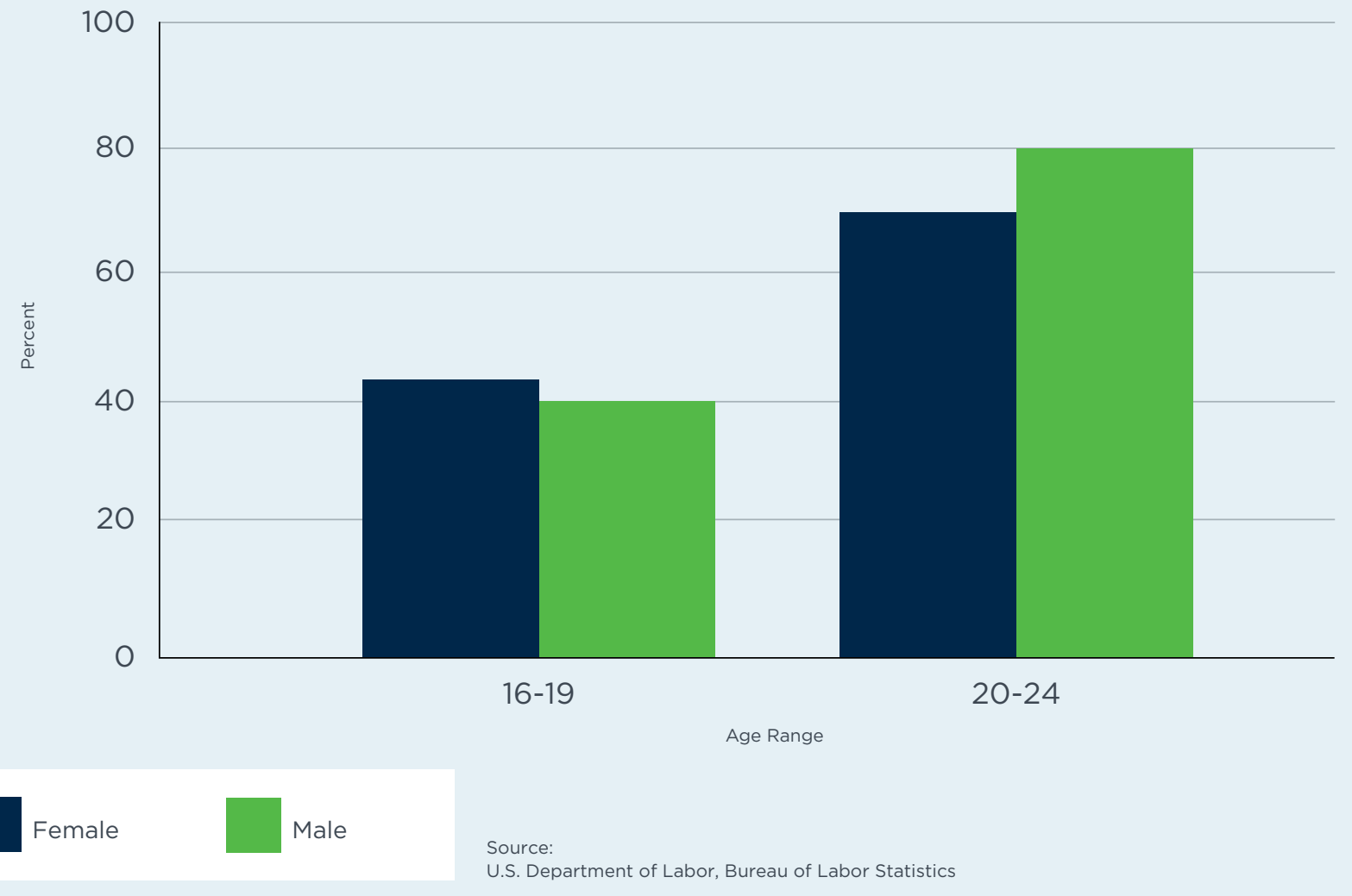

of the gender gap in labor force entry. These results were driven primarily by simulated improvements in the labor force participation of the poorest women.

\section{By working in their communities and participating in civic life, girls contribute to economic and social development}

Greater investments in girls' schooling can also lead to improvements in gender equality and a reduction in the incidence of poverty at the community level, as women are able to take a greater economic role in the family and citizenship role in the community (Lloyd ed. 2005; World Bank 2007). Educational reforms designed to enhance community involvement in education at the local level are often stymied when mothers of school-aged children are poorly educated and lack the knowledge and skills needed for civic engagement and educational decisionmaking. For an expansion of school participation and attainment among girls to have its strongest impact on poverty alleviation in the community, adolescents need to develop more egalitarian gender norms, and girls need training in group participation, civic engagement, and assertiveness so that they can become full 
participants in the life of the community. Indeed, the best place to begin is within the school with opportunities for decisionmaking and leadership.

The benefits of girls' schooling ripple out within the family, within the community, and across generations. Communities with educated women are able to staff their basic health facilities with nurses and health aides and their primary schools with local teachers and teaching assistants - two important occupational groups that increasingly rely on female secondary school graduates as men find greater employment opportunities in other sectors of the economy. Communities without educated women find themselves with unstaffed or understaffed clinics and with nonresident and absentee teachers. Pakistan is a case in point. In rural communities that have had a secondary girls' school for some time, girls' schools are well staffed with female teachers from the local community; in rural communities that do not have a secondary school for girls, there is no local supply of teachers and local schools have to hire teachers from outside the community. These non-resident teachers typically have higher rates of absenteeism due to limitations on their mobility and concerns for their safety, with negative consequences for the next generation of female students (Lloyd et al. 2007; Ghuman and Lloyd 2007).

\section{When girls attend non-formal educational programs, the current and future benefits are unknown}

There are no estimates of the economic returns on investments in education and learning outside the formal school setting. Indeed, no data are currently collected on levels of participation in non-formal programs that could be linked with measured earnings at older ages using the classic approach to estimation of rates of return. Given the growth of non-formal programs, it is critical to begin to set up longer-term evaluations of these programs so that actual effects can be tracked in relation to program goals.

One recent study summarizing evidence on returns to investment in post-school education and training, such as on-the-job training, employer-sponsored offthe-job training, apprenticeships, and separate formal adult education, is potentially relevant to our interest in education for adolescents and our particular concern for transitions from school to work (McMahon
2003). The study finds that private rates of return for post-school training opportunities are high, particularly for employer-sponsored training, but employers in developing countries tend to under-invest in workers because of their poor educational backgrounds. Thus under-investment in formal schooling stymies the spread of lifelong-learning programs. Given high rates of return and the current lack of investments in lifelong learning, McMahon (2003) recommends public and/or donor intervention in non-formal schooling such as primary and secondary school equivalency programs and literacy programs for youth in order to reap these high returns while making complementary investments by employers more attractive.

The evidence summarized here provides a compelling case for educating adolescent girls. At the same time, it raises questions about the extent to which curricula are meeting all of their needs, given the enormous gap between their schooling gains and their employment gains. It is unlikely that girls will be able to overcome centuries of disadvantage and discrimination in one generation without an extra boost from the educational system. That system is the most important socializing institution outside the family and is strategically placed to play a transformative role in preparing girls to seize opportunities that were out of reach for their mothers and grandmothers. 


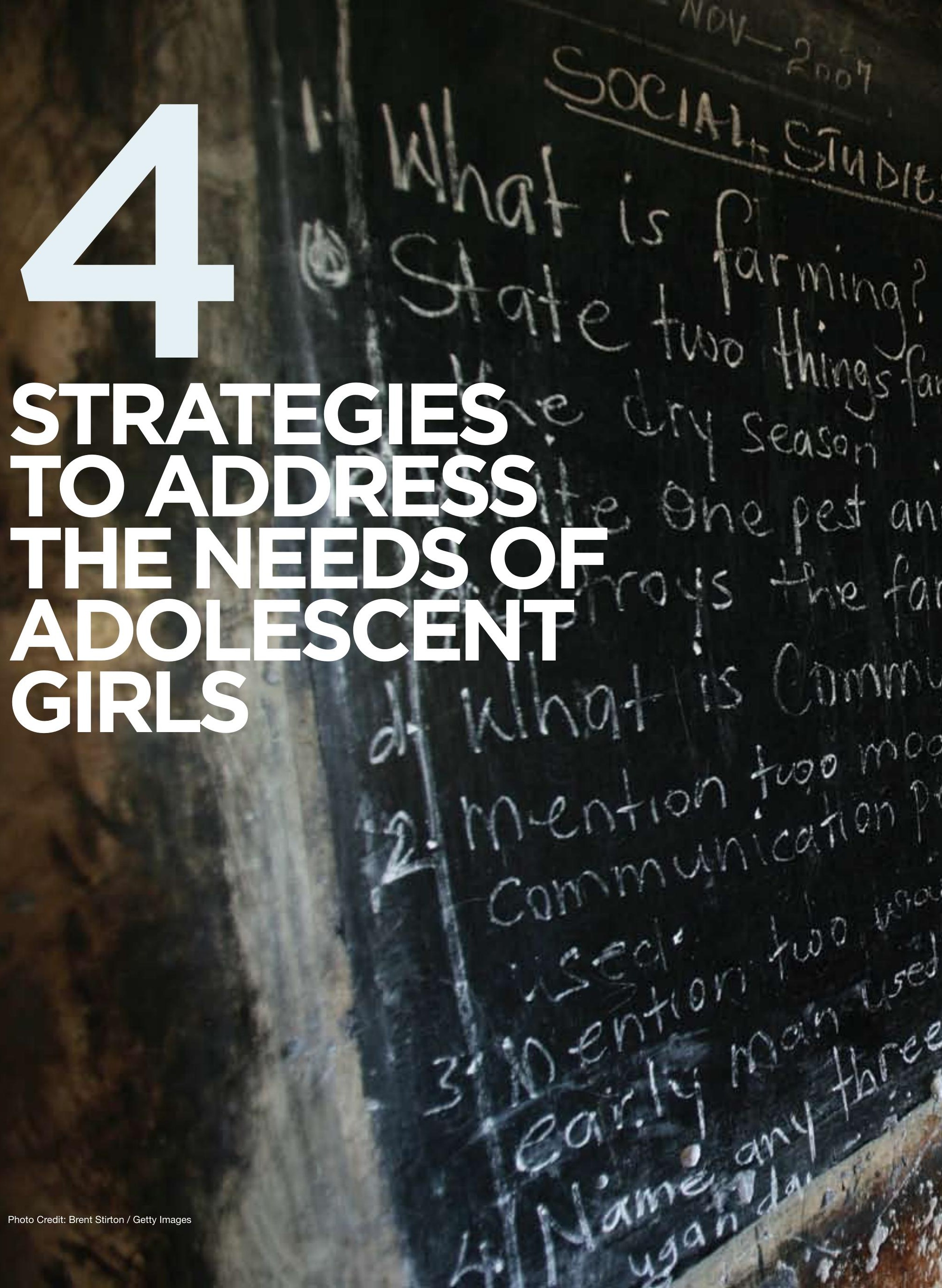


TEST

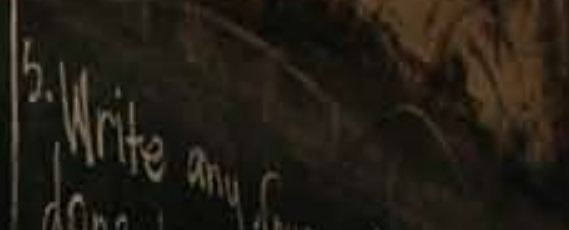

distiog.

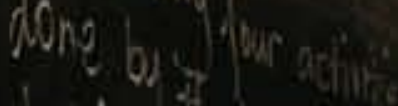

mers do auring

o' tol corom
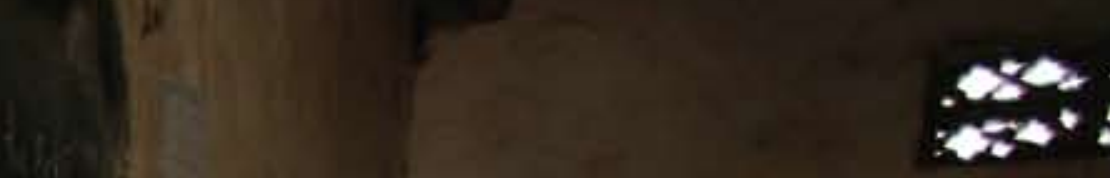

mal rinat

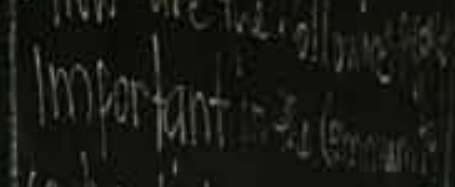

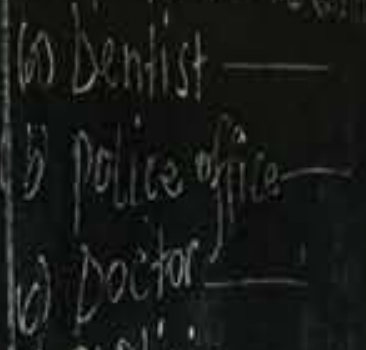

merscroas

(1) $)^{2}$ Hican-

bard?

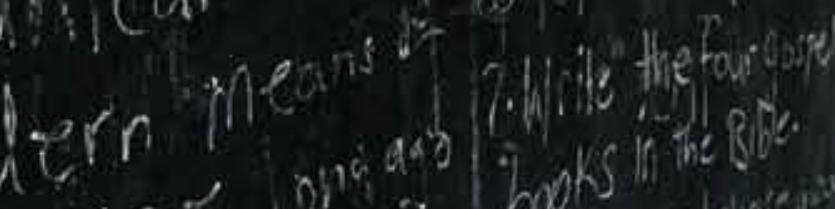

20012,

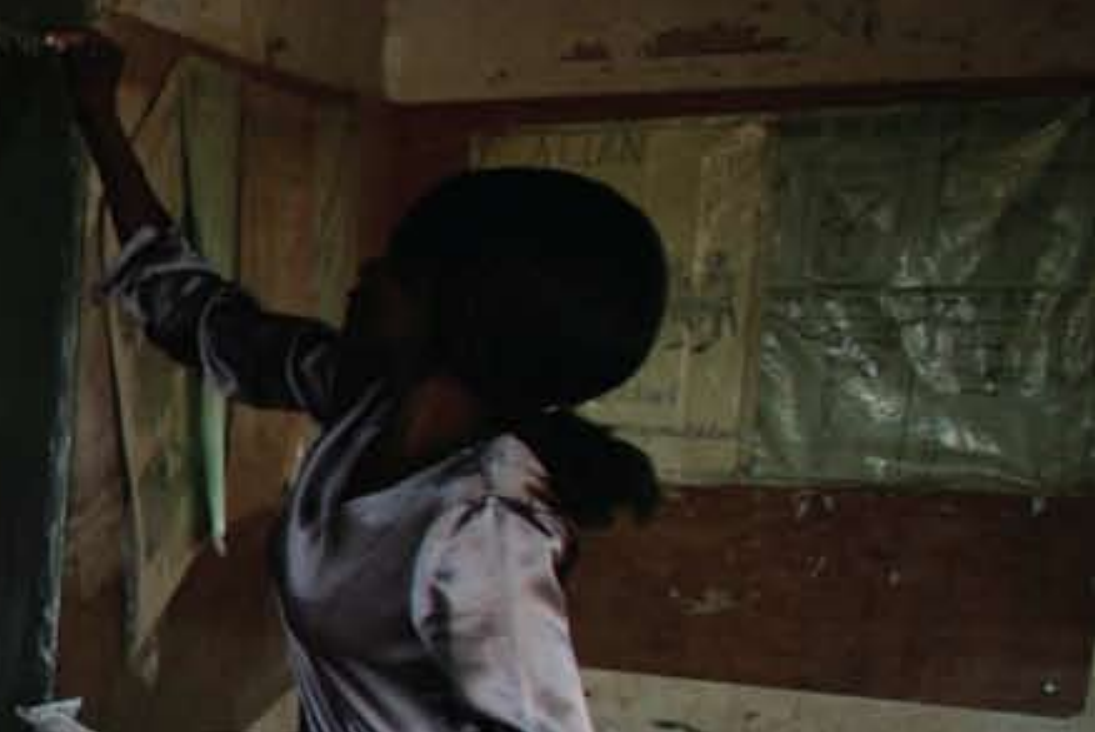

12. 54 in Atam and $x$.

drene $x$ it

Lo ef etranspert

1
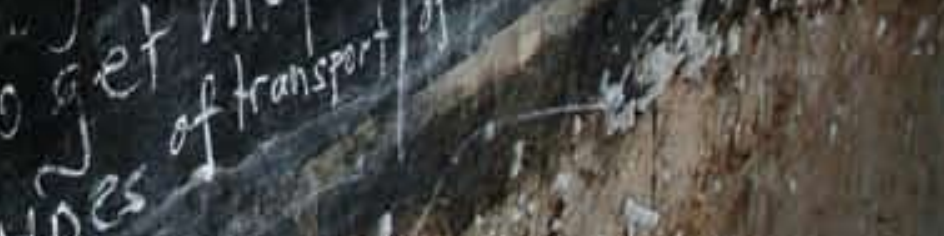
Investments in education for girls have been based on research findings of the positive association between years of education in the formal system and various social and economic outcomes for women and their families. Over the past 15-20 years the accumulated knowledge from this research has provided the impetus for a first generation of educational programming for girls by governments, international agencies, and NGOs. The primary goal has been to increase girls' enrollment in formal schooling, typically by reducing costs on the demand-side and increasing access on the supply-side. While most of these initiatives have not been formally evaluated, the rapid rise in girls' enrollment around the world is likely to reflect the cumulative contribution of these initiatives, among many other factors.

Now that the majority of girls are enrolled in formal schooling in almost every country, and most are still in school as they enter adolescence, there is a need for a second generation of research and programming to address the unique challenges in educating girls during adolescence. Girls need protection, respect, empowerment, and economically productive learning to overcome deeply embedded discrimination both in the family and the workplace. On the demand-side are strategies that address parental and adolescent concerns about safety, costs, and family responsibilities. On the supply-side are strategies that increase access to education through the creation of non-formal schools or that address the quality of the education provided, including the learning environment and the "relevance" of curriculum for historically disadvantaged girls either in the formal or non-formal educational system.

Actions on the demand-side are primarily designed to increase enrollment and retention in school while actions on the supply-side, to the extent they relate to improvements in school quality, are designed primarily to enhance learning outcomes. But supply-side strategies can also affect enrollment and retention, and demand-side strategies can improve learning outcomes. In the longer term, higher levels of grade attainment, better learning outcomes, and enhanced skills will all improve civic participation and gainful employment (Chart 4.1).

In Box 4.1 we list the most typical of these strategies to provide a frame for subsequent discussion. The framework of educational programs for girls reflects some of these concerns, but lacks both a strong research base from which to draw lessons about the relative benefits of alternative strategies and a strong and coherent management structure at the national level within which formal and non-formal approaches can be coordinated and monitored.

We start this chapter with a review of past educational initiatives on behalf of girls undertaken by some key international education donors and agencies. We also review research addressing the effectiveness of some of the approaches listed in Box 4.1. These reviews serve as background for the presentation of the main findings in Chapter 5, which are based on information compiled from a compendium of current programs and projects in developing countries supporting adolescent girls' education. The compendium is not exhaustive, being necessarily restricted to those programs and projects for which data are available from websites, printed materials, or individual program officers. As far as we know, this is the first time such a compendium of education programs and projects for adolescent girls has been attempted. The results prove informative, even provocative, both with respect to what they show and even more importantly what they don't show. The gap between research and practice with respect to adolescent girls remains substantial in terms of the unmet educational needs of adolescent girls and of program effectiveness. 


\section{CHART 4.1}

\section{Girl-friendly strategies and desired outcomes}

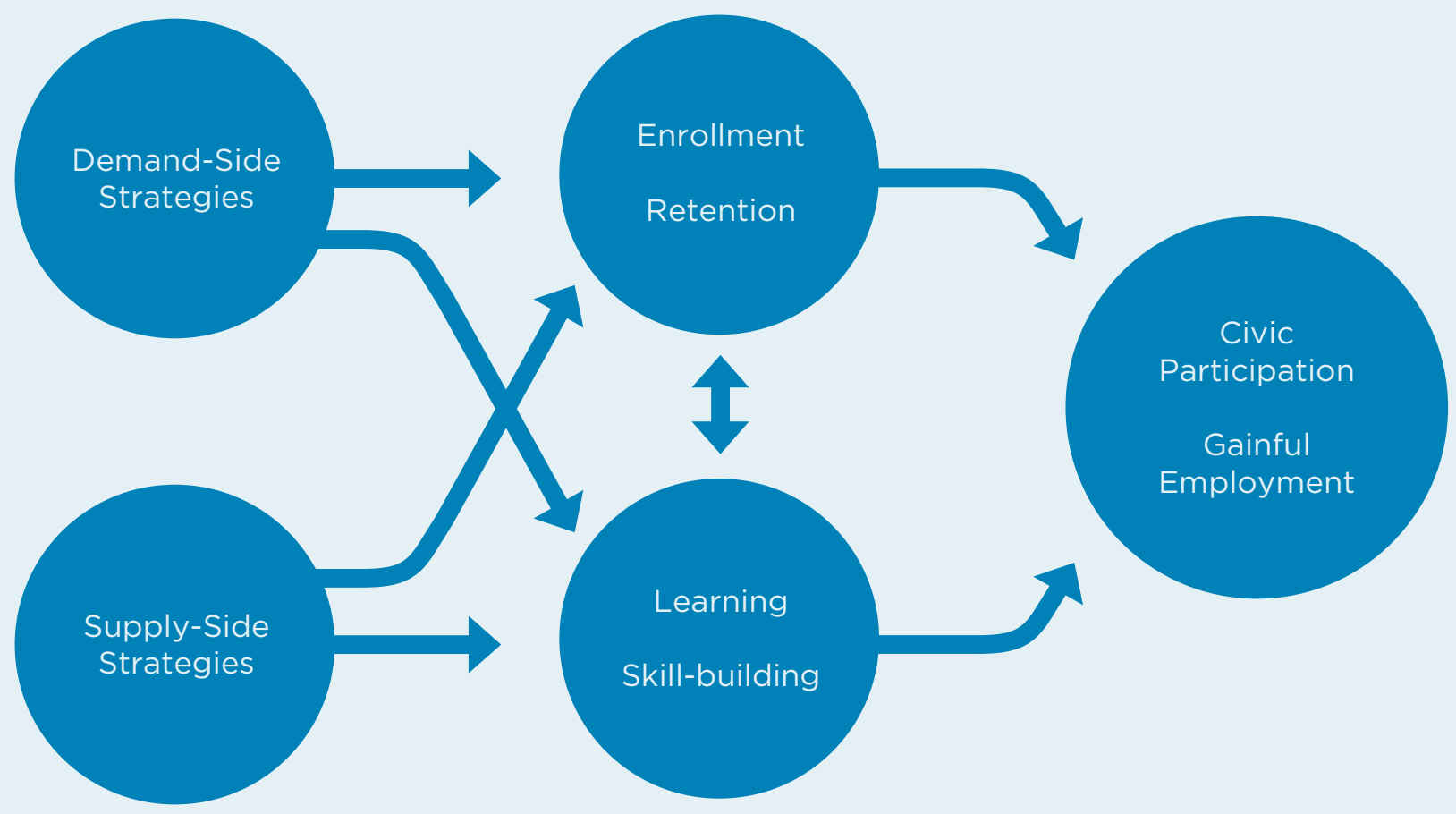

\section{Lessons from past practice}

Some lessons from earlier experiences with programs to support girls' schooling can be gleaned from commissioned program reviews, including reviews of programs funded or initiated by many key players in the girls' education field. These include a recent thorough internal assessment of World Bank projects supporting girls' schooling from 1990-2005 (World Bank 2007), several assessments of USAID girls' education projects in the late 1990s, and several assessments of UNICEF projects benefiting girls' education (including an in-depth review of the African Girls' Education Initiative which ran from 1994-2003). None of these reviews were informed by impact evaluation research but instead involved desk research, country visits, and conversations with key program staff to reflect on program experiences. Criteria for terminology like "success," "lessons learned," "major strides," or "disappointments" used in these reports were not defined and are presumed to reflect the opinions of the authors. Nonetheless, these reviews give us a sense of program objectives, scope, and strategies as reflected in this first generation of educational programming for girls.

Although a wide variety of strategies was tried, certain approaches predominated. These approaches fall into three categories, two on the demand-side and one on the supply-side: (1) making formal schools more accessible to girls by lowering or eliminating financial barriers through stipends, scholarships, or other 


\section{BOX 4.1}

\section{Alternative approaches to addressing the educational needs of adolescent girls}

\section{Demand-side strategies to support adolescent girls in school}

- Scholarships and stipends

- Transportation and boarding

- Advocacy or community engagement in girls' education

- Safety policies and training; codes of conduct

- Toilets and provision of sanitary supplies

\section{Supply-side strategies to enhance educational access, the learning environment, and curricu- lar relevance for adolescent girls}

- Creation of non-formal educational programs, either complementary or alternative

- Recruitment/training of female teachers, para-teachers, and other educators

- Gender training for teachers

- Mentoring, tutoring, and peer support

- Life skills/literacy training

- Livelihoods/vocational training forms of subsidy; (2) mobilizing at the community level to advocate girls' schooling in order to address cultural and social barriers to schooling for girls; and (3) providing non-formal educational alternatives to girls who never went to school or who dropped out after only a few years. Relatively little attention was given in these programs to school quality, and no attention was given to assessing the short- or longerterm benefits for girls of participating in non-formal educational alternatives. This has been a missed opportunity since the rationale for investing in education for girls was originally derived from data based on number of years spent in formal school systems. We still do not know the longer-term benefits for girls of participating in non-formal educational programs and how they might compare with the benefits to those participating in the formal educational system.

UNICEF's African Girls' Education Initiative (AGEI) was the first major international effort to promote girls' education broadly across Africa. It started in 1994 with funding from Canadian International Development Agency (CIDA), expanded considerably to 18 countries in 1996 with funding from Norway, and expanded again in 2001, ultimately reaching a total of 34 countries by 2003 (Miske 2008). Participating countries experimented with as many as 180 strategies designed to benefit girls. The approach was eclectic and country-specific, ranging from math and science camps for girls in South Africa, to separate latrines for girls in 16 countries, training in school management and governance in 13 countries, and the creation of non-formal education centers in Guinea (Chapman and Miske forthcoming). Despite this level of activity, a recent review of initiatives to improve the quality of teaching and learning commissioned for UNESCO's 2008 EFA report (UNESCO 2007) found few examples of gender-sensitive approaches to teaching and learning in Africa (Barrett et al. 2007). While AGEI heightened attention to girls' education as a policy issue within participating countries, Chapman and Miske (forthcoming) found little evidence of sustainability or mainstreaming of AGEl activities in their comprehensive review of the program. Furthermore, even "successful" projects were not necessarily sustained, given costs and competing alternatives, unless external funding was available. Non-formal educational alternatives and "second-chance" approaches were not always easily integrated into existing systems. For example, while Guinea incor- 
porated the non-formal model developed under AGEI funding into their formal educational system, Uganda was reluctant to do so, even though the program was widely recognized to be "effective" (UNICEF 2004).

During this same time frame, the Forum for African Women Educationalists (FAWE), founded in 1992, emerged as an important pan-African NGO committed to girls' education. Its presence and commitment have facilitated many of the initiatives described above. As the interest in girls' schooling heightened over the decade, FAWE expanded its role from an advocacy organization to an operational agency, partnering with governments to mainstream gender equity into education policy and using demonstration projects to showcase good ideas and operational concepts, always with a commitment to educational quality (Diaw 2008). Without national partners such as FAWE possessing vision, commitment, and familiarity with local conditions, much of the donor activity described here would not have been possible.

In her comprehensive review of UNICEF evaluations and studies relating to girls' education and gender equality, Miske (2008) assesses the extent to which accumulated experience provides the basis of action. Reports and studies are presented in diverse ways (even in many cases lacking gender-disaggregated data), possibly because of inconsistencies in expectations for how reports are to be written and/ or diverse requests for reports for different organizational purposes, making it difficult to draw lessons that can be generalized across contexts. Project evaluations are few, and even when the term evaluation is used it is more likely to be an evaluation of project implementation (e.g. counting the number of girls served, the number of training sessions implemented, etc.) than one which assesses impact using baseline and endline surveys and some comparison between participating and non-participating groups. Furthermore, evaluations were more likely to be conducted internally rather than externally.

USAID has also been funding girls' education projects in a range of settings since the mid-1990s through various American contracting organizations, using multi-sectoral approaches to encourage collaboration among traditional and non-traditional partners (NGOs, businesses, religious organizations, and media) (Williams 2001; Rugh and Brush 2002). Their success, if any, may be more in relation to the mobilization of national networks in support of girls' schooling than in the demonstration of effective strategies that can be scaled up. There is no evidence that any of the projects initiated in prior rounds of funding have been locally sustained beyond the project-funding cycle or evaluated in terms of impact. However, among the current round of projects funded by USAID (reviewed in Chapter 6), including the multi-country Ambassadors' Girls' Scholarship Program, impact evaluations have been included.

Among the World Bank projects financed over the past 15 years (1990-2005), 22\% (82 out of 372 projects) had components with interventions specifically aimed at improving girls' educational outcomes (World Bank 2007). The largest proportion of these

\section{programs and how they might compare with the benefits to those participating in the formal educational system.}




\section{Past practice provides little guidance for the future because of the absence of high-quality documentation and impact evaluation.}

targeted primary schooling (71\%) - a sector receiving a growing proportion of financial resources over this period. Given the World Bank's approach to lending and grant-making, most of its resources dedicated to girls' schooling would typically be channeled through national governments, with the result that they are likely to affect primarily each country's formal educational system. Funding was concentrated in regions with the greatest gender disparities, including sub-Saharan Africa, South Asia, the Middle East, and North Africa, and has increased over the time period. Three-quarters of projects included school and classroom construction, but other infrastructural elements were also common such as water supply and latrine provision. A third of projects included gender sensitization of personnel and/or the recruitment and training of female teachers. Projects addressing demand-side issues often included scholarships or stipends and/or some community involvement or management. However, it is likely that boys have benefited more than girls from World Bank investments in education, since boys form the majority of students in most school systems.
The World Bank report (2007) concludes that the beneficial impact of these projects on girls is hard to evaluate, particularly those with infrastructural or learning-related elements, because of the lack of monitoring and evaluation indicators. Demand-related elements, in particular stipends and scholarships, have proved their success in increasing enrollment (see further discussion below in "Lessons from research") but more needs to be done to determine the extent to which intended target populations have been the actual beneficiaries and at what cost. For example, the secondary girls' scholarship scheme in Bangladesh was intended to boost enrollment and completion rates and delay the marriage of girls from the poorest families in low-literacy areas (World Bank 2007). While girls' enrollment rates in secondary school increased substantially, completion rates were disappointing. Furthermore, questions have been raised as to whether targeting mechanisms were effective, since many of the benefits of the program actually accrued to girls from better-off families (Khandker et al. 2003).

While much good work has been accomplished and is spelled out in this report, past practice provides little guidance for the future because of the absence of high-quality documentation and impact evaluation. Furthermore, projects often ended with a particular funding cycle, and donor interests shifted, making it hard for local groups to sustain promising approaches. Nonetheless, these conclusions should not detract from the fact that the World Bank has become a leader in undertaking and encouraging impact evaluation and has been much more transparent than most other agencies in providing information about its programs.

\section{Lessons from research}

Insights about educational policies and programs with the potential to benefit adolescent girls can be derived from impact evaluations of pilot interventions and empirical studies of educational outcomes in relation to various household, school, and community characteristics. Some studies have addressed features of the environment external to the school that affect parental demand for schooling (e.g. school fees and related educational costs) or adolescent demand (e.g. provision of hygiene supplies for girls). Other studies explore features of the school environment which might differentially benefit or harm girls - in particular 
the availability of female teachers for girls and the extent to which teachers treat boys and girls equitably in the classroom. Several assess the potential role of alternative or complementary non-formal schools in enhancing girls' enrollment. Educational outcomes assessed are typically short term; longer-term consequences of educational policies and programs for employment, parenthood, or citizenship have rarely been the subject of research studies given lack of appropriate data.

\section{Demand-side strategies}

We can cite a host of studies addressing the enrollment gains for girls both absolutely and relative to boys stemming from various types of tuition waivers, scholarships, or cash transfers conditional on school attendance. Since much of the early attention in the policy community focused on reaching the out-ofschool population-typically a poor, marginalized, rural, and disproportionately female population-the universal waiving of primary school fees was found to be particularly effective, with the parents of girls even more sensitive to changes in school costs than the parents of boys (Kattan and Burnett 2004). For example, in Uganda, when school fees were waived in 1997, the gender gap in primary school enrollment was eliminated (Deininger 2003). While most conditional cash transfer programs have been designed to address family poverty rather than girls' educational disadvantage, the Mexican program Oportunidades, formerly Progresa, did give mothers a slightly larger cash transfer for their girls' attendance in formal secondary school; and, not surprisingly, girls' enrollments increased slightly more than boys' in response (Behrman et al. 2005). A recent assessment of the Mexican program has concluded that cash transfers to mothers that are conditional on their children's entry into formal secondary school have been particularly effective in raising secondary enrollment above levels that would have been achieved if the resources had been provided without conditions. This is an important finding given adolescent girls' typical falloff in enrollment at that stage of their education (de Brauw and Hoddinott 2008).

As attention has shifted to transitions to secondary school-a transition that girls have traditionally been less likely to make than boys in many poor settingsa variety of girls-only scholarship schemes have been implemented, some of which have been the subject of
BOX 4.2

\section{The feminization of Islamic secondary schools in Bangladesh}

In the early 1980 s, the government of Bangladesh introduced reform to the madrasa education system, offering to provide public recognition and subsidies to cover teachers' salaries to those madrasas agreeing to modernize their curriculum by teaching secular subjects such as English, Bengali, science, and math in addition to their regular religious subjects. Given these incentives, many orthodox madrasas chose to modernize and accept government subsidies despite traditional principles favoring financial autonomy. Today, $30 \%$ of all students enrolled in secondary school in Bangladesh attend government-recognized madrasas. The incentive for orthodox madrasas to modernize was given further support in 1994 when female students attending recognized madrasas became eligible to receive a stipend under the government's female stipend program (FSP). Most orthodox madrasas had traditionally been all male. The percent of female students enrolled in madrasas has risen from $5 \%$ in 1980 to $30 \%$ in 1995 to nearly $50 \%$ today. As a result of the FSP, gender equity has been achieved in secondary school enrollment. Furthermore, and probably in response to growing female enrollment, recognized madrasas are increasingly recruiting female teachers, most of whom are graduates of secular schools (Asadullah and Chaudhury 2008). 
BOX 4.3

\section{Menstruation and education in Nepal}

Many in the policy community fear that menstruation and the lack of proper sanitary hygiene compromise the school attendance and performance of adolescent girls and therefore put them at a disadvantage relative to their male peers (see Kristof and WuDunn 2009 for a recent example). In a randomized trial of the provision of menstrual cups in four schools in Nepal from November 2006 to January 2008, the attendance and performance of girls in seventh and eighth grade was compared. The menstrual cup, MoonCup, is a small, silicone, bell-shaped cup inserted in the vagina to collect menstrual blood and can be used continuously without emptying for 12 hours. Among girls in the treatment arm of the trial, $60 \%$ adopted the cup as reported by the nurse on monthly school visits, suggesting that most girls welcomed its convenience. Nonetheless, there was no statistically significant difference between the girls in the treatment arm and the control arm of the experiment in attendance rates or test scores. Indeed, absenteeism due to menstruation was small to begin with, with an average of 1.3 days of school over the course of the year missed due to menstruation (Oster and Thornton 2009).

15

This program is currently called the Ambassador's Scholarship Program because both boys and girls are beneficiaries. typically ex-post evaluation studies. To our knowledge only one girls-only scholarship scheme included a prospective evaluation design with random assignment. This pilot intervention in Kenya introduced merit scholarships for girls at the end of grade 6 on a randomized basis in two rural districts and evaluated impacts on test scores, with results showing academic improvement after a year, not only for girls eligible for the scholarship but for others as well (Kremer et al. 2008). As this was just a demonstration project designed to generate research findings that could inform educational policy, it was not, to our knowledge, continued after the pilot phase.

The largest and best-known girls' secondary school scholarship scheme began in 1991 in Bangladesh. While large improvements in girls' enrollment in secondary school were attributed to the program, there have been lingering questions about the targeting of the scholarship as well as about educational quality (Khandker et al. 2003). The rapid expansion of secondary school places was partially achieved through the feminization of Islamic schools (see further discussion in Box 4.2).

This may be one of the most dramatic expansions of formal secondary school in history, yet we know nothing about how the quality of schooling in madrasas compares with other types of public and private schools, in terms of learning outcomes and gender differences in school experiences. We do know, however, that girls who attend secondary madrasas have a more conservative social outlook than girls attending secular secondary schools: favoring their sons rather than their daughters for higher education, preferring larger families, and considering it best for mothers not to work while they are raising children (Asadullah and Chaudhury 2006). Nonetheless, this provides an interesting case study of the potential for rapid expansion of secondary school access for girls in settings where religious schools already exist (Asadullah and Chaudhury 2008).

Questions of targeting have plagued the U.S-sponsored Ambassadors' Girls' Scholarship Program, begun in 2004 and now covering 41 countries in Africa. ${ }^{15}$ A commissioned ex-post evaluation, based on field visits and interviews, of several of the earliest programs implemented in Sierra Leone and Djibouti found problems at the community and school levels. Many more girls qualified for scholarships in each school than could be funded with available resources. Because of ad hoc and arbitrary systems of selection within each school, it appears that some scholarship recipients might have continued in secondary school even without the scholarships, and there was some backlash from non-recipients (Chapman and Mushlin 2008). Other large-scale girls-only scholarship schemes were launched in Cambodia with Japanese funding and in Punjab, Pakistan, with World Bank funding in 2004. Ex-post evaluations found that, in Cambodia, enrollment and attendance rates were approximately $30 \%$ higher than they would have been in the absence of the program (Filmer and Schady 2008), and in Pakistan, female enrollment increased by $9 \%$ over two years in stipend-eligible middle schools (grades 6-8) (Chaudhury and Parajuli 2006).

The provision of other amenities has been considered important to the enrollment of girls and 
has been part of many of the initiatives mentioned above, particularly those sponsored by UNICEF.

These include textbooks and/or uniform provision to reduce costs, transportation or boarding facilities to increase safety and reduce costs, and sensitization to gender-based violence to increase safety. Some initiatives have also supplied sanitary products for girls, although recent research (see Box 4.3 and discussion below) suggests that this approach may be less likely to increase girls' attendance rates.

These are all elements that have been presumed to make parents more comfortable sending their girls to school and school attendance less costly. Some insights about sanitary supplies for girls comes from a recent randomized trial in Nepal (Oster and Thornton 2009). In general, adolescent girls' overall absenteeism rates are about the same as and sometimes lower than those of adolescent boys, but the reasons may differ (Loaiza and Lloyd 2008).

To date there has been almost no research on the effect of the presence of non-state providers of education - the other main supply-side intervention on educational outcomes for girls. The one exception is Bangladesh, which has a rich tradition of NGOs providing complementary non-formal education to the poor in more remote rural areas lacking government schools, BRAC being the most notable example. While these schools did not target girls specifically, their programs appear to have differentially benefited them. Many features may have been particularly supportive to girls, including a higher percentage of female teachers. As $90 \%$ of BRAC graduates made the transition to formal government schools in grade 4, these schools provided out-of-school girls with an opportunity to reenter the formal system with accelerated learning, multi-grade classrooms, and progress beyond primary school (Sukontamarn 2005). At the secondary level, another type of alternative schooling-madrasashas provided a boost to female enrollment after the government offered financial support for teacher salaries to those madrasas that agreed to register with the government, teach modern subjects, and accept female students (see Box 4.2).

\section{Supply-side strategies}

Research has also informed us about some of the other potential pathways on the supply-side through which girls' enrollment and attendance can be enhanced and learning outcomes improved. The most
Some initiatives have also supplied sanitary products for girls, although recent research suggests that this approach may be less likely to increase girls attendance rates. 


\section{Much has been}

written about

gender treatment

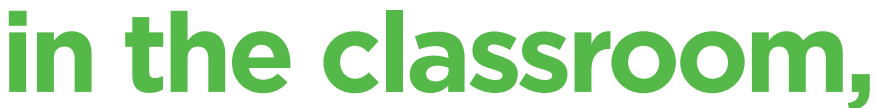

but little research

has explored the

association between

teacher treatment

of boys and girls in

the classroom

and differences

a 90000

outcomes by gender. consistent finding relates to the positive effects of the presence of female teachers and/or other female staff on girls' enrollment and learning. In Bangladesh, having female teachers in local schools was found to increase girls' enrollment (Khandker 1996, cited in Glick 2008), increase the percent of correct answers in secondary-level mathematics (Asadullah et al. 2006), and be associated with more enlightened attitudes towards working women and higher education for girls (Asadullah and Chaudhury 2006). Similar results were found in Mozambique, but only if the female teachers were trained (Handa 2002). A recent multi-level analysis of primary school enrollment in 30 developing countries linking household- and district-level data found that girls' enrollment, but not boys', was positively associated with the percent of female teachers in the district (Huisman and Smits 2009). Even more importantly, in a five-country African study, fifth-grade girls' knowledge gains were larger when taught by a female teacher, whereas boys benefited more from a male teacher (Michaelowa 2001). Similar effects were found in US-based longitudinal data (Dee 2007).

Many programs with potentially girl-friendly features have not been evaluated separately for boys and girls, e.g., a remedial education program using young women as tutors in India (Banerjee et al. 2007). On the other hand, studies of pilot educational interventions that were not designed specifically for girls, but where girls have been shown to have benefited more than boys, suggest the importance of further research to identify those features that were particularly girl-friendly. A randomized study of a program in a low-literacy area of rural India involved the assignment of additional teachers, primarily female, to non-formal, single-teacher schools. Girls' attendance increased by $50 \%$, while boys' attendance was not affected (Banerjee et al. 2001, cited in JPAL newsletter). However, it is not clear whether the gains can be entirely attributed to the fact that teachers were female, since their presence also increased the number of days schools were open and generally enhanced the quality of the school due to increased staffing. A randomized trial in Kenya of assigning students to academic tracks on the basis of prior academic performance (so as to reduce heterogeneity in the classroom) found that tracking improved test scores, with girls showing greater gains than boys, particularly in math (Duflo et al. 2008). While this was not designed as a girl-friendly program, it turned out to have been one. Similarly, in 
rural Pakistan the beneficial effects on girls' enrollment attributable to the presence of a local teacher, rather than a teacher from out of town, may be explained by the greater likelihood that local teachers will have regular attendance, giving parents an increased sense of safety and security when sending their girls to school (Lloyd et al. 2005). ${ }^{16}$

Much has been written about gender treatment in the classroom, but little research has explored the association between teacher treatment of boys and girls in the classroom and differences in educational outcomes by gender. Studies in Kenya have explored effects on student achievement and dropout rates as well as on reproductive outcomes. Appleton (1995) explored the determinants of gender differences in the scores of primary school leaving exams ${ }^{17}$ in a sample of schools in Nairobi and found that boys performed better than girls in schools where teachers express the opinion that girls are less capable than boys; boys, on the other hand, were not affected by these attitudes. Lloyd, Mensch, and Clark (2000) found that various measures of gender treatment were significantly associated with dropout rates for girls but not for boys. These included teacher attitudes about differences in the learning abilities of boys and girls and gender differences in classroom treatment; school environments that were differentially discouraging to girls or differentially encouraging to boys had higher dropout rates for girls than those with more equitable environments. Interestingly, it was also found that girls who attended schools with greater gender equity in attitudes and treatment were less likely to have had premarital sex than girls attending more inequitable schools (Mensch et al. 2001). Given that premarital sex is often a precursor to school dropout (Biddlecom et al. 2008) and is often associated with early marriage, gender equity in the classroom may be particularly important for girls in assuring them of the protection and respect that they need to thrive as adults.

Based on our review of program experience and research, we can re-categorize the approaches to addressing the educational needs of adolescent girls presented in Box 4.1 according to whether or not their success has been proven, they appear to be promising but are still unproven, or are unlikely to succeed. In categorizing these approaches, we primarily assess evidence relating to enrollment and retention rather than evidence relating to learning outcomes (see Chart 4.1). This is because it is only recently that learning
BOX 4.4

\section{Evidence on the effectiveness of alternative approaches to addressing the educational needs of adolescent girls}

\author{
Demand-side strategies to support \\ adolescent girls in school:
}

Scholarships and stipends - PROVEN SUCCESSFUL

Transportation and boarding - PROMISING BUT UNPROVEN

Advocacy or community engagement in girls' education - PROMISING BUT UNPROVEN

Safety policies and training; codes of conduct - PROMISING BUT UNPROVEN

Toilets and provision of sanitary supplies - UNLIKELY TO SUCCEED

\section{Supply-side strategies to enhance educational access, the learning environment, and curricu- lar relevance for adolescent girls}

The creation of non-formal educational programs, either complementary or alternative - PROMISING BUT UNPROVEN

Recruitment/training of female teachers, para-teachers, and other educators - PROVEN SUCCESSFUL

Gender training for teachers - PROMISING BUT UNPROVEN

Mentoring, tutoring, and peer support - PROMISING BUT UNPROVEN

Life skills/literacy training - PROMISING BUT UNPROVEN

Livelihoods/vocational training - PROMISING BUT UNPROVEN 


\section{Little research}

or programmatic attention has

been given to

educational quality

and relevance, in

particular those

aspects that may

be beneficial to

girls, including

curricular content. outcomes are being measured more systematically and thus almost no evaluations to date have assessed program impact against this standard. In Box 4.4 we repeat the list using this categorization. Two approaches have already proven successful - scholarships and stipends, and recruitment and training of female teachers. Most others appear promising but unproven. However, one popular approach - toilets and the provision of sanitary supplies - does not appear promising as a strategy for increasing enrollment and retention given the accumulation of research evidence presented here. ${ }^{18}$ While girls definitely benefit from the strategy, it does not appear to materially alter their behavior vis-à-vis school outcomes. ${ }^{19}$

From this review, we can see that relatively little research or programmatic attention has been given to educational quality and relevance, in particular those aspects that may be beneficial to girls, including curricular content. Since the rationale for educational investments in girls has been based primarily on beneficial effects later in life with respect to employment, wages, and household management and parenting skills, research and programming in the area of educational quality should be a priority. Only in the past few years are we beginning to learn that primary school completion does not necessarily result in literacy and numeracy and that children who do not acquire the basic educational building blocks typically falter in later grades and are less likely to continue in school (Jukes et al. 2006). More recently, some educational programs have added curricular enhancements such as sports, life skills, livelihoods training, financial literacy, and health education to build confidence, enhance productivity and employability, and teach life skills. Unfortunately, these are often layered onto already heavy teaching loads in schools where many adolescent students still lack basic reading and numeracy skills.
18

It was most recently promoted as

a strategy by Nicholas Kristof and

Sheryl WuDunn (2009) in their book

Half the Sky: Turning Oppression

into Opportunity for Women World-

Wide. New York: Knopf.

See Boxes 2.1 and 4.3 

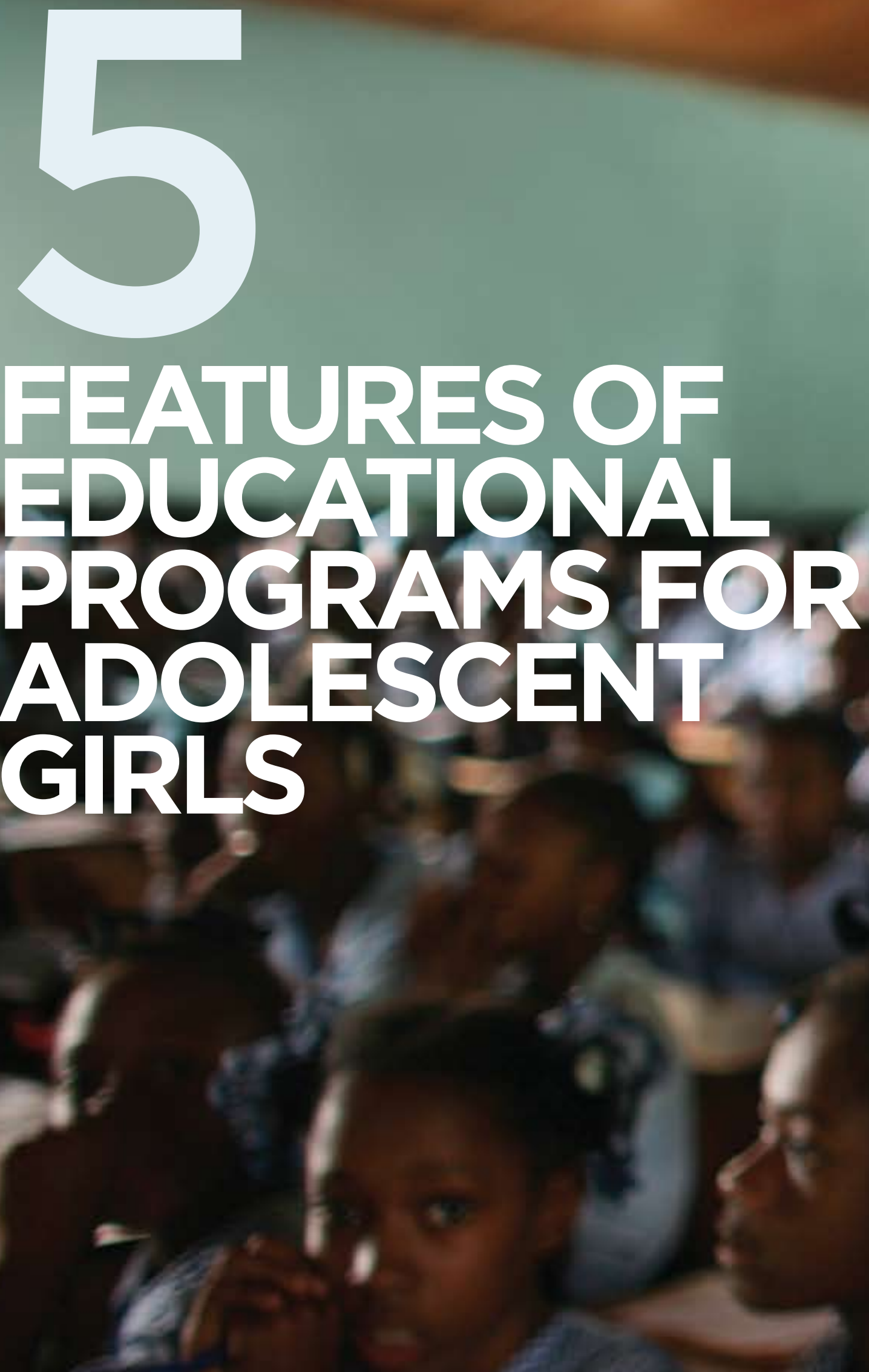

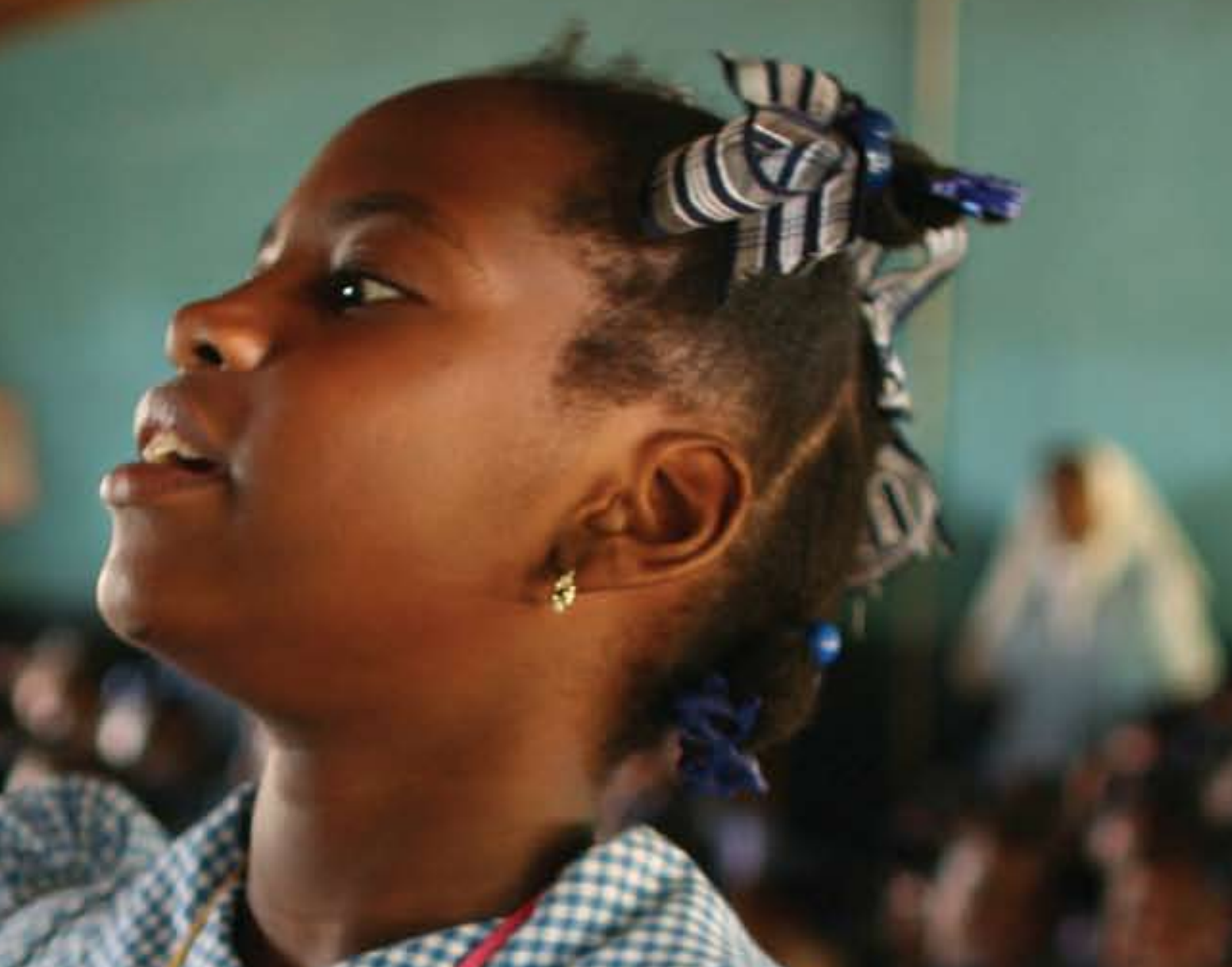

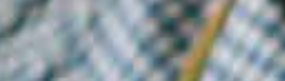

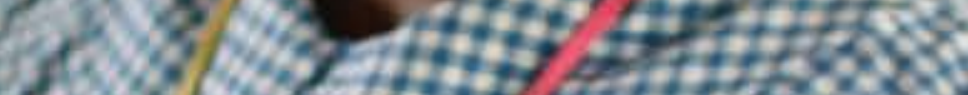

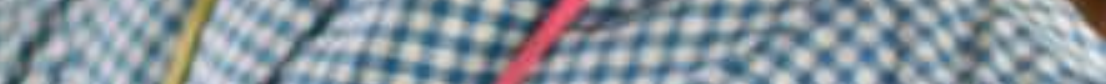

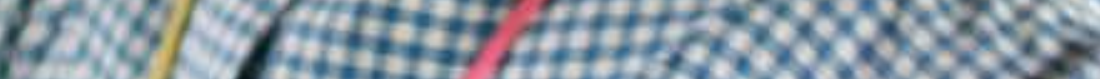

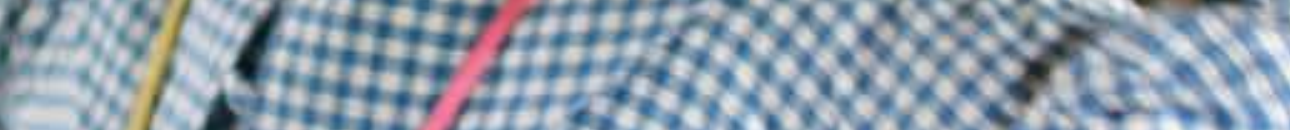

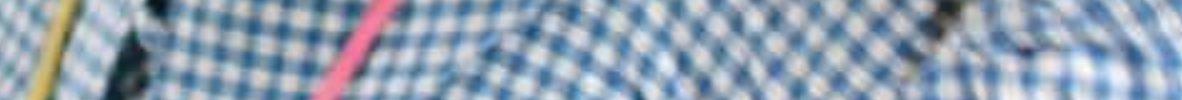

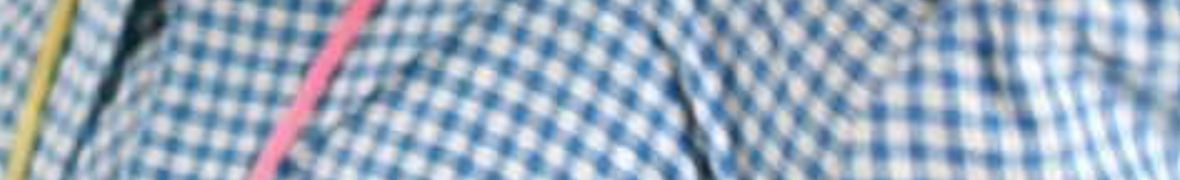

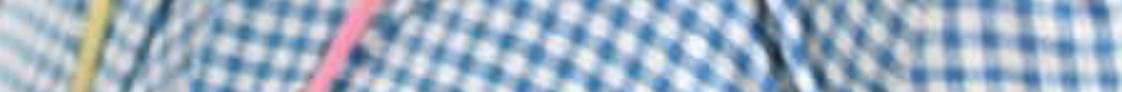

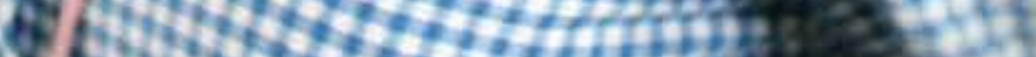

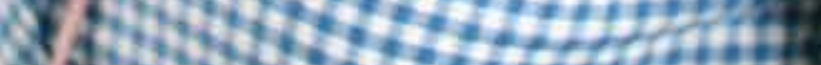

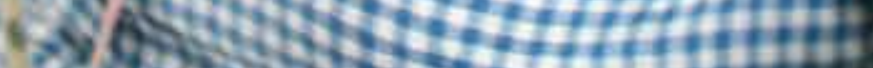

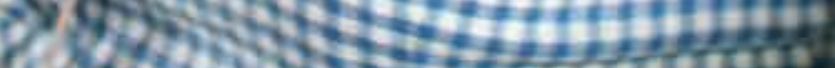

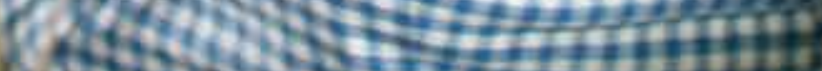

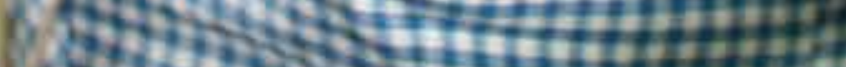

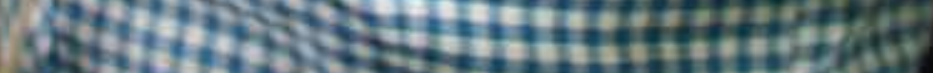

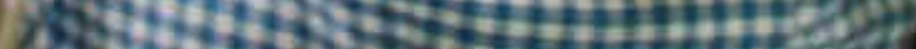

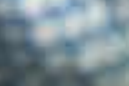

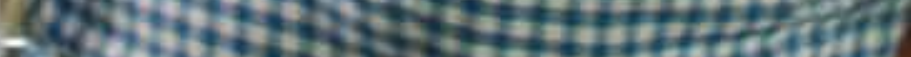

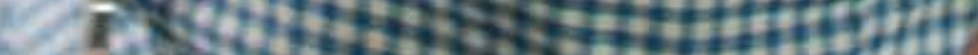

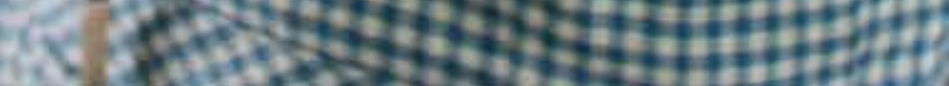




Chapter 4 laid out alternative
strategies for addressing the
educational needs of adolescent
girls using demand and sup-
ply as an organizing framework.
Under demand were grouped
approaches that address some
of the constraints and barriers
that are presumed to prevent
adolescent girls from attend-
ing school (or their families from
sending them). Under supply
were grouped approaches that
improve access to educational
opportunities, enhance the edu-
cational environment, or address
directly some of adolescent
girls' developmental and learn-
ing needs. These two sets of
approaches are mutually rein-
forcing. This chapter refines the
framework set out in Chapter 4
to highlight the features of for-
mal and non-formal educational
programs for adolescent girls.

In developing a compendium on such programs, our goal has been to learn about the strategies of governments, NGOs, UN agencies, and other actors to support adolescent girls' education. Are these strategies already known to be successful? Are they promising but unproven? Or are they unlikely to improve girls' educational outcomes? We are also interested in the lessons about program impact.

\section{Framework for the compendium}

The development of a workable framework for the compendium was an iterative process involving interaction over time between our deepening understanding of educational programs and our need to find conceptual organizing principles to guide the presentation and interpretation of the information gathered. The framework we ultimately settled on included reasonably unambiguous criteria for the inclusion of a program in our compendium and a typology of the different contexts and arenas of action for such programs within national educational systems.

Criteria for inclusion:

An educational program was listed in this compendium if all of the following conditions applied:

- It serves girls within the age range 10-19.

- It was operational, to the best of our knowledge, in December 2008.

- It serves girls only and/or has as its stated objective the expansion of educational opportunities for girls or the equalization of gender disparities in education, and;

- It has at least one girl-friendly feature.

We define girl-friendly features of a program to be features specifically designed to support girls in overcoming obstacles to attending and participating in school or to reaping the full and equal benefits and rewards of education, as well as features designed to enhance the existing educational environment or address more directly some of adolescent girls' development and learning needs. The girl-friendly features include all the most common strategies listed in Box 4.1 as well as other less common strategies that we identified in the course of data collection. Box 5.1 provides more detail.

Program types:

For each program that fits our inclusion criteria, we indicate whether it falls into one or more program types. These five types include programs (1) creating enabling conditions for school attendance, completion, and progression; (2) providing alternative educational programs; (3) providing complementary educational programs; (4) creating new formal schools or enhancing existing formal schools; and/ or (5) providing after-school programs. As discussed in Chapter 2, there is a complete absence of data on participation in non-formal educational programs. Thus, in researching current education programs for adolescent girls, we developed a typology that allows considerable space for non-formal programs. The girlfriendly features enumerated in Box 5.1 can appear in some or all of these program types and thus cut across this typology. For example, female teachers 


\section{BOX 5.1}

\section{Common girl-friendly features}

\section{Demand-side strategies to remove constraints to school attendance}

Scholarships/stipends: Cash and in-kind contributions to girls and/or families for the purpose of school attendance

Transportation/boarding: Interventions to reduce or eliminate the costs for girls traveling to/from school and ensure their safety

Advocacy or community engagement in girls' education: Efforts to promote positive attitudes and other community and social resources that support girls in obtaining an education

Safety policies and training; codes of conduct: Interventions to ensure girls' safety within the school environment

Toilets and provision of sanitary supplies: The provision of separate toilet facilities for girls at school and/or the provision of sanitary supplies to adolescent students

\section{Supply-side strategies to enhance the learning environment}

Recruitment/training of female teachers, para-teachers, and other educators: Training programs that target young women, hiring policies to support women in entering and remaining in the teaching force, and the use of complementary teaching staff-such as para-teachers - to support girls in large classes

Gender training for teachers: Training to promote positive attitudes towards the learning capacities of girls and boys, and/or training in teaching methodologies that are effective in engaging and supporting girls' learning

\section{Supply-side strategies directed at girls' developmental and learning needs}

Mentoring, tutoring, and peer support: Activities to support girls' development and learning needs by engaging them in supportive relationships with peers, older girls, or adults, especially women

Life skills or literacy training: An umbrella category encompassing a variety of approaches to training girls in skills they did not learn as younger children and that they need for life

Livelihoods or vocational training: Any training to support girls in developing specific skills that will help them to earn income either as employees or as entrepreneurs 
In developing the compendium, our goal has been to learn about the strategies of governments, NGOs, UN agencies, and others to support adolescent girls education. and educators are relevant for all types of educational programs. Livelihoods can be taught as part of the regular curriculum in various types of formal or nonformal schools, as well as be part of an after-school program. Advocacy or community engagement in girls' education can support attendance in both formal and non-formal schools depending on the context.

Programs creating enabling conditions for girls' education include scholarship and stipend schemes, the provision of transportation or meals, and campaigns to build family/community and societal commitment to and capacity for educating girls. Under this first category, our intention was to identify activities that do not affect the school experience itself, but that encourage and support attendance in school by providing girls and families with material resources, logistical support, and a supportive community environment for their schooling. Other types of activities that take place outside the school setting, and which also fall in this category include: child care for younger siblings to free older girls from babysitting responsibilities, the provision of sanitary napkins, "mothers' clubs," 20 and projects to build community capacity to support and manage schools.

Alternative programs provide girls with skills that they did not acquire because they did not attend and/or complete formal school, as well as life and/ or job skills that they might not have acquired even if they had attended formal school. Typically these include second-chance programs, literacy or basic skills programs, and livelihoods or vocational skills programs. The goal of these programs is skill acquisition; typically they are designed as a final stage in the beneficiaries' education and do not serve as a conduit back into the formal educational system. ${ }^{21}$ We did not include under this category short training/education programs that focus on only one topic or skill, such as HIV education or arts programs, if they function completely independently of a school.

Complementary programs support previously outof-school younger adolescent girls as they enter or reenter the formal education system and/or provide them with certification equivalent to accreditation from the formal system. These include accelerated learning or catch-up programs to enable children who have missed formal school to reenter the school system. They also include programs to support chil- 
dren in sitting for, and succeeding on, examinations required to enter formal school.

Programs to create formal schools include initiatives to establish primary or secondary schools that follow the same grade sequence and basic course of study as formal government schools in the host country and are accredited (or the local equivalent). Those include schools established, administered, and funded by private institutions, such as the Oprah Winfrey Leadership Academy in South Africa. They also include schools established as partnerships between NGOs and the government, such as "community schools," which receive government funding and oversight. In those schools, NGOs support curriculum development, teacher training, community management, transportation, and other special activities and programs. Programs that enhance formal schools include investments in school facilities, training for teachers in gender sensitivity, training or other measures to ensure girls' safety from gender-based violence, recruitment and training of female teaching staff, development of curriculum, and educational materials. ${ }^{22}$

After-school programs include any activity that takes place outside the regular curriculum and school hours to provide beneficiaries with direct support for their learning, development, and psychosocial needs so that they may continue their education and enjoy the full benefits of an education upon leaving school. These activities may be sponsored by or fully independent of schools, and may take place on school grounds or in other venues. Some of the programs in this category focus on tutoring to support girls' academic success (see Box 5.2 for further discussion of tutoring). Also in this category are training programs to provide girls with the skills they need to overcome obstacles to their education and will need in later life, such those that focus on life skills, decisionmaking, health, or hygiene. Almost all of these programs are designed to support students attending formal schools, but some after-school programs are designed to support students in non-formal education programs, or out-of-school young people who may reenter formal school. Training on sexual and reproductive health or HIV/AIDS prevention was included if the specific intent of the program was to prevent girls from dropping out. Mentoring and counseling programs, including those involving adults or peers as mentors or counselors, also fall in this category.

\section{BOX 5.2}

\section{Tutoring: an important but contentious issue}

In many countries, "tutoring" has become a contentious issue, because it is increasingly seen as a potential locus of corruption and, paradoxically, a practice that some say results in a reduction in educational quality and equity. Better-off parents are able to pay for private tutoring to help their children succeed in school. In settings such as Egypt, where public school teachers can supplement their salaries by tutoring some of the same students they teach in class in the mornings, teachers may reduce their efforts during regular class time, which has implications for school quality (Lloyd ed. 2005). Curricula based on testing and memorization, including high-stakes tests, are especially conducive to the worst practices associated with tutoring. However, in theory, tutoring-providing students with additional support after school, during which they can practice skills or reinforce knowledge that they are developing in their regular curriculum -is a logical strategy to ensure academic success for most students. There may be special benefits to girls of tutoring programs; if girls are provided with space and time after school, without extra fees, to continue to focus on their studies, this may help to ensure that they are able to spend as much time on their studies as boys, especially where girls are expected to carry a heavier burden of domestic chores at home (Lloyd et al. 2008). Moreover, studying outside school is critical to the success of students in secondary school where curricula and teaching methods often require individual studying time to memorize facts, practice problem-solving skills, or write essays and reports. Thus, programs that provide tutoring support free of charge may be of particular help to girls.

When identifying the appropriate category for a program or project in our compendium, we selected any of the categories that apply. Some specific activities or interventions bridge more than one category or program type. ${ }^{23}$ Furthermore, many programs have multiple components, in which case all categories that describe any component of a program are checked.
23

Some after-school programs, notably the FAWE "Tuseme" ("We can overcome"), are designed to help girls develop leadership skills to overcome obstacles to their schooling and advocate for their own learning, as well as to participate in advocating for and improving educational opportunities for other girls. As this activity is also intended to support the development of a supportive environment for girls' education, we identified thes programs in the "enabled 


\section{The actual}

impact of the

overwhelming

majority of

programs listed in our database is unknown or known to only a few insiders.

\section{Challenges and caveats}

We encountered numerous challenges in assembling the compendium, with the result that our findings must be assessed with certain caveats in mind. First, many potentially relevant programs are not included because their existence is not documented in a format readily available to a researcher not directly associated with the program. We suspect that many organizations devote all of their time and resources to delivering educational services, leaving little left for documentation and dissemination. Local groups, in particular, may not have adequate resources to report on activities in a format that would be accessible internationally, such as a website. Additionally, in some cases, there was not sufficient information in the sources available to determine that a program met our criteria for inclusion. These included websites hosted by NGOs; the publications and reports of various donors, governments, and NGOs; and articles from leading U.S. newspapers. Thus the 322 programs reflected in our compendium undoubtedly understate the number of programs that would merit inclusion if more complete information were available.

Second, programs often involve many partners, donors, international NGOs, and local implementing agencies-all or some of whom report on selective aspects of the same program in different ways. In some instances we found it was impossible to determine whether activities described by different agencies were the same project, were different components of the same program, or were simply similar but unrelated activities in the same country. Even more difficult to determine were the roles and relationships of multiple partners collaborating on the same project. For this reason, we do not distinguish between "lead partners" and implementing agencies.

Third, organizations and agencies develop and disseminate descriptions of their activities with different audiences in mind. This results in inconsistent data. Many NGO web sites are designed to interest potential donors, focusing on basic information that is useful to the general public in understanding development or humanitarian aid issues but providing sketchy details about project and program activities, including the number and type of beneficiaries served. Some reports are designed to please existing donors with impressive lists of scholarships granted, toilets built, 
and training sessions provided and do not indicate the time frame encompassed in the report or which aspects of the program are currently operational. By contrast, for example, the World Bank's web site, which is addressed to a more technical audience, includes a vast archive of technical documents that are most likely to be read by policymakers, practitioners, and researchers, as well as constituents concerned with transparency in international development projects and funding.

Fourth, some issues related to girls' schooling may be sensitive, and agencies and organizations implementing programs may be reluctant to discuss them overtly, even when they are working on them quietly. For example, in some settings organizations working to prevent sexual exploitation of girls by teachers or administrators may fear that acknowledging these patterns of harmful behavior in program descriptions would be detrimental to potentially productive relationships that they are building locally with educators or government ministries. Information about budgets can also be sensitive, particularly when local programs are supported by international NGOs, because the money flowing to in-country activities may represent a fraction of the overall budget for the project.

Finally and most importantly, even among those few organizations that have allowed for external evaluations of their programs, far fewer have shared the results of these evaluations with others. Organizations and the donors who support them may be especially reluctant to share findings when outcomes fall short of program objectives, despite the fact that lessons learned from those outcomes, if properly evaluated, could be of great value to other practitioners and donors. Thus, the actual impact of the overwhelming majority of programs listed in our compendium is unknown or known to only a few insiders.

In our final compendium, we present information on 322 programs to provide or support education for adolescent girls fitting our criteria. There is considerable diversity in the types of programs we include as single entries; these include:

Individual projects, including pilot projects, with specific features or interventions, underway in a set location, and serving a specific community or cohort;

\section{Given our focus on adolescents, one of the most interesting findings from our compendium was the notable absence of the word adolescent in any project document.}

Programs, often with multiple components, with various activities or interventions to serve various beneficiaries, and/or operating in different locations;

Government policies or reform initiatives, usually at the national level, also with a variety of activities and interventions implemented in different locations and contexts, and sometimes with the support of outside donors or other agencies.

For simplicity in our discussion, we refer to all of these as programs. Whenever possible, we disaggregate our entries to describe individual projects or interventions. However, when only more general information about multifaceted initiatives was available 
to us, we include these as single entries. Thus, readers should note that if they are reading an entry about any program that includes multiple activities, the characteristics and features identified refer to at least one of those components, but may not describe all of them.

Programs are only included if there was sufficient information from available sources to ensure that they met the inclusion criteria listed above. Thus, if a feature is not identified as part of a program's activities, readers should infer that we don't know whether the characteristic is included, not conclusively that it is absent. Furthermore, some entries may refer to initiatives serving a small number of girls, whereas others are country-wide programs implemented across regions, or throughout entire regions.

We made a field visit to one CARE educational program for adolescent girls in Mali and learned firsthand how limited even the most detailed information can be when read without knowledge of the context or the history of program development. In Box 5.3, we describe the CARE program and highlight some of the special features of the program that cannot be understood well from a distance, even though the sponsor is one of the most thorough and responsible when it comes to documentation. It was only through field visits and interviews that we learned how CARE and its partners developed girl-friendly strategies specific to adolescent girls within the social, economic, and institutional context of rural Mali.

Nonetheless, despite these caveats, we feel that the data provided here will have enormous value not only in framing discussion on the subject of education for adolescent girls, but also in laying the foundation for recommendations about future priorities. By mirroring back to organizations the information that we were able to find, we hope that other organizations whose projects and programs have been excluded will use the framework provided here as a guideline for future reporting. We also hope that they will share this information with others, including practitioners, researchers, donors, policymakers, and stakeholders at all levels. And for the organizations whose programs have been included but who find gaps or errors in the information provided, we hope that they will respond with more regular updating and consistent reporting.

\section{Results}

The great majority of programs in our compendium are operating in sub-Saharan Africa (69\%), and nearly a quarter are in Asia (23\%). It is surprising that only $4 \%$ of the programs are in the Middle East, as there are significant gender disparities in labor force transition rates despite narrowing gender gaps in education (see Figure 3.5 for Egypt as an example). The scarcity of programs in Latin America and the Caribbean (4\%) was less surprising, as average educational attainment for girls exceeds that of boys in many of these countries.

Many programs were multifaceted, were encompassed within several of our program types, and were characterized by more than one girl-friendly feature. See Table 5.1. The majority of the programs in our compendium included enabling activities (70\%), and the majority of these were combined with efforts to improve formal schools or after-school programs or both. Roughly a quarter of the programs included alternative education programs (23\%), and only $15 \%$ were complementary programs. ${ }^{24}$ Nearly half of programs were involved with the formal school system (46\%), and many of these were national programs, including large-scale reform programs. Forty-three percent of programs included support for after-school activities. There has been a great interest in the potential of after-school programs for girls, given the opportunity these programs present for supplementing, reinforcing, and expanding the school experience in a more supportive environment. Roughly $38 \%$ of these programs are restricted to girls only. ${ }^{25}$

\section{Girl-friendly Target populations:}

Given our focus on adolescents, one of the most interesting findings from our compendium was the notable absence of the word adolescent in any project document. Indeed, we found the word adolescent in only $7 \%$ of the program descriptions. In cases where the word did appear, it was often used in the description of efforts to provide training and supplies for girls' hygiene during menstruation. This omission suggests that few of the programs included in our compendium were designed with the developmental and learning needs of adolescent girls in mind, even though all the programs serve beneficiaries within the adolescent age range. 


\section{BOX 5.3}

\section{Alternative education for adolescent girls in Mali}

CARE initiated the Developing Education for Girls Empowerment project in 2005 in two counties in Mali. In Mopti, the project focuses on Centres Education par Development (CEDs), which provide education to children ages 9-15 who did not attend formal primary school. In Mali, CEDs are non-formal schools but part of the government system. CARE worked in collaboration with local governments at the commune and village level to sensitize the communities about the importance of girls' education. They identified villages with an appropriate level of need for a CED serving at least 30 children, as well as the capacity to contribute income, material resources, and human resources to the management of the project.

At the village level, Community Management Committees coordinate the management of the CED. Their responsibilities include monitoring teachers' attendance, ensuring that CEDs have the materials they need, keeping the environment secure, and ensuring that all children have transportation to and from the CED. Committee members are trained to identify girls in the community who are eligible for participation in the CEDs, and to keep track of their attendance, following up with parents if they notice a pattern of absenteeism. While girls and boys have equal rights to attend the CEDs, these special outreach efforts focus on girls. In addition, Education Committee members are encouraged to ensure that women are represented in their ranks.

The curricula of CEDs are distinct from those of formal primary school in a few key respects. Instruction in CEDs is in local languages, whereas instruction in formal schools is in French. Topics of study include literacy and arithmetic during the first years of the program, and vocational studies for the final years. In government-run CEDs, the academic cycle lasts four years. After completing the academic portion, students spend two years in a vocational training program. CARE has developed a different cycle for their CEDs to balance the time students spend studying with the demands on their schedule at different stages in their adolescence, concentrating the entire program into three years. Students complete the academic portion in two years. The vocational training thus far has been structured as a one-year program, but may be extended for an additional year. CARE's CEDs have added instruction in life skills into their program. Teaching methods focus on student-centered learning techniques. Teachers in Mali's formal schools must have a college degree, but instructors at CEDs may be secondary school graduates who have passed the baccalaureate examination and received training. CARE and its partners recruit candidates from the local communities, and a partner organization provides training. Recognizing the added value of having women instructors, especially for girls, CARE and its partners have made an effort to recruit women, and at least one candidate completed the training program, but ultimately did not begin work as an instructor. One manager noted that to live and work in Mopti's village is a challenge for women, as married women have significant family responsibilities. 


\section{Programs in compendium by type and region}

\begin{tabular}{|c|c|c|c|c|c|c|c|c|c|c|}
\hline \multicolumn{6}{|c|}{ Number of programs/projects according to characteristics } & \multicolumn{5}{|c|}{$\begin{array}{c}\text { Percent of programs with particular } \\
\text { characteristics }\end{array}$} \\
\hline & \multicolumn{5}{|c|}{ Region (number of countries) } & \multicolumn{5}{|c|}{ Region (number of countries) } \\
\hline & $\begin{array}{l}\text { AFRICA } \\
\text { (43) }\end{array}$ & $\begin{array}{l}\text { ASIA } \\
(13)\end{array}$ & $\begin{array}{c}\text { LATIN } \\
\text { AMERICA/ } \\
\text { CARIBBEAN } \\
\text { (6) }\end{array}$ & $\begin{array}{l}\text { MIDDLE } \\
\text { EAST (4) }\end{array}$ & $\begin{array}{l}\text { TOTAL } \\
\text { (66) }\end{array}$ & $\begin{array}{l}\text { AFRICA } \\
\text { (43) }\end{array}$ & $\begin{array}{l}\text { ASIA } \\
(13)\end{array}$ & $\begin{array}{c}\text { LATIN } \\
\text { AMERICA/ } \\
\text { CARIBBEAN } \\
(6)\end{array}$ & $\begin{array}{l}\text { MIDDLE } \\
\text { EAST (4) }\end{array}$ & $\begin{array}{l}\text { TOTAL } \\
(66)\end{array}$ \\
\hline $\begin{array}{l}\text { Total number } \\
\text { of programs }\end{array}$ & 222 & 75 & 13 & 12 & 322 & $100 \%$ & $100 \%$ & $100 \%$ & $100 \%$ & $100 \%$ \\
\hline \multicolumn{11}{|l|}{ TARGET GROUP } \\
\hline Girls only & 79 & 33 & 4 & 7 & 123 & $36 \%$ & $44 \%$ & $31 \%$ & $58 \%$ & $38 \%$ \\
\hline \multicolumn{11}{|l|}{ PROGRAM TYPE } \\
\hline Enabling & 162 & 45 & 10 & 7 & 224 & $73 \%$ & $60 \%$ & $77 \%$ & $58 \%$ & $70 \%$ \\
\hline Alternative & 43 & 22 & 6 & 4 & 75 & $19 \%$ & $29 \%$ & $46 \%$ & $33 \%$ & $23 \%$ \\
\hline Complementary & 23 & 19 & 3 & 2 & 47 & $10 \%$ & $25 \%$ & $23 \%$ & $17 \%$ & $15 \%$ \\
\hline $\begin{array}{l}\text { Creating or enhancing } \\
\text { formal schools }\end{array}$ & 100 & 32 & 10 & 8 & 150 & $46 \%$ & $43 \%$ & $77 \%$ & $67 \%$ & $46 \%$ \\
\hline After school & 110 & 24 & 1 & 3 & 138 & $50 \%$ & $32 \%$ & $8 \%$ & $25 \%$ & $43 \%$ \\
\hline
\end{tabular}

To determine whether or not those aged 10-19 were included in a program's target populations, we had to seek indirect clues. In only $12 \%$ of the programs were specific age ranges provided, and in many of these cases we acquired the information not from reports and web sites but from follow-up queries to the organizations. More often, we found descriptive words that give a general indication of potential age ranges. Because the age range of adolescents (10 to 19) cuts across several other internationally recognized categories, including children (0-17), adults (18+), and youth (15-24), it is likely that adolescent girls are often grouped with one of these other designations rather than with other girls of their own age.

Slightly more than a third of the programs in our compendium were for girls only. ${ }^{26}$ The regions with the largest percentage of girls-only programs are Asia (44\%) and the Middle East (58\%). This is not surprising given the tendency towards sex-segregated formal education in some parts of Asia
(Afghanistan, Pakistan) and most of the Middle East. For an additional $14 \%$ of the programs, girls represent the substantial majority (i.e., more than $75 \%$ ) of the beneficiaries. Many initiatives in this category are part of the USAID-funded scholarship program, originally entitled the Ambassadors' Girls' Scholarship Program, which served only girls in its first years. Many more programs included the phrase "especially girls" in their description of beneficiaries, but if data were not available to ascertain that the majority of beneficiaries served were girls, we did not count them in this category.

Nearly three-quarters of the programs serve only students attending formal schools, and an additional $12 \%$ serve a mix of students and out-ofschool children or young people. Seventeen percent serve beneficiaries described as having little or no schooling, being illiterate, or having low levels of literacy, but in these cases, typically no details are provided on how the learning needs of girls with 
diverse educational backgrounds are assessed. Given the diversity of education experiences and learning levels among adolescent girls, as noted in Chapter 2, such background information would be important if girls' educational needs are going to be effectively met.

Some programs serve girls living in specific communities or groups while others serve girls with certain vulnerabilities. ${ }^{27}$ For many of the programs, the description of beneficiaries includes a wide range of categories, without further information about the definitions or percentages of beneficiaries served in each category. For example, many of the Ambassadors' Girls' Scholarship programs in Africa include all of the following: girls, orphans and vulnerable children (OVC), HIV-affected children, and povertyaffected children. Identifying patterns in types of beneficiaries is all the more difficult due to the variety of terms used. ${ }^{28}$ In the final analysis, we found very little information about the process by which individuals, families, or communities are selected to benefit from or participate in a program. Given the many challenges associated with targeting, this represents a regrettable gap in our information.

\section{Girl-friendly features:}

We will discuss these features in the order presented in Box 5.1, starting with demand-side strategies and followed by two types of supply-side strategies: those focused on the learning environment within the school and those focused directly on the developmental and learning needs of adolescent girls. The number of programs and percentages are presented by region in Table 5.2.

Scholarships and stipends were provided in some form in $43 \%$ of programs. Nearly half of programs in Africa included this feature, and roughly a third in Asia and the Middle East, with very few in Latin America. Benefits in this category included monetary contributions, and in-kind support in the form of books, uniforms, food rations, pens and paper, hurricane lamps, and other supplies. Some program descriptions specified that the benefits were conditional on indicators of girls' participation or success in school, but most did not. Of the programs in this category, the great majority $(80 \%)$ appear in combination with programs designed to improve formal schools, and/or with after-school programs.

\section{Scholarships and stipends were provided in some form in $43 \%$ of programs.}

Transportation and boarding facilities: Providing transportation or boarding facilities near schools was one of the least common girl-friendly features in our compendium (16\%). Typically, this feature was associated with formal schools or after-school programs. The provision of bicycles for girls to travel to and from schools - a resource that would provide them with considerable independence-was an interesting example mentioned in a few programs. With respect to activities to build or maintain boarding houses or dormitories, descriptions were also general; it would be interesting to know more about how such facilities are maintained and supervised, and what other support resources may be available to girls who stay in these facilities.

\section{Advocacy or community engagement in girls'} education: Advocacy or community-engagement programs were the most prevalent strategy (57\%). The majority of activities in this category involve mobilizing and training community members to assume active
26

Included in our counts for "girls only" are programs for women only, which appear to include older girls.

27

Sixteen percent of programs listed children and families in poverty among their beneficiaries. Orphans and vulnerable children (often an overlapping category) were another group often identified (14\%). Eight percent of programs mention

"HIV-affected" children and young people among their beneficiaries. Only $5 \%$ refer to disabled girls, and even fewer include specific references to activities to serve such girls. Thirty-two programs (10\%) serve conflict-affected girls or young people; $82 \%$ of those are either alternative or complementary programs, or both. Eleven percent of programs are directed at rural and/or nomadic and/or pastoral communities; in contrast, only $3 \%$ of programs listed urban regions as their target. Five percent of programs were described as serving communities with limited or no access to formal schools; most of these were in the "creating or enhancing formal schools" program type.

28

Some of the terms are common among international agencies and organizations, such as "HIV-affected," "associated with fighting forces," "at risk of early marriage," or "low literacy levels, but are nonetheless difficult to operationalize, given challenges of measurement and lack of clearly specified indicators. Other more general terms imply different meanings to different agencies, such as "vulnerable," "marginalized," or "at risk" (without further specifying the risk). Still others, such as "indigenous," "nomadic," and "conflict-affected," may have clear meanings, but are likely to over with each other h other or with other categories. 
$27 \%$ of the

programs include efforts to recruit, train, or retain women teachers.

roles in supporting schools and ensuring the attendance and participation of girls in their communities. Few were described as exclusively awareness-raising campaigns focused on the importance of girls' education. This probably reflects a natural evolution as resistance to the education of girls has fallen over time, and costs, access, and quality have become the more salient issues.

However, while these community-engagement activities are identified as ways to promote girls' schooling, it is not always clear how they benefit girls. For example, with respect to community-based management teams, in many cases there is no mention of whether or how women are engaged in the process, nor of specific actions undertaken by the committee to ensure girls' attendance, safety, or success in school. By contrast, in our case study of Mali (see Box 5.3), community-based management committees undertake activities that are clearly and explicitly designed to support girls.

Safety policies and training; codes of conduct: We found the fewest references to promoting girls' safety in school through teacher codes of conduct or safety training for girls, or related training for teachers (11\%). One possible reason is that teacher conduct is a sensitive topic in certain settings, one that agencies/ organizations are less likely to discuss in publicly available descriptions of their programs. Another possibility is that training related to teacher conduct or girls' safety is included under the often general (and less sensitive) rubric of "gender training."

Toilets and provision of sanitary supplies: Twenty percent of the programs included improvements or enhancements to sanitation facilities in schools or the provision of sanitary supplies. Almost all of these involved building or improving toilets, including efforts to make separate toilets available for boys and girls. The provision of toilets and sanitary supplies for girls surely improves the quality of life for all students, especially for girls, given their physical and hygiene needs. However, research evidence presented in Chapter 3 raises doubts about the significance of this strategy for adolescent girls' attendance and completion of school.

Recruitment and training of female teachers, parateachers, and other educators: Overall, $27 \%$ of the programs include efforts to recruit, train, or retain women teachers, with nearly a third of the programs in Asia and the Middle East including this feature. In some countries in these regions, a cadre of women teachers may be an essential requirement to establish schools for girls in communities where formal schools are segregated by sex. We note that $42 \%$ of the programs that create enabling conditions for girls included this activity, suggesting that many program managers see this as an attractive feature for girls' parents. In Mali we learned that some efforts to recruit and retain women in a challenging setting had been unsuccessful (see Box 5.3); it is possible that, given the challenges in certain settings, some agencies may be reluctant to explicitly state this as a goal of their programs.

We also included in this category examples of projects for older girls and young women that were entirely structured as formal training programs for female teachers. Indeed, some of the initiatives to establish formal secondary schools for adolescent girls in countries such as Afghanistan and Pakistan include, as an explicit objective, support for the development of a strong force of women teachers. These programs also account for some of the vocational training programs in our compendium. 
TABLE 5.2

\section{Girl-friendly features of programs in compendium}

\begin{tabular}{|c|c|c|c|c|c|c|c|c|c|c|}
\hline \multicolumn{6}{|c|}{ Number of programs/projects according to characteristics } & \multicolumn{5}{|c|}{$\begin{array}{c}\text { Percent of programs with particular } \\
\text { characteristics }\end{array}$} \\
\hline & \multicolumn{5}{|c|}{ Region (number of countries) } & \multicolumn{5}{|c|}{ Region (number of countries) } \\
\hline & $\begin{array}{l}\text { AFRICA } \\
(43)\end{array}$ & ASIA (13) & $\begin{array}{l}\text { LATIN } \\
\text { AMERICA/ } \\
\text { CARIBBEAN } \\
(6)\end{array}$ & $\begin{array}{l}\text { MIDDLE } \\
\text { EAST (4) }\end{array}$ & $\begin{array}{l}\text { TOTAL } \\
(66)\end{array}$ & $\begin{array}{l}\text { AFRICA } \\
(43)\end{array}$ & ASIA (13) & $\begin{array}{c}\text { LATIN } \\
\text { AMERICA/ } \\
\text { CARIBBEAN } \\
(6)\end{array}$ & $\begin{array}{l}\text { MIDDLE } \\
\text { EAST (4) }\end{array}$ & $\begin{array}{l}\text { TOTAL } \\
(66)\end{array}$ \\
\hline $\begin{array}{l}\text { Total number } \\
\text { of programs }\end{array}$ & 222 & 75 & 13 & 12 & 322 & $100 \%$ & $100 \%$ & $100 \%$ & $100 \%$ & $100 \%$ \\
\hline \multicolumn{11}{|c|}{ GIRL-FRIENDLY FEATURES } \\
\hline Scholarships/stipends & 107 & 26 & 1 & 4 & 138 & $48 \%$ & $35 \%$ & $8 \%$ & $33 \%$ & $43 \%$ \\
\hline $\begin{array}{l}\text { Transportation/ } \\
\text { boarding }\end{array}$ & 30 & 14 & 2 & 5 & 51 & $14 \%$ & $19 \%$ & $15 \%$ & $42 \%$ & $16 \%$ \\
\hline $\begin{array}{l}\text { Advocacy and/ } \\
\text { or community } \\
\text { engagement in girls' } \\
\text { education }\end{array}$ & 135 & 38 & 5 & 7 & 185 & $61 \%$ & $51 \%$ & $38 \%$ & $58 \%$ & $57 \%$ \\
\hline $\begin{array}{l}\text { Safety policies and } \\
\text { training; codes of } \\
\text { conduct }\end{array}$ & 31 & 2 & 3 & 0 & 36 & $14 \%$ & $3 \%$ & $23 \%$ & $0 \%$ & $11 \%$ \\
\hline $\begin{array}{l}\text { Toilets or provision of } \\
\text { sanitary supplies }\end{array}$ & 45 & 15 & 1 & 4 & 65 & $20 \%$ & $20 \%$ & $8 \%$ & $33 \%$ & $20 \%$ \\
\hline $\begin{array}{l}\text { Recruitment/training } \\
\text { female teachers, para- } \\
\text { teachers, and other } \\
\text { educators }\end{array}$ & 54 & 27 & 1 & 4 & 86 & $24 \%$ & $36 \%$ & $8 \%$ & $33 \%$ & $27 \%$ \\
\hline $\begin{array}{l}\text { Gender training for } \\
\text { teachers }\end{array}$ & 69 & 9 & 1 & 4 & 83 & $31 \%$ & $12 \%$ & $8 \%$ & $33 \%$ & $26 \%$ \\
\hline $\begin{array}{l}\text { Mentoring, tutoring, } \\
\text { and peer support }\end{array}$ & 130 & 22 & 2 & 2 & 156 & $59 \%$ & $29 \%$ & $15 \%$ & $17 \%$ & $48 \%$ \\
\hline $\begin{array}{l}\text { Life skills or literacy } \\
\text { training }\end{array}$ & 100 & 43 & 5 & 7 & 155 & $45 \%$ & $57 \%$ & $38 \%$ & $58 \%$ & $48 \%$ \\
\hline $\begin{array}{l}\text { Livelihoods or } \\
\text { vocational training }\end{array}$ & 33 & 22 & 3 & 1 & 59 & $15 \%$ & $29 \%$ & $23 \%$ & $8 \%$ & $18 \%$ \\
\hline Other & 64 & 28 & 10 & 6 & 109 & $29 \%$ & $39 \%$ & $77 \%$ & $60 \%$ & $34 \%$ \\
\hline
\end{tabular}


Gender training for teachers: Gender training programs for educators were approximately as prevalent as activities to recruit, train, and retain female teachers, comprising $26 \%$ of entries in our compendium. However, within programs to create or enhance formal schools, gender training is much more prevalent, with slightly over half including this strategy as part of their programs. The results of research in Kenya, cited in Chapter 4, suggest that this is a potentially beneficial approach for adolescent girls, but there are many "unknowns" in the program descriptions. For example, few program descriptions mention the duration of the training, nor do they provide details about the content or objectives of the training curriculum. Even less information is available about whether such activities have had an impact on
A cadre of women teachers may be an essential requirement to establish schools for girls in

communities where formal schools are segregated by sex. teachers' attitudes or methods or on girls' enrollment or academic performance.

Mentoring, tutoring, and peer support: Nearly half of the programs $(48 \%)$ include activities to support girls individually or in small groups through mentoring, counseling, or tutoring. Not surprisingly, nearly threequarters of programs with these features fall in the after-school category. The program descriptions give very little insight about the structure, content, and duration of these activities, including whether or not groups are single-sex or coed.

It is noteworthy that mentoring and peer-support strategies are often combined with enabling programs, with slightly over $50 \%$ of enabling programs having mentoring and peer support as a feature. These programs are more likely to be part of a formal school enhancement program than of a non-formal, alternative, or complementary program. It could be that many non-formal programs are already structured to provide more individualized, holistic, or flexible support to beneficiaries and therefore are less likely to describe these features as an added component.

Life skills and literacy training: Roughly half of all programs include a life skills and/or literacy training component. Almost all (88\%) alternative programs include this girl-friendly feature, and about half of complementary programs include some aspect of this strategy as well. The venue in which these types of training activities take place is not always indicated. Some are integrated into the regular curricula of alternative, complementary, or even formal programs, whereas others take place after school.

Moreover, the types of training described vary considerably. In some cases the topic of the training is clearly meant to target specific needs of the beneficiaries; for example, literacy or numeracy for girls lacking education, and/or financial literacy or budgeting for girls who were also training to start small businesses. Generally, however, the descriptions we found do not provide details of the content or methodology of these training activities, nor of their duration. Some commonly used terms, such as life skills, leadership, or even health or hygiene, may refer to very different types of curriculum content. Many of these activities were described as having the objective of providing girls with skills, knowledge, 
or attitudes that would help them avoid obstacles to their formal education. Yet, as with many of the activities in the after-school category, it was not clear whether or how the impact of these training programs on girls' education indicators is being assessed.

Livelihoods or vocational training: Given the challenges girls face in the transition from school to work, we were interested in strategies to help girls develop employable skills. We discovered that only $18 \%$ of the programs in the compendium include livelihoods or vocational training. These activities were much more prevalent among alternative programs (57\%). By contrast, only $9 \%$ of the programs in formal schools include training in vocational skills. Of those, several were programs to prepare girls to enter the teaching profession. ${ }^{29}$

Almost all programs which included job-related training also included training in other skills, such as literacy, life skills, health, and hygiene. Some advocacy organizations argue that girls and young women who are beneficiaries of vocational and "livelihoods" programs are more likely to be economically successful if they are also supported in developing literacy, numeracy, and financial management skills (Bidwell et al. 2008; Young et al. 2007; Buscher 2007). Nonetheless, very little is known about whether, or under what circumstances, alternative vocational training programs lead to gainful income-generating activities or employment. Some researchers have raised questions regarding whether the skills in which beneficiaries of vocational training and "livelihoods" programs are trained are based on current assessments of market conditions (Buscher 2007).

Other girl-friendly features: Roughly a third of our programs included one or more features that were clearly girl-friendly but that were much less commonly used. Examples are listed in Box 5.4. Some of these offer creative ways to combine and link more familiar approaches. For example, several programs included support to "mothers' clubs" (or equivalent organizations) in undertaking income-generating activities to cover the costs of their daughters' education; this strategy encompasses community engagement and is similar in purpose to stipend and scholarship programs. In FAWE's Tuseme program, girls are trained in leadership and self-advocacy skills (activities that fall neatly into the after-school and life skills training

\section{We discovered that only $18 \%$ of the programs in the compendium include livelihoods or vocat}

categories), and in doing so become community advocates for their own rights and the rights of other girls - thus contributing to an enabling environment for girls' education.

Most of the entries in the "other" category were programs or projects currently being implemented, but a few were related to policy development or other activities related to advocacy. For example, in Kenya, FAWE is advocating for the inclusion of education about child-labor prevention policies in formal curricula. In Côte d'Ivoire, EMpower advocates for changes to entry requirements for vocational technical school to reduce barriers to girls' enrollment.

Holistic, girl-friendly approaches: One of the most important and valuable elements of effective programming may be "holistic design" - that is, a package of activities to address girls' comprehensive needs (including economic, developmental, social, and learning) that are thoughtfully and meaningfully integrated. A drawback of categorizing "girl-friendly features" of programs individually, as we do by identifying the relevant characteristic for each entry in Table 5.2 and in the compendium, is that we do not describe the relationships among program features. Thus, useful information is sometimes lost. Some examples of holistic programs include UNICEF's child-friendly schools, Escuela Nueva's child-centered schools, FAWE's Gender-Responsive Schools (GRS) or Centres
29

A few others provided interesting examples, worth further examination. For example, the organization Developments in Literacy in Pakistan lists among its objectives to provide girls with skills needed to participate in a global workforce, and supports formal schools in providing all students, especially girls, with information and communication technology skills as well as English-language skills. We include English-language instruction in the "vocational and professional skills" category in this context because the organization has framed this activity specifically as a strategy to

promote girls' professional skills and economic empowerment. The "Girls Be Ambitious" program, implemented collaboratively by the NGOs American Assistance for Cambodia and Japan Relief for Cambodia, also provides girls in school with English, computer, and other vocation trainiter, "Girls Power Initiative" in Nigeria, a girls-only program implemented by the NGO EMpower, supports students in finding internships with NGOs, sponsors career fairs, and provides beneficiaries with

counseling to encourage them to pursue more lucrative professions traditionally held by men. 


\section{BOX 5.4}

\section{Examples of "other" girl-friendly strategies}

- Child care for young children, either to ensure that mothers do not rely on their adolescent daughters to care for younger siblings (and thus miss time for school or study) or to allow young mothers (adolescents among them) time to attend school.

- Flexible hours for education programs, to accommodate the different needs and responsibilities of boys and girls.

- Mobile schools, to reduce the transportation costs and risks for girls.

- Seed money or other support to cooperative ventures and other new businesses established by beneficiaries of vocational programs.

- Math and science clinics and discussions, to encourage girls' interest and success in traditionally male-dominated fields.

- Dowry payment to parents of Massai girls at birth, to commit them to school rather than to early marriage

- Support for families to obtain birth certificates or poverty certificates for girls, to facilitate their enrollment in formal schools.

- Literacy classes for mothers, so that they can better support their adolescent daughters' education.

- Campaigns and advocacy against practices that are obstacles to girls' education and well-being, such as female genital mutilation (FGM/C), early marriage, or child labor.

- Encouragement for girls to participate in school governance in Swaziland and Colombia.

- "Girl-friendly" curriculum topics that include gender awareness and rights, as well as the right to education.

- Men's clubs to promote positive attitudes towards women's rights, including girls' right to education.

- The development of a "virtual," Internet-based cultural exchange between girls in the United States and India. of Excellence (COE), and CAMFED's participatory approach to program development.

There are also teaching styles, such as small-group instruction, and cooperative learning and management styles that are implicitly girl-friendly. Moreover, efforts to make the curriculum more relevant may benefit girls more than boys, even if the intended outcome did not include addressing gender disparities. Ultimately these effects may be more promising and supportive of girls than many of the programs listed in our compendium, which rely on one or two simple elements that are easy to introduce within the existing system.

Evaluations: With so many activities underway, there should be many potential lessons to be learned about which strategies are most effective in ensuring education for adolescent girls. However, we found very little evidence that the activities currently underway have been evaluated or that evaluations are being planned (see Table 5.3). Without well-conceived, well-constructed evaluations, little enduring evidence will be available of lessons learned or strategies that can be effectively replicated or scaled up. A little more than a quarter of the programs $(28 \%)$ reported that an evaluation had been conducted or planned. Fewer than $10 \%$ of the evaluations reported have been or will be carried out by external partners or agencies that can bring more objectivity and scientific rigor to the evaluation. The rest are presumably internal. We found only three comprehensive evaluation reports publicly and readily available on organizations' web sites: two provided by the World Bank, and one by BRAC.

\section{Implications}

The findings reported in this chapter have implications for program directions and for data gathering and information exchange. First, very few educational programs that serve adolescent girls appear to be designed with the developmental and learning needs of adolescents in mind. In some sense our compendium of 322 programs is misleading in that most programs listed are targeting primary-school students, secondary-school students, children, youth, or adults and not specifically adolescent girls. We include these programs in our compendium because adolescent girls happen to be part of the group being served. Thus, a priority for future educational program development for adolescent girls 
TABLE 5.3

\section{Programs in compendium according to extent and type of evaluation}

\begin{tabular}{|l|c|c|c|c|c|c|c|c|c|c|}
\hline & AFRICA & ASIA & $\begin{array}{c}\text { LATIN } \\
\text { AMERICA }\end{array}$ & $\begin{array}{c}\text { MIDDLE } \\
\text { EAST }\end{array}$ & TOTAL & AFRICA & ASIA & $\begin{array}{c}\text { LATIN } \\
\text { AMERICA }\end{array}$ & $\begin{array}{c}\text { MIDDLE } \\
\text { EAST }\end{array}$ & \begin{tabular}{c} 
TOTAL \\
\hline Total programs
\end{tabular} \\
\hline & 222 & 75 & 13 & 12 & 322 & 100 & 100 & 100 & 100 & 100 \\
\hline $\begin{array}{l}\text { ANY } \\
\text { EVALUATION }\end{array}$ & 54 & 28 & 4 & 3 & 89 & $24 \%$ & $37 \%$ & $31 \%$ & $25 \%$ & $27 \%$ \\
\hline Planned & 5 & 10 & 0 & 1 & 16 & $2 \%$ & $13 \%$ & $0 \%$ & $8 \%$ & $5 \%$ \\
\hline Completed & 49 & 18 & 4 & 2 & 73 & $22 \%$ & $24 \%$ & $31 \%$ & $17 \%$ & $23 \%$ \\
\hline & 18 & 9 & 0 & 1 & 28 & $8 \%$ & $12 \%$ & $0 \%$ & $8 \%$ & $9 \%$ \\
\hline $\begin{array}{l}\text { EXTERNAL } \\
\text { EVALUATION }\end{array}$ & 1 & 1 & 0 & 0 & 2 & $0 \%$ & $1 \%$ & $0 \%$ & $0 \%$ & $1 \%$ \\
\hline Planned & 17 & 8 & 0 & 1 & 26 & $8 \%$ & $11 \%$ & $0 \%$ & $8 \%$ & $8 \%$ \\
\hline Completed & & & & & & & & & & \\
\hline
\end{tabular}

should be a much more self-conscious approach to program design to meet the particular developmental and learning needs of adolescent girls as they are understood within each context.

Second, despite the documented high returns to formal secondary schooling for girls, relatively few programs are focused on the transition to secondary school either through the development of complementary programs that give girls an extra chance to go on to secondary school or through after-school programs that focus on success in primary school and preparation for secondary school. Thus, we see a need for a much greater emphasis on the development of programs that are directed towards supporting girls' transitions to and success in formal secondary school.

Third, few livelihood or vocational programs are integrated into formal schools, even though we know that transitions to work are more difficult for girls than boys. The academic orientation of secondary schools and the focus on university placement remains a limitation in many settings where a secondary school degree is often a terminal degree and where girls in particular need training in "relevant," marketable skills. Given the gender gap that rises with age between the percent who have left school and the percent who have entered the labor force, the relevance of their education should be addressed through various approaches both inside the classroom and after school. The examples we noted earlier of innovative efforts to integrate professional training and skills into formal education programs for girls are worth further examination as potential models.

Fourth, insufficient information is available about the organization and structure of after-school programs in terms of venues, program content, and beneficiaries. For example, we do not know whether groups are organized by sex, by need, or by subject area. More research should be done to find the best approaches to addressing girls' development and learning needs in each context. 
Few livelihood

or vocational

programs are integrated into formal schools, even though we know that transitions to work are more difficult for girls than boys.
Finally, almost no information is available about the impact of these programs on adolescent girls, either in the short run in terms of their school progress (which is typically a program objective), or in the longer run on their transitions to civic, work, and family lives. Programs are being designed with much good will and common sense but without the benefit of evidence derived through careful research and impact evaluation. To increase cross-program learning and to enhance the chances of programmatic success, external evaluation needs to become a priority for donors and program managers.

The limited data available on programs and their lack of consistency directly shortchanges girls in their educational progress. The framework we have developed for our compendium has many practical and immediate uses in addition to being available for further analysis. These include:

- an organizational structure to assist donors and program managers in their reporting of program activities in order to improve transparency and consistency;

- a model for information-gathering at the country level, for both donors and NGOs, to identify funding gaps and potential partners;

- a guide for the improvement of data collection on educational participation in household surveys;

- a road map for donors interested in particular countries or programmatic approaches, to identify windows of opportunity for new program development. 


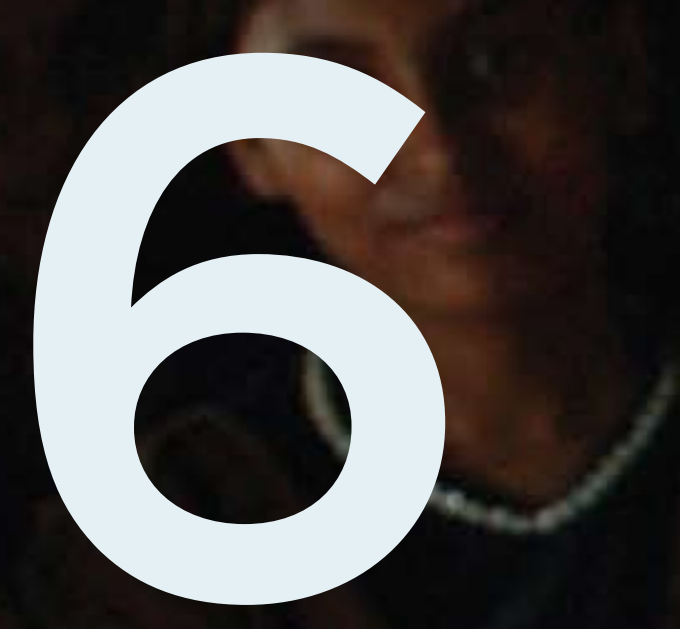

AN

EDUCATIONAL

MANIFESTO FOR

ADOLESCENT

GIRLS 


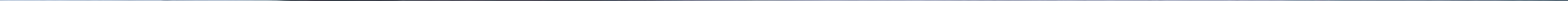




\section{This report builds a case for the education of adolescent girls. It provides a framework for locat- ing them within the educational system. And it assesses past and current educational programs for girls in relation to the evidence on successful and promising approaches.}

Flowing from the evidence in this report is our educational manifesto for adolescent girls. In this manifesto we outline three developmental and learning phases during adolescence and, within each, identify learning goals and preferred educational pathways for girls (Box 6.1). The strong evidence of a high return to girls from formal secondary school and the lack of evidence of returns from non-formal alternatives underlie our preference for formal school at each phase of adolescent development. In our view, continuing education during adolescence is a necessary first step for girls if they are to overcome a history of disadvantage in paid employment and civic life. We thus identify curricular building blocks that can support girls in their transition to adulthood.

Obviously, other complementary social efforts will be required to open previously closed pathways for girls. But if girls themselves are not adequately educated during childhood and adolescence, they will not be in a position to seize those opportunities when they are available. These complementary efforts, well outlined in Girls Count, include a supportive legal environment to fully recognize the equal rights of girls and women and to enshrine those rights in law and practice.

For girls to have the educational opportunities described in our manifesto:

- The supply of places in formal secondary schools needs to be significantly expanded.

- Cash or in-kind resources should be carefully targeted to support girls who would not otherwise be able to stay in school.

- Non-formal education for girls should focus on complementary approaches that offer younger adolescents the opportunity to reenter the formal educational system.

The quality and relevance of post-primary education, including non-formal educational alternatives for adolescent girls, need to be substantially upgraded so that critical thinking and problem-solving skills, rather than memorization, are emphasized, as these are the skills that will be of most value in later life. In many settings this will involve new approaches to teaching and a reorientation of educational goals at the secondary level. It will also require, in some settings, a greater presence of female teachers in the classroom to serve as role models for girls. The school can be a place for girls to gain opportunities for participation and leadership within and outside regular classroom activities.

Given the promising but unproven approaches identified in chapters 4 and 5 , we suggest the implementation of some worthwhile experiments in collaboration with a research partner, initially on a pilot basis, so that the programs' impact on girls can be measured and assessed. We focus particularly on supply-side strategies to ease transitions to secondary school, to enhance the learning environment for girls, and to address girls' developmental and learning needs more directly. The reason is that there has been much more attention to access to educational opportunity and less to educational quality and relevance. Furthermore, we strongly recommend that, in assessing outcomes, impact evaluations become a routine and standardized practice in all education activities. We also recommend that evaluations go beyond the assessment of outcomes such as enrollment and grade attainment to assess the acquisition of knowledge and skills, particularly critical thinking and problem-solving skills, as well as longer-term outcomes such as work transitions, gender role attitudes, and measures of civic participation.
Previous Page

Laita, 18 , stands in front of her class in the Women's Education Centre in India's Gaya District. A graduate of a Centre program, she is the first child in her familyand her entire village - to attend school. Adolescent girls and young women, many of whom previously never went to school, attend the centers as part of a government program to encourage educ among village children. 


\section{BOX 6.1}

\section{An educational manifesto for adolescent girls}

\section{Early adolescence: Ages 10-12}

Where every girl should be: Formal primary school or accelerated complementary school

What every girl should be acquiring: Literacy, numeracy, critical thinking skills, basic health knowledge, knowledge about their communities and the world

\section{Middle adolescence: Ages 13-15}

Where every girl should be: Post-primary formal school or accelerated complementary school

What every girl should be acquiring: Reading and writing fluency for lifelong learning, critical thinking skills, fluency in an internationally spoken language, computer skills, proficiency in math/science, health and reproductive health knowledge, financial literacy, skills for social and civic participation, knowledge about social systems and local and global issues

\section{Late adolescence: Ages 16-19}

Where every girl should be: Formal secondary school or alternative education with a vocational or livelihoods focus

What every girl should be acquiring: Marketable skills, information-gathering skills and habits for lifelong learning, financial knowledge and skills 


\section{COMPENDIUM}

\section{Compendium: Guide for readers}

For a full discussion of the format of this compendium, criteria for inclusion, and descriptions of each category, see Chapter 5.

\section{General Guide}

The entries in all columns in this compendium are based on the information available to us in the sources cited in the column headed "sources of information." If a characteristic or component of a program is not indicated in any given entry, this is because they were not mentioned in our sources. For example, if one or more partner organizations involved in a program are not listed in the "partners" column, those organizations were not mentioned in the sources to which we gained access.

An empty field indicates that no information was available about a given program with respect to that category. It should not be interpreted to mean that a feature is necessarily absent from that program. For example, if the "evaluation conducted" field is not checked, this indicates that we could not determine from our sources whether an evaluation had been conducted. It does not mean definitively that an evaluation has not been conducted.

Some names of programs, organizations, agencies, and categories of beneficiaries are described by acronyms or abbreviations, which are identified in the "Guide to Acronyms and Abbreviations" that follows.

\section{Guide to Columns}

Partners: All partners contributing to the management, oversight, or implementation of a program are listed. The order in which they are listed does not indicate role or relationship. If the name of an organization is followed by "(research)," this indicates that the organization was responsible for research for and/ or evaluation of that program.
Donors: All donors contributing funding to a program are listed. The order in which they are listed does not indicate relationship or level of funding.

Target population: Descriptions of program beneficiaries are based on the terminology used in the available sources.

Girls only: $A \checkmark$ indicates that the entire project, including all components and activities, includes or serves girls only.

Age range: The age range column is filled in if a numerical age range was indicated in the program description.

Program type: A colored square indicates that one or more components or activities of a program fall under the category of a given program type, based on the definitions in Chapter 5. Corresponding descriptions of program type appear on the far right.

Girl-friendly features: A colored circle indicates that a given "girl-friendly feature" is a characteristic of that program. These column entries indicate specific characteristics of programs, but do not represent a comprehensive description of all features of that program. Corresponding descriptions of girl-friendly features appear on the far right.

"Other" girl-friendly features: Many programs in this compendium include activities to support girls that do not fit into any of the other categories in the preceding columns. Numbers within the colored circles in this column correspond to descriptions on the far right.

Evaluation conducted: $A \checkmark$ in this column indicates that an evaluation has been completed according to the program description available to us. It does not necessarily indicate that an evaluation report was available to us. 
Evaluation planned: $\mathrm{A} \checkmark$ in this column indicates that an evaluation has been planned according to the program description available to us.

External: $A \checkmark$ appears in this column if the evaluation indicated in the field to the left (conducted or planned) was described as an external evaluation.

Sources of information: Shorthand descriptions of sources (e.g., website, questionnaire, interview) are given in this column. Full source citations appear immediately following the compendium. Additional notes on some entries, signaled by an asterisk in this column, appear immediately following the full source. 


\section{ACRONYMS \& ABBREVIATIONS}

ABBA-RPC

Addressing the Balance of the Burden in AIDS, Research

Programme Consortium

AED

AGSP

AIR

ANCEFA

AUSAID

AVSI

BRAC

CAI

CAMFED

CAUSE Canada Christian Aid for Under-Assisted

CBO

CCF

CEDPA

CHEP
The Campaign for Female

Education Societies Everywhere

Community-based organization

Christian Children's Fund

The Academy for Educational

Development

Ambassadors' Girls' Scholarship

Program

American Institute for Research

The African National Campaign

on Education For All

Australian Agency for International Development

The Association of Volunteers in International Service

Bangladesh Rural Advancement Committee

Creative Associates International

FAWE

FGM

FHT

GE Found

GEM

Gov.

Centre for Development and Population Activities

The Copperbelt Health Education

Project

CRS

DANIDA

DCI

DFID

DIL

EDC

ESRC

AWE

ICT
CordAid

CIDA

General Electric Foundation

Girls' Education Movement

Government agencies or ministries (including national, province/state, and local levels)

IRC

Catholic Organization for Relief and Development Aid

Canadian International

Development Agency

Catholic Relief Services

Danish International

Development Agency

Development Cooperation Ireland

Department for International Development (United Kingdom)

Developments in Literacy

Education Development Center

Economic and Social Research Council

Forum for African Women Educationalists

Female genital mutilation

Family Health Trust

Information and communication technology

International Rescue Committee 


\begin{tabular}{|c|c|c|c|}
\hline \multirow[t]{2}{*}{ MIT } & $\begin{array}{l}\text { Massachusetts Institute } \\
\text { of Technology }\end{array}$ & WFP & World Food Program \\
\hline & & USDOL & United States Department of Labor \\
\hline \multirow[t]{2}{*}{ NGO } & Nongovernmental organization & & \\
\hline & & YMCA & Young Men's Christian Association \\
\hline \multirow[t]{2}{*}{ NORAD } & Norwegian Agency for Development & & \\
\hline & Cooperation & & \\
\hline NRC & Norwegian Refugee Council & & \\
\hline \multirow[t]{2}{*}{ OSISA } & The Open Society Initiative for & & \\
\hline & Southern Africa & & \\
\hline OVC & Orphans and Vulnerable Children & & \\
\hline PCTFI & Patsy Collins Trust Fund Initiative & & \\
\hline PTA & Parent-teacher association & & \\
\hline RET & Refugee Education Trust & & \\
\hline RTI & Research Triangle Institute & & \\
\hline \multirow[t]{2}{*}{ Swiss Aid } & Switzerland Agency for International & & \\
\hline & Development & & \\
\hline \multirow[t]{2}{*}{ USAID } & United States Agency for & & \\
\hline & International Development & & \\
\hline \multirow[t]{2}{*}{ UNESCO } & United Nations Educational, & & \\
\hline & Scientific and Cultural Organization & & \\
\hline UNFPA & United Nations Population Fund & & \\
\hline \multirow[t]{2}{*}{ UNGEI } & United Nations Girls' & & \\
\hline & Education Initiative & & \\
\hline UNICEF & United Nations Children's Fund & & \\
\hline USBPRM & $\begin{array}{l}\text { United States Bureau of Population, } \\
\text { Refugees and Migration }\end{array}$ & & \\
\hline
\end{tabular}




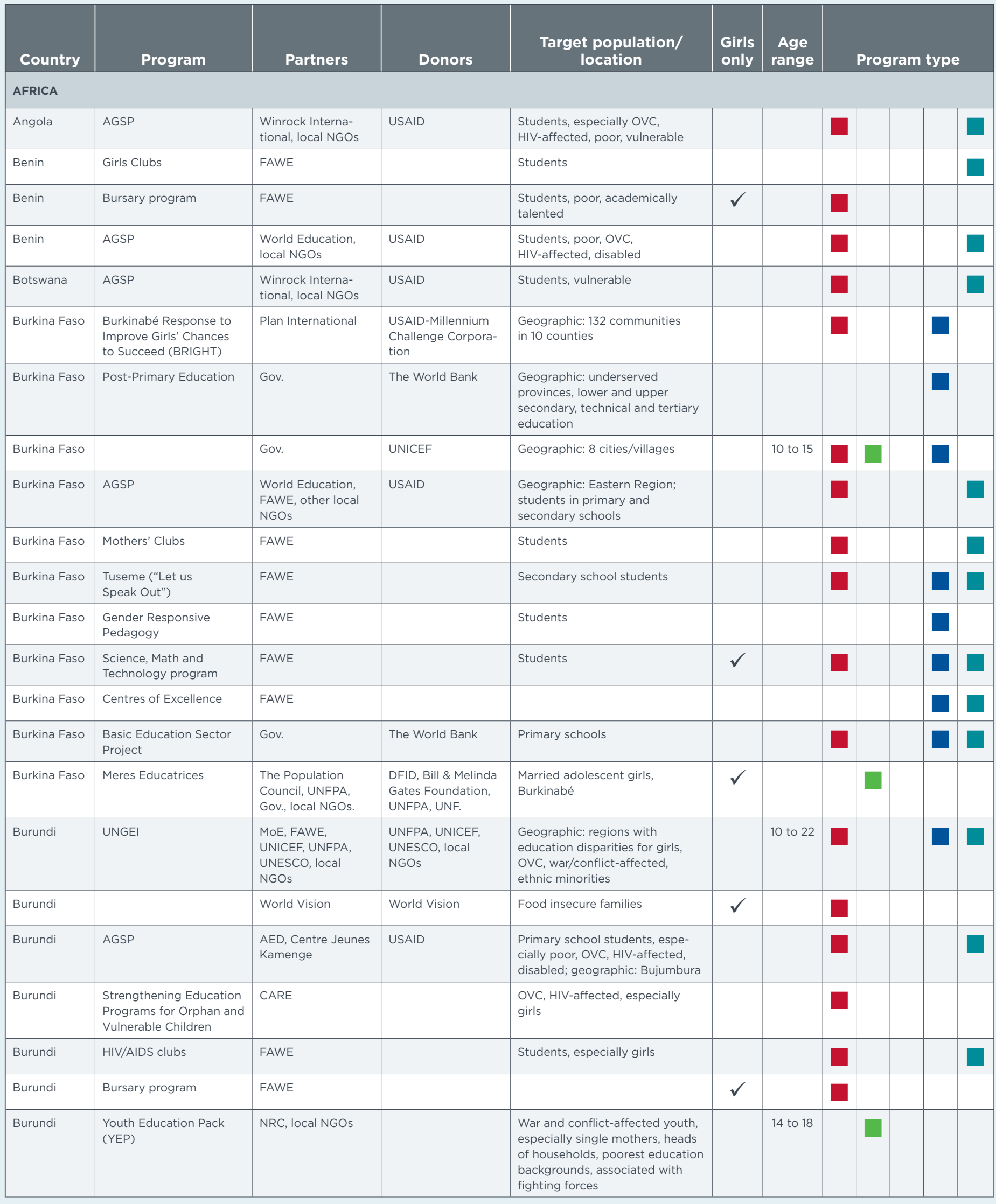




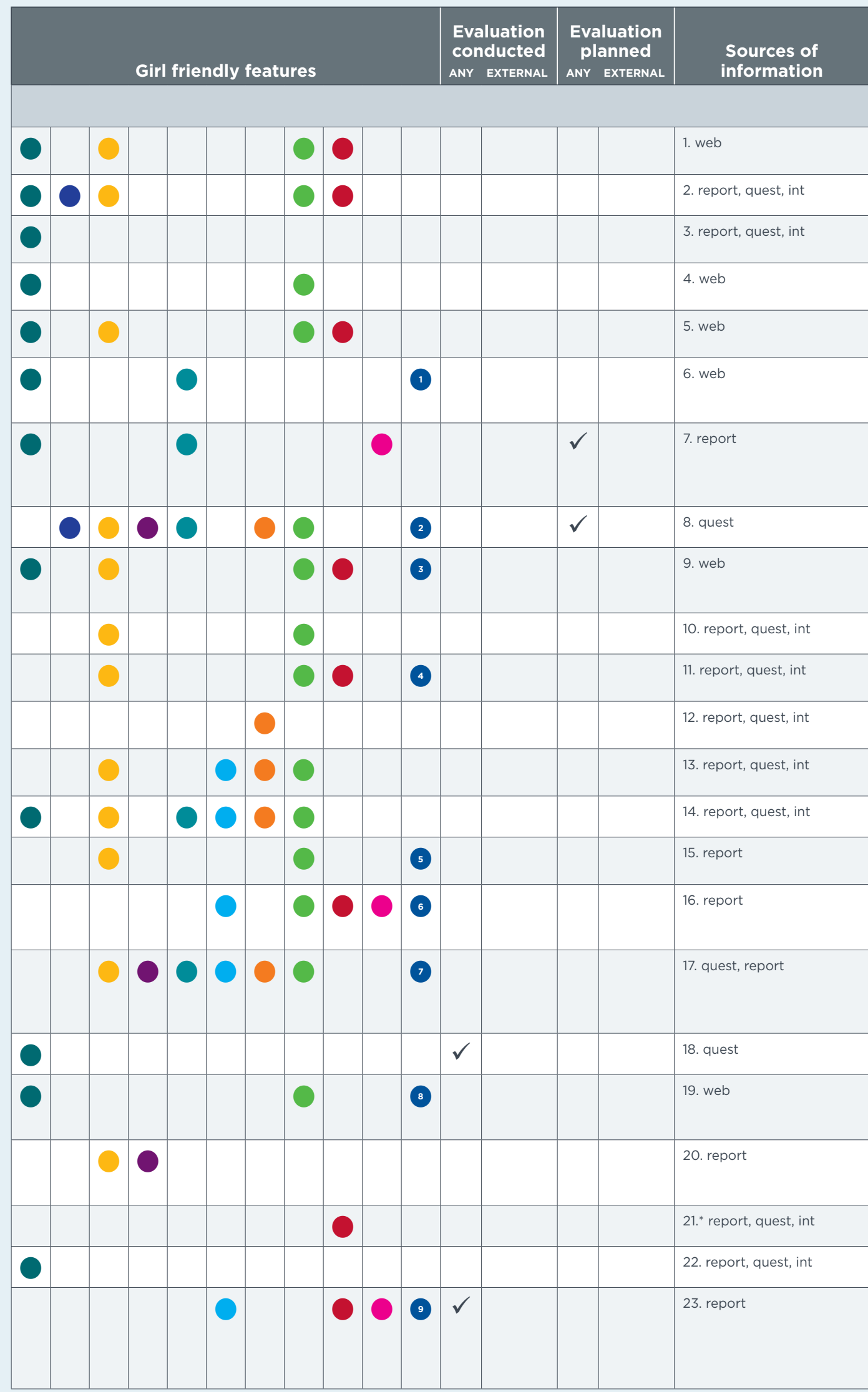

\section{PROGRAM TYPE}

Creating enabling conditions

Alternative education program

Complementary education program

Creating or enhancing formal schools

After school

\section{GIRL-FRIENDLY FEATURES}

Scholarship/stipends

Transportation/boarding

Advocacy and/or community engagement in girls' education

Safety policies and training; codes of conduct

Toilets or provision of sanitary napkins

Recruitment/training female teachers, para-teachers and other educators

Gender training for teachers

Mentoring, tutoring, peer support

Life-skills or literacy training

Livelihood or vocational training

Other

1. Child care for mothers to ensure older daughters can attend school rather than care for younger siblings.

2. Mothers' clubs support schools.

3. Community food production programs to support school feeding program.

4. Girls become community advocates for their right to education.

5. Micronutrient provision to promote girls' health.

6. Young mothers from the community trained as "educatrices."

7. Gender-sensitive curriculum; advocacy for gender policy at national level.

8. Enhancing CBOs' and local NGOs' capacity to support girls' education.

9. Care for students' children; meal provision; follow-up support for skill training including apprenticeships and support for forming cooperatives. 


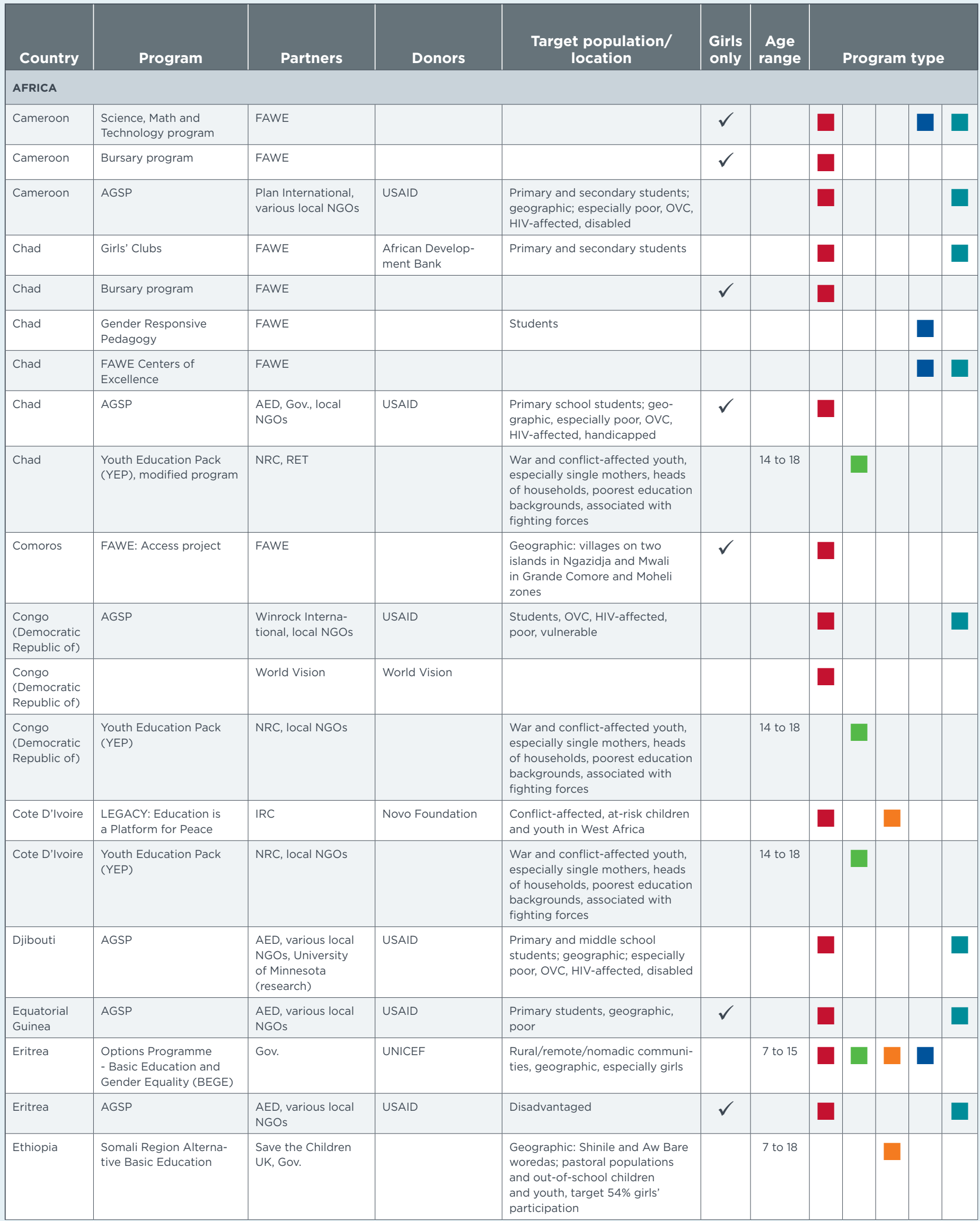




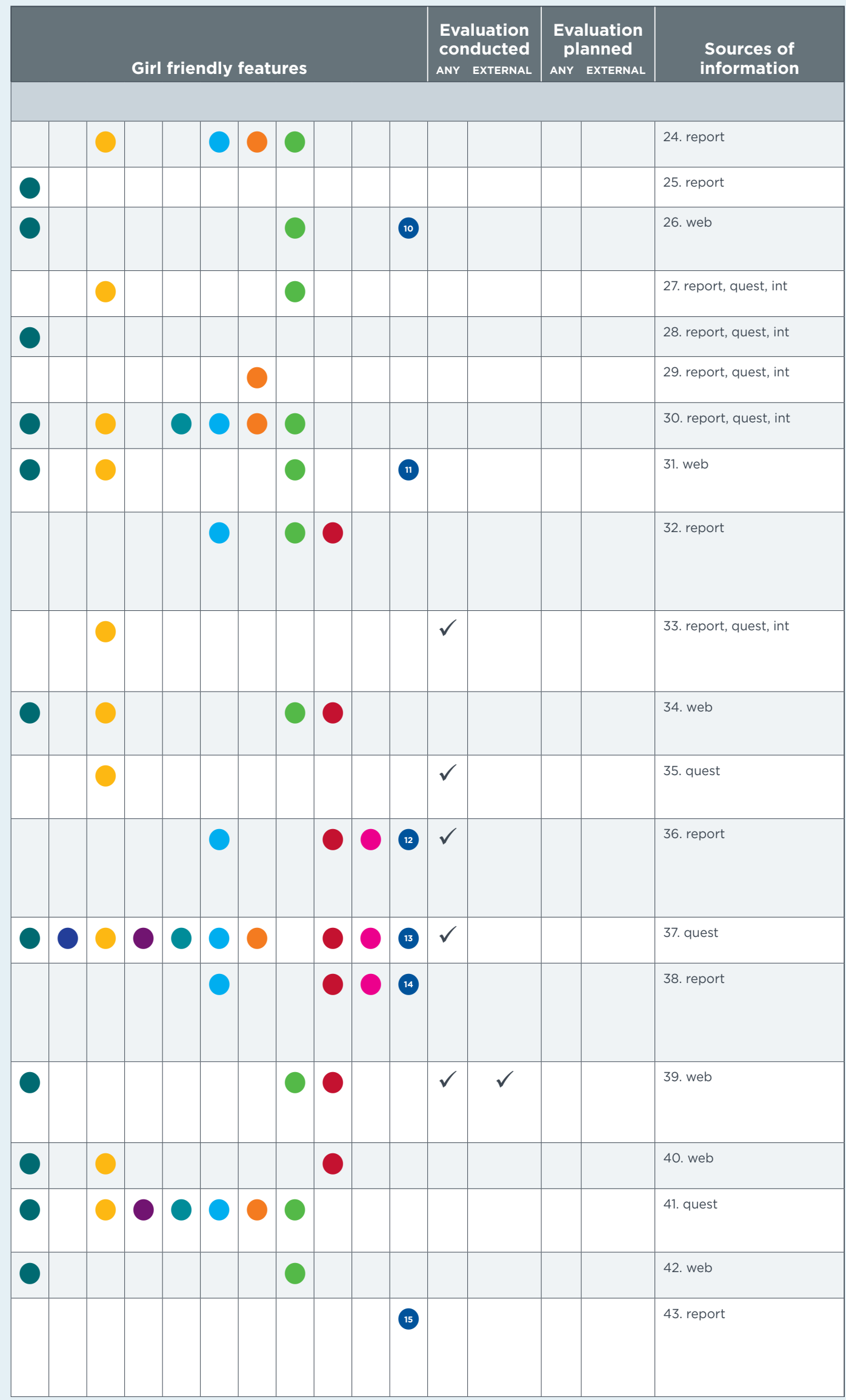

\section{PROGRAM TYPE}

Creating enabling conditions

Alternative education program

Complementary education program

Creating or enhancing formal schools

After school

\section{GIRL-FRIENDLY FEATURES}

Scholarship/stipends

Transportation/boarding

Advocacy and/or community engagement in girls' education

Safety policies and training; codes of conduct

Toilets or provision of sanitary napkins

Recruitment/training female teachers, para-teachers and other educators

Gender training for teachers

Mentoring, tutoring, peer support

Life-skills or literacy training

Livelihood or vocational training

Other

10. Support for girls to obtain birth certificates to facilitate school enrollment.

11. Mothers' associations engage in income generating activities to support mentors for girls.

12. Care for students' children; meal provision; follow-up support for skill training including apprenticeships and support for forming cooperatives.

13. Women are recruited to implement program; career counseling to encourage girls to enter well-paid professions; advocacy for changes to vocational technical school entry requirements to reduce barriers to girls' enrollment.

14. Care for students' children; mea provision; follow-up support for skill training including apprenticeships and support for forming cooperatives.

15. Flexible hours to accommodate the different needs and responsibilities of boys and girls. 


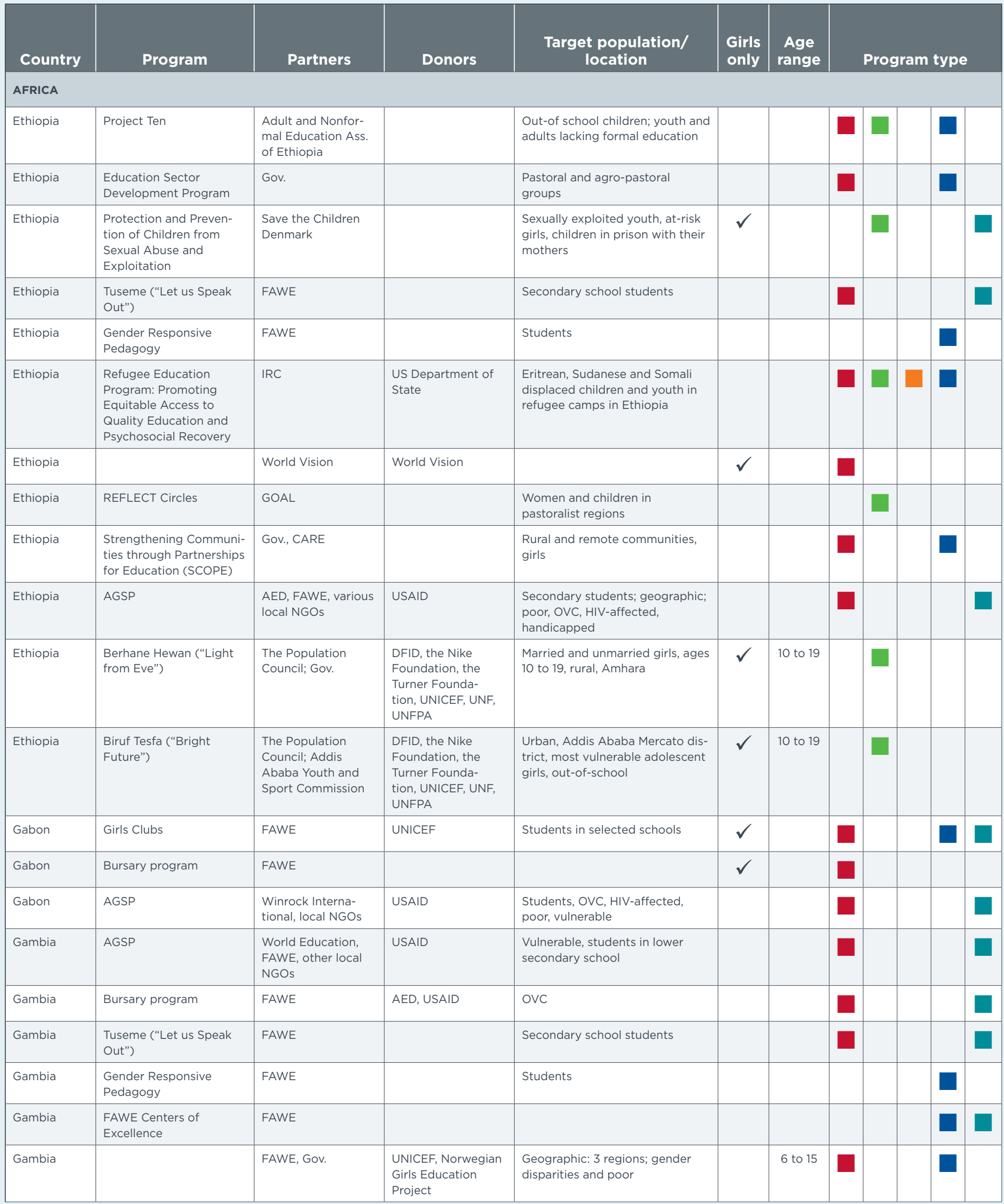




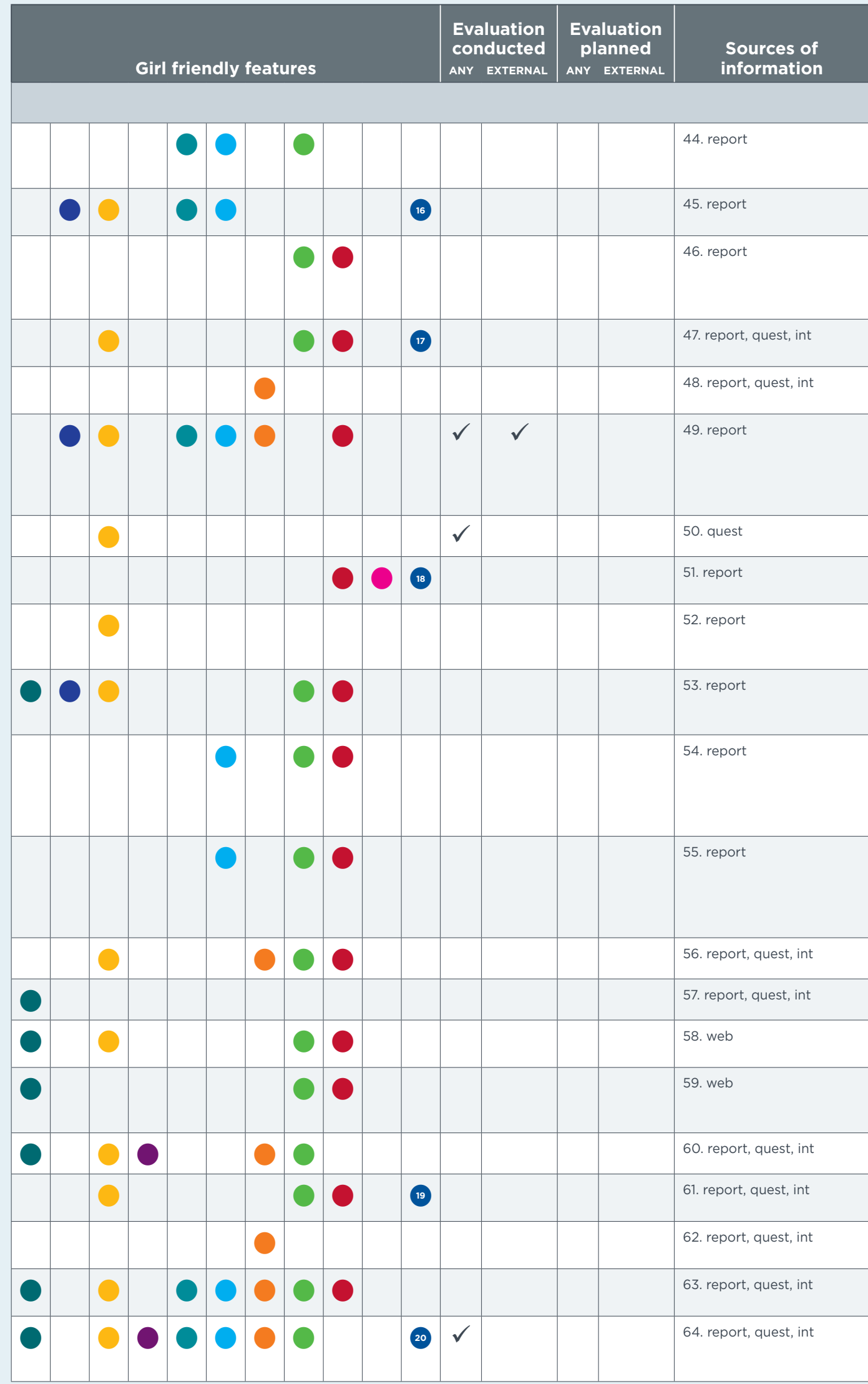

\section{PROGRAM TYPE}

Creating enabling conditions

Alternative education program

Complementary education program

Creating or enhancing formal schools

After school

\section{GIRL-FRIENDLY FEATURES}

Scholarship/stipends

Transportation/boarding

Advocacy and/or community engagement in girls' education

Safety policies and training; codes of conduct

Toilets or provision of sanitary napkins

Recruitment/training female teachers, para-teachers and other educators

Gender training for teachers

Mentoring, tutoring, peer support

Life-skills or literacy training

Livelihood or vocational training

Other

16. Mobile schools.

17. Girls are community advocates for their right to education.

18. Seed money and group facilitation for "circles" of women to start income generating activities.

19. Girls are community advocates for their right to education.

20. Gender sensitive curriculum, mothers' clubs. 


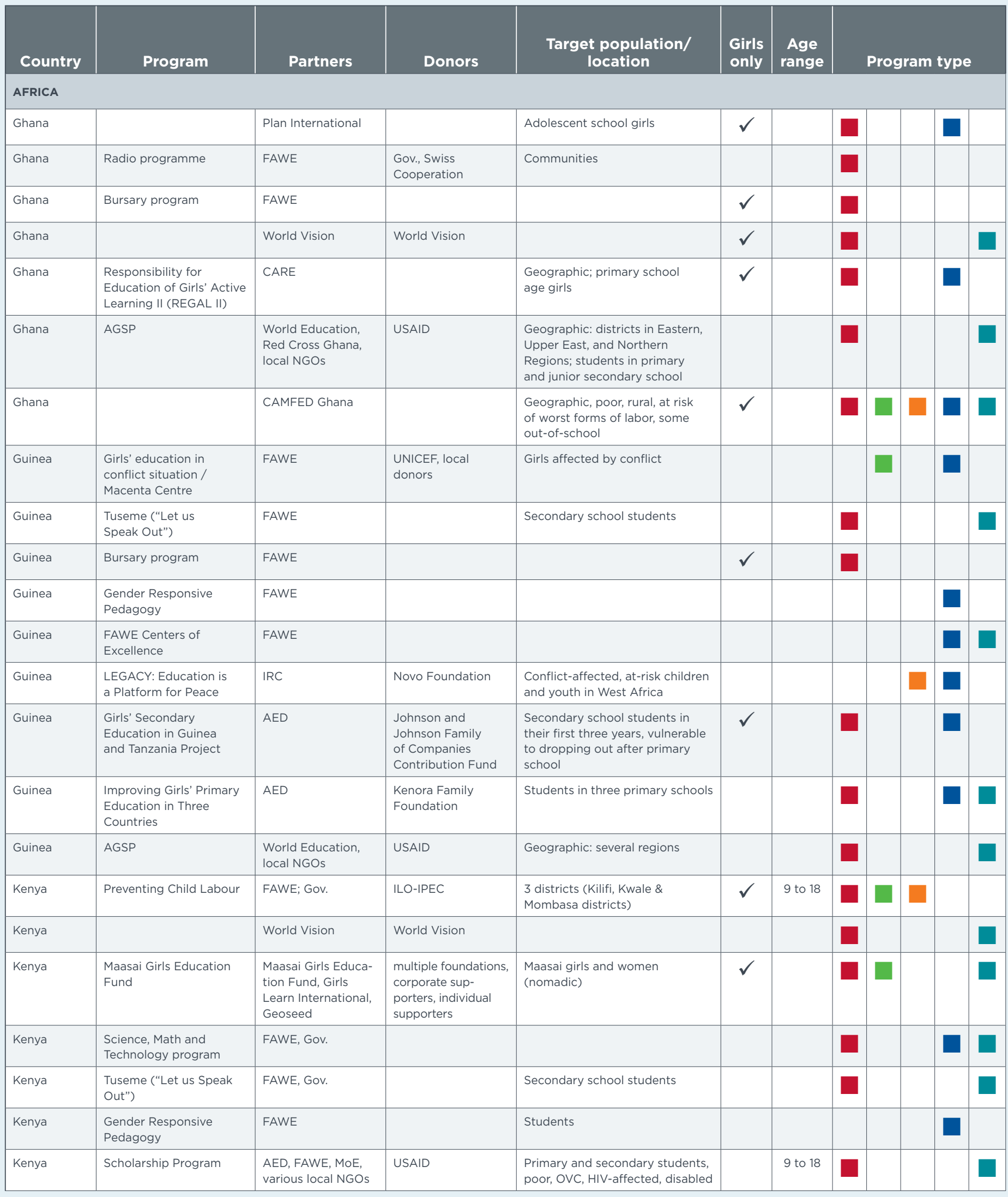




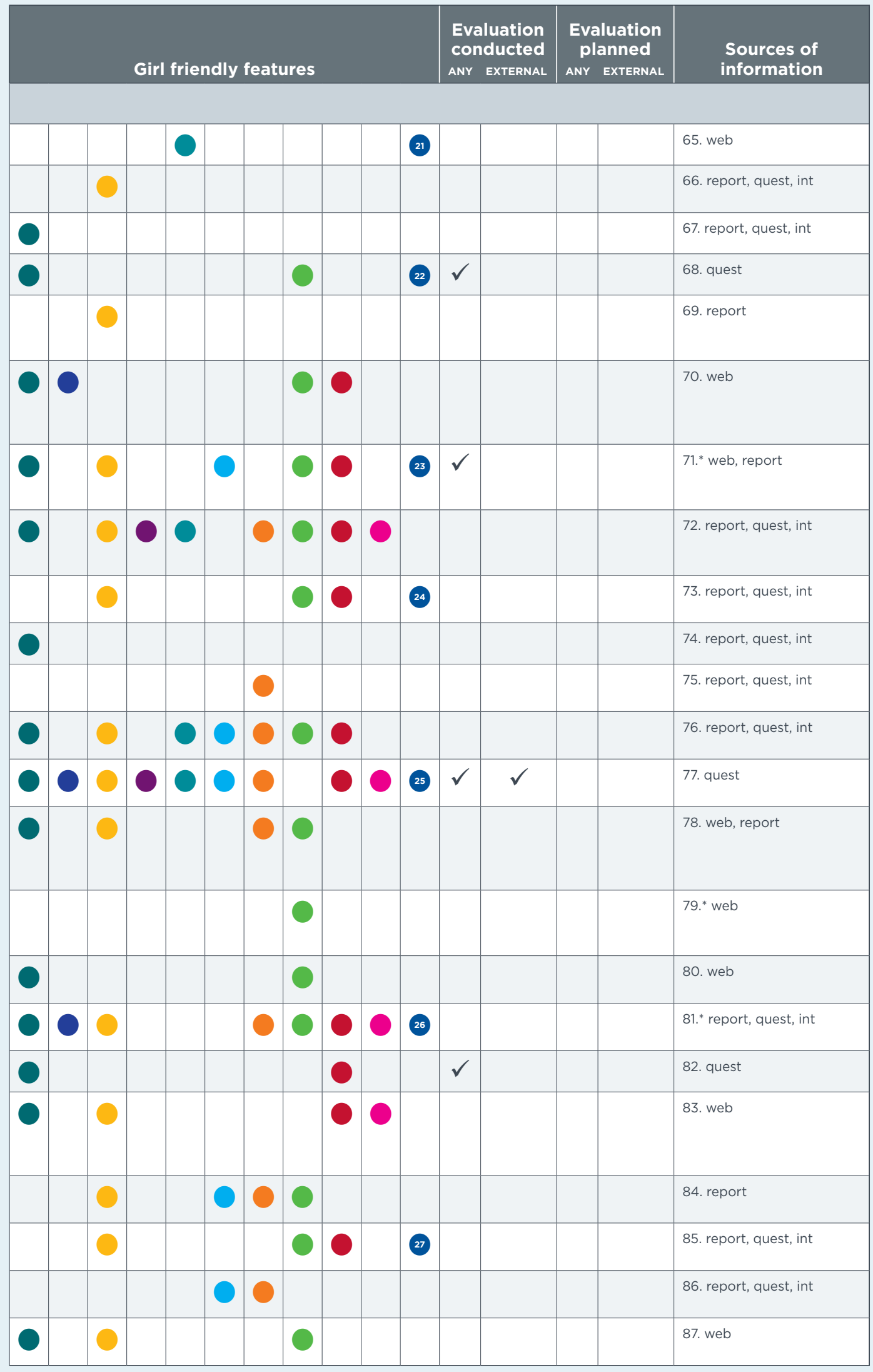

\section{PROGRAM TYPE}

Creating enabling conditions

Alternative education program

Complementary education program

Creating or enhancing formal schools

After school

\section{GIRL-FRIENDLY FEATURES}

Scholarship/stipends

Transportation/boarding

Advocacy and/or community engagement in girls' education

Safety policies and training; codes of conduct

Toilets or provision of sanitary napkins

Recruitment/training female teachers, para-teachers and other educators

Gender training for teachers

Mentoring, tutoring, peer support

Life-skills or literacy training

Livelihood or vocational training

Other

21. Hygiene education for girls about self-care during menstruation to prevent school absenteeism.

22. Math and science clinics for girls.

23. Seed money to new women-owned businesses.

24. Girls are community advocates for their right to education.

25. Women recruited to implement program; career counseling to encourage girls to enter well-paid professions.

26. Policy advocacy to mainstream child labour policy into gender policy in education.

27. Girls are community advocates for their right to education. 


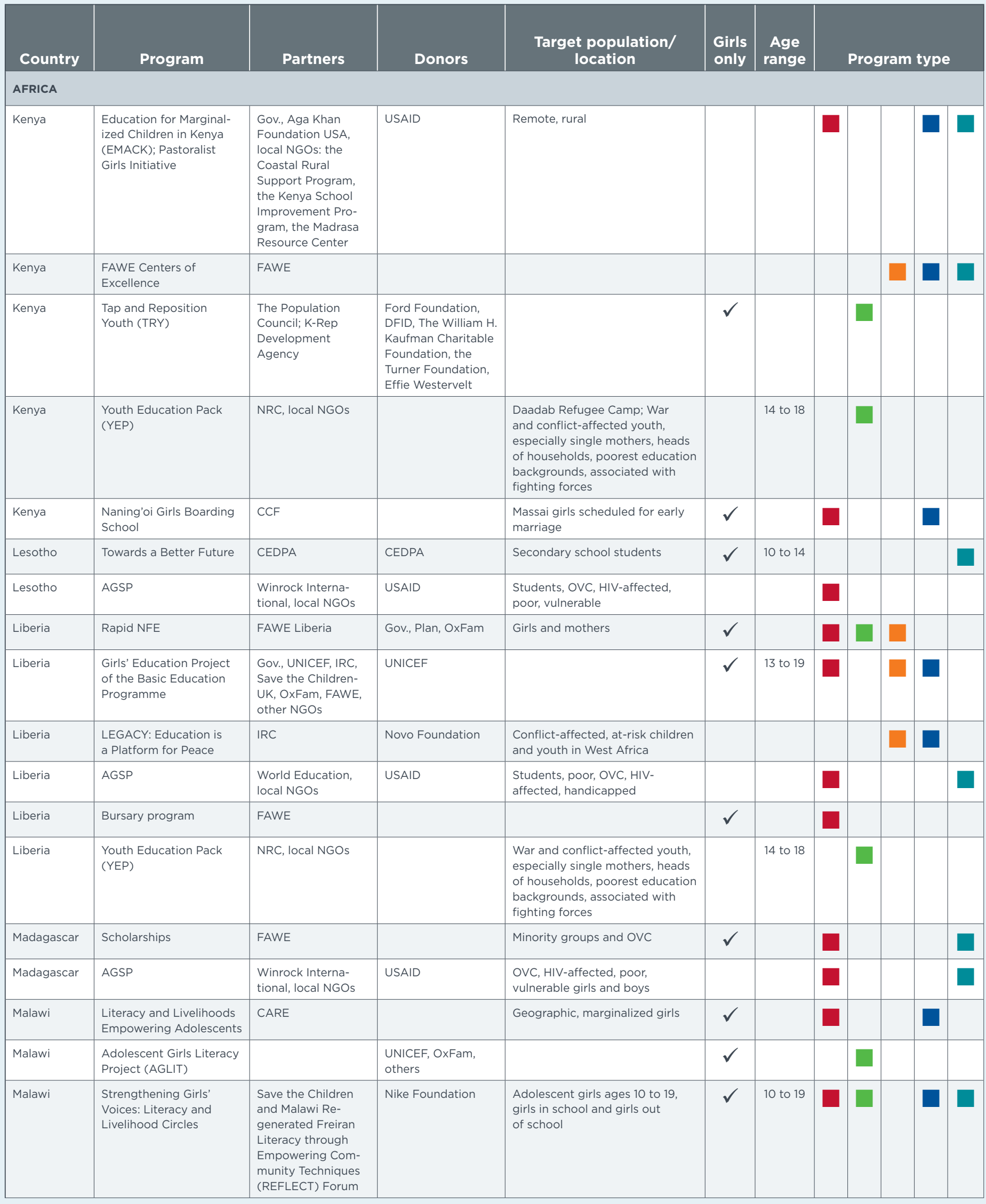




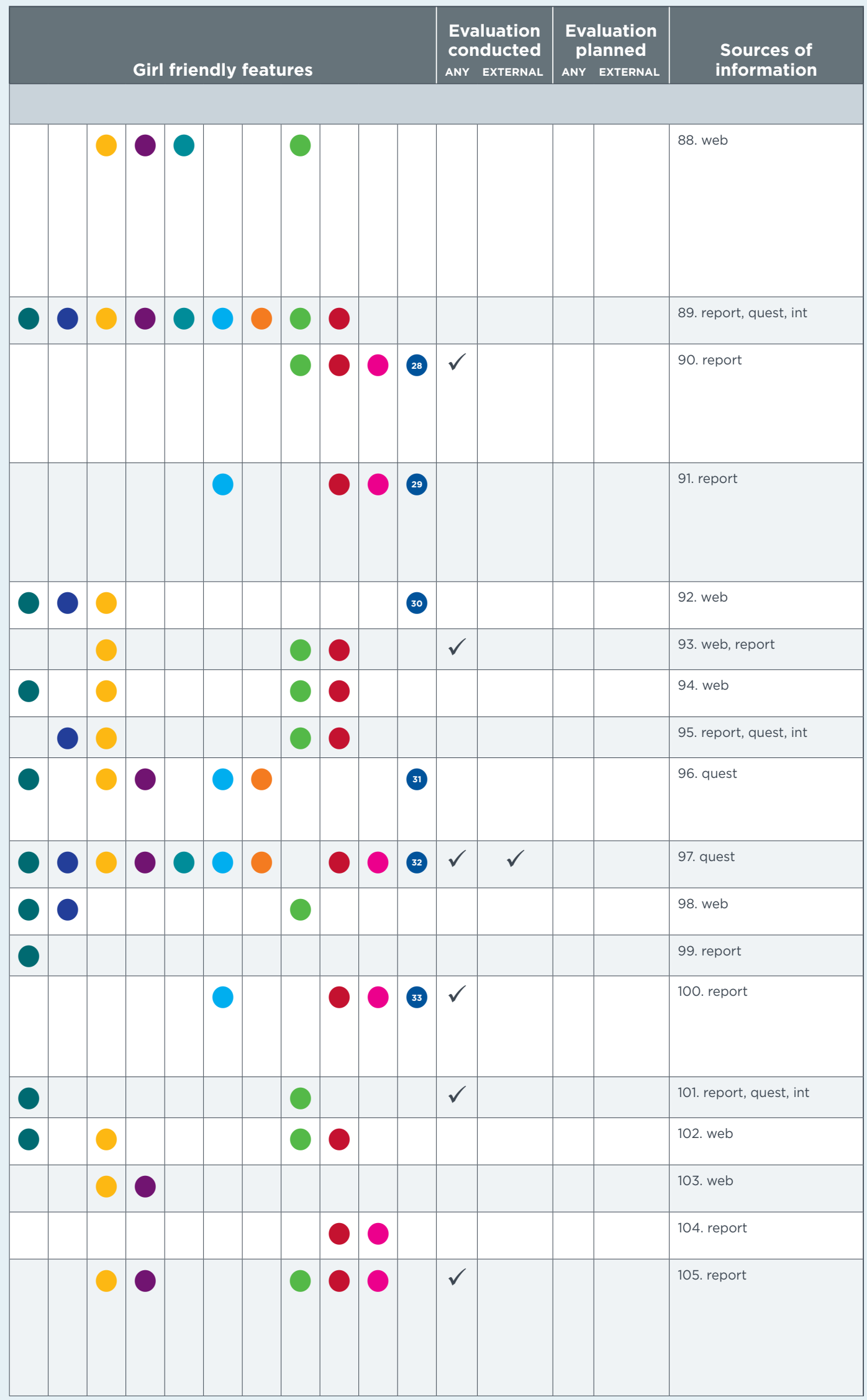

\section{PROGRAM TYPE}

Creating enabling conditions

Alternative education program

Complementary education program

Creating or enhancing formal schools

After school

\section{GIRL-FRIENDLY FEATURES}

Scholarship/stipends

Transportation/boarding

Advocacy and/or community engagement in girls' education

Safety policies and training; codes of conduct

Toilets or provision of sanitary napkins

Recruitment/training female teachers, para-teachers and other educators

Gender training for teachers

Mentoring, tutoring, peer support

Life-skills or literacy training

Livelihood or vocational training

Other

28. Microcredit and savings support in a voluntary association for beneficiaries.

29. Care for students' children; meal provision; follow-up support for skill training including apprenticeships and support to forming cooperatives.

30. "Booking" girls for enrollment into school as an alternative to "booking" them for early marriage, including use of a dowry payment to parents.

31. Mothers' clubs generate income to support girls' schooling, promotion of a gender-sensitive environment in all schools.

32. Women recruited to implement program; career counseling to encourage girls to enter well-paid professions.

33. Care for students' children; meal provision; follow-up support for skill training including apprenticeships and support to forming cooperatives. 


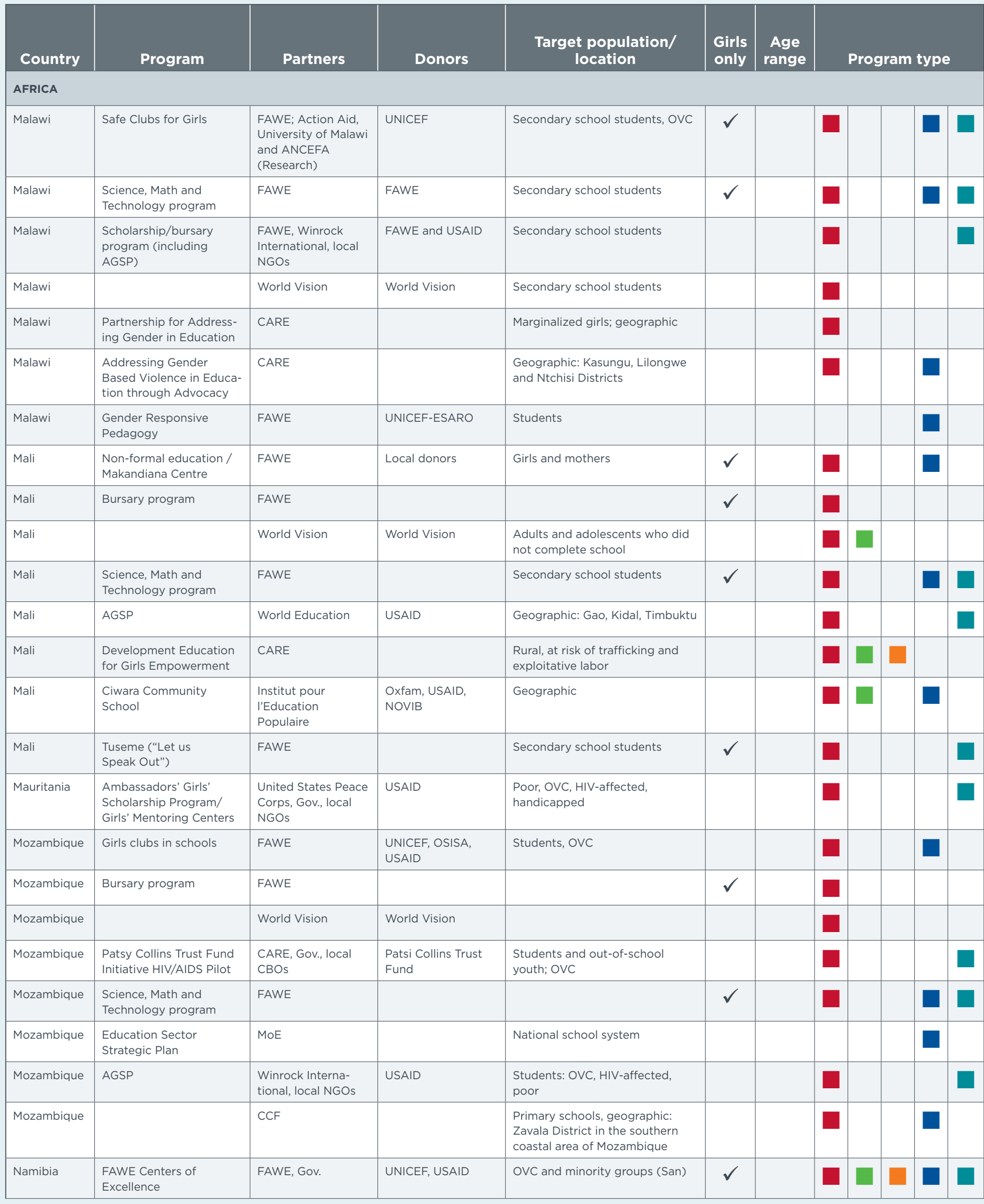




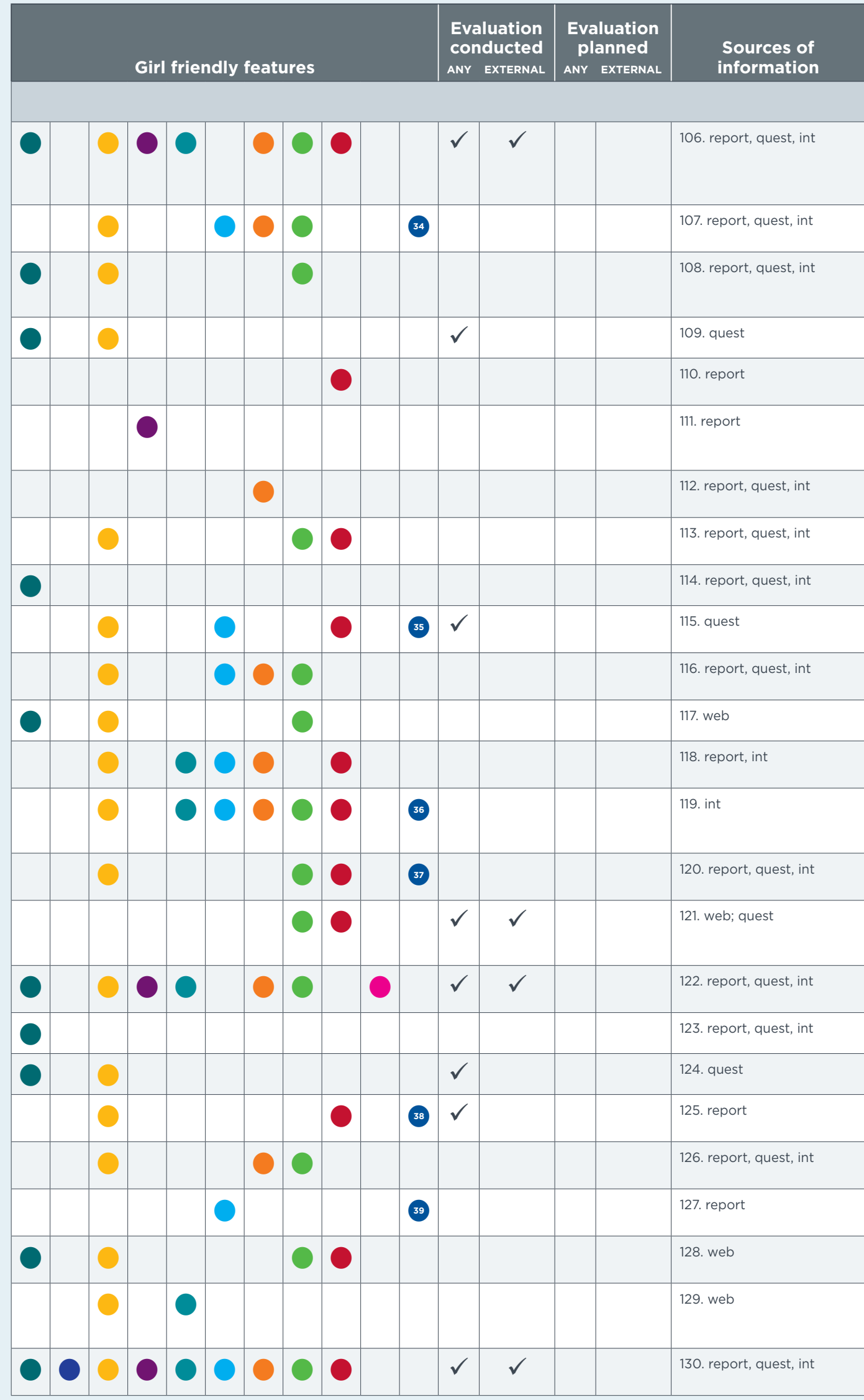

\section{PROGRAM TYPE}

Creating enabling conditions

Alternative education program

Complementary education program

Creating or enhancing formal schools

After school

\section{GIRL-FRIENDLY FEATURES}

Scholarship/stipends

Transportation/boarding

Advocacy and/or community engagement in girls' education

Safety policies and training; codes of conduct

Toilets or provision of sanitary napkins

Recruitment/training female teachers, para-teachers and other educators

Gender training for teachers

Mentoring, tutoring, peer support

Life-skills or literacy training

Livelihood or vocational training

Other

34. Science camps and science discussions for girls.

35. Income generating activities to support schooling.

36. Advocacy to families discourage practices that interfere with education: early marriage, FGM chore burden carried by girls only: curriculum focuses on social justice.

37. Girls are community advocates for their right to education.

38. Support in obtaining birth certificates and poverty certificates to facilitate school enrollment.

39. Abolition of school fees. 


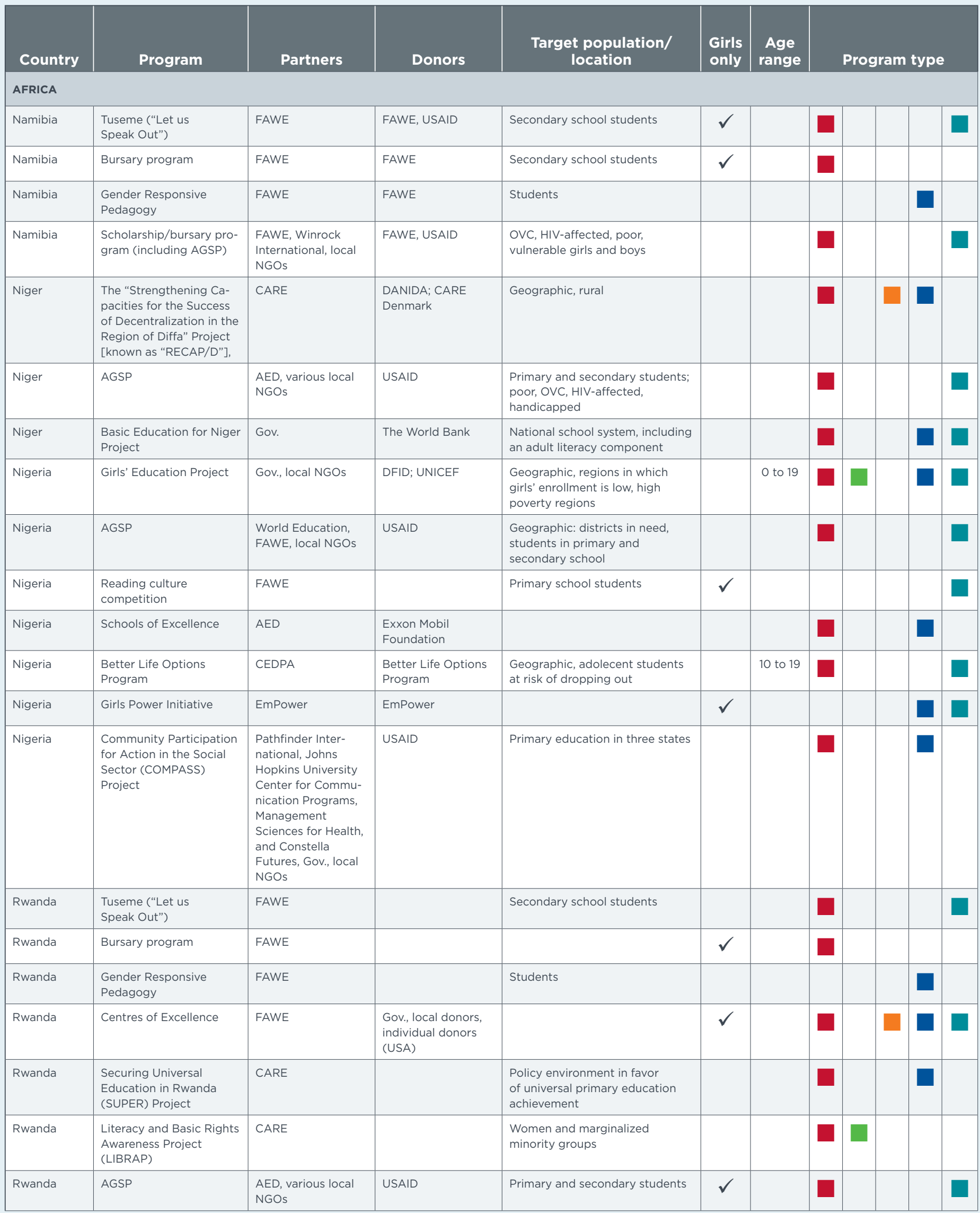




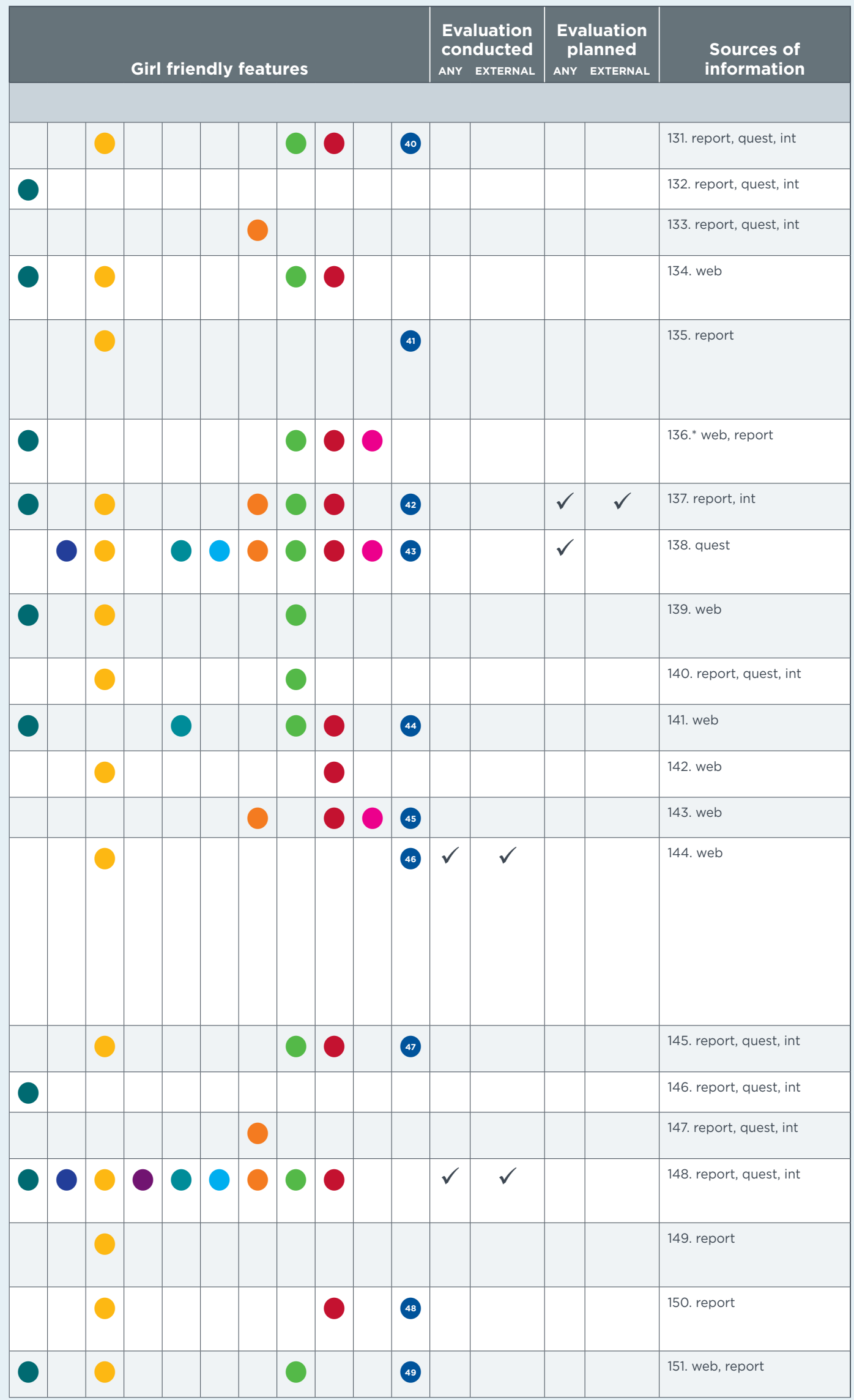

\section{PROGRAM TYPE}

Creating enabling conditions

Alternative education program

Complementary education program

Creating or enhancing formal schools

After school

\section{GIRL-FRIENDLY FEATURES}

Scholarship/stipends

Transportation/boarding

Advocacy and/or community engagement in girls' education

Safety policies and training; codes of conduct

Toilets or provision of sanitary napkins

Recruitment/training female teachers, para-teachers and other educators

Gender training for teachers

Mentoring, tutoring, peer support

Life-skills or literacy training

Livelihood or vocational training

Other

40. Girls are community advocates for their right to education.

41. Facilitation of girls' enrollment into secondary or technical education.

42. Women's literacy program is connected to tutoring program and to promoting an environment conducive to girls' education.

43. National level policy development for girls education; integrating life skills education in "Islamiya" (religious) schools; wheelchairs for girls with disabilities; adult literacy classes target mothers of girls.

44. Schools choose from a range of interventions; also includes: schoo renovation and clean water.

45. Internships for girls at NGOs, career fairs for girls to learn about professions dominated by men. training for teachers in counselling and reproductive health issues for adolescents,

46. Grants and technical support to PTAs.

47. Girls are community advocates for their right to education.

48. Focus on skills for engagement in local decisionmaking processes, awareness of human rights.

49. Policy advocacy at the national level, rewards to schools demonstrating gender sensitivity. 


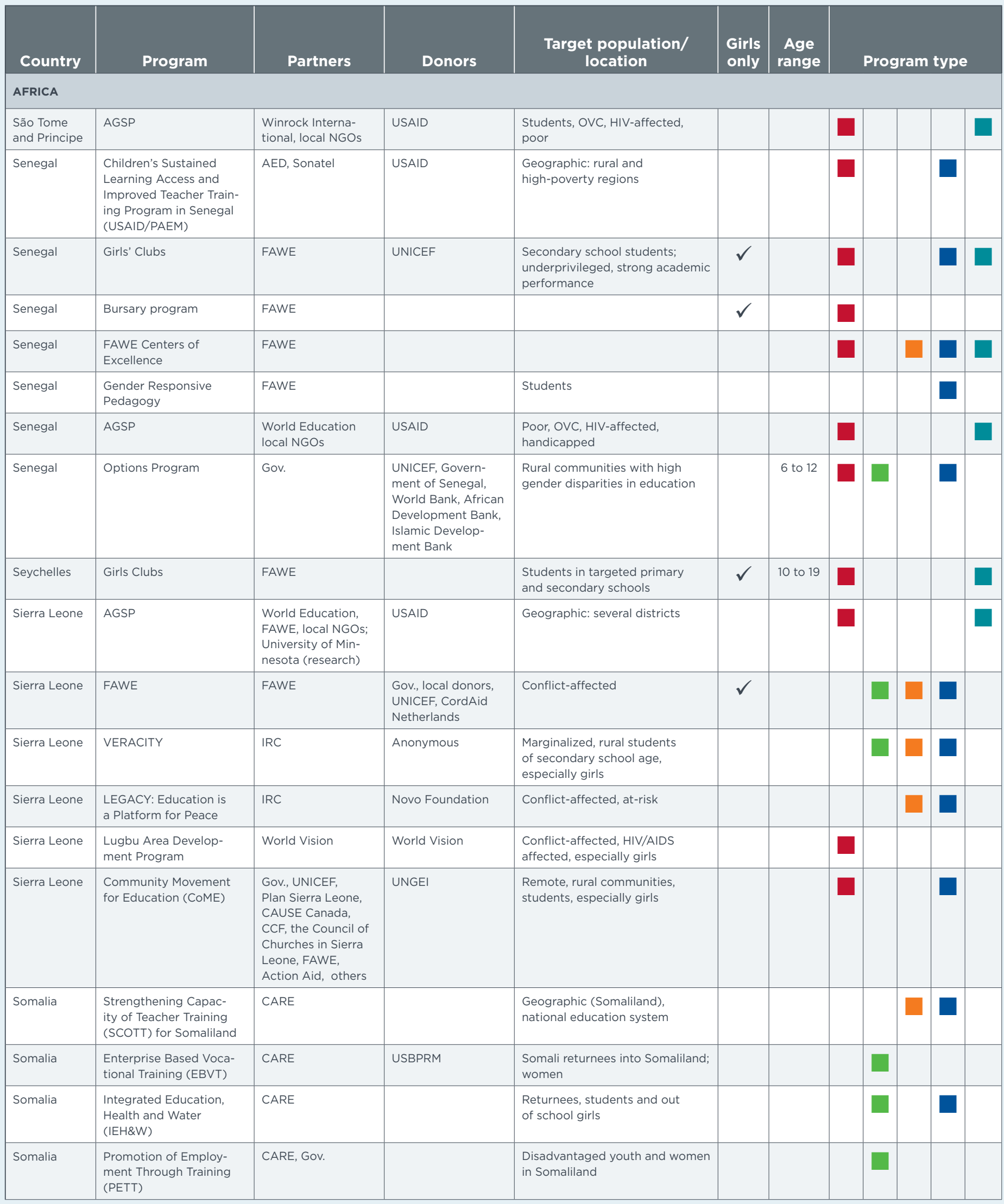




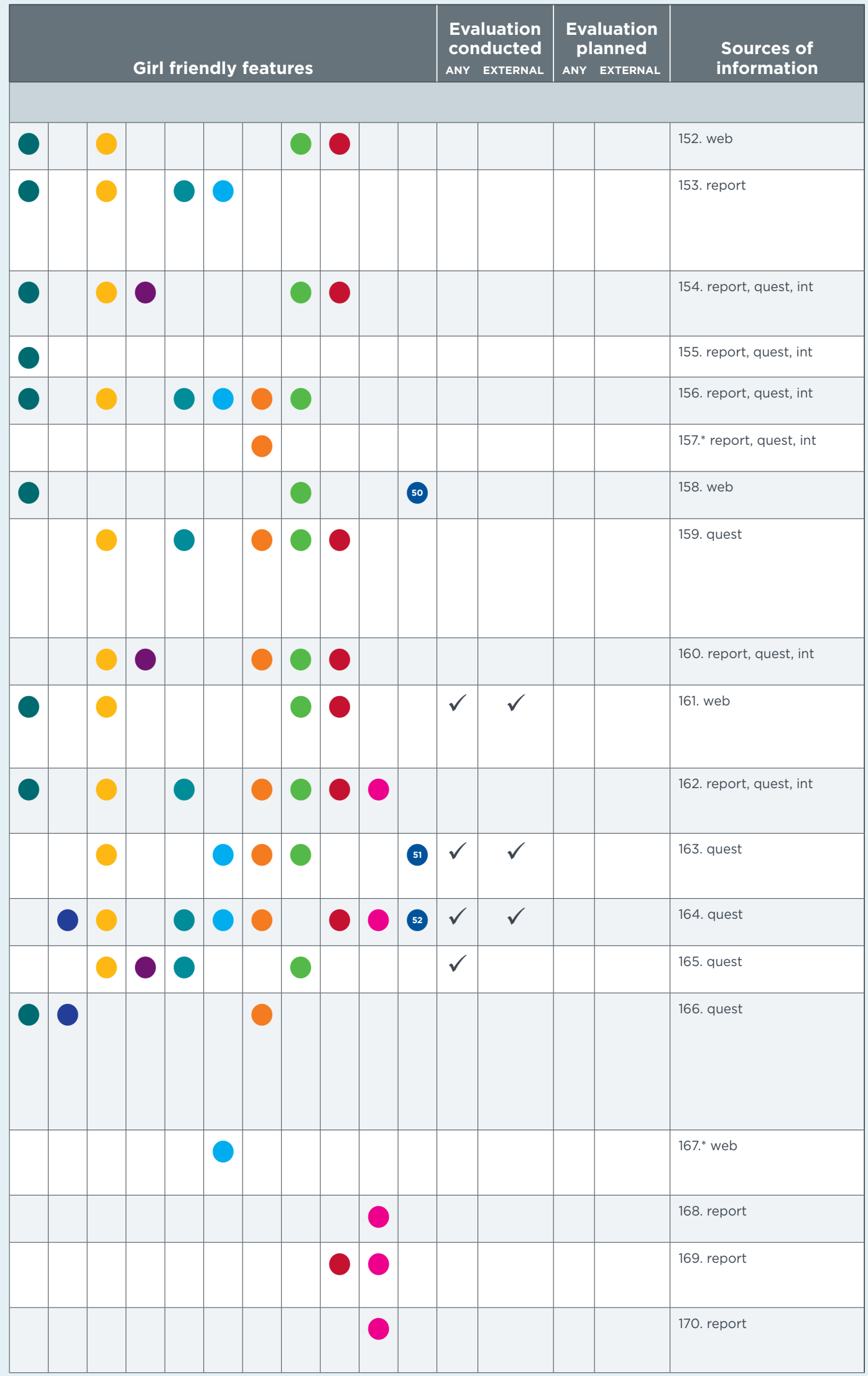

\section{PROGRAM TYPE}

Creating enabling conditions

Alternative education program

Complementary education program

Creating or enhancing formal schools

After school

\section{GIRL-FRIENDLY FEATURES}

Scholarship/stipends

Transportation/boarding

Advocacy and/or community engagement in girls' education

Safety policies and training; codes of conduct

Toilets or provision of sanitary napkins

Recruitment/training female teachers, para-teachers and other educators

Gender training for teachers

Mentoring, tutoring, peer support

Life-skills or literacy training

Livelihood or vocational training

Other

50. Campaign against practices that interfere with education (e.g. early marriage and migration forced labor).

51. Curriculum includes gender studies.

52. Women recruited to implement program. 


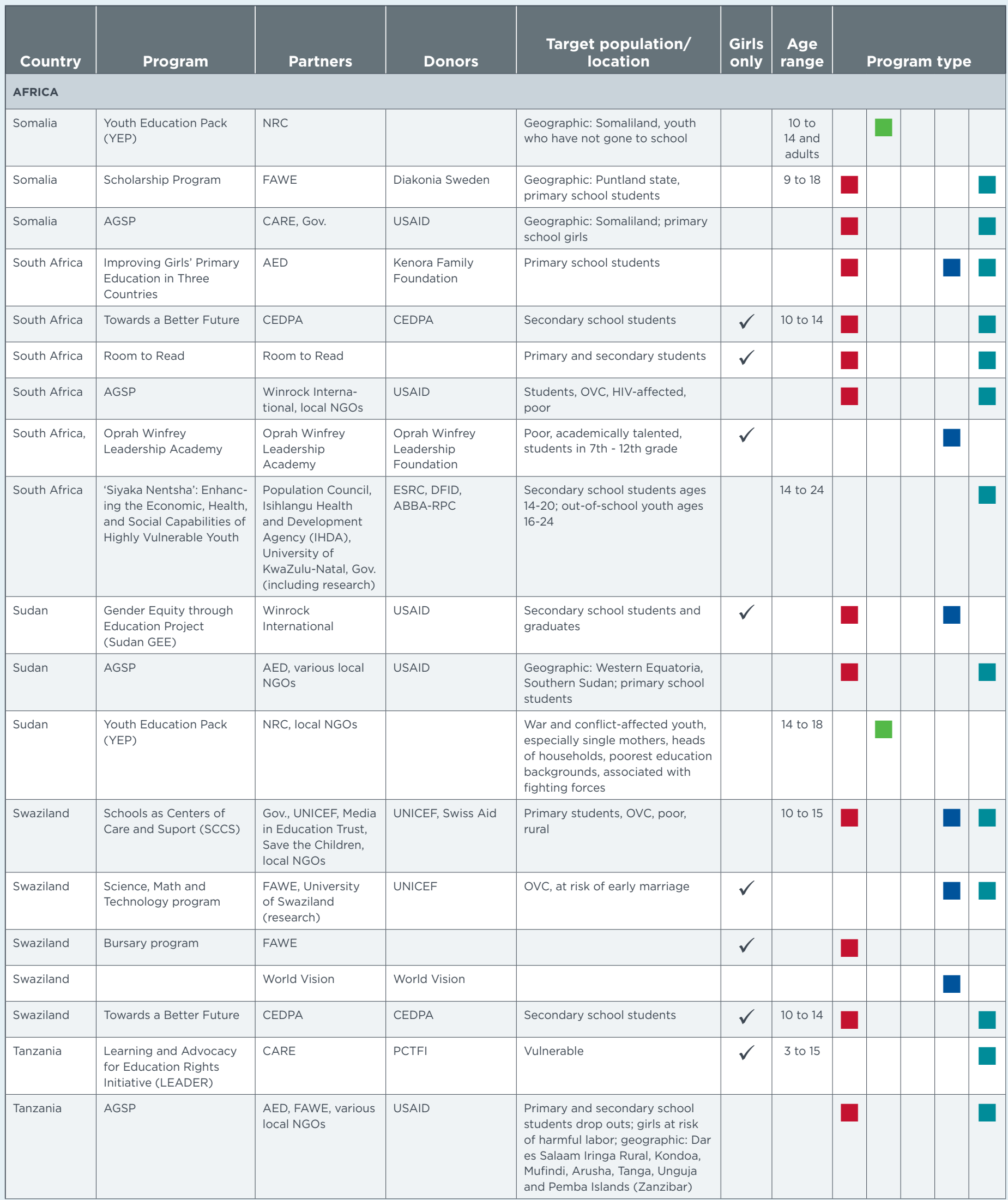




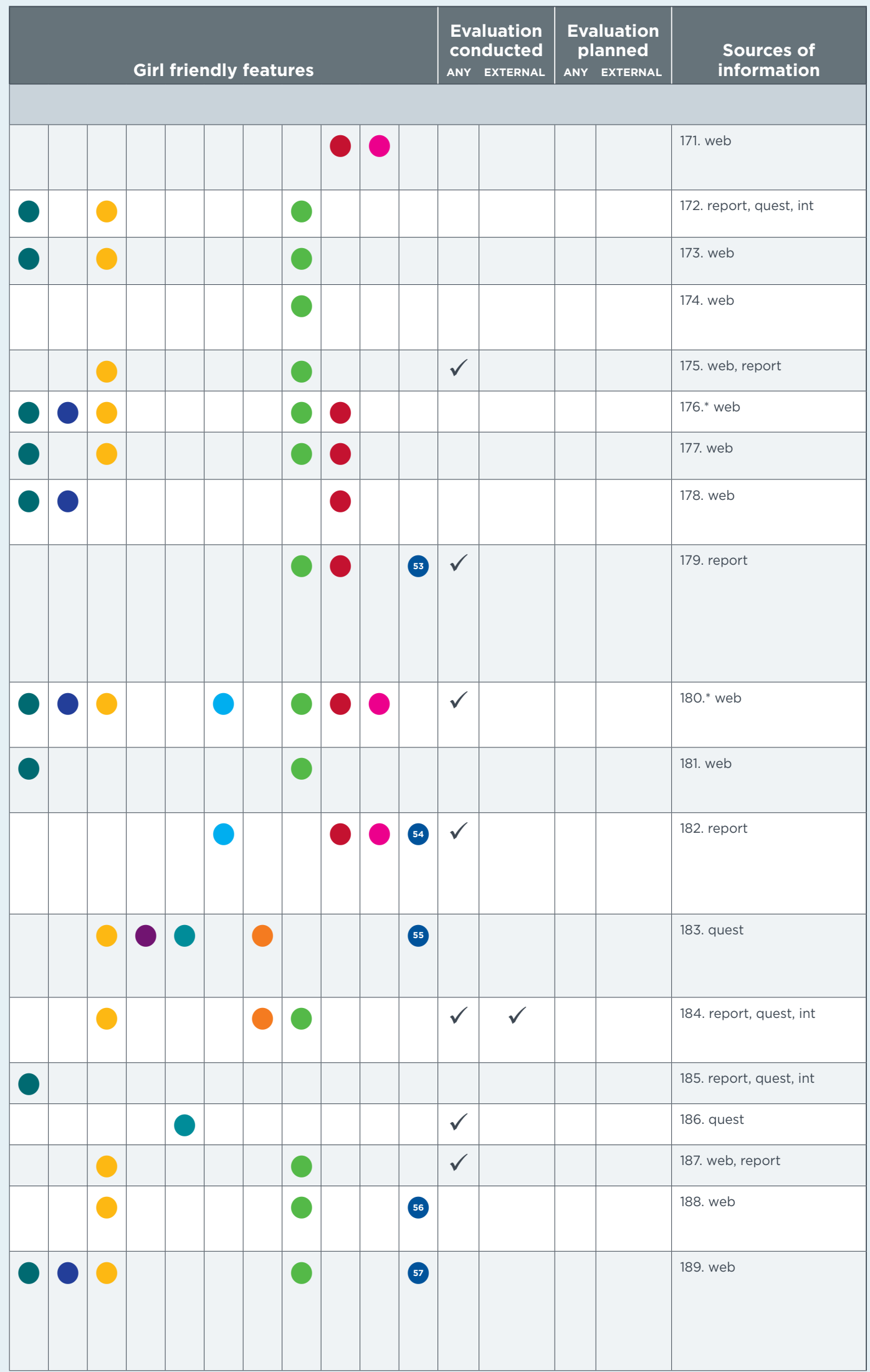

\section{PROGRAM TYPE}

Creating enabling conditions

Alternative education program

Complementary education program

Creating or enhancing formal schools

After school

\section{GIRL-FRIENDLY FEATURES}

Scholarship/stipends

Transportation/boarding

Advocacy and/or community engagement in girls' education

Safety policies and training; codes of conduct

Toilets or provision of sanitary napkins

Recruitment/training female teachers, para-teachers and other educators

Gender training for teachers

Mentoring, tutoring, peer support

Life-skills or literacy training

Livelihood or vocational training

Other

53. Financial literacy, skills for career and family planning and decisionmaking. support to building social networks. Beneficiaries receive governmentaccredited certificate.

54. Care for students' children; meal provision; follow-up support for skil training including apprenticeships and support to forming cooperatives.

55. Girls' participation in school governance.

56. Building girls' awareness of their education rights, supporting girls participation in education/community leadership to avail themselves of their rights.

57. Income generating activities for parents. 


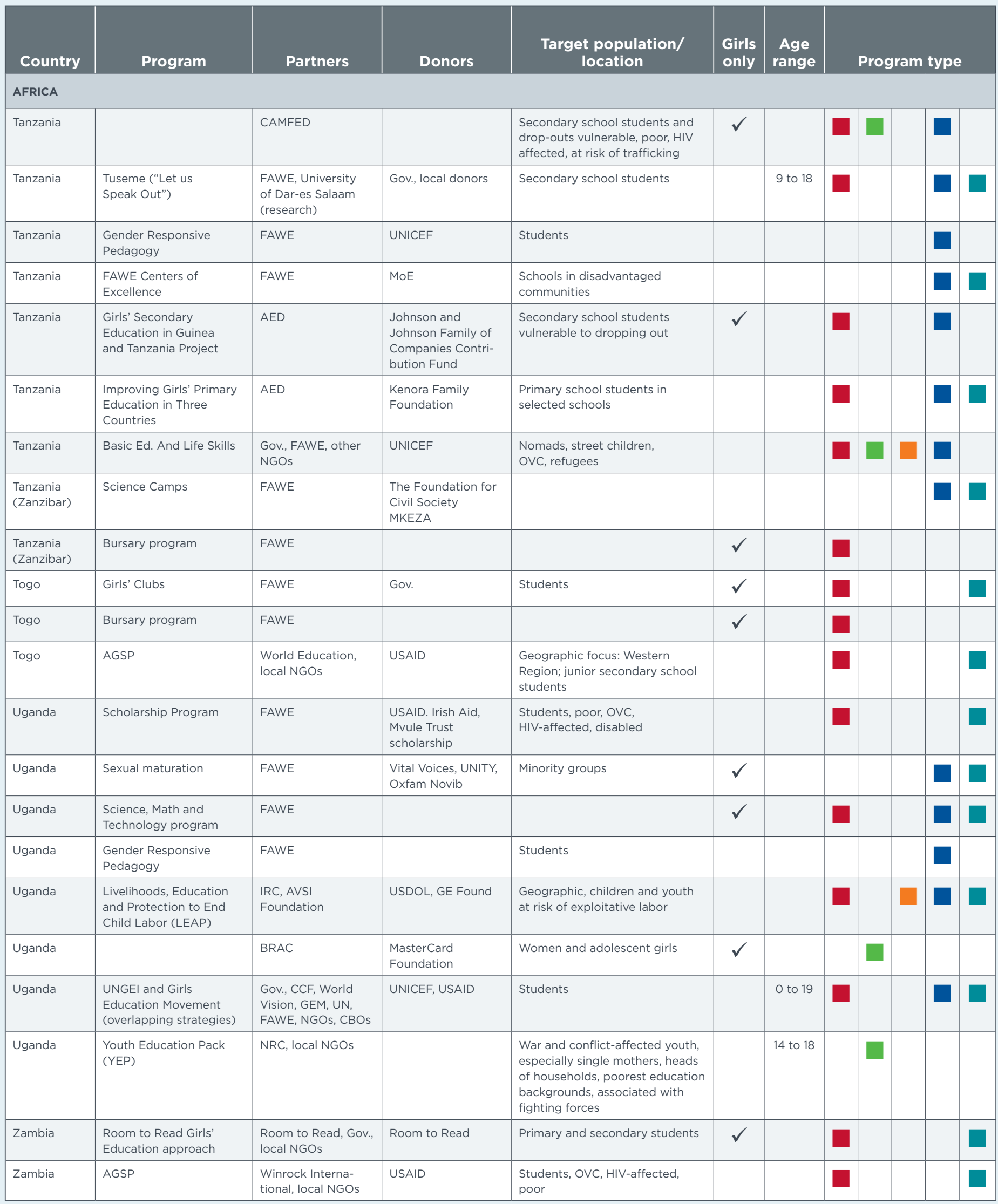




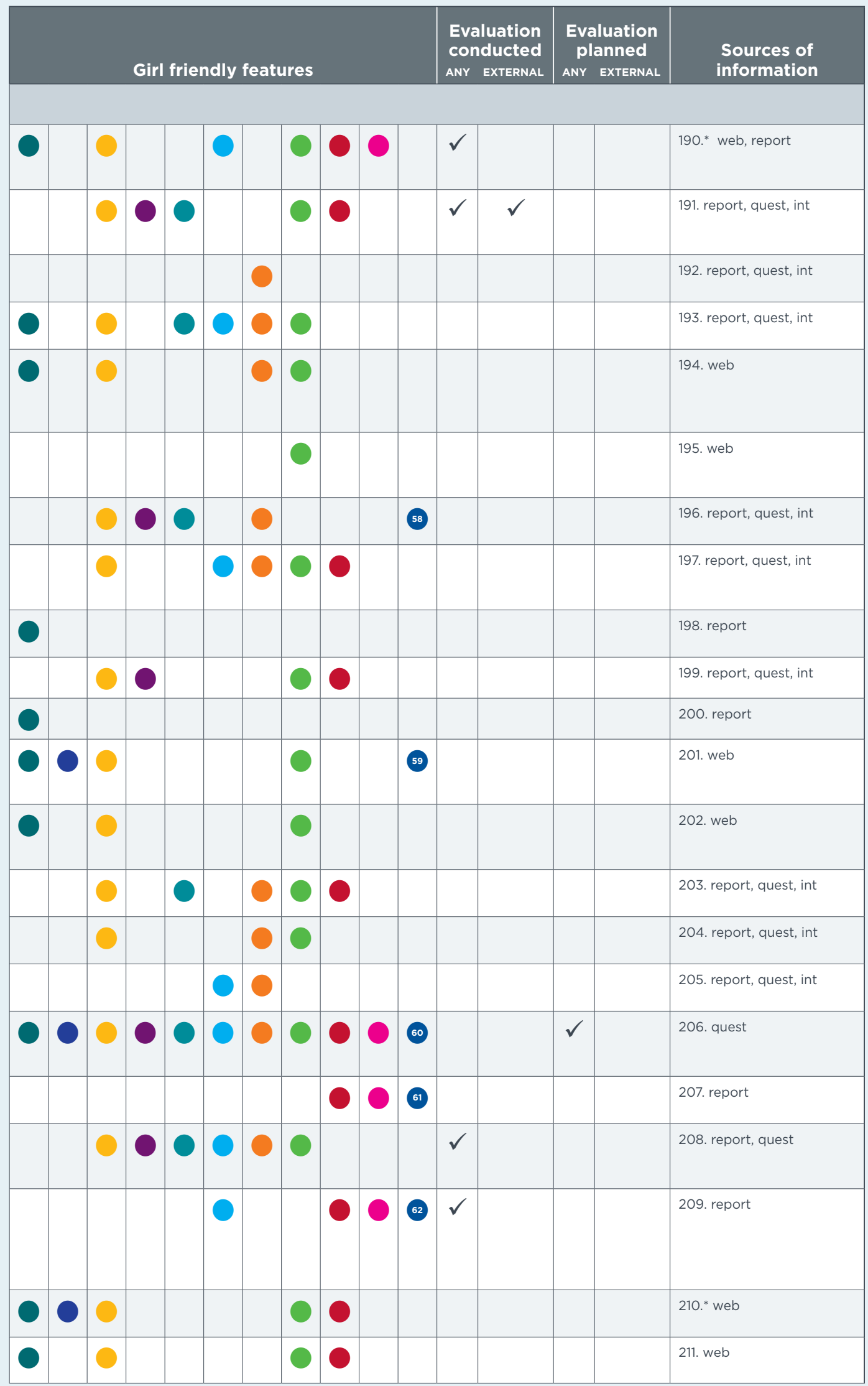

\section{PROGRAM TYPE}

Creating enabling conditions

Alternative education program

Complementary education program

Creating or enhancing formal schools

After school

\section{GIRL-FRIENDLY FEATURES}

Scholarship/stipends

Transportation/boarding

Advocacy and/or community engagement in girls' education

Safety policies and training; codes of conduct

Toilets or provision of sanitary napkins

Recruitment/training female teachers, para-teachers and other educators

Gender training for teachers

Mentoring, tutoring, peer support

Life-skills or literacy training

Livelihood or vocational training

Other

58. Policies for pregnant girls to continue schooling: gender-sensitive national assessment frameworks; EFA/Girls Education Forums.

59. Advocacy against early marriage and trafficking.

60. Support to female students entering the teaching profession; support to the teaching profession; support to and Coordinating Center Tutors and Coordinating Center Tutors improve teacher retention through
in-service monitoring and support.

61. Program is connected with microcredit for women starting their own businesses.

62. Care for students' children, meal provision; follow-up support for skill training including apprenticeships and support to forming cooperatives. 


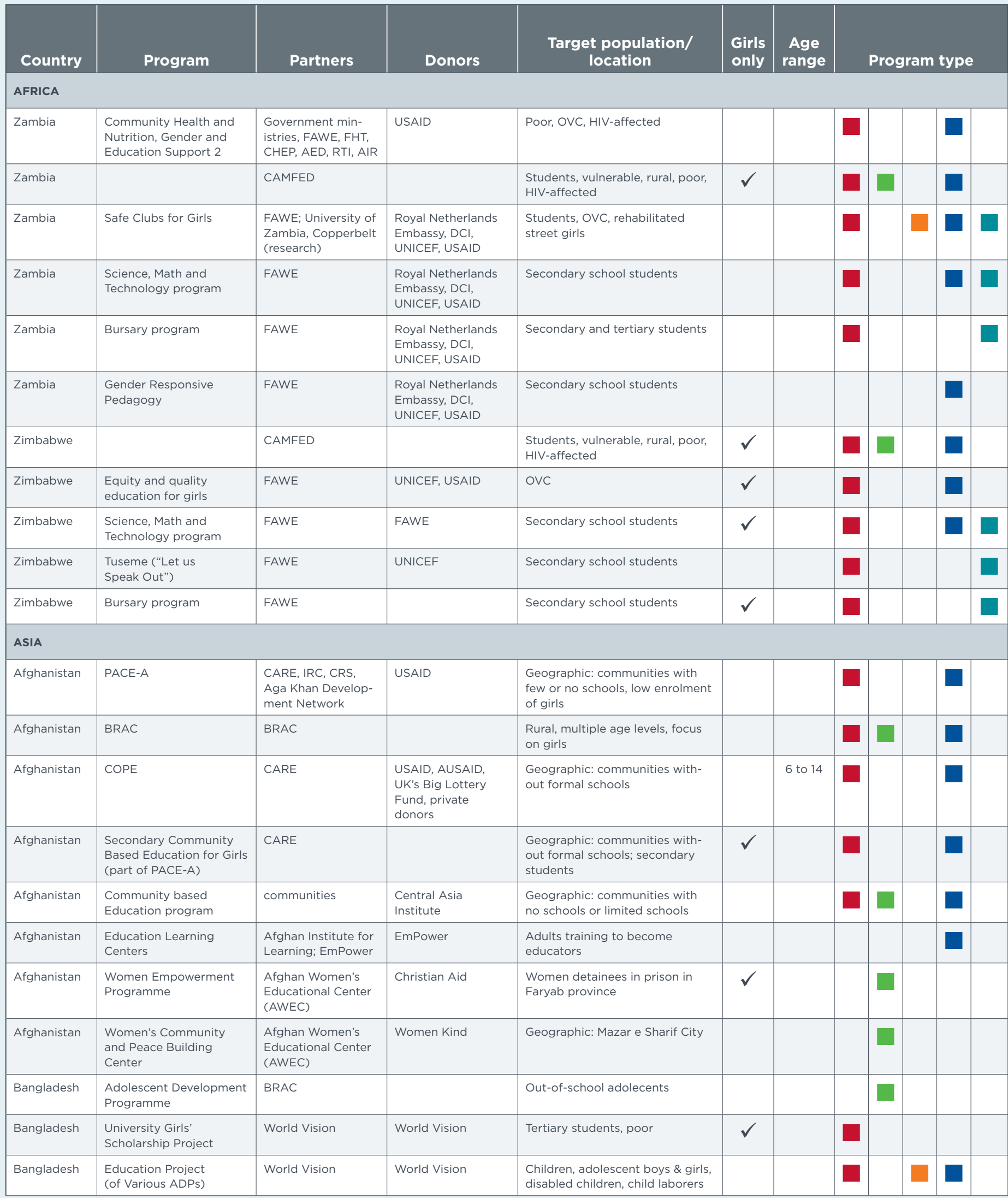




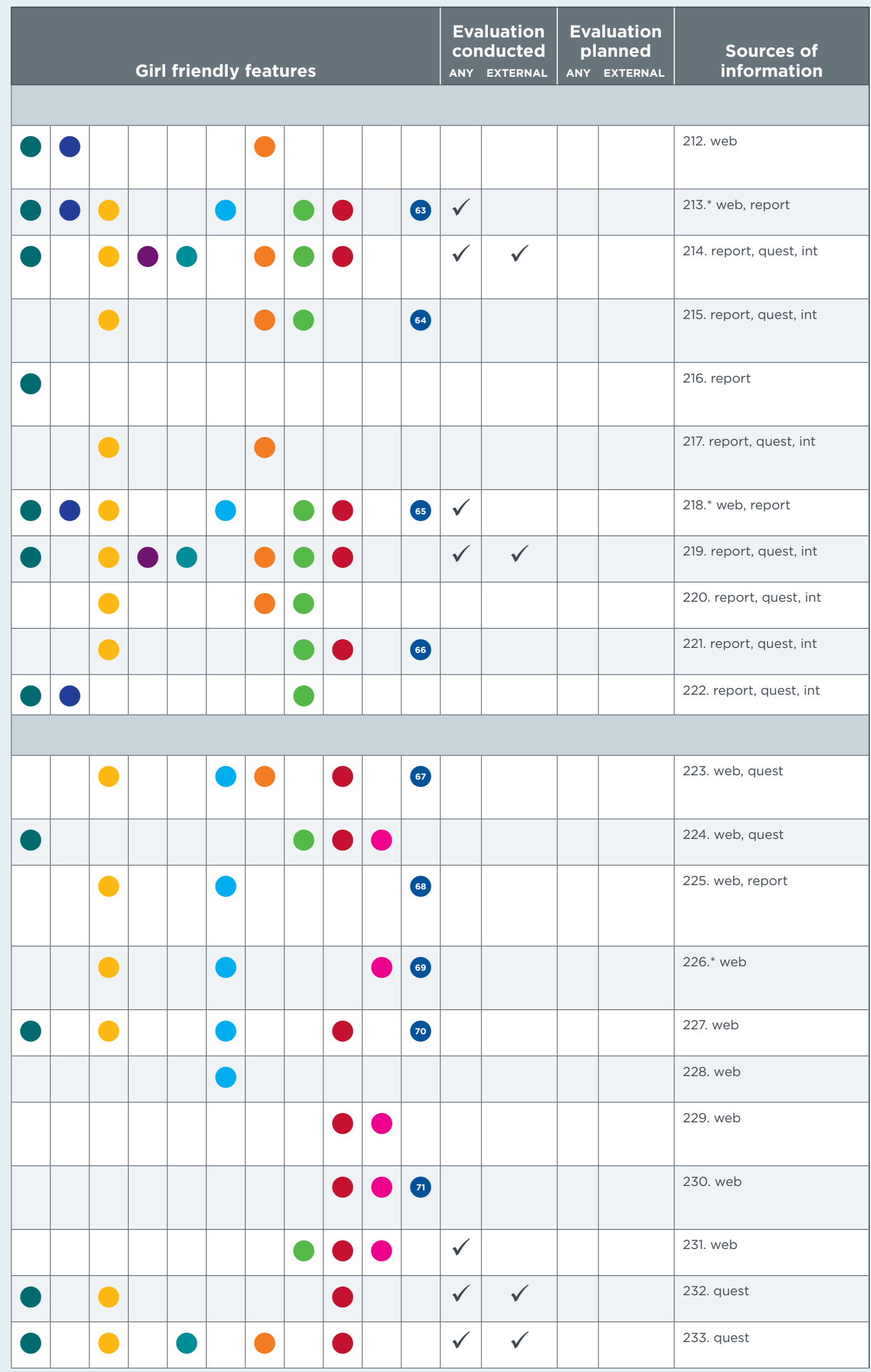

\section{PROGRAM TYPE}

Creating enabling conditions

Alternative education program

Complementary education program

Creating or enhancing formal schools

After school

\section{GIRL-FRIENDLY FEATURES}

Scholarship/stipends

Transportation/boarding

Advocacy and/or community engagement in girls' education

Safety policies and training; codes of conduct

Toilets or provision of sanitary napkins

Recruitment/training female teachers, para-teachers and other educators

Gender training for teachers

Mentoring, tutoring, peer support

Life-skills or literacy training

Livelihood or vocational training

Other

63. Support networks for young women seed money to girl school leavers starting small businesses

64. Science camps for girls.

65. Support networks for young women mens clubs to change negative attitudes about girls' and women's empowerment, mothers clubs, seed money to school leavers creating small businesses.

66. Girls are community advocates for their right to education.

67. Community-based schools located near homes.

68. Establishing "home schools" in communities with few or no schools to increase girls' access to education.

69. Establishing schools in areas with few or no secondary schools for girls.

70. Building schools in regions where there are no schools for girls.

71. Education for civic participation and peacebuilding; support to women starting small businesses. 


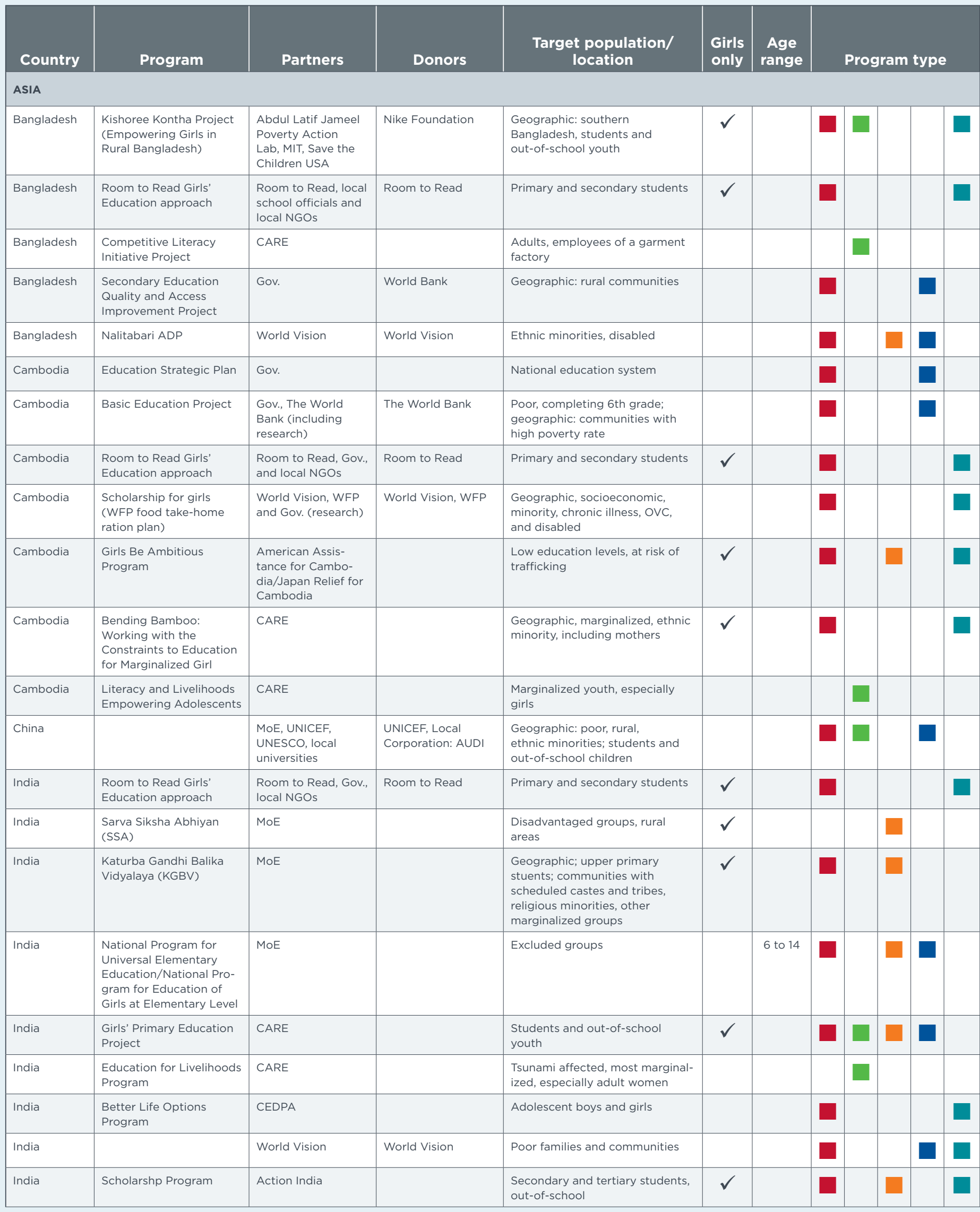




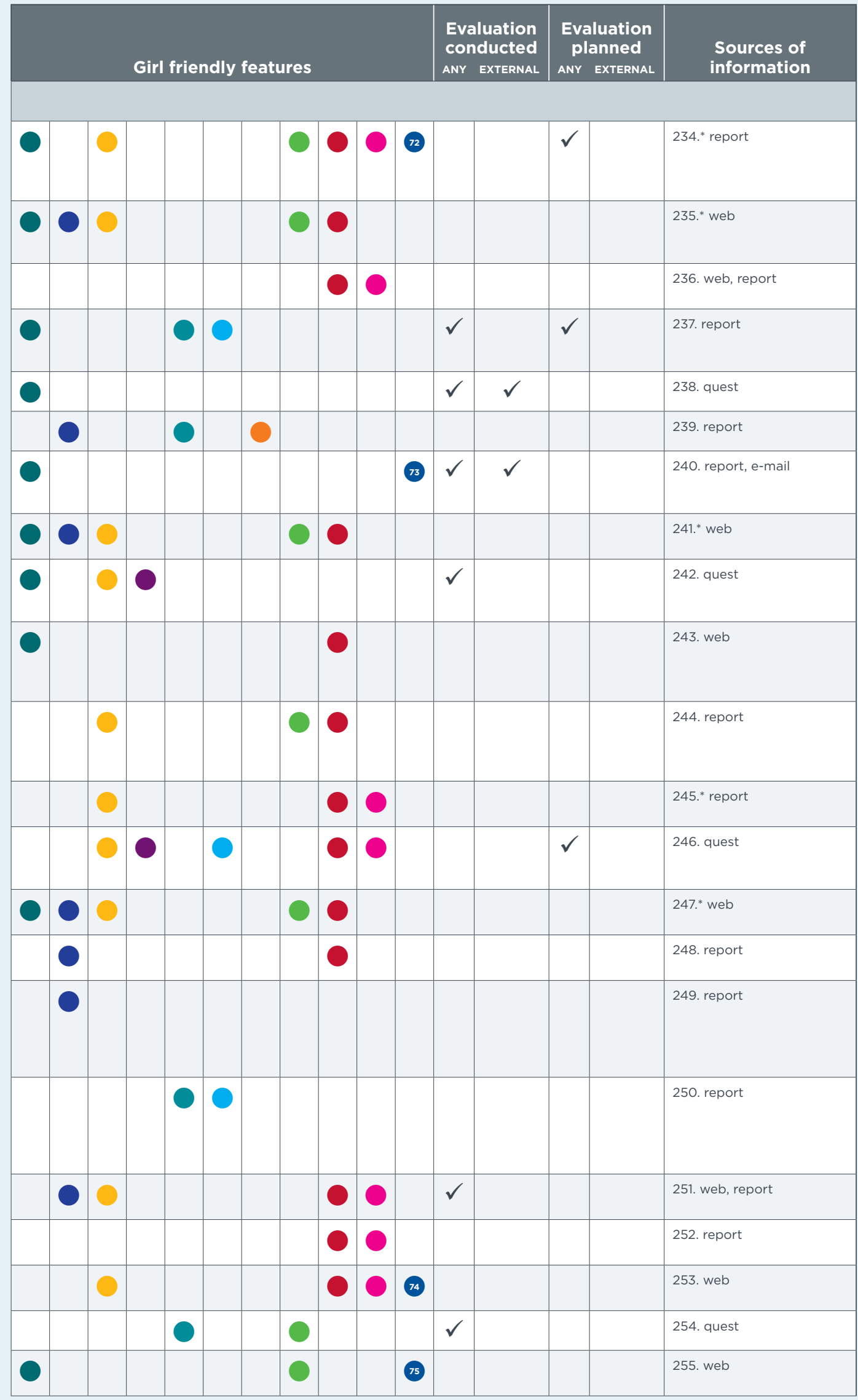

\section{PROGRAM TYPE}

Creating enabling conditions

Alternative education program

Complementary education program

Creating or enhancing formal schools

After school

\section{GIRL-FRIENDLY FEATURES}

Scholarship/stipends

Transportation/boarding

Advocacy and/or community engagement in girls' education

Safety policies and training; codes of conduct

Toilets or provision of sanitary napkins

Recruitment/training female teachers, para-teachers and other educators

Gender training for teachers

Mentoring, tutoring, peer support

Life-skills or literacy training

Livelihood or vocational training

Other

72. Four different packages of interventions to delay marriage in a pilot project. Other interventions include financial incentives to delay marriage, nutritional packages as an incentive to delay marriage.

73. Comprehensive program focuses on building schools and improving school conditions, one component of program focuses on scholarships for girls.

74. Gender training for boys; training to facilitators working with youth organizations.

75. Support for out-of-school girls taking national exams to reenroll; career counseling. 


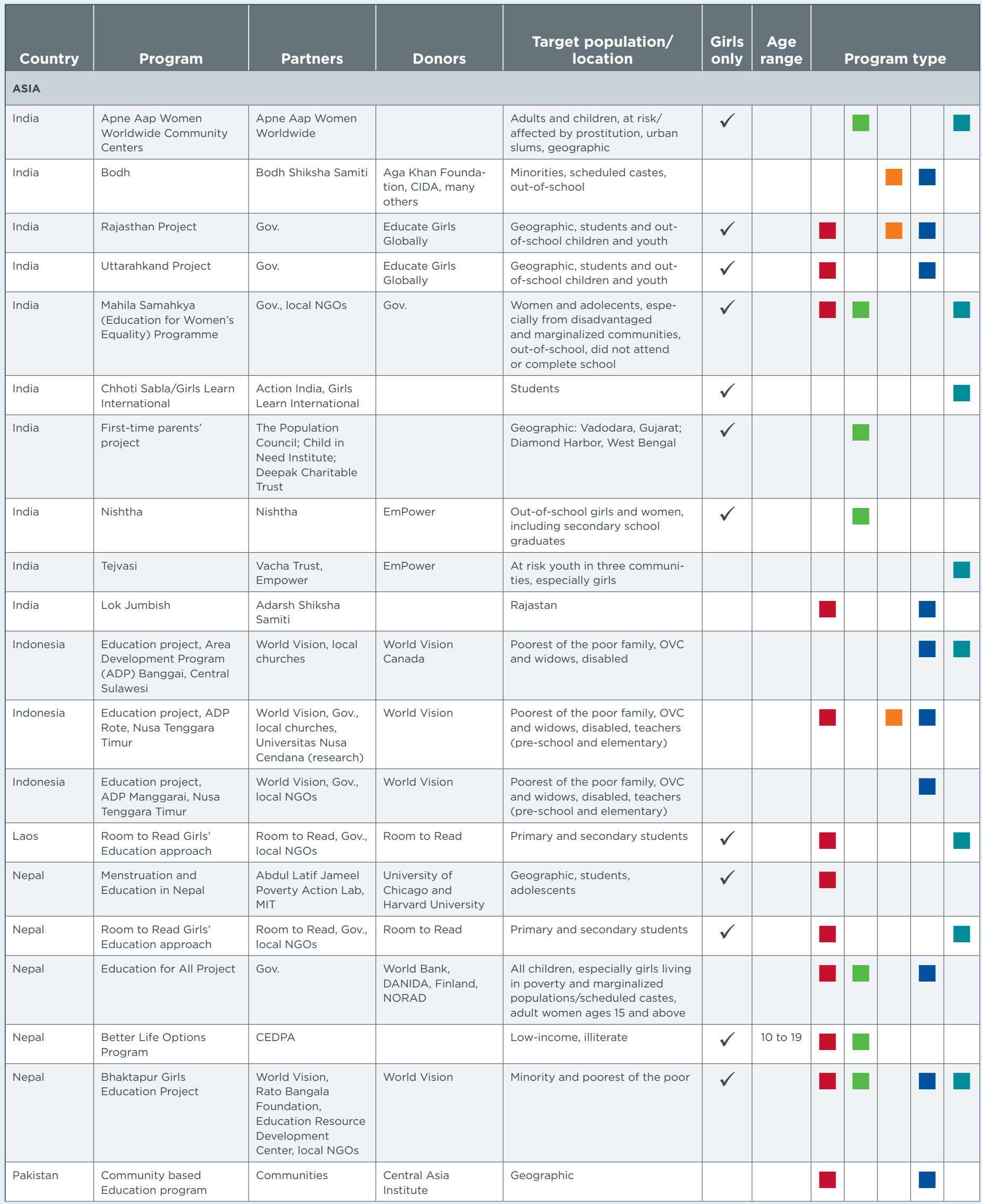




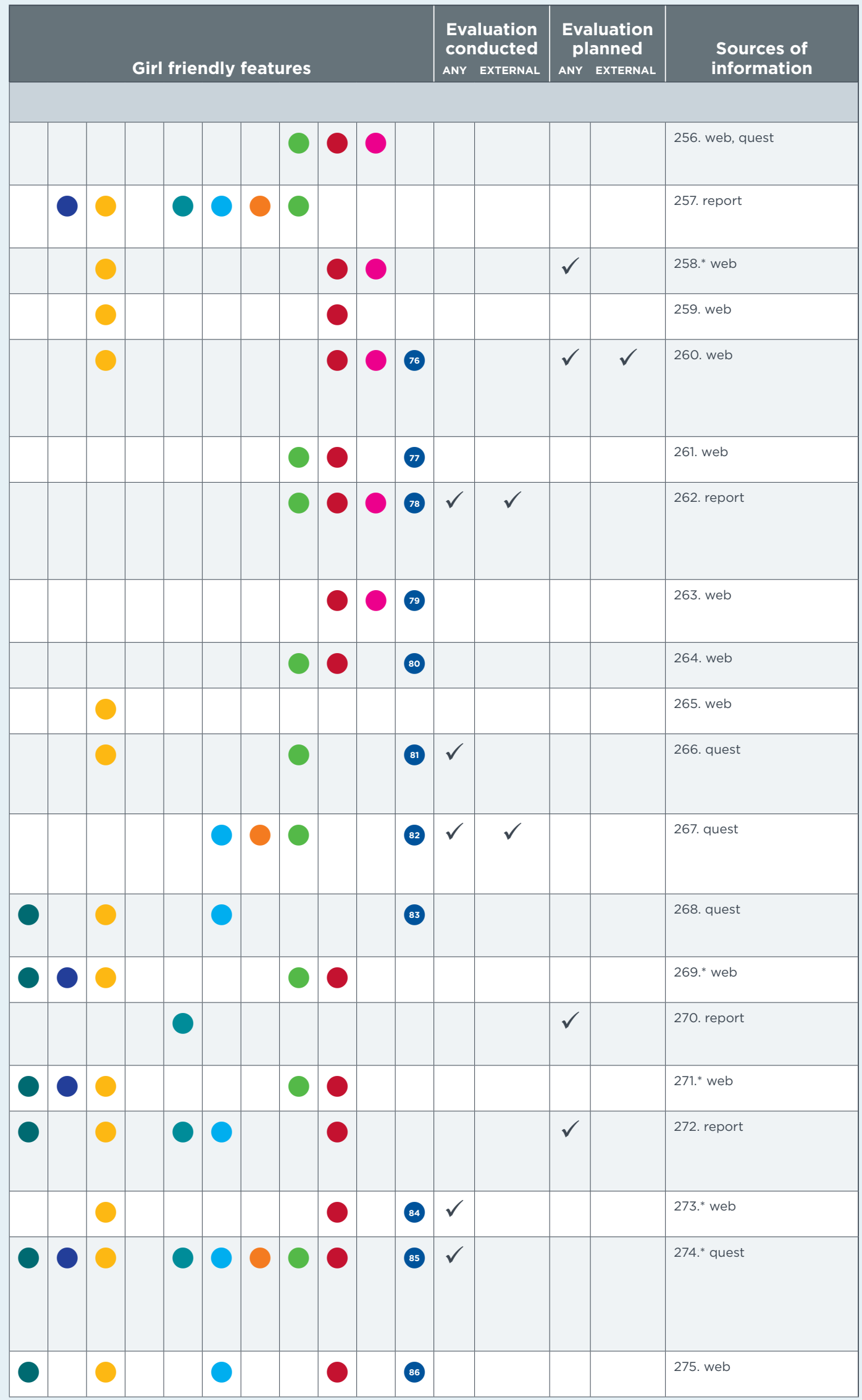

\section{PROGRAM TYPE}

Creating enabling conditions

Alternative education program

Complementary education program

Creating or enhancing formal schools

After school

\section{GIRL-FRIENDLY FEATURES}

Scholarship/stipends

Transportation/boarding

Advocacy and/or community engagement in girls' education

Safety policies and training; codes of conduct

Toilets or provision of sanitary napkins

Recruitment/training female teachers, para-teachers and other educators

Gender training for teachers

Mentoring, tutoring, peer support

Life-skills or literacy training

Livelihood or vocational training

Other

76. Women's organizations form and lead their own education and empowerment projects, including education programs for girls or support for school fees and transportation.

77. Key project activity is a cultural exchange and mentoring between girls in India and girls in the United States through ICT, to encourage their continued education.

78. Participatory education program led and run by girls in small groups.

79. Assisting women with access to savings and credit to support daughters' schooling. Vocational training and job placement support to girls who have completed secondary school.

80. Training in technology, human rights, English language instruction, arts. Field trips, mobile library, cultural arts events.

81. Training on the Convention on the Rights of Children.

82. Advocacy to reduce harmful practices (e.g. FGM, early marriage)

83. Advocacy to reduce harmful practices (e.g. FGM, early marriage)

84. Dialogues between girls, educators, health workers, and parents to advocate to leaders for girls to be the focus of health and development efforts.

85. Girls learn livelihoods/income generating skills to support themselves in continuing their studies; literacy classes for mothers; advocacy to reduce harmful practices (e.g. FGM, early marriage)

86. Construction of schools in areas with few or no educational institutions. 


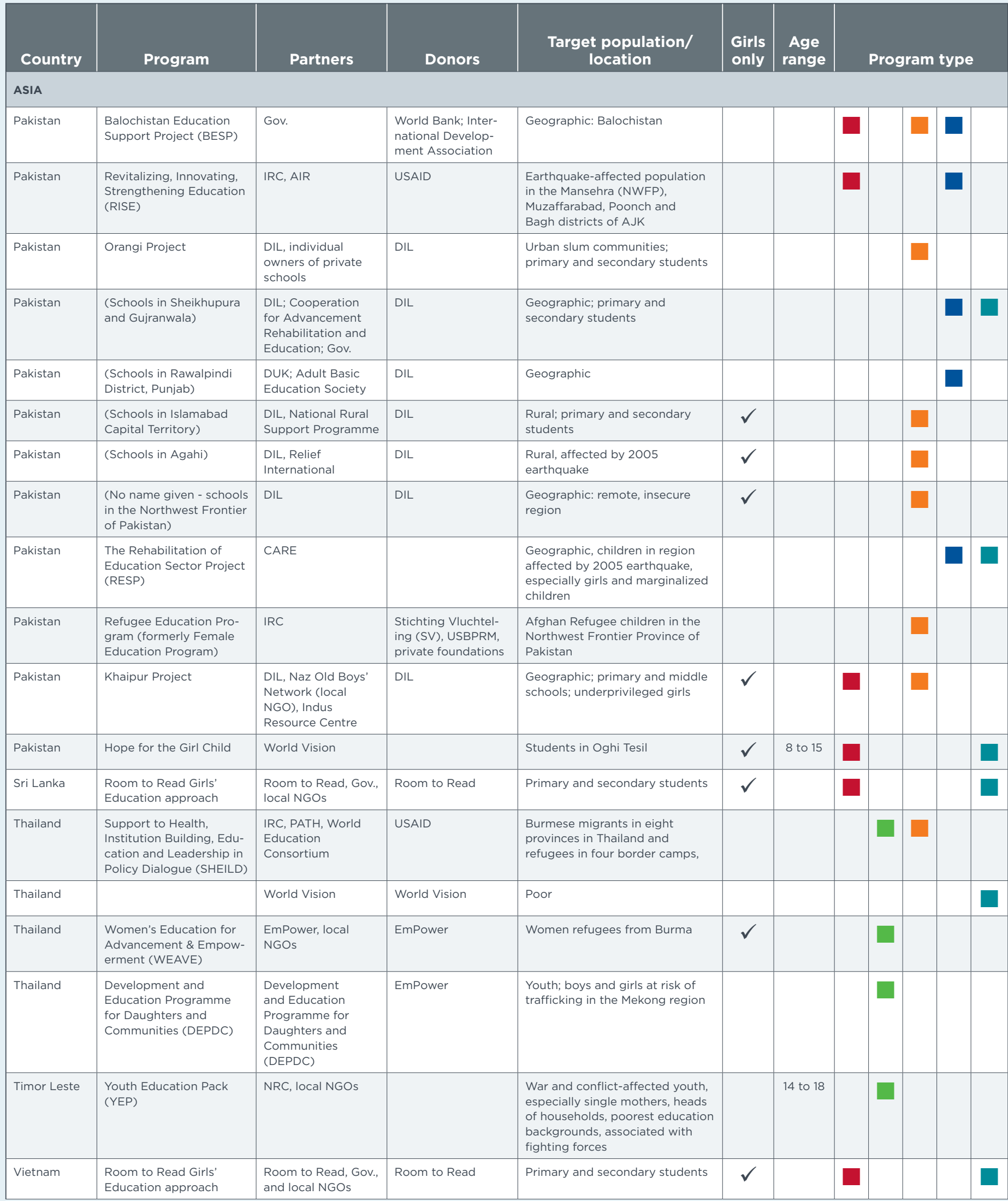




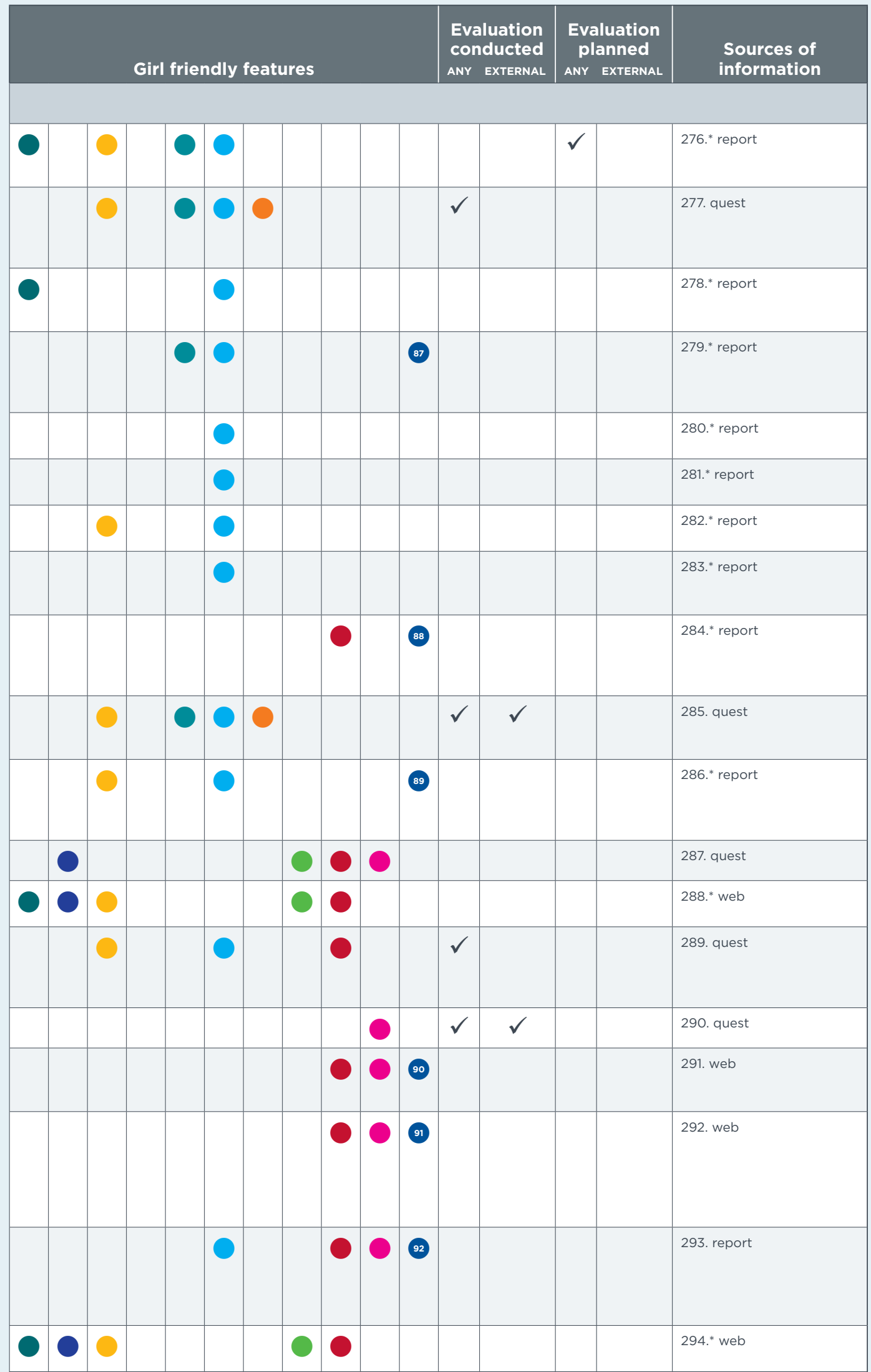

\section{PROGRAM TYPE}

Creating enabling conditions

Alternative education program

Complementary education program

Creating or enhancing formal schools

After school

\section{GIRL-FRIENDLY FEATURES}

Scholarship/stipends

Transportation/boarding

Advocacy and/or community engagement in girls' education

Safety policies and training; codes of conduct

Toilets or provision of sanitary napkins

Recruitment/training female teachers, para-teachers and other educators

Gender training for teachers

Mentoring, tutoring, peer support

Life-skills or literacy training

Livelihood or vocational training

Other

87. Curriculum enhancements include use of computers to make learning relevant for employment.

88. Extracurricular activities in which girls and boys interact outside of a segregated environment.

89. Computer classes; microcredit and income generation activities for mothers; participatory theater to advocate against practices that interfere with girls' schooling.

90. Leadership, decision-making, and planning skills for women, to support their capacity to form and lead community organizations.

91. Training for youth to lead organizations to implement trafficking prevention programs.

92. Care for children of students; meal provision; follow-up support for skil training including apprenticeships and support to forming Cooperatives. 


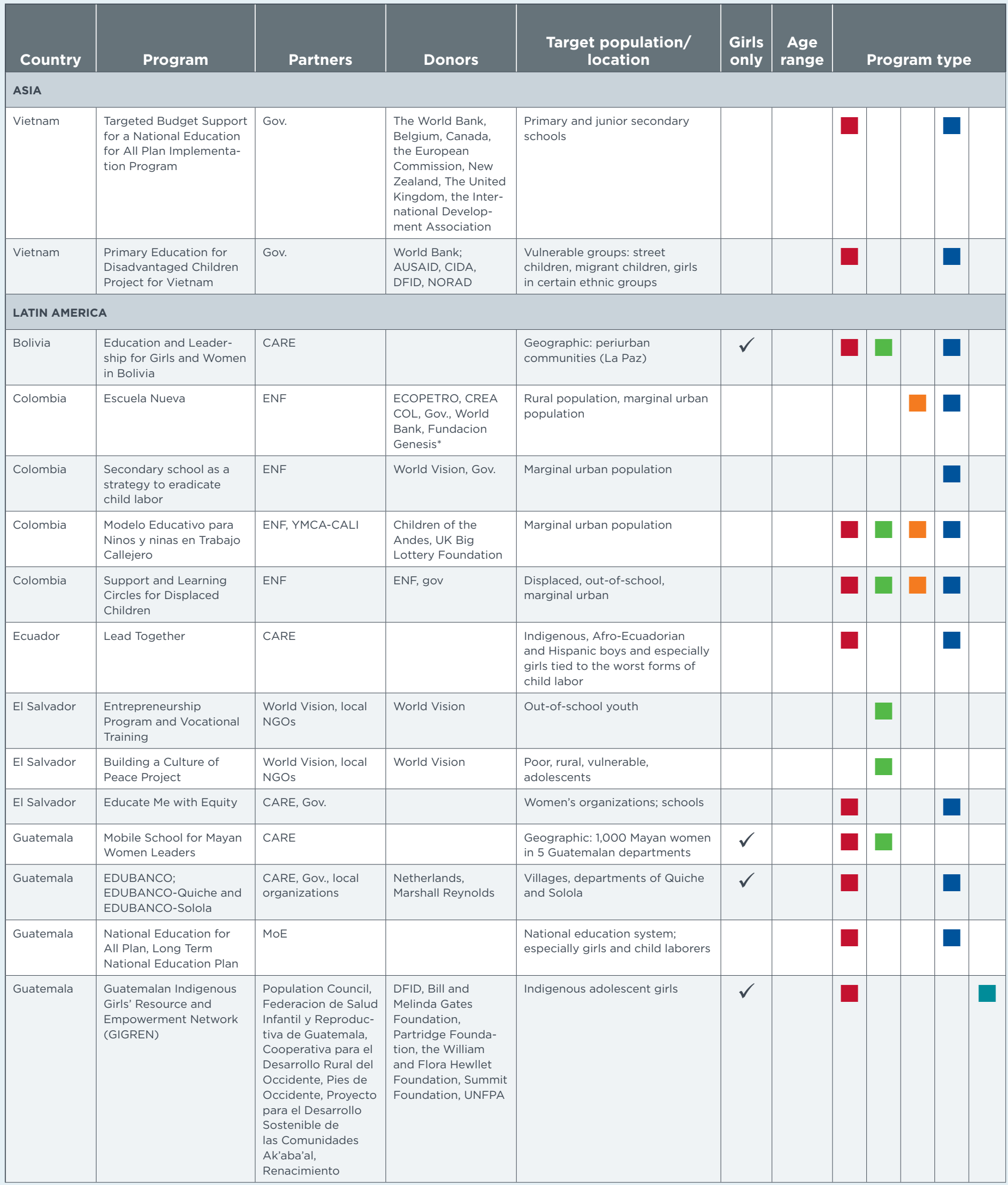




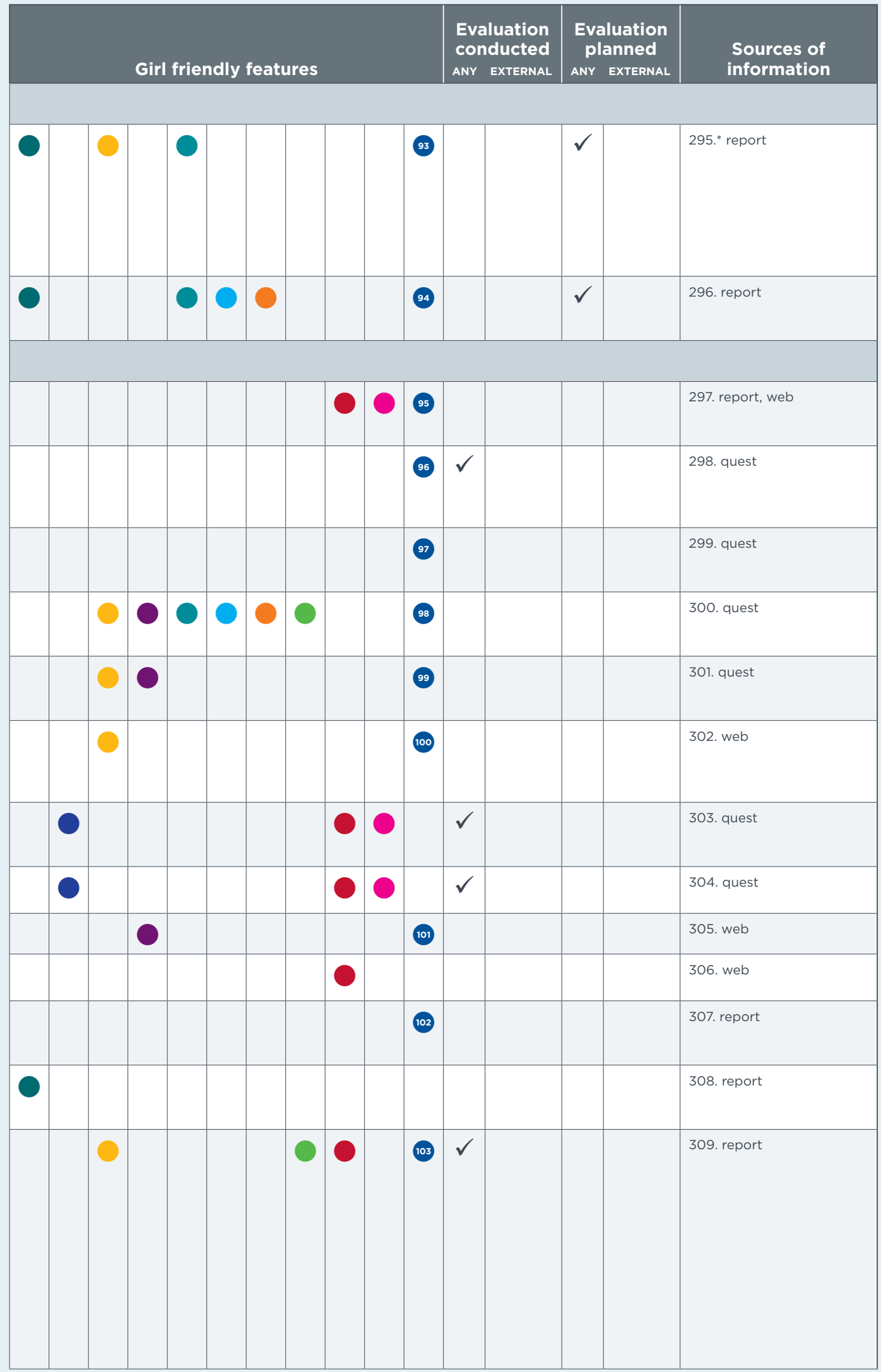

\section{PROGRAM TYPE}

Creating enabling conditions

Alternative education program

Complementary education program

Creating or enhancing formal schools

After school

\section{GIRL-FRIENDLY FEATURES}

Scholarship/stipends

Transportation/boarding

Advocacy and/or community engagement in girls' education

Safety policies and training; codes of conduct

Toilets or provision of sanitary napkins

Recruitment/training female teachers, para-teachers and other educators

Gender training for teachers

Mentoring, tutoring, peer support

Life-skills or literacy training

Livelihood or vocational training

Other

93. Promoting school administrators' and local government leaders gender awareness; collecting gender-disaggregated data.

94. Increased availability of early childhood development programs to reduce girls' time spent caring for younger siblings; systematizing collection of gender-disaggregated data in schools.

95. Incorporation of human rights, democracy and citizenship approach in the curriculum.

96. Girls' participation in school governance.

97. Girls' participation in school governance.

98. Girls' participation in schoo governance.

99. Girls' participation in school governance.

100. Advocating for policies to promote education for children vulnerable to exploitation, especially girls, and to protect them from harmful forms of labor; developing leadership capacity among girls.

101. Engagement of local women's organizations in improving gender equality in education; advocacy for Law for Teaching to create protective environment for girls in school and other policies to ensure gender equity in schools.

102. Utilizes village banks to increase income of families, and income incoring both for support to girls education.

3. Developing networks of girls for ongoing support and advocacy. 


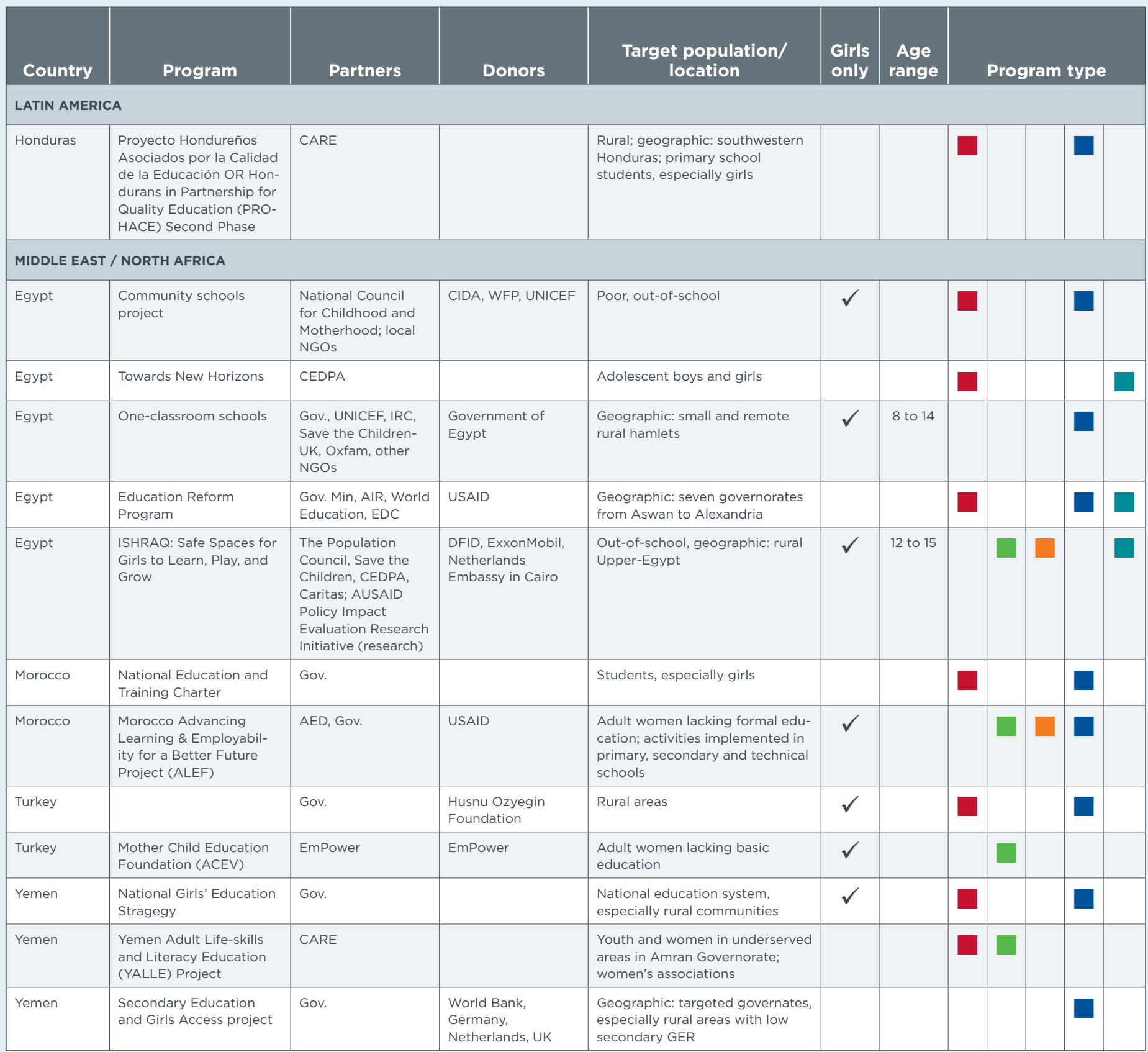




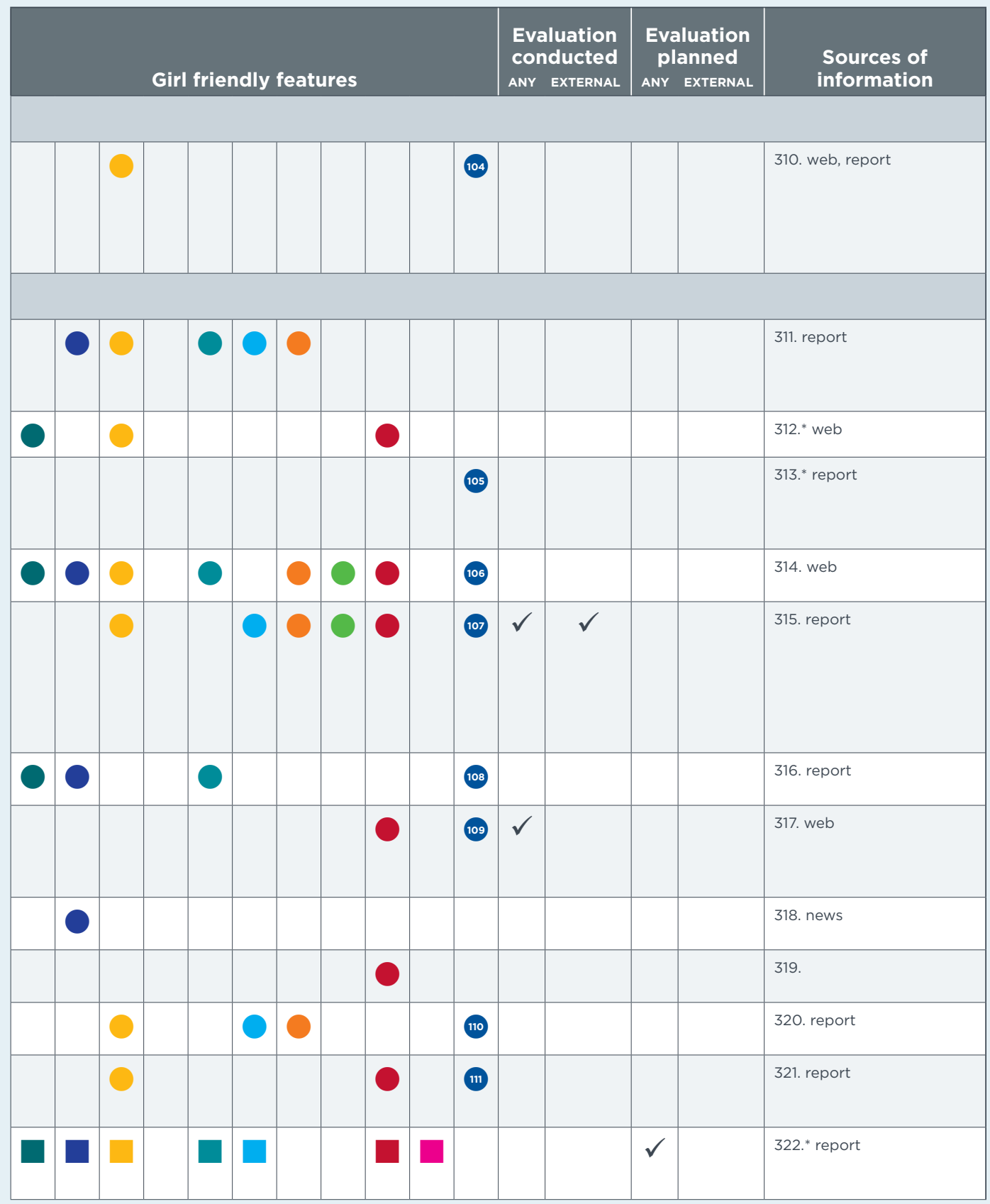

\section{PROGRAM TYPE}

Creating enabling conditions

Alternative education program

Complementary education program

Creating or enhancing formal schools

After school

\section{GIRL-FRIENDLY FEATURES}

Scholarship/stipends

Transportation/boarding

Advocacy and/or community engagement in girls' education

Safety policies and training; codes of conduct

Toilets or provision of sanitary napkins

Recruitment/training female teachers, para-teachers and other educators

Gender training for teachers

Mentoring, tutoring, peer support

Life-skills or literacy training

Livelihood or vocational training

Other

104. Increasing participatory methodologies in rural schools to enhance girls learning opportunities.

105. Combatting social/traditional obstacles to girls' access to formal education by locating the service within educationally-deprived or disadvantaged communities.

106. Obtaining birth certificates,

linking girls with vision and hearing impairments to health services, building girl-friendly environment with adminstrators and teachers.

107. Sports activities for girls.

108. School construction targets regions with low girls enrollment.

109. Training in women's legal rights.

110. Constructing all-girls and coeducational schools especially in rural areas; reducing male-only schools; gender-sensitive curriculum: capacity building to identify gaps and design strategies especially for girls education.

111. Developing women's associations capacities to implement literacy programs. 


\section{SOURCES OF INFORMATION}

1 Winrock International. "Scholarships for African Girls and Boys." (Little Rock: Winrock International). http://www. winrock.org/fact/facts.asp?CC $=5544 \&$ bu= 9056 (Consulted 13 March 2009).

2 Forum for African Women Educationalists, FAWE: 15 Years of advancing girls' education in Africa. (Nairobi, Forum for African Women Educationalists); Responses to questionnaire completed by FAWE employee. November 26, 2008; Interview with FAWE employees. March 26, 2009; E-mail from FAWE employees, March 31, 2009.

3 Forum for African Women Educationalists, FAWE: 15 Years of advancing girls' education in Africa. (Nairobi, Forum for African Women Educationalists); Responses to questionnaire completed by FAWE employee. November 26, 2008; Interview with FAWE employees. March 26, 2009; E-mail from FAWE employees, March 31, 2009.

4 USAID. "Africa Education Initiative, Ambassadors' Girls' Scholarship Program.” (Washington, DC: USAID). http://agsp.worlded.org/benin.htm (Consulted 13 March 2009).

5 Winrock International. "Scholarships for African Girls and Boys.” (Little Rock: Winrock International). http://www. winrock.org/fact/facts.asp?CC=5544\&bu= 9056 (Consulted 13 March 2009).

6 Plan International. 2008. "Girl-friendly schools see enrolment rates soar - Burkina Faso." (Warwick, Rhode Island: Plan International). http://www. plan-international.org/news/bright/ (Consulted March 9, 2009).

7 The World Bank. 2006. Project Appraisal Document on a proposed credit in the amount of SDR 16 million (US\$22.9 million equivalent) to the Republic of Burkina Faso for a Post-Primary Education Project. Washington, DC: The World Bank. http://www-wds.
worldbank.org/external/default/WDSContentServer/ WDSP/IB/2006/06/01/000012009_2006060109291 3/Rendered/INDEX/360960rev0pdf.txt (Consulted 9 March 2009).

8 Responses to questionnaire by UNGEI employee. 2008.

9 USAID. Africa Education Initiative, Ambassadors' Girls' Scholarship Program. (Washington, DC: USAID.) http://agsp.worlded.org/burkinafaso.htm (Consulted 13 March 2009).

10 Forum for African Women Educationalists, FAWE: 15 Years of advancing girls' education in Africa. (Nairobi, Forum for African Women Educationalists); Responses to questionnaire completed by FAWE employee. November 26, 2008; Interview with FAWE employees. March 26, 2009; E-mail from FAWE employees, March 31, 2009.

11 Forum for African Women Educationalists, FAWE: 15 Years of advancing girls' education in Africa. (Nairobi, Forum for African Women Educationalists); Responses to questionnaire completed by FAWE employee. November 26, 2008; Interview with FAWE employees. March 26, 2009; E-mail from FAWE employees, March 31, 2009.

12 Forum for African Women Educationalists, FAWE: 15 Years of advancing girls' education in Africa. (Nairobi, Forum for African Women Educationalists); Responses to questionnaire completed by FAWE employee. November 26, 2008; Interview with FAWE employees. March 26, 2009; E-mail from FAWE employees, March 31, 2009.

13 Forum for African Women Educationalists, FAWE: 15 Years of advancing girls' education in Africa. (Nairobi, Forum for African Women Educationalists); Responses to questionnaire completed by FAWE employee. November 26, 2008; Interview with FAWE 
employees. March 26, 2009; E-mail from FAWE employees, March 31, 2009.

14 Forum for African Women Educationalists, FAWE: 15 Years of advancing girls' education in Africa. (Nairobi, Forum for African Women Educationalists); Responses to questionnaire completed by FAWE employee. November 26, 2008; Interview with FAWE employees. March 26, 2009; E-mail from FAWE employees, March 31, 2009.

15 The World Bank. 2002. Burkina Faso Basic Education Sector Project: Overview, 22 January 2002. (Washington, DC: The World Bank). http://web. worldbank.org/external/projects/main?pagePK=6431 2881\&piPK=64302848\&theSitePK=40941\&Projectid= P000309 (Consulted 9 March 2009).

16 Brady, Martha, and Lydia Saloucou, Addressing the needs of married adolescent girls in Burkina Faso. (New York: The Population Council, 2007). www.popcouncil.org/pdfs/TABriefs/PGY_Brief09_BurkinaFaso. pdf - 2008-01-10.

17 Responses to questionnaire by UNGEI employee. 2008. UNICEF and United Nations Girls' Education Initiative. 2007. Making UNGEI Work: Lessons from Four African Countries. (Nairobi: UNICEF ESARO).

18 Response to questionnaire from World Vision employee. March 2006.

19 USAID. Africa Education Initiative, Ambassadors' Girls' Scholarship Program. (Washington, DC: USAID.) http://agsp.worlded.org/burundi.htm (Consulted 13 March 2009).

20 CARE. 2008 Basic Girls Education Project Briefs. (Atlanta: CARE, 2008).

21 Forum for African Women Educationalists, FAWE: 15 Years of advancing girls' education in Africa.
(Nairobi, Forum for African Women Educationalists); Responses to questionnaire completed by FAWE employee. November 26, 2008; Interview with FAWE employees. March 26, 2009; E-mail from FAWE employees, March 31, 2009.

${ }^{*}$ HIV/AIDS prevention training is specifically for the purpose of preventing girls from dropping out of school.

22 Forum for African Women Educationalists, FAWE: 15 Years of advancing girls' education in Africa. (Nairobi, Forum for African Women Educationalists); Responses to questionnaire completed by FAWE employee. November 26, 2008; Interview with FAWE employees. March 26, 2009; E-mail from FAWE employees, March 31, 2009.

23 The Norwegian Refugee Council. 2008. NRC Core Activity Education, Youth Education Pack in Brief, Background, Concept, Evaluations, and Development Plans. (Oslo: The Norwegian Refugee Council).

24 Forum for African Women Educationalists, FAWE: 15 Years of advancing girls' education in Africa. (Nairobi, Forum for African Women Educationalists); Responses to questionnaire completed by FAWE employee. November 26, 2008; Interview with FAWE employees. March 26, 2009; E-mail from FAWE employees, March 31, 2009.

25 Forum for African Women Educationalists, FAWE: 15 Years of advancing girls' education in Africa. (Nairobi, Forum for African Women Educationalists); Responses to questionnaire completed by FAWE employee. November 26, 2008; Interview with FAWE employees. March 26, 2009; E-mail from FAWE employees, March 31, 2009.

26 Academy for Educational Development. Ambassadors Girls Scholarship Program (AGSP). (Washington, 
DC: Academy for Educational Development). http:// www.aed.org/Projects/AGSP_Africa.cfm.

27 Forum for African Women Educationalists, FAWE: 15 Years of advancing girls' education in Africa. (Nairobi, Forum for African Women Educationalists); Responses to questionnaire completed by FAWE employee. November 26, 2008; Interview with FAWE employees. March 26, 2009; E-mail from FAWE employees, March 31, 2009.

28 Forum for African Women Educationalists, FAWE: 15 Years of advancing girls' education in Africa. (Nairobi, Forum for African Women Educationalists); Responses to questionnaire completed by FAWE employee. November 26, 2008; Interview with FAWE employees. March 26, 2009; E-mail from FAWE employees, March 31, 2009.

29 Forum for African Women Educationalists, FAWE: 15 Years of advancing girls' education in Africa. (Nairobi, Forum for African Women Educationalists); Responses to questionnaire completed by FAWE employee. November 26, 2008; Interview with FAWE employees. March 26, 2009; E-mail from FAWE employees, March 31, 2009.

30 Forum for African Women Educationalists, FAWE: 15 Years of advancing girls' education in Africa. (Nairobi, Forum for African Women Educationalists); Responses to questionnaire completed by FAWE employee. November 26, 2008; Interview with FAWE employees. March 26, 2009; E-mail from FAWE employees, March 31, 2009.

31 Academy for Educational Development. Ambassadors Girls Scholarship Program (AGSP). (Washington, DC: Academy for Educational Development). http:// www.aed.org/Projects/AGSP_Africa.cfm.

32The Norwegian Refugee Council, 2008. NRC Core Activity Education, Youth Education Pack in Brief, Background, Concept, Evaluations, and Development Plans. (Oslo: The Norwegian Refugee Council).

33 Forum for African Women Educationalists, FAWE: 15 Years of advancing girls' education in Africa. (Nairobi, Forum for African Women Educationalists); Responses to questionnaire completed by FAWE employee. November 26, 2008; Interview with FAWE employees. March 26, 2009; E-mail from FAWE employees, March 31, 2009.

34 Winrock International. "Scholarships for African Girls and Boys." (Little Rock: Winrock International). http://www. winrock.org/fact/facts. asp?CC=5544\&bu=9056 (Consulted 13 March 2009).

35 Response to questionnaire from World Vision employee. March 2006.

36 The Norwegian Refugee Council, 2008. NRC Core Activity Education, Youth Education Pack in Brief, Background, Concept, Evaluations, and Development Plans. (Oslo: The Norwegian Refugee Council).

37 Response to questionnaires from International Rescue Committee e-mail. January 14, 2009.

38 The Norwegian Refugee Council, 2008. NRC Core Activity Education, Youth Education Pack in Brief, Background, Concept, Evaluations, and Development Plans. (Oslo: The Norwegian Refugee Council).

39 Academy for Educational Development. Ambassadors Girls Scholarship Program (AGSP). (Washington, DC: Academy for Educational Development). http:// www.aed.org/Projects/AGSP_Africa.cfm.

40 Academy for Educational Development. Ambassadors Girls Scholarship Program (AGSP). (Washington, DC: Academy for Educational Development). http:// www.aed.org/Projects/AGSP_Africa.cfm.

41 Responses to questionnaire by UNGEI employee. 2008.

42 Academy for Educational Development Center for Gender Equity, Eritrea: Ambassadors Girls Scholarship Program http://cge.aed.org/Projects/SSAfrica/ AGSP_Eritrea.cfm.

43 Anís, Katy, Ethiopia: Nonformal and basic education activity descriptions. Country Profile Prepared for the Education for All Global Monitoring Report, Education for All: will we make it by 2015. (Paris: UNESCO, 2007).

44 Anís, Katy, Ethiopia: Nonformal and basic education activity descriptions. Country Profile Prepared 
for the Education for All Global Monitoring Report, Education for All: will we make it by 2015. (Paris: UNESCO, 2007).

45 UNESCO. 2007. Education for All by 2015: Will we make it? (Paris: UNESCO).

46 Anís, Katy, Ethiopia: Nonformal and basic education activity descriptions. Country Profile Prepared for the Education for All Global Monitoring Report, Education for All: will we make it by 2015. (Paris: UNESCO, 2007)

47 Forum for African Women Educationalists, FAWE: 15 Years of advancing girls' education in Africa. (Nairobi, Forum for African Women Educationalists); Responses to questionnaire completed by FAWE employee. November 26, 2008; Interview with FAWE employees. March 26, 2009; E-mail from FAWE employees, March 31, 2009.

48 Forum for African Women Educationalists, FAWE: 15 Years of advancing girls' education in Africa. (Nairobi, Forum for African Women Educationalists); Responses to questionnaire completed by FAWE employee. November 26, 2008; Interview with FAWE employees. March 26, 2009; E-mail from FAWE employees, March 31, 2009.

49 The Norwegian Refugee Council, 2008. NRC Core Activity Education, Youth Education Pack in Brief, Background, Concept, Evaluations, and Development Plans. (Oslo: The Norwegian Refugee Council).

50 Response to questionnaire from World Vision employee. March 2006.

51 Anís, Katy, Ethiopia: Nonformal and basic education activity descriptions. Country Profile Prepared for the Education for All Global Monitoring Report, Education for All: will we make it by 2015. (Paris: UNESCO, 2007).

52 CARE. 2008 Basic Girls Education Project Briefs. (Atlanta: CARE, 2008).

53 Academy for Educational Development. Ambassadors Girls Scholarship Program (AGSP). (Washington, DC: Academy for Educational Development). http:// www.aed.org/Projects/AGSP_Africa.cfm.
54 Erulkar, Annabelle, and Tekle-ab Mekbib, Reaching Vulnerable Youth in Ethiopia. The Population Council, 2007.

55 Erulkar, Annabelle, and Tekle-ab Mekbib, Reaching Vulnerable Youth in Ethiopia. The Population Council, 2007.

56 Forum for African Women Educationalists, FAWE: 15 Years of advancing girls' education in Africa. (Nairobi, Forum for African Women Educationalists); Responses to questionnaire completed by FAWE employee. November 26, 2008; Interview with FAWE employees. March 26, 2009; E-mail from FAWE employees, March 31, 2009.

57 Forum for African Women Educationalists, FAWE: 15 Years of advancing girls' education in Africa. (Nairobi, Forum for African Women Educationalists); Responses to questionnaire completed by FAWE employee. November 26, 2008; Interview with FAWE employees. March 26, 2009; E-mail from FAWE employees, March 31, 2009.

58 Winrock International. "Scholarships for African Girls and Boys." (Little Rock: Winrock International). http://www.winrock.org/fact/ facts. asp?CC $=5544 \&$ bu $=9056$ (Consulted 13 March 2009).

59 USAID, Africa Education Initiative, Ambassadors' Girls' Scholarship Program. (Washington, DC: USAID) http://agsp.worlded.org/gambia.htm (Consulted 13 March 2009).

60 Forum for African Women Educationalists, FAWE: 15 Years of advancing girls' education in Africa. (Nairobi, Forum for African Women Educationalists); Responses to questionnaire completed by FAWE employee. November 26, 2008; Interview with FAWE employees. March 26, 2009; E-mail from FAWE employees, March 31, 2009.

61 Forum for African Women Educationalists, FAWE: 15 Years of advancing girls' education in Africa. (Nairobi, Forum for African Women Educationalists); Responses to questionnaire completed by FAWE employee. November 26, 2008; Interview with FAWE employees. March 26, 2009; E-mail from FAWE employees, March 31, 2009. 
62 Forum for African Women Educationalists, FAWE: 15 Years of advancing girls' education in Africa. (Nairobi, Forum for African Women Educationalists); Responses to questionnaire completed by FAWE employee. November 26, 2008; Interview with FAWE employees. March 26, 2009; E-mail from FAWE employees, March 31, 2009.

63 Forum for African Women Educationalists, FAWE: 15 Years of advancing girls' education in Africa. (Nairobi, Forum for African Women Educationalists); Responses to questionnaire completed by FAWE employee. November 26, 2008; Interview with FAWE employees. March 26, 2009; E-mail from FAWE employees, March 31, 2009.

64 Responses to questionnaire by UNGEI employee. 2008.

65 Plan International, 2007."Girl-friendly latrines reduce school absenteeism" (Warwick, Ri: Plan International) http://www.plan-international.org/ wherewework/westafrica/ghana/ghanalatrines/ (Consulted 9 March 2009).

66 Forum for African Women Educationalists. FAWE: 15 Years of advancing girls' education in Africa. (Nairobi: Forum for African Women Educationalists). Responses to questionnaire completed by FAWE employee. November 26, 2008. Interview with FAWE employee. March 26, 2009.

67 Forum for African Women Educationalists, FAWE: 15 Years of advancing girls' education in Africa. (Nairobi, Forum for African Women Educationalists); Responses to questionnaire completed by FAWE employee. November 26, 2008; Interview with FAWE employees. March 26, 2009; E-mail from FAWE employees, March 31, 2009.

68 Response to questionnaire from World Vision employee. March 2006.

69 CARE. 2008 Basic Girls Education Project Briefs. (Atlanta: CARE, 2008).

70 USAID, Africa Education Initiative, Ambassadors' Girls' Scholarship Program. (Washington, DC: USAID) http://agsp.worlded.org/ghana.htm (Consulted 13 March 2009).
71 CAMFED, "CAMFED's Response." (Cambridge, CAMFED International) http://us.camfed.org/where/ ghana/response.html (Consulted 9 March 2009); CAMFED International, CAMFED International Strategic Plan 2006 - 2010 (Cambridge: CAMFED International, 2006).

* For young women lacking formal education, business management, internships, seed money. For women teachers, training and student teaching.

72 Forum for African Women Educationalists, FAWE: 15 Years of advancing girls' education in Africa. (Nairobi, Forum for African Women Educationalists); Responses to questionnaire completed by FAWE employee. November 26, 2008; Interview with FAWE employees. March 26, 2009; E-mail from FAWE employees, March 31, 2009.

73 Forum for African Women Educationalists, FAWE 15 Years of advancing girls' education in Africa. (Nairobi, Forum for African Women Educationalists); Responses to questionnaire completed by FAWE employee. November 26, 2008; Interview with FAWE employees. March 26, 2009; E-mail from FAWE employees, March 31, 2009.

74 Forum for African Women Educationalists, FAWE: 15 Years of advancing girls' education in Africa. (Nairobi, Forum for African Women Educationalists); Responses to questionnaire completed by FAWE employee. November 26, 2008; Interview with FAWE employees. March 26, 2009; E-mail from FAWE employees, March 31, 2009.

75 Forum for African Women Educationalists, FAWE: 15 Years of advancing girls' education in Africa. (Nairobi, Forum for African Women Educationalists); Responses to questionnaire completed by FAWE employee. November 26, 2008; Interview with FAWE employees. March 26, 2009; E-mail from FAWE employees, March 31, 2009.

76 Forum for African Women Educationalists, FAWE: 15 Years of advancing girls' education in Africa. (Nairobi, Forum for African Women Educationalists); Responses to questionnaire completed by FAWE employee. November 26, 2008; Interview with FAWE employees. March 26, 2009; E-mail from FAWE employees, March 31, 2009. 
77 Response to questionnaires from International Rescue Committee. January 14, 2009.

78 The Academy for Educational Development, Girls Secondary Education in Guinea and Tanzania Project. (Washington, DC: The Academy for Educational Development). http://cge.aed.org/Projects/SSAfrica/ Copy-of-girlssecondary_guinea.cfm, (Consulted 9 March 2009).

79 The Academy for Educational Development, "Improving Girls' Primary Education in Three Countries." (Washington, DC: The Academy for Educational Development) http://cge.aed.org/ Projects/SSAfrica/c_guinea_girlsprimary.cfm (Consulted 9 March 2009).

* Scholarships in the form of educational materials to all students; tutoring to girl students.

80 USAID, Africa Education Initiative, Ambassadors' Girls' Scholarship Program. (Washington, DC: USAID) http://agsp.worlded.org/guinea.htm (Consulted 13 March 2009).

81 Forum for African Women Educationalists, FAWE: 15 Years of advancing girls' education in Africa. (Nairobi, Forum for African Women Educationalists); Responses to questionnaire completed by FAWE employee. November 26, 2008; Interview with FAWE employees. March 26, 2009; E-mail from FAWE employees, March 31, 2009.

* Instruction in polytechnics is included in the curriculum as a job-related skill.

82 Response to questionnaire from World Vision employee. March 2006.

83 Maasai Girls Education Fund. http://www.maasaigirlseducation.org/about/index.html (Consulted 10 March 2009).

84 Forum for African Women Educationalists, FAWE: 15 Years of advancing girls' education in Africa. (Nairobi, Forum for African Women Educationalists); Responses to questionnaire completed by FAWE employee. November 26, 2008; Interview with FAWE employees. March 26, 2009; E-mail from FAWE employees, March 31, 2009.
85 Forum for African Women Educationalists, FAWE: 15 Years of advancing girls' education in Africa. (Nairobi, Forum for African Women Educationalists); Responses to questionnaire completed by FAWE employee. November 26, 2008; Interview with FAWE employees. March 26, 2009; E-mail from FAWE employees, March 31, 2009.

86 Forum for African Women Educationalists, FAWE: 15 Years of advancing girls' education in Africa. (Nairobi, Forum for African Women Educationalists); Responses to questionnaire completed by FAWE employee. November 26, 2008; Interview with FAWE employees. March 26, 2009; E-mail from FAWE employees, March 31, 2009.

87 Academy for Educational Development. Ambassadors Girls Scholarship Program (AGSP). (Washington, DC: Academy for Educational Development). http:// www.aed.org/Projects/AGSP_Africa.cfm.

88 Educational Quality Improvement Program, "Education Support for Children of Marginalized Populations (EMACK), Kenya," http://www.equip123. net/webarticles/anmviewer.asp?a=348\&z=16 (Consulted 10 March 2009).

89 Forum for African Women Educationalists, FAWE: 15 Years of advancing girls' education in Africa. (Nairobi, Forum for African Women Educationalists); Responses to questionnaire completed by FAWE employee. November 26, 2008; Interview with FAWE employees. March 26, 2009; E-mail from FAWE employees, March 31, 2009.

90 Eruklar, Annabelle, Judith Bruce, Erica Chong, Aleke Dondo, Jennefer Sebstad, James Matheka, Arjmand Banu Khan, Anne Gathuku, Tap and Reposition Youth (TRY): Providing social Support, microcredit and savings opportunities for young women in areas with high HIV prevalence. (New York: The Population Council, 2007).

91 The Norwegian Refugee Council, 2008. NRC Core Activity Education, Youth Education Pack in Brief, Background, Concept, Evaluations, and Development Plans. (Oslo: The Norwegian Refugee Council). 
92 Christian Children's Fund, "Turning Child Brides into Scholars" http://www.christianchildrensfund.org/ content.aspx?id=792 (Consulted 2 May 2009).

93 The Center for Development and Population Activities, "Where We Work - South Africa" (Washington, DC: The Center for Development and Population Activities). http://www.cedpa.org/ section/wherewework/southafrica (Consulted 10 March 2009); CEDPA, Reaching out to Young Girls in Southern Africa: Towards a Better Future. (Washington, DC: The Center for Development and Population Activities, 2008).

94 Winrock International. "Scholarships for African Girls and Boys." (Little Rock: Winrock International). www. winrock.org/fact/facts.ask?CC=5544\&bu= (Consulted 13 March 2009).

95 Forum for African Women Educationalists, FAWE: 15 Years of advancing girls' education in Africa. (Nairobi, Forum for African Women Educationalists); Responses to questionnaire completed by FAWE employee. November 26, 2008; Interview with FAWE employees. March 26, 2009; E-mail from FAWE employees, March 31, 2009.

96 Responses to questionnaire by UNGEI employee. 2008.

97 Response to questionnaires from International Rescue Committee. January 14, 2009.

98 USAID, Africa Education Initiative: Ambassador's Girls' Scholarship Program Replaces Child Labor with Homework in Liberia, 21 December 2007. http://www. usaid.gov/locations/sub-saharan_africa/features/ aei_liberia.html (Consulted 13 March 2009).

99 Forum for African Women Educationalists, FAWE: 15 Years of advancing girls' education in Africa. (Nairobi, Forum for African Women Educationalists); Responses to questionnaire completed by FAWE employee. November 26, 2008; Interview with FAWE employees. March 26, 2009; E-mail from FAWE employees, March 31, 2009.

100 The Norwegian Refugee Council, 2008. NRC Core Activity Education, Youth Education Pack in Brief, Background, Concept, Evaluations, and Devel- opment Plans. (Oslo: The Norwegian

Refugee Council).

101 Forum for African Women Educationalists, FAWE: 15 Years of advancing girls' education in Africa. (Nairobi, Forum for African Women Educationalists); Responses to questionnaire completed by FAWE employee. November 26, 2008; Interview with FAWE employees. March 26, 2009; E-mail from FAWE employees, March 31, 2009.

102 Winrock International. "Scholarships for African Girls and Boys." (Little Rock: Winrock International). http://www. winrock.org/fact/facts. asp?CC=5544\&bu=9056 (Consulted 13 March 2009).

103 CARE, Literacy and Livelihoods Empowering Adolescents Project. (Atlanta: CARE). http://www. care.org/careswork/projects/MWI029.asp (Consulted April 2009).

104 Swann, Celia, Malawi: Nonformal education. Country Profile Prepared for the Education for All Global Monitoring Report, Education for All: will we make it by 2015. (Paris: UNESCO, 2007).

105 Save the Children, Annual Report to Nike Foundation: "Strengthening Adolescent Girls' Voices" Project in Malawi, June 2006-May 2007, Revised October 2007."

106 Forum for African Women Educationalists, FAWE: 15 Years of advancing girls' education in Africa. (Nairobi, Forum for African Women Educationalists); Responses to questionnaire completed by FAWE employee. November 26, 2008; Interview with FAWE employees. March 26, 2009; E-mail from FAWE employees, March 31, 2009.

107 Forum for African Women Educationalists, FAWE: 15 Years of advancing girls' education in Africa. (Nairobi, Forum for African Women Educationalists); Responses to questionnaire completed by FAWE employee. November 26, 2008; Interview with FAWE employees. March 26, 2009; E-mail from FAWE employees, March 31, 2009.

108 Forum for African Women Educationalists. FAWE: 15 Years of advancing girls' education in Africa. (Nairobi: Forum for African Women Educationalists). 
109 Response to questionnaire from World Vision employee. March 2006.

110 CARE. 2008 Basic Girls Education Project Briefs. (Atlanta: CARE, 2008).

111 Forum for African Women Educationalists, FAWE: 15 Years of advancing girls' education in Africa. (Nairobi, Forum for African Women Educationalists); Responses to questionnaire completed by FAWE employee. November 26, 2008; Interview with FAWE employees. March 26, 2009; E-mail from FAWE employees, March 31, 2009.

112 Forum for African Women Educationalists, FAWE: 15 Years of advancing girls' education in Africa. (Nairobi, Forum for African Women Educationalists); Responses to questionnaire completed by FAWE employee. November 26, 2008; Interview with FAWE employees. March 26, 2009; E-mail from FAWE employees, March 31, 2009.

113 Forum for African Women Educationalists, FAWE: 15 Years of advancing girls' education in Africa. (Nairobi, Forum for African Women Educationalists); Responses to questionnaire completed by FAWE employee. November 26, 2008; Interview with FAWE employees. March 26, 2009; E-mail from FAWE employees, March 31, 2009.

114 Forum for African Women Educationalists, FAWE: 15 Years of advancing girls' education in Africa. (Nairobi, Forum for African Women Educationalists); Responses to questionnaire completed by FAWE employee. November 26, 2008; Interview with FAWE employees. March 26, 2009; E-mail from FAWE employees, March 31, 2009.

115 Response to questionnaire from World Vision employee. March 2006.

116 Forum for African Women Educationalists, FAWE: 15 Years of advancing girls' education in Africa. (Nairobi, Forum for African Women Educationalists); Responses to questionnaire completed by FAWE employee. November 26, 2008; Interview with FAWE employees. March 26, 2009; E-mail from FAWE employees, March 31, 2009.
117 USAID, Africa Education Initiative, Ambassadors' Girls' Scholarship Program. (Washington, DC: USAID) http://agsp.worlded.org/mali.htm (Consulted 13 March 2009).

118 CARE. 2008 Basic Girls Education Project Briefs. (Atlanta: CARE, 2008). Interview with CARE employee, January 23, 2009. Bamako, Mali. Interview with CARE employees and partners, January 27, 2009. Barasara Commune, Mali.

119 Interview, Institut pour l'Education Populaire employees and partners. February 6, 2009. Bamako, Mali.

120 Forum for African Women Educationalists, FAWE: 15 Years of advancing girls' education in Africa. (Nairobi, Forum for African Women Educationalists); Responses to questionnaire completed by FAWE employee. November 26, 2008; Interview with FAWE employees. March 26, 2009; E-mail from FAWE employees, March 31, 2009.

121 USAID, Africa Education Initiative, Ambassadors' Girls' Scholarship Program. (Washington, DC: USAID) http://agsp.worlded.org/mauritania.htm (Consulted 13 March 2009) Response to questionnaire from United States Peace Corps employee, March 18, 2009.

122 Forum for African Women Educationalists, FAWE: 15 Years of advancing girls' education in Africa. (Nairobi, Forum for African Women Educationalists); Responses to questionnaire completed by FAWE employee. November 26, 2008; Interview with FAWE employees. March 26, 2009; E-mail from FAWE employees, March 31, 2009.

123 Forum for African Women Educationalists, FAWE: 15 Years of advancing girls' education in Africa. (Nairobi, Forum for African Women Educationalists); Responses to questionnaire completed by FAWE employee. November 26, 2008; Interview with FAWE employees. March 26, 2009; E-mail from FAWE employees, March 31, 2009.

124 Response to questionnaire from World Vision employee. March 2006. 
125 CARE. 2008 Basic Girls Education Project Briefs. (Atlanta: CARE, 2008).

126 Forum for African Women Educationalists. FAWE: 15 Years of advancing girls' education in Africa. (Nairobi: Forum for African Women Educationalists).

127 UNESCO. 2007. Education for All by 2015: Will we make it? (Paris: UNESCO).

128 Winrock International. "Scholarships for African Girls and Boys." (Little Rock: Winrock International). www. winrock.org/fact/facts.ask?CC $=5544 \& b u=$ (Consulted 13 March 2009).

129 Christian Children's Fund, 2006. "CCF is Bringing New Life to Village Schools in Mozambique." (Richmond: Christian Children's Fund). http://www. christianchildrensfund.org/content.aspx?id=3831 (Consulted 2 May 2009) .

130 Forum for African Women Educationalists, FAWE: 15 Years of advancing girls' education in Africa. (Nairobi, Forum for African Women Educationalists); Responses to questionnaire completed by FAWE employee. November 26, 2008; Interview with FAWE employees. March 26, 2009; E-mail from FAWE employees, March 31, 2009.

131 Forum for African Women Educationalists, FAWE: 15 Years of advancing girls' education in Africa. (Nairobi, Forum for African Women Educationalists); Responses to questionnaire completed by FAWE employee. November 26, 2008; Interview with FAWE employees. March 26, 2009; E-mail from FAWE employees, March 31, 2009.

132 Forum for African Women Educationalists, FAWE: 15 Years of advancing girls' education in Africa. (Nairobi, Forum for African Women Educationalists); Responses to questionnaire completed by FAWE employee. November 26, 2008; Interview with FAWE employees. March 26, 2009; E-mail from FAWE employees, March 31, 2009.

133 Forum for African Women Educationalists, FAWE: 15 Years of advancing girls' education in Africa. (Nairobi, Forum for African Women Educationalists); Responses to questionnaire completed by FAWE employee. November 26, 2008; Interview with FAWE employees. March 26, 2009; E-mail from FAWE employees, March 31, 2009.

134 Winrock International. "Scholarships for African Girls and Boys.” (Little Rock: Winrock International). http://www.winrock.org/fact/facts. asp?CC $=5544 \&$ bu=9056 (Consulted 13 March 2009).

135 CARE. 2008 Basic Girls Education Project Briefs. (Atlanta: CARE, 2008).

136 Academy for Educational Development. Ambassadors Girls Scholarship Program (AGSP). (Washington, DC: Academy for Educational Development). http://www.aed.org/Projects/AGSP_Africa.cfm.

* The majority of scholarships are for girls. Some of the skill training described is relevant for livelihoods or vocational training, e.g. leatherwork.

137 The World Bank, 2003. Project Appraisal Document on a Proposed Development Credit in the amount of SDR 4.1 million (USD 5.2 million equivalent) and a development grant in the amount of SDR 17.7 million (USD 24.38 million equivalent) to the Republic of Niger for a Basic Education Project, June 2003. (Washington, DC: The World Bank, 2003). http://wwwwds.worldbank.org/external/default/main?pagePK=64 193027\&piPK=64187937\&theSitePK=523679\&menuP $\mathrm{K}=64187510$ \&searchMenuPK $=64187283$ \&siteName= WDS\&entityID=000112742_20030626162228.

138 Responses to questionnaire by UNGEI employee. 2008.

139 USAID, Africa Education Initiative, Ambassadors' Girls' Scholarship Program. (Washington, DC: USAID) http://agsp.worlded.org/nigeria.htm (Consulted 13 March 2009).

140 Forum for African Women Educationalists, FAWE: 15 Years of advancing girls' education in Africa. (Nairobi, Forum for African Women Educationalists); Responses to questionnaire completed by FAWE employee. November 26, 2008; Interview with FAWE employees. March 26, 2009; E-mail from FAWE employees, March 31, 2009.

141 The Academy for Educational Development, "Nigeria Schools of Excellence Project." (Washington, 
DC: The Academy for Educational Development.) http://cge.aed.org/Projects/SSAfrica/nigeria_excellence.cfm (Consulted 10 March 2009).

142 The Centre for Education and Development Popluation Activities, 2008. Building Healthy Futures for Nigerian Youth. (Washington, DC: The Center for Education and Development Population Activities) http://www.cedpa.org/content/publication/ detail/2053.

143 EMpower, Girls Power Initiative. (New York: EMpower). http://www.empowerweb.org/grantees/ girls-power-initiative-gpi (Consulted April 2009).

144 Creative Associates International. Nigeria/Community Participation for Action in the Social Sectors (COMPASS). (Washington, DC: Creative Associates International) http://www.caii-dc.com/ (Consulted April 2009).

145 Forum for African Women Educationalists, FAWE: 15 Years of advancing girls' education in Africa. (Nairobi, Forum for African Women Educationalists); Responses to questionnaire completed by FAWE employee. November 26, 2008; Interview with FAWE employees. March 26, 2009; E-mail from FAWE employees, March 31, 2009.

146 Forum for African Women Educationalists, FAWE: 15 Years of advancing girls' education in Africa. (Nairobi, Forum for African Women Educationalists); Responses to questionnaire completed by FAWE employee. November 26, 2008; Interview with FAWE employees. March 26, 2009; E-mail from FAWE employees, March 31, 2009.

147 Forum for African Women Educationalists, FAWE: 15 Years of advancing girls' education in Africa. (Nairobi, Forum for African Women Educationalists); Responses to questionnaire completed by FAWE employee. November 26, 2008; Interview with FAWE employees. March 26, 2009; E-mail from FAWE employees, March 31, 2009.

148 Forum for African Women Educationalists, FAWE: 15 Years of advancing girls' education in Africa. (Nairobi, Forum for African Women Educationalists); Responses to questionnaire completed by FAWE employee. November 26, 2008; Interview with FAWE employees. March 26, 2009; E-mail from FAWE employees, March 31, 2009.

149 CARE. 2008 Basic Girls Education Project Briefs. (Atlanta: CARE, 2008).

150 CARE. 2008 Basic Girls Education Project Briefs. (Atlanta: CARE, 2008).

151 Academy for Educational Development, Ambassadors' Girls' Scholarship Program, Rwanda. (Washington, DC: Academy for Educational Development). http://cge.aed.org/Projects/SSAfrica/ AGSP_Rwanda.cfm (Consulted 12 March 2009).

152 Winrock International. "Scholarships for African Girls and Boys." (Little Rock: Winrock International). www. winrock. org/fact/facts.ask?CC=5544\&bu= (Consulted 13 March 2009).

153 USAID Senegal and Academy for Educational Development, EQUIP 1-2-3. 2008. Annual Report USAID Projet d'Appui a l'Ensengement Moyen.

154 Forum for African Women Educationalists, FAWE: 15 Years of advancing girls' education in Africa. (Nairobi, Forum for African Women Educationalists); Responses to questionnaire completed by FAWE employee. November 26, 2008; Interview with FAWE employees. March 26, 2009; E-mail from FAWE employees, March 31, 2009.

155 Forum for African Women Educationalists, FAWE: 15 Years of advancing girls' education in Africa. (Nairobi, Forum for African Women Educationalists); Responses to questionnaire completed by FAWE employee. November 26, 2008; Interview with FAWE employees. March 26, 2009; E-mail from FAWE employees, March 31, 2009.

156 Forum for African Women Educationalists, FAWE: 15 Years of advancing girls' education in Africa. (Nairobi, Forum for African Women Educationalists); Responses to questionnaire completed by FAWE employee. November 26, 2008; Interview with FAWE employees. March 26, 2009; E-mail from FAWE employees, March 31, 2009.

157 Forum for African Women Educationalists, FAWE: 15 Years of advancing girls' education in Africa. 
(Nairobi, Forum for African Women Educationalists); Responses to questionnaire completed by FAWE employee. November 26, 2008; Interview with FAWE employees. March 26, 2009; E-mail from FAWE employees, March 31, 2009.

* This training program targets teachers; students are long-term beneficiaries.

158 USAID, Africa Education Initiative, Ambassadors' Girls' Scholarship Program. (Washington, DC: USAID) http://agsp.worlded.org/senegal.htm (Consulted 13 March 2009).

159 Responses to questionnaire by UNGEI employee. 2008.

160 Forum for African Women Educationalists, FAWE: 15 Years of advancing girls' education in Africa. (Nairobi, Forum for African Women Educationalists); Responses to questionnaire completed by FAWE employee. November 26, 2008; Interview with FAWE employees. March 26, 2009; E-mail from FAWE employees, March 31, 2009.

161 USAID, Africa Education Initiative, Ambassadors' Girls' Scholarship Program. (Washington, DC: USAID) http://agsp.worlded.org/sierra-leone.htm (Consulted 13 March 2009).

162 Forum for African Women Educationalists, FAWE: 15 Years of advancing girls' education in Africa. (Nairobi, Forum for African Women Educationalists); Responses to questionnaire completed by FAWE employee. November 26, 2008; Interview with FAWE employees. March 26, 2009; E-mail from FAWE employees, March 31, 2009.

163 Response to questionnaires from International Rescue Committee. January 14, 2009.

164 Response to questionnaires from International Rescue Committee. January 14, 2009.

165 Response to questionnaire from World Vision employee. March 2006.

166 Responses to questionnaire by UNGEI employee. 2008.
167 CARE, "Somalia: Strengthening Capacity for Teacher Training." (Atlanta: CARE). http://www.care. org/careswork/projects/SOM075.asp. (Consulted 10 March 2009).

* The activity in this program is to train teachers, especially women, and thereby improve the quality of education for primary students.

168 CARE. 2008 Basic Girls Education Project Briefs. (Atlanta: CARE, 2008).

169 CARE. 2008 Basic Girls Education Project Briefs. (Atlanta: CARE, 2008).

170 CARE. 2008 Basic Girls Education Project Briefs. (Atlanta: CARE, 2008).

171 Norwegian Refugee Council, 2008. "Somalia: Girls Pave the Way in Somaliland,. (Oslow: The Norwegian Refugee Council). http://www.nrc. no/?did=9283955 (Consulted 10 March 2009).

172 Forum for African Women Educationalists, FAWE: 15 Years of advancing girls' education in Africa. (Nairobi, Forum for African Women Educationalists); Responses to questionnaire completed by FAWE employee. November 26, 2008; Interview with FAWE employees. March 26, 2009; E-mail from FAWE employees, March 31, 2009.

173 Academy for Educational Development, Ambassadors' Girls' Scholarship Program, Somalia (Washington, DC: Academy for Educational Development). http://cge.aed.org/Projects/SSAfrica/ AGSP_Somalia.cfm (Consulted 12 March 2009).

174 The Academy for Educational Development, “Improving Girls' Primary Education in Three Countries." (Washington, DC: The Academy for Educational Development) http://cge.aed.org/Projects/SSAfrica/c_ guinea_girlsprimary.cfm (Consulted 9 March 2009).

175 The Centre for Development and Popuation Activities, "South Africa." (Washington, DC: The Centre for Development and Popluation Activities). http:// www.cedpa.org/section/wherewework/southafrica (Consulted 10 March 2009); CEDPA, 2008. Reaching out to Young Girls in Southern Africa: Towards a 
Better Future (Washington, DC: The Centre for Development and Population Activities).

176 Room to Read, Girls Education: The Challenge. (San Francisco: Room to Read). www.roomtoread. org/programs/girls_education.html (Consulted March 2009).

* According to a general description of this program, transportation for students is provided when needed in the country contexts in which this program is implemented.

177 Winrock International. "Scholarships for African Girls and Boys." (Little Rock: Winrock International). http://www.winrock.org/fact/facts. asp?CC $=5544 \&$ bu=9056 (Consulted 13 March 2009).

178 The Oprah Winfrey Leadership Foundation, "Building a Dream: More about the Academy" (Chicago: The Oprah Winfrey Leadership Foundation) http://oprahwinfreyleadershipacademy.o-philanthropy. org/site/PageServer?pagename=owla_about (Consulted 10 March 2009).

179 Hallman, Kelly; Kasthuri Govender, Eva Roca, Rob Pattman, Emmanuel Mbatha, Deevia Bhana, Enhancing Literacy, HIV/AIDS Skills, and Safe Social Spaces among Vulnerable South African Youth. The Population Council, 2007; Responses to questionnaire from Population Council employees, May 2009.

180 Winrock International, "Gender Equity through Education Fact Sheet." (Little Rock: Winrock International). http://www. winrock.org/fact/facts. asp?CC=5791\&bu=9056 (Consulted 3 April 2009).

* "Livelihoods or vocational training" refers only to the component of this program which supports teacher training institutes.

181 Academy for Educational Development, Ambassadors' Girls' Scholarship Program, Sudan (Washington, DC: Academy for Educational Development). http://cge.aed.org/Projects/SSAfrica/ AGSP_Sudan.cfm (Consulted 12 March 2009).

182 The Norwegian Refugee Council, NRC Core Activity Education, Youth Education Pack in Brief,
Background, Concept, Evaluations, and Development Plans. (Oslo, Sweden: The Norwegian Refugee Council, 2008).

183 Responses to questionnaire by UNGEI employee. 2008. UNICEF, Schools as Centers of Care and Support, Swaziland. (Mbabane: UNICEF-Swaziland).

184 Forum for African Women Educationalists. FAWE: 15 Years of advancing girls' education in Africa. (Nairobi: Forum for African Women Educationalists).

185 Forum for African Women Educationalists, FAWE: 15 Years of advancing girls' education in Africa. (Nairobi, Forum for African Women Educationalists); Responses to questionnaire completed by FAWE employee. November 26, 2008; Interview with FAWE employees. March 26, 2009; E-mail from FAWE employees, March 31, 2009.

186 Response to questionnaire from World Vision employee. March 2006.

187 The Centre for Development and Popuation Activities, "Swaziland." (Washington, DC: The Centre for Development and Popluation Activities). http:// www.cedpa.org/section/wherewework/southafrica (Consulted 10 March 2009); CEDPA, 2008. Reaching out to Young Girls in Southern Africa: Towards a Better Future (Washington, DC: The Centre for Development and Population Activities).

188 CARE, "Projects: Learning and Advocacy for Education Rights Initiative (LEADER)." (Atlanta: CARE). http://www.care.org/careswork/projects/ TZA042.asp (Consulted May 2009).

189 Academy for Educational Development, Ambassadors' Girls' Scholarship Program, Tanzania (Washington, DC: Academy for Educational Development). http://cge.aed.org/Projects/SSAfrica/ AGSP_Tanzania.cfm (Consulted 12 March 2009).

190 CAMFED, Tanzania: CAMFED's response. http://us.camfed.org/where/tanzania/response.html. (Consulted 10 March 2009); CAMFED International, CAMFED International Strategic Plan 2006 - 2010 (Cambridge: CAMFED International, 2006). 
* "Livelihoods or vocational training" refers to a component of the program which offers teacher training only to secondary school drop-outs and young women.

191 Forum for African Women Educationalists, FAWE: 15 Years of advancing girls' education in Africa. (Nairobi, Forum for African Women Educationalists); Responses to questionnaire completed by FAWE employee. November 26, 2008; Interview with FAWE employees. March 26, 2009; E-mail from FAWE employees, March 31, 2009.

192 Forum for African Women Educationalists, FAWE: 15 Years of advancing girls' education in Africa. (Nairobi, Forum for African Women Educationalists); Responses to questionnaire completed by FAWE employee. November 26, 2008; Interview with FAWE employees. March 26, 2009; E-mail from FAWE employees, March 31, 2009.

193 Forum for African Women Educationalists, FAWE: 15 Years of advancing girls' education in Africa. (Nairobi, Forum for African Women Educationalists); Responses to questionnaire completed by FAWE employee. November 26, 2008; Interview with FAWE employees. March 26, 2009; E-mail from FAWE employees, March 31, 2009.

194 The Academy for Educational Development, "Girls Secondary Education in Guinea and Tanzania Project." (Washington, DC: The Academy for Educational Development). http://cge.aed.org/Projects/ SSAfrica/Copy-of-girlssecondary_guinea.cfm, (Consulted 9 March 2009).

195 The Academy for Educational Development, "Improving Girls' Primary Education in Three Countries." (Washington, DC: TH Academy for Educational Development). http://cge.aed.org/ Projects/SSAfrica/c_guinea_girlsprimary.cfm (Consulted 9 March 2009).

196 Responses to questionnaire by UNGEI employee. 2008.

197 Forum for African Women Educationalists, FAWE: 15 Years of advancing girls' education in Africa. (Nairobi, Forum for African Women Educationalists); Responses to questionnaire completed by FAWE employee. November 26, 2008; Interview with FAWE employees. March 26, 2009; E-mail from FAWE employees, March 31, 2009.

198 Forum for African Women Educationalists, FAWE: 15 Years of advancing girls' education in Africa. (Nairobi, Forum for African Women Educationalists); Responses to questionnaire completed by FAWE employee. November 26, 2008; Interview with FAWE employees. March 26, 2009; E-mail from FAWE employees, March 31, 2009.

199 Forum for African Women Educationalists, FAWE: 15 Years of advancing girls' education in Africa. (Nairobi, Forum for African Women Educationalists); Responses to questionnaire completed by FAWE employee. November 26, 2008; Interview with FAWE employees. March 26, 2009; E-mail from FAWE employees, March 31, 2009.

200 Forum for African Women Educationalists, FAWE: 15 Years of advancing girls' education in Africa. (Nairobi, Forum for African Women Educationalists); Responses to questionnaire completed by FAWE employee. November 26, 2008; Interview with FAWE employees. March 26, 2009; E-mail from FAWE employees, March 31, 2009.

201 USAID, Africa Education Initiative, Ambassadors' Girls' Scholarship Program, http://agsp.worlded.org/ togo.htm (Consulted 13 March 2009).

202 Academy for Educational Development, Ambassadors' Girls' Scholarship Program, Uganda (Washington, DC: Academy for Educational Development). http://cge.aed.org/Projects/SSAfrica/ AGSP_Uganda.cfm (Consulted 12 March 2009). Responses to questionnaire completed by FAWE employee. November 26, 2008. Interview with FAWE employee. March 26, 2009.

203 Forum for African Women Educationalists, FAWE: 15 Years of advancing girls' education in Africa. (Nairobi, Forum for African Women Educationalists); Responses to questionnaire completed by FAWE employee. November 26, 2008; Interview with FAWE employees. March 26, 2009; E-mail from FAWE employees, March 31, 2009.

204 Forum for African Women Educationalists, FAWE: 15 Years of advancing girls' education in Africa. 
(Nairobi, Forum for African Women Educationalists); Responses to questionnaire completed by FAWE employee. November 26, 2008; Interview with FAWE employees. March 26, 2009; E-mail from FAWE employees, March 31, 2009.

205 Forum for African Women Educationalists, FAWE: 15 Years of advancing girls' education in Africa. (Nairobi, Forum for African Women Educationalists); Responses to questionnaire completed by FAWE employee. November 26, 2008; Interview with FAWE employees. March 26, 2009; E-mail from FAWE employees, March 31, 2009.

206 Response to questionnaires from International Rescue Committee e-mail. January 14, 2009.

207 BRAC 2009. 2008 Year in Review. (Dhaka: BRAC) http://www.brac.net/index.php?nid=76.

208 UNICEF Eastern and Southern Africa Regional Office, Education Section, United Nations Girls' Education Initiative Making UNGEI Work. Lessons from Four African Countries. September 2007, Nairobi, Kenya; Responses to questionnaire by UNGEI employee. 2008.

209 The Norwegian Refugee Council, 2008. NRC Core Activity Education, Youth Education Pack in Brief, Background, Concept, Evaluations, and Development Plans. (Oslo, Sweden: The Norwegian Refugee Council).

210 Room to Read, Girls Education: The Challenge. (San Francisco: Room to Read). www.roomtoread. org/programs/girls_education.html (Consulted March 2009).

* According to the general description of this program for all countries, transportation is provided when needed in specific contexts.

211 Winrock International, "Gender Equity through Education Fact Sheet." (Little Rock: Winrock International). http://www.winrock.org/fact/facts. asp?CC=5791\&bu=9056 (Consulted 3 April 2009).

212 US Agency for International Development, Improved Quality of Education for More School-aged Children. Development Opportunities." (Washington,
DC: USAID). http://www.usaid.gov/zm/education/ ed.htm (Consulted 10 March 2009).

213 CAMFED, "CAMFED's response." http:// us.camfed.org/where/zambia/response.html. (Consulted 10 March 2009); CAMFED International, CAMFED International Strategic Plan 2006 - 2010 (Cambridge: CAMFED International, 2006).

* "Livelihoods and vocational training" refers to the nonformal track of this program only.

214 Forum for African Women Educationalists, FAWE: 15 Years of advancing girls' education in Africa. (Nairobi, Forum for African Women Educationalists); Responses to questionnaire completed by FAWE employee. November 26, 2008; Interview with FAWE employees. March 26, 2009; E-mail from FAWE employees, March 31, 2009.

215 Forum for African Women Educationalists, FAWE: 15 Years of advancing girls' education in Africa. (Nairobi, Forum for African Women Educationalists); Responses to questionnaire completed by FAWE employee. November 26, 2008; Interview with FAWE employees. March 26, 2009; E-mail from FAWE employees, March 31, 2009.

216 Forum for African Women Educationalists, FAWE: 15 Years of advancing girls' education in Africa. (Nairobi, Forum for African Women Educationalists); Responses to questionnaire completed by FAWE employee. November 26, 2008; Interview with FAWE employees. March 26, 2009; E-mail from FAWE employees, March 31, 2009.

217 Forum for African Women Educationalists, FAWE: 15 Years of advancing girls' education in Africa. (Nairobi, Forum for African Women Educationalists); Responses to questionnaire completed by FAWE employee. November 26, 2008; Interview with FAWE employees. March 26, 2009; E-mail from FAWE employees, March 31, 2009.

218 CAMFED, CAMFED's response. http://us.camfed. org/where/zimbabwe/response.html. (Consulted 10 March 2009); CAMFED International, CAMFED International Strategic Plan 2006 - 2010 (Cambridge: CAMFED International, 2006). 
* "Livelihoods and vocational training" refers to one component of this program for secondary school leavers, and another component of this program for formal school graduates in professions such as doctors, lawyers and teachers.

219 Forum for African Women Educationalists, FAWE: 15 Years of advancing girls' education in Africa. (Nairobi, Forum for African Women Educationalists); Responses to questionnaire completed by FAWE employee. November 26, 2008; Interview with FAWE employees. March 26, 2009; E-mail from FAWE employees, March 31, 2009.

220 Forum for African Women Educationalists, FAWE: 15 Years of advancing girls' education in Africa. (Nairobi, Forum for African Women Educationalists); Responses to questionnaire completed by FAWE employee. November 26, 2008; Interview with FAWE employees. March 26, 2009; E-mail from FAWE employees, March 31, 2009.

221 Forum for African Women Educationalists, FAWE: 15 Years of advancing girls' education in Africa. (Nairobi, Forum for African Women Educationalists); Responses to questionnaire completed by FAWE employee. November 26, 2008; Interview with FAWE employees. March 26, 2009; E-mail from FAWE employees, March 31, 2009.

222 Forum for African Women Educationalists, FAWE: 15 Years of advancing girls' education in Africa. (Nairobi, Forum for African Women Educationalists); Responses to questionnaire completed by FAWE employee. November 26, 2008; Interview with FAWE employees. March 26, 2009; E-mail from FAWE employees, March 31, 2009.

223 CARE, "Education - PACE-A / COPE / Secondary Schools for Girls." (Atlanta: CARE). http://www.care. org/careswork/projects/AFG023.asp (Consulted 10 March 2009); Response to questionnaires from International Rescue Committee. January 14, 2009.

224 BRAC (2009). "BRAC Afghanistan.” (Dhaka: BRAC). http://www.brac.net/index.php?nid=93 (Consulted 10 March 2009).

225 CARE, "Education - PACE-A / COPE / Secondary Schools for Girls." (Atlanta: CARE). http://www.
care.org/careswork/projects/AFG023.asp (Consulted 10 March 2009); DeStefano, Joseph, Ash Hartwell, David Balwanz and Audrey Moore, Effective Schools for Disadvantaged and Underserved Populations. Paris: Association for the Developmentof Education in Africa, 2006.

226 CARE, "Education - PACE-A / COPE / Secondary Schools for Girls." (Atlanta: CARE). http://www.care. org/careswork/projects/AFG023.asp (Consulted 10 March 2009).

* "Livelihoods and vocational training" refers to a stated objective of this program that girls who are educated will become teachers.

227 The Central Asia Institute. "Programs." (Bozeman: The Central Asia Institute). https://www.ikat.org/ projects/cai-programs/. Consulted April 2009.

228 Empower, 2008. "Creating Hope International for the Afghan Institute of Learning." (New York: EMpower). http://www.empowerweb.org/grantees/ creating-hope-international-afghan-institute-learning. Consulted April 2009.

229 Afghan Women's Education Centre, 2009. "Programs." (Kabul: Afghan Women's Education Centre). http://www.awec.info/index.php?option=com_content $\&$ view=category\&layout=blog\&id=41\&ltemid $=64$.

230 Afghan Women's Education Centre, 2009. "Programs.” (Kabul: Afghan Women's Education Centre). http://www.awec.info/index.php?option=com_content $\& v i e w=$ category\&layout=blog\&id $=41 \& \mid$ temid $=64$.

231 BRAC, 2009. Adolescent Development Programme. (Dhaka: BRAC). http://www.brac.net/index. php?nid=277 (Consulted 10 March 2009).

232 Response to questionnaire from World Vision employee. March 2006.

233 Response to questionnaire from World Vision employee. March 2006.

234 Abdul Latif Jameel Poverty Action Lab, Massachusetts Institute of Technology. Empowering Girls in Rural Bangladesh, Project Overview. (Cambridge: Abdul Latif Jameel Poverty Action Lab, 
Massachusetts Institute of Technology.) http://www. povertyactionlab.org/projects/project.php?pid=100 (Consulted 12 March 2009).

* "Livelihoods and vocational training" are included in two of the four educational packages in this pilot program.

235 Room to Read, Girls Education: The Challenge. (San Francisco: Room to Read). www.roomtoread.org/ programs/girls_education.html (Consulted March 2009).

* According to the general description of this program for all countries, transportation is provided when needed in specific contexts.

236 CARE, "Competitive Literacy Initiative - Education / PCTFT." (Atlanta: CARE). http://www.care.org/ careswork/projects/BGD068.asp (Consulted 11 March 2009); CARE. 2008 Basic Girls Education Project Briefs. (Atlanta: CARE, 2008).

237 The World Bank, 2008. Project Appraisal Document on a Proposed Credit in the amount of 80.3 million (USD 130.7 million equivalent) to the People's Republic of Bangladesh for a Secondary Education Quality and Access Project. (Washington, DC: The World Bank). http://www-wds.worldbank.org/ external/default/main?pagePK=64193027\&piPK=6 4187937\&theSitePK=523679\&menuPK=64187510\& searchMenuPK=64187283\&siteName=WDS\&entityl D=000334955_20080711045615.

238 Response to questionnaire from World Vision employee. March 2006.

239 UNESCO. 2007. Education for All by 2015: Will we make it? (Paris: UNESCO).

240 The World Bank, 2009. Cambodia Basic Education Project: Overview. (Washington, DC: The World Bank). http://web.worldbank.org/external/projects/m ain?Projectid=P070668\&Type=Overview\&theSitePK $=40941 \&$ pagePK=64283627\&menuPK=64282134\& piPK=64290415 (Consulted 12 March 2009); Filmer, Deon, E-mail to author, Sept. 3, 2008.

241 Room to Read, Girls Education: The Challenge. (San Francisco: Room to Read). www.roomtoread.org/ programs/girls_education.html (Consulted March 2009).
* According to the general description of this program for all countries, transportation is provided when needed in specific contexts.

242 Response to questionnaire from World Vision employee. March 2006.

243 American Assistance for Cambodia/Japan Relief for Cambodia, "Girls Be Ambitious; An Ounce of Prevention: Eradicating Trafficking of Girls in Cambodia." (Tokyo: American Assistance for Cambodia). http://www.camnet.com.kh/GirlsAmbitious/ (12 March 2009).

244 CARE. 2008 Basic Girls Education Project Briefs. (Atlanta: CARE, 2008).

245 CARE. 2008 Basic Girls Education Project Briefs. (Atlanta: CARE, 2008).

* The beneficiaries of this program appear to be out of school youth but this is not specified in the project description.

246 Response to questionnaire from UNGEI employee, 2008.

247 Room to Read, Girls Education: The Challenge. (San Francisco: Room to Read). www.roomtoread.org/ programs/girls_education.html (Consulted March 2009).

* According to the general description of this program for all countries, transportation is provided when needed in specific contexts.

248 UNESCO. 2007. Education for All by 2015: Will we make it? (Paris: UNESCO).

249 UNESCO. 2007. Education for All by 2015: Will we make it? (Paris: UNESCO).

250 Lewis, Maureen A. and Marlaine E. Lockheed, editors. Exclusion, Gender and Education: Case Studies from the Developing World. 2007: Center for Global Development, Washington, D.C.

251 CARE. 2008 Basic Girls Education Project Briefs. (Atlanta: CARE, 2008); CARE, 2009. "Girls Primary Education Project." (Atlanta: CARE) http://www.care. org/careswork/projects/IND111.asp. 
252 CARE. 2008 Basic Girls Education Project Briefs. (Atlanta: CARE, 2008).

253 Investing in the Next Generation; CEDPA's Youth Development Program. (Washington, DC: The Center for Populiation and Development, 2007). http://www.cedpa.org/content/publication/ detail/2047>.

254 Response to questionnaire from World Vision employee. March 2006.

255 Action India, "Youth Programs." (New Delhi: Action India). http://actionindiaworld.org/pages/ programs-campaigns/youth-programs.php.

256 Apne Aap, The Activities of Apne Aap Women Worldwide, http://www.apneaap.org/activity.html (Consulted 12 March 2009).

257 AKES (Aga Khan Education Services) 2005. Experiences of Working with Girls: Programme for Enrichment of School Level Education (PESLE). Geneva. Aga Khan Foundation. 2007. Mother Teachers: Community Participation in Education and Development. Geneva; UNESCO (United Nations Educational, Cultural and Scientific Organization). 2007. Women and Girls: Education, Not Discrimination. Paris.

258 Educate Girls Globally, 2006. “Uttarakhand, India." (Sausalito: Educate Girls Globally) http://www. educategirls.org/uttaranchal1.htm (Consulted 12 March 2009).

* "Livelihoods and vocational training" refers only to the component of this project which is a bridging program for girls reentering formal school.

259 Educate Girls Globally, 2006. "Uttarakhand, India." (Sausalito: Educate Girls Globally) http://www. educategirls.org/uttaranchal1.htm (Consulted 12 March 2009).

260 Ministry of Human Resource Development, Department of Education and School Literacy, Government of India, 2008. Mahila Samahkya (Education for Women's Equality) Programme 10-year Plan, 2008. (New Delhi:Ministry of Human Resource Develop- ment, Department of Education and School Literacy, Government of India). http://164.100.51.121/girlseducation/mahila-samakhya-scheme.

261 Action India, "Youth Programs." (New Delhi: Action India). http://actionindiaworld.org/pages/ programs-campaigns/youth-programs.php.

262 Haberland, Nicole, Supporting Married Girls: Calling Attention to a Neglected Group. The Population Council, 2007.

263 EMpower, 2008. Nishtha. (New York: EMpower). http://www.empowerweb.org/grantees/nishtha.

264 EMpower, 2008. Vacha Trust. (New York: EMpower). http://www.empowerweb.org/grantees/ vacha-trust.

265 Adarsh Shiksha Samiti, "Programmes: Education." (Udaipur: Adarsh Shiksha Samiti) http://adarshngo.org/education.html.

266 Response to questionnaire from World Vision employee. March 2006.

267 Response to questionnaire from World Vision employee. March 2006.

268 Response to questionnaire from World Vision employee. March 2006.

269 Room to Read, Girls Education: The Challenge. (San Francisco: Room to Read). www.roomtoread. org/programs/girls_education.html (Consulted March 2009).

* According to the general description of this program for all countries, transportation is provided when needed in specific contexts.

270 Abdul Latif Jameel Poverty Action Lab, Massachusetts Institute of Technology. Menstruation and Education in Nepal: Project Overview. (Cambridge: Abdul Latif Jameel Poverty Action Lab, Massachusetts Institute of Technology). http://www.povertyactionlab.org/ projects/project.php?pid=99 (Consulted 12 March 2009). 
271 Room to Read, Girls Education: The Challenge. (San Francisco: Room to Read). www.roomtoread.org/ programs/girls_education.html (Consulted March 2009).

* According to the general description of this program for all countries, transportation is provided when needed in specific contexts.

272 The World Bank, 2004. Project Appraisal Document on a Proposed Credit in the Amount of SDR 34.5 million (USD 50 million equivalent) to the Kingdom of Nepal for an Education for All Project. (Washington, DC: The World Bank).

273 The Center for Population and Development Activities, 2007. Investing in the Next Generation; CEDPA's Youth Development Program. (Washington, DC: The Center for Population and Development Activities.) http://www.cedpa.org/content/publication/detail/2047>.

* Based on the available description, this program is structured as an alternative to formal education, but it is noted that parents are more likely to send their daughters back to school once they have acquired basic literacy skills.

274 Response to questionnaire from World Vision employee. March 2006.

* Program includes training of women and community leaders to advocate for educational opportunities for girls, and includes convening National Congresses for Girls Education.

275 The Central Asia Institute. "Programs." (Bozeman: The Central Asia Institute). https://www.ikat.org/ projects/cai-programs/. Consulted April 2009.

276 The World Bank, 2006. Project Appraisal Document on a Proposed Credit in the amount of SDR 15.1 million (USD 22 million equivalent) to the Islamic Republic of Pakistan for a Balochistan Education Support Project. (Washington, DC: The World Bank).

* The "girl-friendly features" indicate areas of activity that are likely underway based on program descriptions. It appears, but is not explicitly stated in the programme descriptions that the new schools established will be for girls only. However, this project focuses on establishing schools in rural communi- ties in which there are no schools for girls, and in a region in which gender segregated schools are the norm, and builds off an earlier project which enabled girls' attendance at girls-only private schools. Other activities include recruitment and training of teachers and engaging community management committees in school monitoring and management.

277 Response to questionnaires from International Rescue Committee e-mail. January 14, 2009.

278 Developments in Literacy, Annual Report 2007. (Garden Grove, CA: Developments in Literacy, 2008). http://www.dil.org/resources.html.

* One core activity of this organizational is to promote a curriculum relevant for girls' learning for a global workforce; emphasis on language competence and computers are an example of this.

279 Developments in Literacy, Annual Report 2007. (Garden Grove, CA: Developments in Literacy, 2008). http://www.dil.org/resources.html.

* One core activity of this organizational is to promote a curriculum relevant for girls' learning for a global workforce; emphasis on language competence and computers are an example of this.

280 Developments in Literacy, Annual Report 2007. (Garden Grove, CA: Developments in Literacy, 2008). http://www.dil.org/resources.html.

* One core activity of this organizational is to promote a curriculum relevant for girls' learning for a global workforce; emphasis on language competence and computers are an example of this.

281 Developments in Literacy, Annual Report 2007. (Garden Grove, CA: Developments in Literacy, 2008). http://www.dil.org/resources.html.

* One core activity of this organizational is to promote a curriculum relevant for girls' learning for a global workforce; emphasis on language competence and computers are an example of this.

282 Developments in Literacy, Annual Report 2007. (Garden Grove, CA: Developments in Literacy, 2008). http://www.dil.org/resources.html. 
* One core activity of this organizational is to promote a curriculum relevant for girls' learning for a global workforce; emphasis on language competence and computers are an example of this.

283 Developments in Literacy, Annual Report 2007. (Garden Grove, CA: Developments in Literacy, 2008). http://www.dil.org/resources.html.

* One core activity of this organizational is to promote a curriculum relevant for girls' learning for a global workforce; emphasis on language competence and computers are an example of this.

284 CARE. 2008 Basic Girls Education Project Briefs. (Atlanta: CARE, 2008).

* It appears, but is not stated explicitly, that some of the schools built in this transitional environment are for girls only, given the tradition of gender-segregated schooling in this region.

285 Response to questionnaires from International Rescue Committee e-mail. January 14, 2009.

286 Developments in Literacy, Annual Report 2007. (Garden Grove, CA: Developments in Literacy, 2008). http://www.dil.org/resources.html.

* One core activity of this organizational is to promote a curriculum relevant for girls' learning for a global workforce; emphasis on language competence and computers are an example of this.

287 Response to questionnaire from World Vision employee. March 2006.

288 Room to Read, Girls Education: The Challenge. (San Francisco: Room to Read). www.roomtoread. org/programs/girls_education.html (Consulted March 2009).

* According to the general description of this program for all countries, transportation is provided when needed in specific contexts.

289 Response to questionnaires from International Rescue Committee e-mail. January 14, 2009.
290 Response to questionnaire from World Vision employee. March 2006.

291 Empower, 2008. "Women's Education for Advancement \& Empowerment (WEAVE)." (New York: EMpower). http://www.empowerweb.org/grantees/ women039s-education-advancement-amp-empowerment-weave.

292 Empower, 2008. "Development and Education Programme for Daughters and Communities (DEPDC)." (New York: Empower). http://www.empowerweb.org/grantees/depdc.

293 The Norwegian Refugee Council, 2008. NRC Core Activity Education, Youth Education Pack in Brief, Background, Concept, Evaluations, and Development Plans. (Oslo, Sweden: The Norwegian Refugee Council).

294 Room to Read, Girls Education: The Challenge. (San Francisco: Room to Read). www.roomtoread. org/programs/girls_education.html (Consulted March 2009).

* According to the general description of this program for all countries, transportation is provided when needed in specific contexts.

295 The World Bank, 2005. Project Appraisal Document on a Proposed Credit in the amount of SDR 33 Million (USD \$50 million equivalent) to the Socialist Republic of Vietnam for a Targeted Budget Support for a National Education for All Plan Implementation Program. (Washington, DC: The World Bank).

* Project documents note that the teaching force in this context is predominantly female.

296 The World Bank, 2003. Project Appraisal Document on a Proposed Credit in the amount of SDR 101.4 Milion (US \$138.76 Million Equivalent) to the Socialist Republic of Vietnam for a Primary Education for Disadvantaged Children Project. (Washington, DC: The World Bank).

297 CARE. 2008 Basic Girls Education Project Briefs. (Atlanta: CARE, 2008); CARE, "Education and Leader- 
ship for Girls and Young Women Bolivia." (Atlanta: CARE). http://www.care.org/careswork/projects/ BOL081.asp (Consulted April 2009).

298 Response to questionnaire from employee at Escuela Nueva Foundation. January 2009.

299 Response to questionnaire from employee at Escuela Nueva Foundation. January 2009.

300 Response to questionnaire from employee at Escuela Nueva Foundation. January 2009.

301 Response to questionnaire from employee at Escuela Nueva Foundation. January 2009.

302 CARE, "Lead Together." (Atlanta: CARE). http:// www.care.org/careswork/projects/ECU104.asp (Consulted April 2009).

303 Response to questionnaire from World Vision employee. March 2006.

304 Response to questionnaire from World Vision employee. March 2006.

305 CARE, "Educate Me with Equity." (Atlanta: CARE). http://www.care.org/careswork/projects/ SLV067.asp (Consulted April 2009).

306 CARE, "EDUBASICO: Mobile School for Mayan Women Leaders.” (Atlanta: CARE.) http://www.care. org/careswork/projects/GTM090.asp (Consulted April 2009).

307 CARE. 2008 Basic Girls Education Project Briefs. (Atlanta: CARE, 2008).

308 UNESCO. 2007. Education for All by 2015: Will we make it? (Paris: UNESCO).

309 Hallman, Kelly, Eva Roca, Marta Julia Ruiz, Jennifer Catino, Alejandra Colom, and Sandra Contreras Aprile, For Mayan Girls, Safe Spaces Lead to Social Gains. (New York: The Population Council, 2007).

310 CARE, "PROHACE- Hondurans in Partnership for Quality Education Phase I and 2." (Atlanta: CARE) http://www.care.org/careswork/projects/HND057. asp; CARE, 2008 Basic Girls Education Project Briefs. (Atlanta: CARE, 2008).

311 Aisha Sabri, Egypt: Non-formal education. Country profile prepared for the Education for All Global Monitoring report 2009. UNESCO, 2007; DeStefano, Joseph, Ash Hartwell, David Balwanz and Audrey Moore, Effective Schools for Disadvantaged and Underserved Populations. Paris: Association for the Developmentof Education in Africa, 2006; Responses to questionnaire by UNGEI employee. 2008.

312 The Center for Population and Development Activities, 2007. Investing in the Next Generation; CEDPA's Youth Development Program. (Washington, DC: The Center for Population and Development Activities.) http://www.cedpa.org/content/publication/ detail/2047>.

* It appears, but is not stated explicitly, that the clubs in this program function outside schools. The program description refers to scholarships but not clear if all beneficiaries are in school.

313 Aisha Sabri, Egypt: Non-formal education. Country profile prepared for the Education for All Global Monitoring report 2009. (Paris: UNESCO, 2007).

* As the program was established by government decree it appears that the government is also the donor.

314 American Institutes for Research, "Education Reform Program - Egypt." (Washington, DC: American Institutes for Research). http://www.air.org/ projects/idp_egypt.aspx (Consulted 9 March 2009).

315 The Population Council, Ishraq: Safe Spaces for Girls to Learn, Play, and Grow. (New York: The Population Council). http://www.popcouncil.org/projects/ TA_Egyptlshraq.html (Consulted April 2009).

316 UNESCO. 2007. Education for All by 2015: Will we make it? (Paris: UNESCO).

317 Academy for Educational Development, Center for Gender Equity, "Middle East and North Africa: ALEF Report Shows High Success Rate of Women's Literacy Program." (Washington, DC: The Academy for 
Educational Development, 2008). http://cge.aed.org/ Highlights.cfm\#MENA. (Consulted 10 March 2009).

318 Thomas Jr., Landon, "A New Breed of Billionnaire," The New York Times, 14 December 2007. (http://www.nytimes.com/2007/12/14/ business/14billionaire.html).

319 EMpower, "Mother Child Education Foundation (ACEV)." (New York: Empower, 2009). http://www. empowerweb.org/grantees/mother-child-educationfoundation-acev (Consulted April 2009).

320 UNESCO. 2007. Education for All by 2015:

Will we make it? (Paris: UNESCO).

321 CARE. 2008 Basic Girls Education Project Briefs. (Atlanta: CARE, 2008).

322 The World Bank, 2009, Project Appraisal Document on a Proposed Credit in the amount of SDR 12.76 million (USD 20.0 million equivalent) to the Republic of Yemen for a Secondary Education Development and Girls Access Project. (Washington, DC: The World Bank).

* Some of the skill training described is relevant for livelihoods or vocational training; possible curriculum topics include "cooking and preserving food for business purposes." 


\section{NEW LESSONS REFERENCES}

Angrist, Joshua D. and Lavy, Victor. 1997. "The effect of a change in language of instruction on the returns to schooling in Morocco." Journal of Labor Economics, 15(1, pt. 2): S48-S76.

Appleton, S. 1995. Exam Determinants in Kenyan Primary School: Determinants and Gender Differences. McNamara Fellowships Program Washington, DC: Economic Development Institute of the World Bank.

Asadullah, Mohammad N. and Chaudhury, Nazmul. 2006. "Religious schools, social values and economic attitudes: Evidence from Bangladesh." Queen Elizabeth House (QEH) Working Paper No. 139. Oxford, UK: University of Oxford.

Asadullah, Mohammad N. and Chaudhury, Nazmul. 2008. "Holy alliances: Public subsidies, Islamic high schools, and female schooling in Bangladesh." pp. 209-238 in M. Tembon and L. Fort, Eds., Girls' Education in the 21st Century: Gender Equality, Empowerment and Economic Growth. Washington, DC: World Bank.

Asadullah, Mohammad N., Chaudhury, Nazmul, and Dar, Amit. 2006. "Student achievement conditioned upon school selection: Religious and secular secondary school quality in Bangladesh." Queen Elizabeth House (QEH) Working Paper No. 140. Oxford, UK: University of Oxford.

Aslam, Monazza, Kingdon, Geeta, and Söderbom, Mans. 2008. "Is female education a pathway to gender equality in the labor market? Some evidence from Pakistan." pp. 67-92 in M. Tembon and L. Fort, Eds., Girls' Education in the 21st Century: Gender Equality, Empowerment and Economic Growth. Washington, DC: World Bank.

Assaad, Ragui and Mohie Doaa. 2008 "School-towork transition indicators: an application to Egypt" report presented to World Bank Human Development Education and Social Protection Sectors. Cairo: Population Council.

Banerjee, Abhijit, Cole, Shawn, Duflo, Esther, and Linden, Leigh. 2007. "Remedying education: Evidence from two randomized experiments in India." Quarterly Journal of Economics, 122(3): 1235-1264.

Banerjee, Abhijit, Jacob, Suraj, Kremer, Michael, with Lanjouw, Jenny, and Lanjouw, Peter. 2001. "Promoting school participation in rural Rajasthan: Results from some prospective trials." MIT: Mimeo.

Barrett, Angeline, Ali, Sajid, Clegg, John, Hinostroza, J. E., Lowe, John, Nikel, Jutta, Novelli, Mario, Oduro, George, Pillay, Mario, Tikly, Leon, and Yu, Guoxing. 2007. "Initiatives to improve the quality of teaching and learning: A review of recent literature." Paper Commissioned for the EFA Global Monitoring Report 2008, Education for All by 2015: Will We Make It? UNESCO.

Behrman, Jere R., Birdsall, Nancy, and Székely, Miguel. 2003. "Economic policy and wage differentials in Latin America." CGD Working Paper No. 29. Washington, DC: Center for Global Development.

Behrman, Jere R., Murphy, Alexis, Quisumbing, Agnes R., and Yount, Kathryn. 2009. "Are returns to mothers' human capital realized in the next generation? The impact of mothers' intellectual human capital and long-run nutritional status on children's human capital in Guatemala." IFPRI Discussion Paper 00850. Washington, DC: IFPRI Food Consumption and Nutrition Division.

Behrman, Jere R., Sengupta, Piyali, and Todd, Petra. 2005. "Progressing through PROGRESA: An impact assessment of Mexico's school subsidy experiment." Economic Development and Cultural Change, 54(1): 237-275. 
Benavot, Aaron and Resnik, Julia. 2006. "Lessons from the past: A comparative socio-historical analysis of primary and secondary education.” pp. 123-230 in J. E. Cohen, D. E. Bloom, and M. B. Malin, Eds., Educating All Children: A Global Agenda. Cambridge, MA: MIT Press.

Biddlecom, Ann R., Gregory, Richard, Mensch, Barbara S., and Lloyd, Cynthia B. 2008. "Associations between premarital sex and leaving school in four sub-Saharan African countries." Studies in Family Planning, 39(4): 337-350.

Bidwell, Kelly, Galbraith, Colleen, Haddad, Linda, Hermes, Rachel, Kleiner, Sarah, Raheem, Zaki, and Schefler, Kenneth. 2008. Linking Vocational Training Programs to Market Opportunities in Northern Uganda. New York: Women's Commission for Refugee Women and Children and School of International and Public Affairs, Columbia University.

Bledsoe, Caroline H. 1990. "School fees and the marriage process for Mende girls in Sierra Leone." P. R. Sanday and R. G. Goodenough, Eds., New Directions in the Anthropology of Gender. Philadelphia: University of Pennsylvania.

Bledsoe, Caroline H., Cohen, Barney, and Working Group on the Social Dynamics of Adolescent Fertility. 1993. Social Dynamics of Adolescent Fertility in Sub-Saharan Africa. Washington, DC: National Academies Press.

Buscher, Dale. 2007. Build the Peace: Creating Economic Opportunities in Post-Conflict Liberia. New York: Women's Commission for Refugee Women and Children.

Buvinic, Maya., J.C. Guzmán, and Lloyd, Cynthia B 2007. "Gender shapes adolescence," Development Outreach, June (12-15).
Chapman, David and Miske, Shirley J. Forthcoming. "Promoting girls' education in Africa: Evidence from the field." M. A. Maslak, Ed., The Agency and Structure of Women's Education. SUNY Press.

Chapman, David W. and Mushlin, Sarah. 2008.

"Do girls' scholarship programs work: Evidence from two countries." International Journal of Educational Development, 28(4): 460-472.

Chaudhury, Nazmul, Hammer, Jeffrey, Kremer, Michael, Muralidharan, Karthik, and Rogers, F. H. 2006. "Missing in action: Teacher and health worker absence in developing countries." Journal of Economic Perspectives, 20(1,Winter): 91-116.

Chaudhury, Nazmul and Parajuli, Dilip. 2006. Conditional Cash Transfers and Female Schooling: The Impact of the Female School Stipend Program on Public School Enrollments in Punjab, Pakistan. Impact Evaluation Series No. 9, Washington, DC: World Bank.

Costa, Joana, Silva, Elydia, and Vaz, Fabio. 2009. "The role of gender inequalities in explaining income growth, poverty and inequality: Evidence from Latin American countries." Working Paper Number 52. Brasilia: International Poverty Centre for Inclusive Growth.

deBrauw, Alan and Hoddinott, John. 2008. "Must conditional cash transfer programs be conditioned to be effective? The impact of conditioning transfers on school enrollment in Mexico." Washington, DC: IFPRI.

Dee, Thomas S. 2007. "Teachers and the gender gaps in student achievement." Journal of Human Resources, 42(3): 528-554.

Deininger, Klaus. 2003. "Does cost of schooling affect enrollment by the poor? Universal primary education in Uganda." Economics of Education Review, 22: 291-305. 
Desai, Sonalde, Dubey, Amaresh, Vanneman, Reeve, and Banerji, Rukmini. 2008. "Private schooling in India: A new educational landscape." Manuscript.

DeStefano, Joseph, with Hartwell, Ash, Balwanz, David, and Moore, Audrey. 2006. "Effective schools for disadvantaged and underserved populations." Prepared by USAID's Education Quality Improvement Project for the Association for the Development of Education in Africa (ADEA) Biennale on Education in Africa. Libreville, Gabon.

Diaw, Codou. 2008. "Quality and gender equality in education: What have we learned from FAWE's 15 years of experience?" pp. 253-268 in M. Tembon and L. Fort, Eds., Girls' Education in the 21st Century: Gender Equality, Empowerment and Economic Growth. Washington, DC: World Bank.

Duflo, Esther, Dupas, Pascaline, and Kremer, Michael. 2009. "Peer effects and the impact of tracking: Evidence from a randomized evaluation in Kenya." Cambridge, MA: Poverty Action Lab, MIT.

Duraisamy, P. 2002. "Changes in returns to education in India, 1983-94: By gender, age-cohort and location." Economics of Education Review, 21(2): 609-622.

Education Policy and Data Center. 2008. "The extent and impact of non-formal education in 28 developing countries" EPDC No 08-05. Working Paper Series, Washington, DC: Academy for Educational Development.

Filmer, Deon and Schady, Norbert. 2008. "Getting girls into school: Evidence from a scholarship program in Cambodia." Economic Development and Cultural Change, 56: 581-617.

Ghuman, Sharon and Lloyd, Cynthia B. 2007.

"Teacher absence as a factor in gender inequalities in access to primary schooling in rural Pakistan." Poverty, Gender, and Youth Working Paper No. 1. New York: Population Council.

Glewwe, Paul. 1999. "Why does mother's schooling raise child health in developing countries? Evidence from Morocco." The Journal of Human Resources, 34: 124-159.
Glewwe, Paul and Kremer, Michael. 2006. "Schools, teachers and education outcomes in developing countries." pp. 945-1017 in E. Hanushek and F. Welch, Eds., Handbook of the Economics of Education, Vol. 2. Amsterdam: Elsevier.

Glick, Peter. 2008. "What policies will reduce gender schooling gaps in developing countries: Evidence and interpretation." World Development, 36(9): 1623-1646.

Grant, Monica and Hallman, Kelly. 2008. "Pregnancyrelated school dropout and prior school performance in KwaZulu-Natal, South Africa." Studies in Family Planning, 39(4): 369-382.

Grant, Monica, Cynthia B. Lloyd and Barbara Mensch. Forthcoming. "Gender and Absenteeism in rural Malawi." University of Wisconsin.

Grown, Caren, Gupta, GeetaRao, and Kes, Aslihan. 2005. Taking Action: Achieving Gender Equality and Empowering Women. UN Millennium Project Task Force on Education and Gender Equality. London: Earthscan Publications.

Handa, Sudhanshu. 2002. "Raising primary school enrolment in development countries: The relative importance of supply and demand." Journal of Development Economics, 69: 103-128.

Hannum, Emily and Buchmann, Claudia. 2004. "Global educational expansion and socio-economic development: An assessment of findings from the social sciences." World Development, 33(3): 1-22.

Hanushek, Eric A. 2006. "School resources" in Handbook of the Economics of Education, Vol 2. Eric A. Hanushek and Finis Welch, Eds., Amsterdam: Elsevier.

Hanushek, Eric A., Lavy, Victor, and Hitomi, Kohtaro. 2008. "Do students care about school quality? Determinants of dropout behavior in developing countries." Journal of Human Capital, 2(1): 69-105.

Heckman, James J. and Li, Xuesong. 2003. "Selection bias, comparative advantage and heterogeneous returns to education." National Bureau of Economic Research Working Paper Number 9877. Cambridge, MA: NBER. 
Heckman, James J. and Rubinstein, Yona. 2001. "The benefits of skill - The importance of noncognitive skills: Lessons from the GED testing program." American Economic Review, 91(2): 145-149.

Herz, Barbara and Sperling, Gene B. 2004. What Works in Girls' Education: Evidence and Policies From the Developing World. New York: Council on Foreign Relations.

Hoppers, Wim. 2008. "Meeting the learning needs of all young people and adults: An exploration of successful policies and strategies in non-formal education." Paper Commissioned for the EFA Global Monitoring Report 2008, Education for All by 2015: Will We Make It? UNESCO.

Huisman, Janine and Smits, Jeroen. 2009. "Effects of household- and district-level factors on primary school enrollment in 30 developing countries." World Development, 37(1): 179-193.

Jukes, Matthew, BanuVagh, Shaher, and Kim, YoungSuk. 2006. "Development of assessments of reading ability and classroom behavior." Background Paper Prepared for EDDATA-II. Cambridge, MA: World Bank.

Kattan, Raja B. and Burnett, Nicholas. 2004. "Education Sector Report, Human Development Network." User Fees in Primary Education. Washington, DC: World Bank.

Khandke, V, Pollitt, E., and Gorman, K. 1999. "The role of maternal literacy in child health and cognitive development in rural Guatemala." Paper presented at the biennial meetings of the Society for Research in Child Development, Albuquerque, NM, April. Albuquerque.

Khandker, Shahidur R. 1996. Education achievements and school efficiency in rural Bangladesh. Washington, DC: World Bank.

Khandker, Shahidur R., Pitt, Mark M., and Fuwa, Nobuhiko. 2003. 'Subsidy to Promote Girls' Secondary Education: The Female Stipend Program in Bangladesh." Unpublished manuscript.

Kremer, Michael, Miguel, Edward, and Thornton, Rebecca. 2008. "Incentives to Learn." Cambridge, MA: Poverty Action Lab.
Kristof, Nicholas and Sheryl WuDunn. 2009. Half the sky: turning oppression into opportunity for women worldwide. New York: Knopf.

Lam, David and Leibbrandt, Murray. 2003. "What Has Happened to Inequality in South Africa Since the End of Apartheid?" Unpublished Manuscript.

Lam, David and Schoeni, R. 1993. "Effects of family background on earnings and returns to schooling: Evidence from Brazil." Journal of Political Economy, 101(4): 213-243.

LeVine, Robert A., LeVine, Sarah E., Rowe, Meredith L., and Schnell-Anzola, Beatrice. 2004. "Maternal literacy and health behavior: A Nepalese case study." Social Science and Medicine, 58: 863-877.

Levine, Ruth, Lloyd, Cynthia, Greene, Margaret, and Grown, Caren. 2008. Girls Count: A Global Investment and Action Agenda. Washington, DC: Center for Global Development.

Lewin, Keith. 2008. Strategies for Sustainable Financing of Secondary Education in Sub-Saharan Africa. Washington, DC: World Bank, Africa Region Human Development Program.

Lincove, Jane A. 2007. "Do private markets improve the quality or quantity of primary schooling in subSaharan Africa?" Manuscript.

Lloyd, Cynthia, Mete, Cem, and Grant, Monica. 2007. "Rural girls in Pakistan: Constraints of policy and culture." M. A. Lewis and M. E. Lockheed, Eds.,Exclusion, Gender and Education: Case Studies From the Developing World. Washington, DC: Center for Global Development.

Lloyd, Cynthia B. Ed. 2005. Growing Up Global: The Changing Transitions to Adulthood in Developing Countries. National Research Council and Institute of Medicine, Panel on Transitions to Adulthood in Developing Countries. Washington, DC: National Academies Press.

Lloyd, Cynthia B. forthcoming. "The role of schools in supporting and promoting sexual and reproductive health among adolescents in developing countries." 
Shawn Malarcher, Ed., Social Determinants of Sexual and Reproductive Health: Informing Programmes and Future Research. Geneva: World Health Organization (Forthcoming).

Lloyd, Cynthia B., Grant, Monica, and Ritchie Amanda. 2008. "Gender differences in time use among adolescents in developing countries: Implications of rising school enrollment rates." Journal of Research on Adolescence, 18(1): 99-120.

Lloyd, C. B. and B. S. Mensch. 1999. "Implications of formal schooling for girls' transitions to adulthood in developing countries," in C. Bledsoe, J. B. Casterline, J. A. Johnson-Kuhn, and J. G. Haaga, Eds., Critical Perspectives on Schooling and Fertility in the Developing World. Washington, DC: National Academy Press, pp. 80-104.

Lloyd, Cynthia B. and Mensch, Barbara S. 2008. "Marriage and childbirth as factors in dropping out from school: An analysis of DHS data from subSaharan Africa." Population Studies, 62(1): 1-13.

Lloyd, Cynthia B., Mensch, Barbara S., and Clark, Wesley H. 2000. "The effects of primary school quality on school dropout among Kenyan girls and boys." Comparative Education Review, 44(2): 113-47.

Lloyd, Cynthia B., Mete, Cem, and Sathar, Zeba A. 2005. "The effect of gender differences in primary school access, type, and quality on the decision to enroll in rural Pakistan." Economic Development and Cultural Change, 53(3): 685-710.

Loaiza, Edilberto and Lloyd, Cynthia B. 2008. "Adolescents and Education in Africa." Manuscript.

MacPherson, Ian. 2007. "Tanzania: Non-formal education." Country Profile Commissioned for the EFA Global Monitoring Report 2008, Education for All by 2015: Will We Make It? UNESCO.

Marteleto, Leticia, Lam, David, and Ranchhod, Vimal. 2008. "Sexual behavior, pregnancy, and schooling among young people in urban South Africa." Studies in Family Planning, 39(4): 351-368.

McMahon, Walter W. 2003. Lifelong Learning in Developing Countries: An Analysis With Estimates of Private Return and Externalities. Washington, DC: World Bank.

Mensch, Barbara S., Clark, Wesley H., Lloyd, Cynthia B., and Erulkar, Annabel. 2001. "Premarital Sex, and Schoolgirl Pregnancy and School Quality in Rural Kenya." Studies in Family Planning, 32(4): 285-301.

Mensch, Barbara S. and Lloyd, Cynthia B. 1998. "Gender differences in the schooling experiences of adolescents in low-income countries: The case of Kenya." Studies in Family Planning, 29(2): 167-184.

Meyer, John W. 1992. "Background: A perspective on the curriculum and curricular research." pp. 18-27 in J. W. Meyer, D. H. Kamens, A. Benavot, Y.-K. Cha, and S.-Y. Wong, Authors, School Knowledge for the Masses: World Models and National Primary Curricular Categories in the Twentieth Century. Washington, DC, London: The Falmer Press.

Michaelowa, K. 2001. "Primary education quality in Francophone sub-Saharan Africa: Determinants of learning achievement and efficiency considerations." World Development, 29(10): 1699-1716.

Miske, Shirley J. 2008. Learning From Girls' Education As an Organizational Priority: A Review of UNICEF Evaluations and Studies: 2000-2005. New York: UNICEF Education Section, Programme Division.

Munshi, Kaivan and Rosenzweig, Mark. 2003. "Traditional institutions meet the modern world: Caste, gender and schooling choice in a globalizing economy." BREAD Working Paper No. 038. Bureau for Research in Economic Analysis of Development Washington, DC: BREAD.

Oster, Emily and Thornton, Rebecca. 2009. "Menstruation and education in Nepal." Manuscript.

Patrinos, Harry. 2008. "Returns to education: The gender perspective." pp. 53-661 in M. Tembon and L. Fort, Eds., Girls' Education in the 21st Century: Gender Equality, Empowerment and Economic Growth. Washington, DC: World Bank.

Phillipson (Ed.), Bob. Editor. 2008. Low-Cost Private Education: Impacts on Achieving Universal Primary Education. London: Commonwealth Secretariat. 
Psacharopoulos, George and Patrinos, Harry A. 2004. "Returns on investment in education: $A$ further update." Education Economics, 12(2): 111-134.

Rihani, May A., with Kays, Lisa, and Psaki, Stephanie. 2006. Keeping the Promise: Five Benefits of Girls' Secondary Education. Washington, DC: Academy for Educational Development.

Rindfuss, Ronald R. 1991. "The young adult years: diversity, structural change, and fertility." Demography, 28(4): 493-512.

Rose, Pauline. 2007. NGO Provision of Basic Education: Alternative or Complementary Service Delivery to Support Access to the Excluded? Sussex: University of Sussex Centre for International Education.

Rugh, Andrea and Brush, Lorelei. 2002. Lessons Learned for the USAID Girls' Education Activity in Guatemala, Morocco and Peru. USAID.

Schultz, T. P. 2003. "Evidence of returns to schooling in Africa from household surveys: Monitoring and restructuring the market for education." Economic Growth Center Discussion Paper No. 875. New Haven: Yale University.

Sukontamarn, Pataporn. 2005. "The entry of NGO schools and girls' educational outcomes in Bangladesh." London: London School of Economics and Political Science.

Summers, Lawrence H. 1994. "Investing in all the people: Educating women in developing countries." Report No. 45. Washington, DC: World Bank.

Thomas, Duncan. 1999. "Fertility, education and resources in South Africa." C. Bledsoe, J. B. Casterline, J. A. Johnson-Kuhn, and J. G. Haaga, Eds., Critical Perspectives on Schooling and Fertility in the Developing World. Washington, DC: National Academy Press.

UNESCO. 2007. "Education for all by 2015: Will we make it?" EFA Global Monitoring Report 2008. Paris: UNESCO.

UNESCO. 2008. "Overcoming inequality: Why governance matters." EFA Global Monitoring Report 2009. Paris: UNESCO.
UNICEF. 2004. "Evaluation Report." Changing Lives of Girls; Evaluation of the African Girls' Education Initiative. New York: UNICEF Evaluation Office.

United Nations. 2008. The Millennium Development Goals Report 2008. New York: United Nations.

US Department of Labor, Bureau of Labor Statistics. 2008. "Women in the labor force: a databook." Report 1011. US Department of Labor. Available: http:// www.bls.gov/cps/wlf-databook-2008.pdf (accessed December 2008)

Williams, Howard. 2001. "SAGE (Strategies for Advancing Girls' Education) Techncial Report No. 3." Multi-Sectoral Strategies for Advancing Girls' Education: Principles and Practice. Washington, DC: Academy for Educational Development.

World Bank. 2005. Expanding Opportunities and Building Competencies for Young People: A New Agenda for Secondary Education. Washington, DC: World Bank.

World Bank. 2007. Moving Forward With Girls' Education in the World Bank: The Changing Context and What It Means for the Future. Washington, DC: World Bank.

World Education Forum. 2000. "Education for All: Meeting our collective commitments." The Dakar Framework for Action. Dakar: UNESCO.

Young, Juliet, Buscher, Dale, and Perlman-Robinson, Jenny. 2007. From the Ground Up: Education and Livelihoods in Southern Sudan. New York: Women's Commission for Refugee Women and Children. 


\section{NEW LESSONS ABOUT THE AUTHORS}

\section{Cynthia B. Lloyd}

Cynthia B. Lloyd is a Consulting Senior Associate with the Poverty, Gender and Youth Program at the Population Council. Prior to her relocation to Berkeley, Calif., in April 2009, Dr. Lloyd was based in New York with the Population Council, serving as a Senior Associate for 20 years, as well as the Director of Social Science Research in the Policy Research Division.

Dr. Lloyd was the chair of the National Academy of Sciences' Panel on Transitions to Adulthood in Developing Countries and editor of the panel's 2005 report, Growing up Global: The Changing Transitions to Adulthood in Developing Countries. Her fields of expertise include: transitions to adulthood, children's schooling, gender and population issues, and household and family demography in developing countries. Dr. Lloyd has worked on these issues in Pakistan, Egypt, Kenya, Ghana, Sudan (Darfur) and other developing countries, as well as comparatively. Her recent research has concentrated on girls' schooling, the relationship between schooling and reproductive health, adolescent time use, and school quality, school attendance, and transitions to adulthood. She has authored more than 80 research articles, books and monographs. She is also coauthor of another report in the Girls Count series: Girls Count: A Global Investment and Action Agenda.

Prior to her work at the Population Council, Dr. Lloyd spent 10 years at the United Nations Population Division (1979-1989), serving as Chief of the Fertility and Family Planning Division, and nine years on the economics faculty of Barnard College, Columbia University (1970-1979). She has M.A. and Ph.D. degrees in economics from Columbia University.

\section{Juliet Young}

Juliet Young is an adolescent education specialist who has worked as a researcher, teacher trainer, curriculum developer and teacher in New York City's public schools, and for UN agencies and various NGOs. Her recent projects include research on youth in northern Uganda for the Graca Machel 10-year Strategic Review of the Impact of Armed Conflict on Children as a consultant for the Women's Refugee Commission, and support to the United Nations Inter-Agency Task Force on Adolescent Girls as a consultant for UNICEF. She has also worked on education and community development projects in Mauritania, Mongolia, Myanmar, Cambodia, and Thailand. In November 2009, she will take up a position as an Education Specialist for UNICEF based in Hargeisa, Somalia. Her commitment to ensuring equal access to quality education for all adolescents was inspired by the students she worked with in her nine years as a social studies teacher at a public high school in Brooklyn, New York. She has a Master's degree in teaching secondary social studies and a Master's of International Affairs, both from Columbia University. 


\section{THE GIRLS COUNT SERIES IS AN INITIATIVE OF THE COALITION FOR ADOLESCENT GIRLS.}

www.coalitionforadolescentgirls.org

\section{The Coalition for Adolescent Girls}

The Coalition gathers over 30 leading international organizations dedicated to bringing adolescent girls to the global development agenda. Launched by the UN Foundation and the Nike Foundation in 2005, the Coalition offers fresh perspectives, diverse resources, and concrete solutions to the challenges facing adolescent girls in developing countries.

\section{UNITED NATIONS $\Rightarrow$ FOUNDATION}

\section{The United Nations Foundation}

The UN Foundation (www.unfoundation.org), a public charity, was created in 1998 with entrepreneur and philanthropist Ted Turner's historic $\$ 1$ billion gift to support UN causes and activities. The UN Foundation is an advocate for the UN and a platform for connecting people, ideas, and capital to help the United Nations solve global problems, including women's and girls' inequality.

\section{Nike Foundation}

\section{The Nike Foundation}

The Nike Foundation (www.nikefoundation.org) is a non-profit organization dedicated to investing in adolescent girls as the most powerful force for change in the developing world. The work of the Nike Foundation is supported by NIKE, Inc., and by significant investments from the NoVo Foundation. 


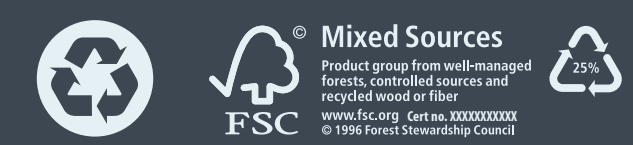

